MEASURING TRANSIT-ORIENTED

DEVELOPMENT (TOD) AT REGIONAL AND

LOCAL SCALES - A PLANNING SUPPORT TOOL

Yamini Jain Singh 


\section{Examining Committee}

Prof.dr. Robert Cervero, University of Califormia, Berkeley, U.S.A.

Prof.dr.ir. Luca Bertolini, University of Amsterdam

Prof.dr.ir. Rob van der Heijden, Radboud University, Nijmegen

Prof.dr.ir. Eric van Berkum, University of Twente,

Dr. Richard Sliuzas, University of Twente

ITC dissertation number 277

ITC, P.O.Box 6, 7500 AA Enschede, The Netherlands

ISBN 978-90-365-3998-2

DOI. $10.3990 / 1.9789036539982$

Images on the cover: Front: Shruti Dimri and Mandvi Kulshreshtha, Back:

photograph by Yamini J. Singh

Printed by ITC Printing Department

Copyright@ 2015 by Yamini Jain Singh

\section{UNIVERSITY OF TWENTE.}

- C FACULTY OF gEO-INFORMATION SCIENCE AND EARTH OBSERVATION 


\title{
MEASURING TRANSIT-ORIENTED DEVELOPMENT (TOD) AT REGIONAL AND LOCAL SCALES - A PLANNING SUPPORT TOOL
}

\author{
DISSERTATION \\ to obtain \\ the degree of doctor at the University of Twente, \\ on the authority of the rector magnificus, \\ prof.dr. H. Brinksma, \\ on account of the decision of the graduation committee, \\ to be publicly defended \\ on $11^{\text {th }}$ of November 2015 at 12.45 hrs
}

by

\section{Yamini Jain Singh}

born on 22 November 1979

in New Delhi, India. 
This thesis is approved by

Prof. Dr. Ir. Martin van Maarseveen, Promoter Dr. Ir. Mark Zuidgeest, Co-Promoter

Dr. Johannes Flacke, Co-Promoter 


\section{Acknowledgements}

They say the best things in life happen when unplanned. I never planned to do a PhD but ended up not just doing it, but learning and enjoying tremendously all along the way. A wonderful period of my life is coming to an end, bringing hopes for a new and a different future. During these four years, I have made some very good friends and have got the help from many people, all of whom I would like to thank in this little dedicated space in my book.

To start with, my sincere thanks are due to Prof. Maarseveen, my promoter and Head of the Department who showed trust and confidence in me when I started my PhD in his department. His words of appreciation and encouragement were very important to me and I sincerely hope I have lived up to his expectations. His critical thinking and a different point of view always brought a new perspective to my work. His take on the topic of discussion would force me to think and rethink and sometimes disagree, but it made sure that I understood my work inside out. That's what discussions should do and I thank him very much for that and a lot more.

My co-promoter, Dr. Mark Zuidgeest has been a complete pillar of support in every which way. He is not just the kindest soul I know, but also the most encouraging and appreciating. At every stage of my work, I could count on his guidance and support. Even when we had a difference of opinion, he gave me a lot of space to think, debate and trusted me to make an informed choice. I cannot thank him enough for all his help and trust. Despite his move to the University of Cape Town, I think we were able to work together quite well.

I would also like to send out my sincere thanks to Dr. Johannes Flacke, also my co-promoter. He has been extremely helpful throughout the thesis but has been especially instrumental in helping me achieve the last objective of this research. I am very thankful for his guidance and critical comments to my work that helped me shape my research better.

I am very grateful for all the help handed out by Jorn Mathijse and Suzan Hesseling, Project Managers at the office of 'Stadsregio Arnhem and Nijmegen'. Jorn helped us tremendously by giving us the launching pad of Stadsregio for our work, providing us the data in proper formats and Suzan was instrumental in conducting the workshop with the Aldermen at Nijmegen. Without their help, this thesis would have taken a lot more time.

During this research, I also got the wonderful opportunity to co-supervise three MSc students - Pedram Fard, Azhari Lukman and Pengwei He, who 
worked with me on smaller parts of my thesis. Working with them gave me an insight into nitty-gritties of the work and how these details should be managed keeping in mind the broad aim of the research. Our discussions also helped me clarify my own thoughts on the topic and get new ideas.

In the year that I spent as the Faculty Council member, I had a great experience working on management related issues and I would like to thank all the council members for contributing to that experience.

I would also like to say special thanks to John Horn, Paul van Dijk, Petra Weber, Theresa, Loes Colenbrander and Marion Pierik who helped me sort out many practical, administrative and financial issues during my research and stay in Enschede.

On a more personal front, I would like to thank all my friends at ITC who made my ITC experience a lot richer. Maitreyi, Parveen, Divyani, Mitva, Priya, Tanmoy, Sandeep, Pankaj, Remi, Paresh, Neetu, Anandita, Sejal, Rishi and Pani are some of the people I would like to mention here. I have many fond memories of them and ITC to cherish for a very long time. Special thanks to Shruti and Mandvi for helping me with the front cover design, despite their very hectic work schedules.

My family is my strength. My husband Gaurav and my daughter Rhea are my heart and soul. We came here 6 years ago, to a new country, new culture, new climate and away from our huge social support system. It was hard, but we did it! Together! This PhD would not have been possible without Gaurav's support, and Rhea who brings direction, joys, love and chaos (!) to my life. Whatever I say about them, will never be sufficient. My parents have raised me to be a very independent and confident woman and I thank them for giving me the chance to grow as I wished. Hopefully my daughter will have something similar to say about her parents, someday! Special thanks are also due, to my in-laws, my brother and my sister. There have been some lovely additions to our family in the last four years, including my sister-in-law and my sister's children Vivaan and Mihika. You all have brought more joy to our lives! 


\section{Table of Contents}

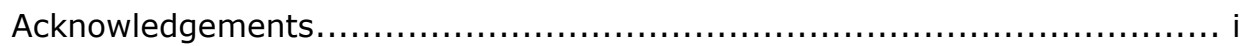

Table of Contents ......................................................................

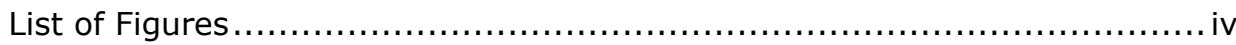

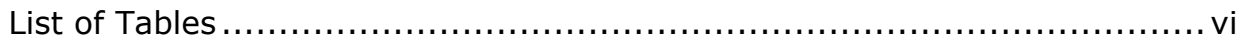

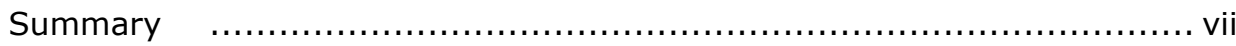

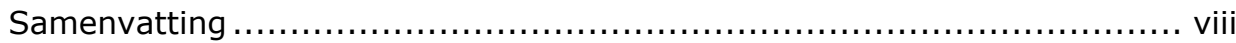

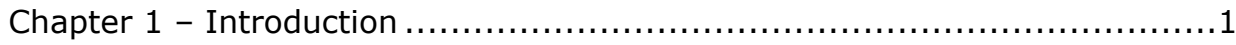

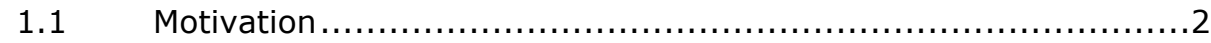

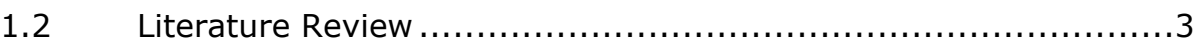

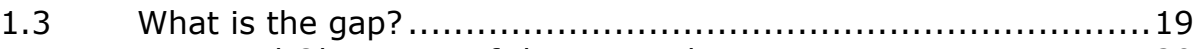

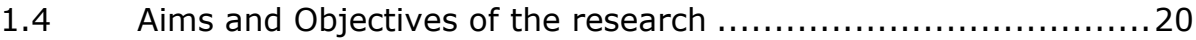

$1.5 \quad$ Methodology........................................................... 22

$1.6 \quad$ Case Study Introduction ............................................ 24

Chapter 2 - Measuring TOD around existing transit nodes ......................29

$2.1 \quad$ Background ......................................................... 30

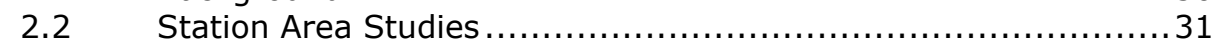

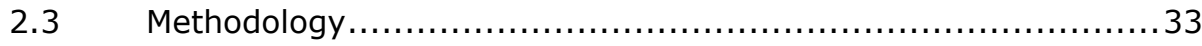

$2.4 \quad$ Calculation of Indicators ........................................... 40

2.5 Results of 'Actual TOD Index' and Sensitivity analysis ...............48

$2.6 \quad$ Inferences and Recommendations .................................. 50

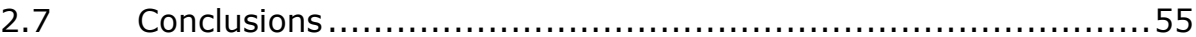

Chapter 3 - Measuring TOD at regional scale ................................. 57

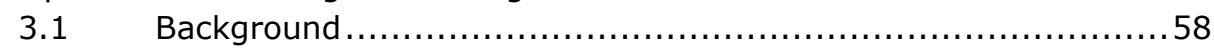

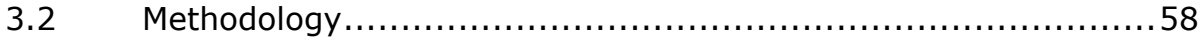

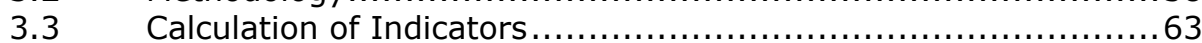

3.4 Results of 'Potential TOD Index' and Sensitivity Analysis ...........70

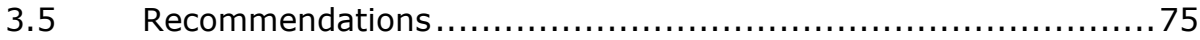

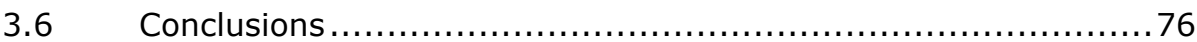

Chapter 4 - A Planning support Tool for TOD planning .......................... 79

$4.1 \quad$ Background ......................................................... 80

4.2 Identifying stations in need of a higher TOD score.................. 81

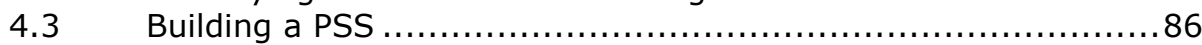

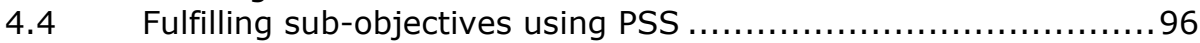

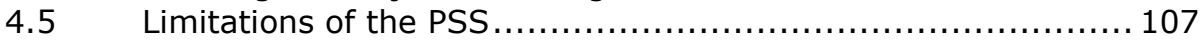

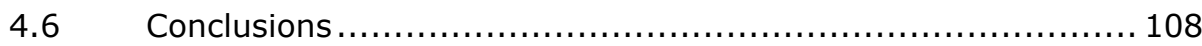

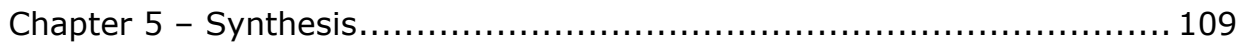

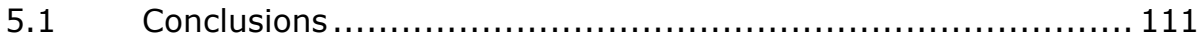

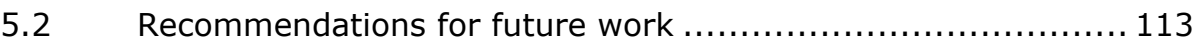

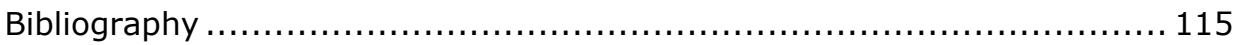

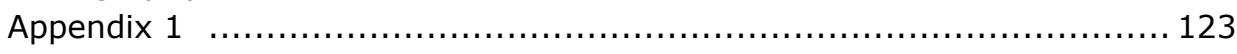

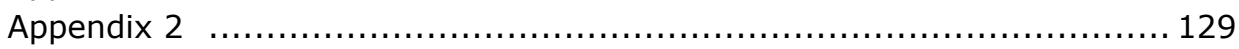

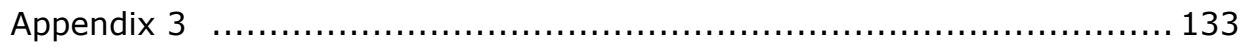

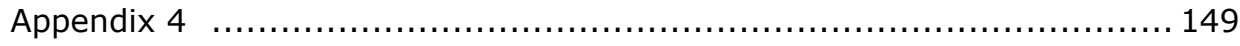

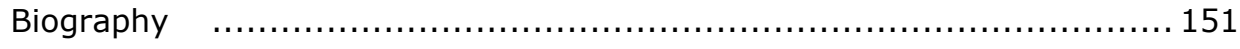

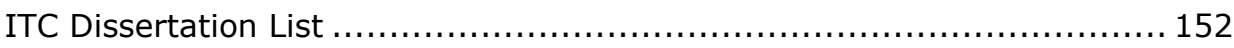




\section{List of Figures}

Figure 1.1: Research Methodology .............................................23

Figure 1.2: Schematic procedure of computing composite index map based on spatial multi criteria analysis ...................................24

Figure 1.3: Arnhem and Nijmegen City Region in context of Netherlands....25

Figure 1.4: The City Region of Arnhem and Nijmegen ..........................26

Figure 2.1: Criteria and measurable indicators to measure TOD at local scale

Figure 2 2: MCA process for TOD Index calculations.... .38

Figure 2.3: Building footprints and their land uses around two stations ......42

Figure 2.4: Impedance Pedestrian Catchment Area (IPCA) for areas around various stations in the City Region................................4 44

Figure 2.5: (a) Station of Nijmegen with many shops and passengers in contrast to (b) the empty looking station of Westervoort ........44 45

Figure 2.6: (a) The Bus terminal just outside Nijmegen station with bigger buses and many lines. (b) A smaller bus terminal outside Zevenaar station with smaller buses and lesser lines.............47

Figure 2.7: (a) Fully utilised cycle parking at Nijmegen station (b) Park and Ride $(P+R)$ Car parking at Zevenaar station (c) Cycle parking also at Zevenaar station........................................... 48

Figure 2.8: TOD Index for all 21 stations in the City Region of Arnhem and Nijmegen ....................................................... 50

Figure 2.9: Web diagrams for the 3 top-scoring stations (transit related indicators are shown on blue side of the web and land use indictors on the light orange side)

Figure 3.1: Criteria and measurable indicators to measure TOD at regional

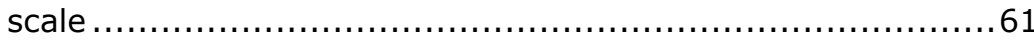

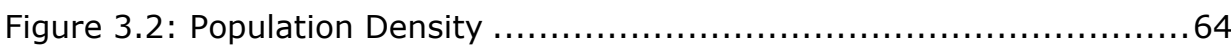

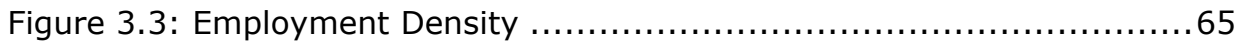

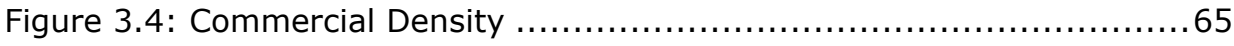

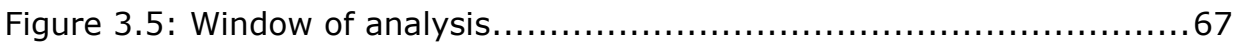

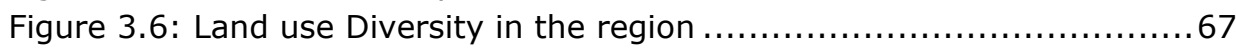

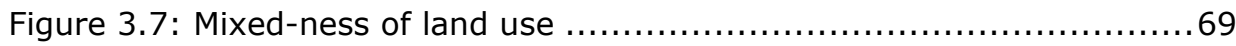

Figure 3.8: Intersection Density ............................................. 70

Figure 3.9: Length of walkable/ cyclable paths ................................... 71

Figure 3.10: Number of business establishments ................................71

Figure 3.11: Potential TOD index values in the City Region.....................72

Figure 3.12: Potential TOD Index hot spots (clusters of high index scores)

identified by both statistics .................................................... 74

Figure 3.13; Final hot spots of Potential TOD Index ............................. 75

Figure 3.14: Hot spots that are sufficiently away from the existing train

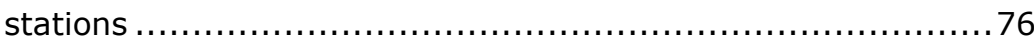

Figure 4.1: Conceptual Framework of our PSS ................................ 91 


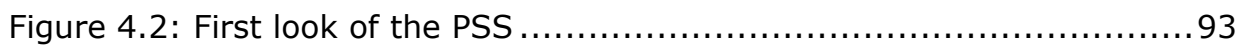

Figure 4.3: Simulated change in TOD index score for selected station ........95

Figure 4.4: Web-diagram of the criteria for TOD score (Arnhem Velperpoort

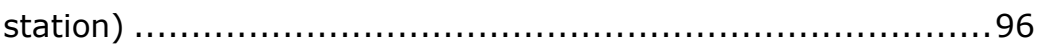

Figure 4.5: Snapshot of the PSS after making changes to assumptions for Arnhem Velperpoort station .................................. 97

Figure 4.6: Web-diagram of the criteria for TOD score (Arnhem Zuid) ........98

Figure 4.7: Development recommendations for area around Arnhem- Zuid

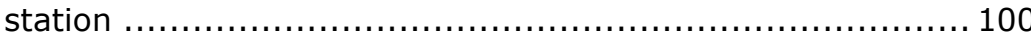

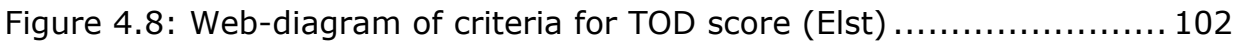

Figure 4.9: Three phases of development of the City Region............... 104 


\section{List of Tables}

Table 1.1: TOD as defined by various authors ....................................

Table 2.1: Criteria and Indicators for measuring TOD Index.....................36

Table 2.2: Criteria, indicators and their weights .................................40

Table 2.3: TOD Index values for all 21 stations in the City Region .............49 49

Table 2.4: Criteria holding potential for improvement at each station.........53

Table 3.1: Criteria and indicators for measuring Potential TOD index .........60

Table 3.2: Indicators, Criteria and their weights .................................63

Table 4.1: OV scores for all 21 stations in the City Region ....................... 83

Table 4.2: Classification of OV and TOD scores ................................... 84

Table 4.3: Matching OV and TOD scores for all stations in the City Region ...85 


\section{Summary}

Transit Oriented Development (TOD) is a planning approach contributing to sustainable development by promoting transit over private transport, in particular for commuting. In the past TOD plans have been drawn and implemented with mixed success in many cities around the world. We believe that planning for TOD can greatly benefit from a comprehensive measurement of its typical physical characteristics using a TOD index. Such an index not only assesses existing TOD conditions at a location but may also identify those characteristics that need improvement. Such an assessment is crucial for drawing specific and more effective policies, programs and physical planning interventions required to create better TOD conditions. In this work, a TOD index is developed, its need, use and functioning are described and demonstrated for the case study of the City Region Arnhem-Nijmegen in the Netherlands. The region consists of 20 municipalities of which Arnhem and Nijmegen are the main urban centres. Traditionally, planning for TOD is about improving 'development' around transit nodes, but this study not only works at the local scale around these nodes, but also expands the domain to the regional scale by suggesting improvements in 'transit accessibility' at the regional level. At the local scale, our TOD index helps in measuring the transit-orientation of the urban development around transit nodes as well as identifying what needs to be done to improve it further. At the regional scale, the TOD index identifies those areas in the region that have high transitorientation but lack good transit connectivity. At the local scale, the focus is more on urban development (i.e. D of TOD) whereas at the regional scale it is more on transit development (i.e. T of TOD). For the local and regional scale, the proposed TOD indices differ. Measuring these TOD indices, as demonstrated in this work, includes measurement of various spatial and nonspatial indicators; Multiple-Criteria Assessment (MCA) and Spatial MCA (SMCA); and involvement of stakeholders and decision makers. Our unique methodology is not only transparent and back-traceable, but also transferrable to other geographies. To assist planners further, we developed a Planning Support System (PSS) that can simulate changes in TOD index values around transit nodes, in response to planning interventions. This PSS supports planners in deciding about the most effective planning interventions and/or in aligning the local planning interventions with regional planning goals. The case study also demonstrated that the PSS was useful in evaluating the impact of existing and future TOD plans on the score of the TOD index. This research demonstrates the utility and potential of the developed TOD index, supported by a PSS, in identifying planning options and evaluating planning proposals for Transit Oriented Development at local and regional scales. 


\section{Samenvatting}

Transit Oriented Development (TOD), een goede Nederlandse equivalent van de term ontbreekt, beoogt via stedelijke planning openbaar vervoer (OV) te bevorderen, met name voor het woon-werk verkeer, en daarmee bij te dragen aan een meer duurzame stedelijke ontwikkeling. In het verleden zijn TOD plannen wereldwijd met wisselend succes toegepast. In dit onderzoek laten we zien dat TOD planning baat kan hebben bij een integrale maat, een zogenaamde TOD index, waarbij ruimtelijke en fysieke karakteristieken van de omgeving worden gekwantificeerd. Deze index kan niet alleen de huidige TOD status van een locatie kwantificeren, maar ook worden gebruikt voor het bepalen en doorrekenen van maatregelen om deze TOD score te verbeteren. Specifieke en mogelijk meer effectieve beleidsmaatregelen, - plannen en interventies kunnen hiermee worden bepaald. In dit proefschrift worden de ontwikkeling van de TOD index, de behoefte aan, het gebruik en de functionaliteit van een dergelijke index besproken en geïllustreerd middels een toepassing voor de Stadsregio Arnhem - Nijmegen in Nederland. Dit studiegebied bestaat uit 20 gemeenten waarvan Arnhem en Nijmegen de belangrijkste kernen vormen. Veel wetenschappelijke literatuur rondom TOD planning gaat over verbeteringen rondom OV knooppunten, op een lokale schaal. Dit onderzoek kijkt ook naar deze lokale schaal, maar richt zich daarnaast ook op een regionale schaal en doet suggesties voor de regionale bereikbaarheid met het openbaar vervoer. Op lokale schaal geeft de TOD index informatie over de mate van openbaar vervoer gerichte stedelijke ontwikkeling rondom oV knooppunten, en de maatregelen die genomen kunnen worden om dit te verbeteren, terwijl op regionale schaal de index kijkt naar locaties in de regio die een hoge mate van openbaar vervoer potentieel hebben - in termen van ruimtelijke en fysieke karakteristieken -, maar waar het ontbreekt aan goede OV bereikbaarheid. Op lokale schaal richt de aandacht zich met name op de verbetering van stedelijke ontwikkeling (de $D$ van 'development' in TOD), terwijl op regionale schaal de aandacht uitgaat naar OV bereikbaarheid (de T van 'transit' in TOD). Voor beide schaalniveaus worden verschillende TOD indices geïntroduceerd. Deze indices omvatten zowel ruimtelijke als niet-ruimtelijke factoren. De indices zijn vervolgens geïmplementeerd in een model voor ruimtelijke multi-criteria analyse ('spatial multi criteria assessment' SMCA) en geoperationaliseerd voor de Stadsregio Arnhem - Nijmegen met betrokkenheid van belanghebbenden en beleidsmakers. De SMCA-methode is transparant en inzichtelijk, en gemakkelijk overdraagbaar naar andere geografische gebieden. Daarnaast is een planningondersteunend systeem ('planning support system' PSS) voor het bepalen van de TOD index score rondom OV knooppunten ontwikkeld en geïmplementeerd. Met het PSS kunnen planners de meest effectieve planningsmaatregelen met het oog op veranderingen in de TOD index score rondom OV knooppunten bepalen. Het PSS helpt bij het afstemmen van 
lokale maatregelen met de doelstellingen van regionale plannen. Daarnaast kan het PSS worden gebruikt voor het evalueren van huidige en toekomstige TOD plannen rondom OV knooppunten. De resultaten van het onderzoek tonen aan dat het mogelijk is om TOD meetbaar te maken voor zowel lokale als regionale toepassingen door gebruik te maken van een TOD index in een PSS omgeving. 


\section{Chapter 1 - Introduction*}

* This chapter is based on the following book chapter:

Singh, Y.J., Zuidgeest, M.H.P., Flacke, J., Van Maarseveen, M.F.A.M., 2012. A design

framework for measuring transit oriented development, In: Longhurst; , J.W.S.,

Brebbia, C.A. (Eds.), Urban Transport XVIII WIT Press, Southampton, U.K., pp. 719730. 


\subsection{Motivation}

Urbanization is an integral component of economic development and levels of urbanization are increasing worldwide. Modern urban life has produced a new environment that relies heavily on scarce natural resources such as fuel and space or land. With increasing population and its increasing demand, this reliance increases, nature is constantly altered and more and more space is acquired for habitation. City officials in various countries face a challenge to manage cities' growth and it is vital for cities to be sustainable.

Cities are shaped by their transport system. In the last few decades, however, many cities all over the world have grown around the road-based transport system instead of the transit system. It has had its unintended side-effects, of those of sprawl, inefficient utilization of resources, worsened environment, higher pollution levels, unequal distribution of opportunities and wealth. This has been criticized time and again by planners and it is also realized that to counter this, cities must take measures to make their transport systems more sustainable and public transport plays a major role in it.

Creating sustainable transport often involves the ASI principle (Dalkmann, 2007). ASI - 'Avoid' (and reduce motorised transport), 'Shift' (to more sustainable modes such as public transport and non-motorised transport) and 'Improve' (greener cleaner technologies for motorized transport) seeks to achieve pollution reductions, reduced energy consumption and less congestion, with the final objective to create more liveable and sustainable cities. The 'Shift' model also tries to maintain existing patronage of public transport, while looking at shifting people from cars to public transport. One of the tools, aiming at increased use of public transport or transit is called 'Transit Oriented Development' (TOD). TOD relates to planning for urban development around transit nodes. TOD as a planning tool is expected to integrate the land use and transport systems, thereby creating lively, sustainable, pedestrian friendly areas/ neighbourhoods. Such a development encourages people to use non-motorised means of transport like cycles for their short trips and use transit for their longer commutes; thus contributing to 'Avoid' and 'Shift' models.

The concept of TOD has been worked upon by many and since many years. Many TOD case studies have also been reviewing and evaluating the success or failures of TOD projects, however no thorough scientific analysis on measuring existing TOD levels has yet been carried out, even though there are many station area studies related to TOD. TOD levels indicate the level of transit-orientation of urban development in an area. Evans and Pratt (2007) also refer to the same as 'TOD-ness' of the urban development in an area. 
Thus, high TOD levels imply higher transit orientation or high TOD-ness. Measuring the existing TOD levels should help us understand how transitoriented an area is and what the reasons are for the same. We believe that this can further support making more effective TOD plans with higher chances of success. As is shown in the next section, planning for TOD in various case studies around the world usually entails increasing the urban densities and/ or creating mixed-use development. Sometimes, it is coupled with improvements in the transit system too. However, all areas have different requirements that can be best understood by a more thorough assessment of the existing situation. A number of station area studies have done so but they classify areas into typologies. The resulting typologies contribute to a more qualitative TOD analysis that contributes to a better understanding of the area but does not directly lead to plans that make it more transit-oriented. This research identifies this gap and aims to measure existing levels of TOD of different areas using a more quantitative approach, the results of which can be directly used for planning TOD projects

In the next section, literature has been extensively reviewed and various case studies have been discussed to understand various aspects of TOD. The gap identification has been done in section 1.3, leading to the aim and objectives of this research in section 1.4. Section 1.5 describes the broad methodology and section 1.6 introduces our case study.

\subsection{Literature Review}

Since the conception of TOD in (Calthorpe, 1993), the subject of TOD has been discussed, studied, and implemented in many cities. The following subsections discuss the concept, definitions and components of TOD, physical characteristics that make a successful TOD, the regional, urban and local scale planning of TOD, the most suitable transit system for TOD development and methods of TOD evaluation and measurement. The case studies found in literature have also been studied.

\section{What is TOD and what is its aim?}

TOD has various definitions given by different authors. Peter Calthorpe, who is considered the pioneer of the TOD concept, has defined TOD as "..... mixed use community within an average 2000 foot walking distance of a transit stop and core commercial area. TODs mix residential, retail, office, open space, and public uses in a walkable environment, making it convenient for residents and employees to travel by transit, bicycle, foot or car" ((Calthorpe, 1993) p56). The walkable environment is the key aspect of TOD, according to him, while through TOD, sprawl can be controlled and car trips reduced by letting people walk to complete their work trips, including walk to and from transit 
stops (access and egress). Transit is hence used for trips that cannot be completed on foot.

According to Schlossberg and Brown (2004)(p2), "Transit Oriented development (TOD) represents an integrated approach to transportation and land use planning". The main goal of TOD, according to them, is to create more benefits than costs at both the regional and local scale.

Boarnet and Crane (1997a)(p191), describe TOD as ".....the idea that land near rail transit stations should be developed or redeveloped in ways that encourage the best use of the transit system and that leverages the public investment in rail transit". They also define TOD as "...the practice of developing or intensifying residential land use near the stations". Since their work was specifically about residential areas near rail stations, their description of the concept is also narrowed down to the residential areas and rail transit.

In 2002, Parker and his colleagues conducted a research on factors for success of TOD in California, for the California Department of Transportation and they defined TOD in their report as ".....moderate to higher density development, located within an easy walk of a major transit stop, generally with a mix of residential, employment and shopping opportunities designed for pedestrians without excluding the auto. TOD can be new construction or redevelopment of one or more buildings whose design and orientation facilitate transit use" ((Parker et al., 2002) p3).

Reconnecting America, a national (US) non-profit organization working on TOD, has defined TOD as "...really about creating walkable, sustainable communities for people of all ages and incomes and providing more transportation and housing choices (including town-homes, apartments, livework spaces and lofts). These neighbourhoods provide for a lifestyle that's convenient, affordable and active, and create places where our children can play and our parents can grow old comfortably" ((CTOD, 2009) p2).

Hale and Charles (2006)(p1), provided a working definition of TOD in their paper as "A vibrant, relatively dense and pedestrianized mixed-use development precinct, featuring quality public space and immediate access to high-frequency public transit."

Dittmar and Poticha (2004) (p22), have given a performance based definition of TOD saying that "The term Transit Oriented Development should be reserved to refer to projects that achieve five main goals - location efficiency, rich mix of choices, value recapture, place making, resolution of tension between node and place." In the same book (p22), they have said 
that the main goal of TOD is not to "....create physical form but rather to create places that function differently than conventional development" and also support functioning transit system. Some more definitions by various other authors have been provided in the table 1.1 .

\section{Table 1.1: TOD as defined by various authors}

\begin{tabular}{ll}
\hline References & Definitions \\
\hline Salvesen (1996) & $\begin{array}{l}\text { Development within a specified geographical area } \\
\text { around a transit station with a variety of land uses } \\
\text { and a multiplicity of landowners }\end{array}$ \\
\hline $\begin{array}{ll}\text { Bernick and Cervero } \\
\text { (1997) }\end{array}$ & $\begin{array}{l}\text { A compact, mixed-use community, centered } \\
\text { around a transit station that, by design, invites } \\
\text { residents, workers, and shoppers to drive their } \\
\text { cars less and ride mass transit more }\end{array}$ \\
\hline Maryland Department & $\begin{array}{l}\text { A place of relatively higher density that includes a } \\
\text { of Transportation }\end{array}$ \\
& $\begin{array}{l}\text { mixture of residential, employment, shopping and } \\
\text { civic uses and types located within an easy walk of } \\
\text { a bus or rail transit centre. }\end{array}$ \\
\hline Bae (2002) & $\begin{array}{l}\text { A means of reducing automobile dependence, } \\
\text { promoting more compact residential development } \\
\text { and fostering mixed land uses. }\end{array}$ \\
\hline Still (2002) & $\begin{array}{l}\text { A mixed-use community that encourages people to } \\
\text { live near transit services and to decrease their } \\
\text { dependence on driving }\end{array}$ \\
\hline Cervero et al (2004) & $\begin{array}{l}\text { TOD is a tool for promoting smart growth, } \\
\text { leveraging economic development, and catering for } \\
\text { shifting housing market demands and lifestyle } \\
\text { preferences. }\end{array}$ \\
\hline The design and mixed-use features of TOD may \\
Thed from Li and Lai \\
reduce both work and non-work automobile trips.
\end{tabular}

Given the diverse nature of definitions for TOD, it can be inferred that there is no standard definition for this concept. Its definition changes as its purpose or aim changes. TOD is expected to aim at integrating land use and transit, encourage the best utilisation of transit, create compact development, create a modal shift from cars to transit and promote smart growth and more. Different stakeholders or involved parties also have different requirements and hence have different aims of developing TOD and hence their definitions of what TOD should contain, differ.

Dittmar and Poticha (2004) observed that the available definitions are more descriptive in nature and mainly talk about physical form, which drew them to provide a performance based definition of TOD (given earlier). However, on further reading of the same, it becomes clear that 'location efficiency' and 'rich mix of choices' translate into medium/high density, transit accessibility, pedestrian friendliness and land use diversity/ mixed land uses. 'Place 
making' and 'resolution of tension between node and place' also translate into mixed use areas with good pedestrian access. There is hence, not much of a difference between their definition and others because measuring TOD under this performance based definition will also involve measuring the physical form, like others. Some of the benefits that TOD projects are expected to bring, can be listed below:

a. Increased access to public transportation and hence to more opportunities,

b. Utilization of already serviced land rather than servicing sprawls

c. Increased location efficiency by allowing people to walk, bike and take transit at the same location

d. Increased transit ridership and reduced vehicular traffic pollution, consumption of oil and gas etc.

e. Financial and economic benefits to public and private sector investors and public at large - increases property values, returns on projects, creates healthy market competition.

f. Bringing the community together - healthier lifestyles, safer neighbourhoods, lively societies.

On careful understanding of the above, one may realize that none of these can be realized by developing mixed use, higher densities or a walkable environment alone. An area with all these features and proper access to a good transit system still require land use -transit integration. This means that urban dwellers should have a clear access to the transit node and transit users should have a purpose to get down at the transit node to access opportunities around it. In the absence of such an interaction, the two systems - land use and transit, shall stand alone, independent like acquaintances but not friends. This is also called TAD, an evil brother of TOD, as categorized in (Halbur, 2007). TAD is 'Transit Adjacent Development', whereby the development around a transit station just sits there and has little or no orientation or interaction with the transit system. Measuring TOD for an area, we believe, can help in identifying reasons due to which an area acts more like a TAD than TOD.

\section{Transit type and TOD}

The design and quality of the transit service has a major impact on success potential of the TOD and a TOD plan can fail if the transit is not attractive enough. As a thumb rule, a good quality transit system must be a high frequency service along fixed lines and fixed times which make it dependable. In addition, a seamless and legible transit network with integrated ticketing, times transfers, digital instant-information displays are required to make transit attractive and user-friendly. 
Generally, the type of transit should not affect the success potential of TOD as long as it is an efficient, dependable and good quality system, but literature shows how there are different views on the same. For example, Newman (2009) opines that for the transit system to be successful, it must be able to compete with private transport in speed and capacity. Buses have higher capacity than cars but are slower since their average speeds do not go beyond $20-25 \mathrm{kmph}$ while those of cars go up to $35-40 \mathrm{kmph}$. Rail-based systems, specifically electric rail, have higher capacities than buses too and have higher speeds to compete with private transport. It also does not have to carry its own fuel. He thus, proposes that a TOD must be around an electric rail-based transit system. Newman and Kenworthy (2007) also state based on an analysis of 84 cities in the Millennium Database, that rail systems are faster in all 84 cities by $10-20 \mathrm{kmph}$ over bus systems that rarely average over $20-25 \mathrm{kmph}$. Busways can only be faster than cars in carsaturated cities but for lower density car-dependent cities, only rail can be faster than cars. The European and Asian cities with the highest ratio of transit to traffic speeds have also achieved it with rail not bus. In a study of over 100 TOD projects in 12 regions across U.S.A. (Cervero, 2004), it has also been found that people are more likely to choose transit over private transport if the transit is heavy rail-based instead of bus-based.

Other researchers suggest that a new generation of high quality rubber tire networks of bus-ways, low-floor buses; separate ROWs provide the modern buses an edge in speed and capacities comparable to rail-based transit system (Hale \& Charles, 2006). Such a modern and prioritized bus system is called the Bus Rapid Transit System or a BRT. McKone (2010) mentions that in the U.S. BRT has not been successful in sparking TOD and therefore developers perceive bus corridors to be less attractive than light or heavy rail. Plus, bus lines are often seen as the degraded mode of transport for lowincome riders in the U.S., in contrast to the Metro/ MRT (heavy-rail-based transit) that connects wealthy suburbs to the centre. In (Newman \& Kenworthy, 2007) also, it is mentioned that BRT is a filling niche between rail and conventional buses. A proper BRT with dedicated lanes, pre-paid fares, level boarding and intelligent information systems, can fit onto an existing road and is a lot cheaper than rail. With dedicated lanes and thus better speeds, BRT can carry 20,000 passengers per hour while a regular bus can carry only 8,000 passengers per hour.

Hoffman (2006) says that on comparing the operating systems and costs of rail and bus, it can be seen that buses can serve more passengers. He mentions that., "rail systems in North America rarely offer operating cost benefits compared to comparable rubber tired-based systems" ((Hoffman, 2006) p107). It is also because the planning studies that show rail systems to have advantages in cost over buses are based on wrong assumptions on 
how the BRT systems are actually deployed. Lower operating costs of BRT permit higher frequencies, flexibility, interconnections to other bus lines. All these reduce the vehicle round-trip cycle times and serve more riders. The BRT systems in Curitiba and Bogota are standing testimonies to these claims. The traditional rail systems, on the other hand, typically stop at every mile and force multiple transfers, slow journeys, lower frequencies and high operating costs. Using buses, some routes can also serve stations that are located off-corridor. The choice of transit type should depend on the number of people to be transported and the space available in central urban areas. For example, in Mumbai, India, 5 million people commute by train daily and the space is so scarce that buses cannot cater to this huge demand (Newman \& Kenworthy, 2007).

According to Cervero and Dai (2014), BRT systems of different shapes and forms, all try to mimic the high capacity and high performance of urban rail. However, the costs of BRT can be 4 to 20 times less than Light-Rail Transit (LRT) systems and 10 to 100 times less than metro-rail systems. A dedicated right-of-way for BRT distinguishes BRT from regular bus operations (typically mixed traffic operations) also called 'BRT Lite'. BRTs are also believed to not just offer metro rail benefits at a lower cost, but also flexibility and versatility advantages that rail-based systems do not offer Because of this inherent flexibility, BRT may well be suited to serve lower density urban developments or the ones that are spread out in nature (Yang et al., 2012).

While there are varied views on suitability of rail or bus systems for a transit oriented development, it is important to keep in mind that success of TOD depends on the quality and design of the transit system, namely speed, capacity, dependability and high frequency. Any transit type that is able to offer these benefits can be effective in supporting TOD. In general, regular buses can be slower and less inefficient than BRT and rail-based systems and thus are not the best choice for creating TOD.

\section{TOD and DOT}

Like the chicken and egg story, transportation and urban development both follow each other. A transport service is meant to cater for travel demand that is generated by urban development but on the other hand urban development cannot start on its own without any kind of transport system. Hence, there is no thumb-rule if transport comes first or development comes first. The case with transit, however, is different from a general transport system. For new developments, a single road (a form of transportation) can also provide connectivity and one doesn't need transit to do so. Transit comes into picture only when there is enough travel demand to justify its need. Hence, transit almost never comes before the development and must follow the travel demand. Thus, in almost all places all over the world, the 
development has to be present to necessitate transit development. And, where travel demand precedes or leads to a transit service, 'Development Oriented Transit' or DOT is created. It is however, possible that after implementation of a transit system, the areas around stations are 'redeveloped' to further orient themselves to the transit. This scenario of redevelopment can be called TOD. While DOT caters for existing travel demand, TOD creates it. The four strategic principles for implementing TODs set by Newman (2009) also put 'planning for centres of development' before the transit development, which is then followed by (re)development of the centres and project level implementation on ground.

\section{Must TOD always be medium/ high density and mixed use areas?}

Curtis et al. (2009a) suggest that transit use can only be encouraged if it is able to compete with the flexibility and speeds of private transport such as the car. This combination of high flexibility and good speed can only be achieved by transit in the presence of short distance trips and/or high urban density patterns. Hence, for TOD to successfully support the transit, it should be medium to high density area.

There is also a stress on mixed use development around the stations/stops in various definitions since the mixed use character creates more balanced and consistent passenger flows - at all times of the day, all days of the week and throughout the year. The increased and varied passenger market contributes to higher revenues and better utilization of transit capacity (Bach et al., 2006). From another point of view, mixed use is important such that all services are available within walking distance of residential areas and in general these places are safer, lighted and allow better interaction among people from all walks of life. Places that are either employment centres or bedroom towns, have only peak hour traffic and stations, transit and areas around transit can be quite dull, unsafe and lack life during off peak hours . Hence, the purpose of mixed use is to create or plan for destinations that have complimentary uses such that they work together to make a neighbourhood focus area.

The case of Singapore ((Yang, 2009)), like most Asian cities, is different in the sense that housing is decentralized and spread out over the CBD while the service/retail/employment centres are intensified in the city centres. The increased distance between the residential location and activity centres gives rise to a demand for travel and hence the ridership on MRT or LRT. The station areas are not all mixed use areas and yet, the development has been called transit-oriented.

There is another argument that if all the station areas are mixed use, then it is plausible that either these areas become self-sufficient or connected to 
nearby stations for the purpose of work, study etc. In these scenarios, the demand for travel will reduce or may be limited to short trips, thereby affecting or even eliminating demand for transit. Various studies have also suggested that rail transit is not preferred for short distance trips. Hence, mixed use may not necessarily lead to increased ridership of rail transit.

Nevertheless, the locations that aren't mixed use cannot and should not be excluded from being counted as TOD, as long as they fulfil the aim of TOD. While planning for TOD, the emphasis is on increasing the supply of mixed use development near transit and mixed use is most often defined as residential over commercial/retail (Zimbabwe \& Anderson, 2011). Studies show that more than $60 \%$ of the transit trips are work trips and also that concentrating work centres or employment opportunities near transit goes together with higher ridership. Hence, locating non-residential uses and increasing jobs near transit nodes should lead to higher ridership, at least in the peak hours.

In a paper by the Centre for Transit Oriented Development (CTOD) on corridor planning (CTOD, Oct. 2010), there are three types of transit corridors based on the type of development along their route and the function they play in commuting people. Different types of corridors have different type of TOD potentials/ opportunities. These corridor types are:

a. Destination Connectors - this corridor type connects residential areas to multiple activity centres such as those of employment or retail, health, education etc. Since multiple centres with different uses are connected, these corridors enjoy patronage at almost all times of the day.

b. Commuter - Unlike the above, this corridor connects residential areas to generally only one activity centre, usually the CBD. Hence, the traffic on this corridor peaks in the mornings and evenings. The transit service accordingly, runs on a high frequency during peak hours and tapers off during off-peak hours.

c. District Circulator - This corridor is localized in nature and typically runs within an activity centre or node such as a downtown, medical centre, university campus etc. Street cars are an excellent example of transit that runs on such corridors

If we look at the types of uses then we see that the destination connectors do not have mixed use at all the stations/stops. But it has a variety of uses along the corridor. In commuter corridors also, there isn't mixed use at all stations. In fact, the variety of uses is also absent along that corridor type. It connects mainly two nodes with two distinct uses. The district circulator corridors run locally within the same activity centre and here too, the land use can be predominantly of one type (except in down-town area). Hence 
according to (CTOD, Oct. 2010), mixed use development may not be necessary for high transit ridership. However, mixed-ness of land uses holds the potential to create a place out of a node, which is also important for TOD.

\section{At which scale is TOD planned?}

The Centre for Transit Oriented Development (CTOD) and Reconnecting America (Zimbabwe \& Anderson, 2011) stress that planning for TOD must be done at regional, urban and local scales as planning goals at each scale can be incorporated properly. At the same time, since the transit oriented development is about conducive development around the stops/stations, this (local) scale of planning for TOD is most crucial. In the TOD handbook of Calgary city (The City of Calgary, 2004), it is mentioned that "The distance that a person is willing to walk to take transit defines the primary area within which TOD should occur. This distance is equivalent to roughly a 5 minute walk, or 400 to 600 meters. At these radii around a station, there is potential for 125 to 250 acres of land for transit oriented development".

However, for the entire transit system to have TOD, it is important for station plans to stitch together in the larger picture at urban and regional level. A successful TOD requires thinking and planning beyond the individual station and understanding the role of each station and its neighbourhood in the regional network of the transit system. Planning for TOD at the regional level aimed at coordinating the existing plans for growth, infrastructure etc. at urban levels and identifying common goals and coordination among all agencies. state that to take TOD plans from the conceptual to the actual stage, investments need to be made in developing projects in key locations throughout the region. At the lowest scale, i.e. station area and its neighbourhood level, it is important to understand the pulse of the community and promote/develop transit oriented activities.

It has been suggested by other authors as well that for a TOD to make a substantial and meaningful difference in development patterns, it must be done at the regional level and not exclusively in the area within the quartermile of a local station/stop. Newman (2009) discusses why planning for TOD cannot be done solely at the local level. He points out that while planning for densities and development mixes, the local government's plans must adhere to regional priorities. Local government is usually very closely tied in the local politics and there may be local groups who are opposed to redevelopment plans and density increases. While TOD should enable affordable housing near the stations, local communities may not prioritize this development as people often believe that high density can be socially dangerous and unhealthy. Thus, to ensure regional priorities do not get diluted at the local level, planning for TOD cannot be left to local politics. 
Hence, it can be inferred that planning for TOD cannot be restricted to any one level as public transport covers large parts of the urban/ regional areas and area-wide planning is very important. At the same time, station level planning remains crucial since that is where the project implementation takes place.

\section{How is TOD planned for?}

Some of the studies (Bertolini, 1999), (Balz \& Schrijnen, 2009), (Reusser et al., 2008), (Zemp et al., 2011), (CTOD, 2013), (DeltaMetropolisAssociation, 2014), (Chorus \& Bertolini, 2011) and (Kamruzzaman et al., 2014) to name a few, have studied the station areas by measuring indicators related to transit and development, called node and place indicators respectively. Models, such as the node-place model by (Bertolini, 1999) and the Butterfly model by (DeltaMetropolisAssociation, 2014), suggest that node should be in balance with the place for all station areas. Based on that suggestion, various station typologies were created depending on that balance and stations were slotted into the 'best-fitting' type. While there is nothing wrong with the methodology, we believe that the recommendations so-made, will not be equally effective for all stations within the same typology. One of these studies, for the Netherlands, has been described below. Some other case studies where TOD has been planned are also discussed.

a. The Stedenbaan, The Netherlands (Balz \& Schrijnen, 2009): In the South Wing of Holland this project is a good example of planning for TOD at the regional scale and adoption of those plans at the urban and further at the station level. The project used the TOD concept to bring the South Wing out of the economic slowdown by creating higher intercity rail connectivity and developing the area around all stations. The project utilized existing lines and intensified service on these and created new stations for higher connectivity. All station areas, existing and proposed, were studied and categorized into nine station typologies. All stations were then planned according to their station typologies. These plans will be adopted by the local municipal bodies for implementation.

b. Regional Metro system of Naples and Campania, Italy (Cascetta \& Pagliara, 2008): The regional train system in Campania, Italy is an example of a regional transit plan forecasting its impact on the urban structure along the transit corridor. The project, however, did not create any transit oriented developments except for allowing higher densities along the transit corridor. The project was more about creating a good, accessible and user-friendly transit system providing high levels of connectivity. In fact, the poorer sections of society had to move out to 
peripheries because of an increase in land prices in the centre due to the project and this is not the intended outcome of TOD.

c. Regional TOD plans - Perth Region, Australia (Renne, 2009a): Perth's regional plans are also an example of promoting TOD at the regional scale. The regional plan consists of a 25 year planning strategy called 'Network city' covering 3 spatial elements namely 'transport corridors', 'activity corridors' and 'activity centres'. An urban level plan named 'Metropolitan Region Scheme' is in accordance with the 'Network City' and has identified station precincts where public interventions like land acquisition etc., will be needed to promote TOD. Planning being a state subject also helps in stitching the plans better at regional and urban level.

d. TOD in Singapore (Yang \& Lew, 2009): At urban level, in Singapore, TOD was planned by developing newer towns at the intersection of rail (MRT) corridors. Intensification of the existing towns was also encouraged by tripling the Floor Area Ratio (FAR) at retail nodes. These retail nodes were also shifted near transit stations to create TOD. Existing towns were made more pedestrian friendly and all these efforts led to a very integrated land use-transit system. The land use near the transit stations however, is not entirely mixed since the central areas are more commercial and have office spaces while the residential areas are farther from the centre, towards the periphery. Yet, this has worked in favour of the MRT because it was found that people prefer to take rail rather than bus for longer commutes as in this case.

e. TOD in Tokyo, Japan (Chorus, 2009): Tokyo boasts of TOD at the urban level, dating back to the Second World War. Railways have historically been owned and operated by the private sector in Tokyo. Since the private sector also owned land adjacent to the railway lines, it promoted development that would increase rail ridership levels. The central circular rail line is owned by the government in Tokyo. The government started TOD measures in the 1970 s after pressure from the private sector that wanted to build more in the centre and other areas connected by rail service. Since the government had limited resources, it allowed higher FARs and changed zoning plans in order to allow for higher densities of development. A combination of FAR tools can lead to a FAR as high as 1650! However, these measures have received flak for not considering the suitability of the development and only focusing on high densities.

f. Subi Centro in Subiaco, near Perth, Australia (Howe et al., 2009): In contrast to the above case studies, the case of Subiaco near Perth is an example of TOD at station level. More specifically, it is about 
redevelopment of a large tract of land (80ha) next to a train station, by creating mixed use development. The project was highly successful in bringing life to an otherwise dull suburb town which is now a profit making venture. This has also led to increased train ridership from this particular station. Most importantly, this is an example where the community stood together and took a project in its own hands, against the local development authority and revitalized the entire place.

g. Portland's TOD evolution, U.S. (Arrington, 2009): Portland is an example of regional level TOD planning, even on green-field, value capture to fund transit development and taking planning to realization by implementing projects. Portland region has the most aggressive TOD planning in the U.S. The region has the ' 2040 Growth Management Strategy' that focuses in 'Build Up' and not 'Build Out'. The authorities believe that market forces will lead to TOD on their own but financial incentives are required to push the private sector to perform better. Hence, the transit agencies TriMet and Metro with PDC (Portland Development Commission) got involved in implementation of various projects at station level by funding directly or in kind (through land) etc. with a focus of not funding financially feasible projects. In 1995, Portland started building transit on green-field in anticipation of travel demand and the project was successful. The region has also used value capture to fund in airport corridor extension in 1996.

h. Curitiba, Brazil (McKone, 2010) (Lindau et al., 2010): Worldwide the Bus Rapid Transit System of Curitiba is famous for first class service levels, high patronage, and meticulous planning that went behind it. Curitiba has also initiated TOD efforts to encourage higher patronage on their buses by allowing very high densities along main corridors of the BRT system. The result is high density tall, commercial offices and residential buildings along the BRT corridor with the skyline flattening away as one moves away from the BRT corridor.

i. Bogota, Columbia: Like Curitiba, Bogota planned for a highly successful BRT with lessons from the former. Bogota built 235mile BRT - all for the cost of a single heavy rail metro line. Its investments in BRT were matched equally with major efforts to expand sidewalks, create parks, civic spaces along the BRT corridor. The city has $17 \mathrm{~km}$ long pedestrian streets along the main BRT axis connecting schools, recreational facilities, parks, neighbourhoods etc. The BRT's operating capacity of 35,000 persons per hour per direction and speeds of $28 \mathrm{kmph}$ are comparable to those of rail systems. 
j. Rail \& Property $(R+P)$ development in Hong Kong (Cervero \& Murakami, 2009; Loo et al., 2010): The city's rail owner and operator - MTRC is one of the few transit agencies in the world to earn profits. The agency works on a rail + property development model effectively capturing the value created by the transit system and using the same in further development of transit. MTRC is $23 \%$ owned by private shareholders and the rest by the government. With a business-minded approach, MTRC buys development rights to land adjacent to train stations (from the government) at before-rail price and sells the rights to private developers at after-rail price. The development that ensues is financially feasible and is transit oriented too. MTRC is able to cover its construction, operation and maintenance costs and to make profit by using value capture mechanism. To make developments more transit-oriented, stress is now more on pedestrian friendly design and building civic amenities and it is estimated that TOD designs will add about 35,000 weekday passengers on transit.

Thus, it can be seen how TOD has been planned at different scales regional, urban and local scales and in different approaches. Some have improved transit services and anticipated a natural growth of TOD, some have improved densities by increasing FARs and some have built a mixed-use development around transit nodes. Value capture mechanisms and the private sector have been involved in some cases.

\section{How are TOD projects evaluated?}

Success or failure can be gauged only when we know the ultimate goal of a step taken. Since stakeholders in TOD projects might have different objectives, the criteria for evaluation will also differ. Renne (2009b) points out that measuring the success of TOD depends upon the perspectives of the stakeholders. Every stakeholder has its own expectation out of the TOD project. While the state and regional level planners want TOD to reduce the urban sprawl, traffic congestion, improve housing etc., transit agencies look for increased fare and non-fare revenues. Local governments look for higher employment, taxes and revenues etc. from TOD. Thus, evaluation of TOD projects can be a daunting task.

Another important issue is deciding on a benchmark for comparison. Renne (2007) recommended two approaches - the Regional Performance Approach (RPA) and Community Performance Approach (CPA). The former includes comparison between
a. Two or more TODs
b. TOD and a non-TOD
c. TODs and regional averages. 
Under the CPA, a monitoring system specific to the community can be created to track TOD indicators towards achieving the local goals. Since communities form the backbone of all stakeholders, it is this level that is most important. It has also been seen that community goals often match those set at regional or state levels. For both the processes, there is an evident need for data to be collected (at regular intervals), compiled and analysed. Over time, a holistic success can be measured using RPA to see how a particular TOD compares with the rest of the region and using CPA to see if the local goals are met.

He also discussed that among the three sub-approaches to RPA, it is better to compare a TOD with regional averages rather than comparing a TOD with non-TOD since it is almost impossible to find two developments that exhibit similar characteristics for comparison purposes. It is however, possible to compare a TOD's success by collecting the baseline data for the same location, before the TOD is initiated and comparing those with the data collected in later years. This can help in the evaluation of a success of a particular TOD project/precinct i.e. at station level. This method was used for the Perth area, Australia. The study collected data through secondary surveys and household surveys for the existing conditions around transit stations. After the implementation of TOD measures, data will be collected again from similar sources and compared with the baseline data to see and measure the differences in the ground conditions due to TOD measures. The collected data report how residents within $800 \mathrm{~m}$ of the transit stations feel about their neighbourhood, use the services and transit and how they commute on a daily basis. It is expected that new data collected post-TOD will present a change in this pattern for better.

A NCHRP Research digest by Renne and Wells (2005) developing a strategy to measure the success of TOD. This digest has built on a number of projects in America such as the New Jersey transit village, Portland, California and other various case studies across America. It has identified and evaluated the indicators and identified the 10 best indicators that can be used to monitor and measure the impacts of TOD. It claims that except for studies focusing on transit ridership and land values near the stations little empirical studies have been carried out to measure the impacts of TOD in a holistic manner. The ten most useful indicators suggested by this report are enumerated (as ranked) below.

1. Transit ridership

2. Density of development

3. Quality of streetscape

4. Quantity of mixed use development

5. Pedestrian activity and safety

6. Increase in property value and 
7. Increase in tax revenue

8. Public perception

9. Number of mode connections at the station/ stop

10. Parking

These indicators were short-listed after studying various indicators, their review on websites, printed material and follow-up on phone calls to transit and other development agencies.

Belzer and Autler (2002) argue that there is no standard benchmark for success of TOD since there is no universally accepted premise about what TOD should accomplish. They also believe that the varied definitions of TOD, available in literature, concentrate more on the physical form or design of TOD rather than the functional outcomes it should achieve. Hence, they propose a set of 6 performance criteria that can be used to evaluate project function and outcomes at station level. Using these, they believe, the real potential of TOD can be gauged. These criteria are:

a. Location Efficiency (ability to access jobs, recreation activities and amenities, retail etc. within walkable or biking distance)

b. Value recapture (location efficient mortgage program, increased home ownership, reduced spending on transport)

c. Liveability (better air, health, safety, economic health, access and reduced congestion etc.)

d. Financial Return (higher tax and fare revenues, return on investment)

e. Choice (of housing, transport modes, retail, recreation etc.)

f. Efficient Land Use patterns at Regional level (lesser sprawls and land used for roads)

It may be noted that the above criteria are very familiar to the performance measures mentioned in the definition of Dittmar and Poticha (2004), mentioned earlier. The authors have also suggested the ways of measuring these criteria using measurable outcomes of each of the above. It may however, be noted that these criteria require a lot of data, the collection of which can be a daunting task and not even possible at all times.

At the urban level, a TOD can be evaluated for success by measuring the increase in tax revenues, increase in transit ridership, increased land values and such. It is however, highly difficult to measure the regional level impact of the TOD. Nelson and Niles (1999) identified and listed 16 factors that can determine the success of TOD at regional as well as local scale as 'Factors Determining the Success of TOD'. They have however, also asserted that the regional level impact of TOD is only a vision in the mind of planners and cannot be quantified. 
An interesting work by Nelson and Niles (1999) proposes an approach called 'Backcasting Delphi' by which planners can understand which measures are required to achieve a desired TOD result. Basically, it works backward by determining what is desired and then identifies the necessary policies and actions that will produce that desired TOD outcome. This approach blends 'Delphi study' with 'Backcasting'. Delphi study is an older approach of using diverse expert opinion to reach consensus through an iterative process and Backcasting is the newer approach to work backwards from the desired result. Even though this work is interesting because it helps in judicious use of resources and justify the necessary large investments that may be required in development actions, it still does not help in assessing/ measuring the existing levels of TOD.

Various indicators discussed above have been recommended for evaluation of TOD projects but the discussion often ends at paucity and difficulty in obtaining data for those criteria. There are very few examples where TOD results were quantified to confirm if the project was successful or failed. Among these too, some urban indicators had been measured separately but a comprehensive TOD measurement was not found. There is no composite indexby which levels of TOD can be measured - for the present or past. One such index - the TOD index - was introduced by Evans and Pratt (2007). Such an index, they said, is helpful in characterizing the TOD-ness of projects or areas around transit. They even suggested a number of essential indicators that are required by a project/ area to qualify as TOD. Those essential indicators are: centrally located transit, pedestrian priority, high quality transit, mix of uses, supportive density and parking management. Some supportive indicators - street widths and driveways, roadway access, housing types, car sharing and transit support - were also proposed. The TOD-index, however, remained only a suggestion for future work and was never realised for any case study.

\section{TOD and Spatial Analyses}

Schlossberg and Brown (2004) p2, point out that it is the "...fine grained, spatially explicit types of analyses that have been lacking in TOD..." efforts. In their work, they have used GIS-based walkability measures and analysed the walkability of 11 TOD sites in Portland. It is also mentioned by them that "Visualizing urban form is also an important component to understanding walkability, especially for public understanding and participation in the planning process." ((Schlossberg \& Brown, 2004) p4).

This has also been stressed upon by Cervero and Bosselmann (1998) in their work on visual simulation of possible TOD scenarios. Their work assesses the market potential of transit villages using visual simulation techniques. Photoslide images were created to simulate a walk through four neighbourhoods 
with different density and amenity mixes to give the residents a visual idea of what their neighbourhood will look like under higher densities and more amenities. It is believed by them that "visual simulations provide a richer context for probing the market potential for transit-oriented development than do traditional market research approaches because visual simulations convey a wider array of environmental choices" ((Cervero \& Bosselmann, 1998) p1).

There are a few basic reasons why TOD needs a spatial analysis platform. Since TOD is all about land use and transport planning, spatial analysis using maps and plans is inevitable. The definitions also suggest that the catchment areas of various transit systems in TOD should be $0.025 \mathrm{~km}$ to $0.5 \mathrm{~km}$. The planning and evaluation of TOD has spatial genesis and implications that needs to be analysed, understood, represented using spatially explicit types of analyses. Various indicators for evaluation of the TOD, as given earlier, are also spatial in nature and those that are not, can be spatially represented on a GIS platform.

Further, TOD assessment or evaluation is done using multiple indicators and hence a multi-criteria assessment is inevitable. Add to that the fact that TOD is planned at different scales - station level, corridor level and area-wide; we need a multi-scalar, multi-criteria spatial assessment tool such as Spatial Multi-Criteria Analysis (SMCA) which is possible only over GIS. To sum up, planning for TOD needs a multi-scalar, multi-criteria spatial assessment tool that also allows incorporation of multi-stakeholder viewpoints.

\subsection{What is the gap?}

Public investments in infrastructure such as for TOD are too often made without understanding the existing situation and possible outcomes of the plans. Renne and Wells (2005) concluded in their report on measuring TOD that there is a lack of comprehensive tools for measurement of TOD or TODness. Measuring TOD-ness will not just help in better planning for TOD but also in evaluating TOD projects (Evans \& Pratt, 2007). There are many indicators to measure TOD as we discussed before, but there is no case in literature, where they have been used jointly to quantify TOD. The case studies that have been discussed earlier were mainly qualitative discussions by authors, who were part of a TOD project at that location and they usually describe one or more success factors behind the success of TOD at that location. These are predominantly discussions about what makes a good TOD while measuring a few urban indicators like density. There is one paper on adjudging a TOD area based on walkability indicators (Schlossberg \& Brown, 2004) using a scientific analysis tool and GIS, but that paper was only about walkability. The case study of Campania, Italy, analysed and predicted the 
impacts of transit onto areas surrounding the stations all along the transit corridor, but it did not assess the TOD levels or TOD potentials nor did it plan for TODs along the corridor. The case study of Stedenbaan, The Netherlands, was a good project where TODs were planned at stations according to their existing development potentials and new stations were planned along the existing corridor to create more TODs at station locations. All stations were mapped, analysed and clustered as mentioned in the earlier section but the TOD-ness of an area was not gauged. A number of station -area case studies discussed in detail in chapter 2 measure the existing urban development conditions, but make station typologies or TOD typologies such that the recommendations are not station-specific, but typology-specific. The implication of implementing these recommendations is that they will be more effective at some stations and less so on others within the same type.

A need for quantification of TOD-ness has also been highlighted by Evans and Pratt (2007) as they proposed a 'TOD index'. They describe a TOD Index as a "...potential device for considering the degree to which a particular project is intrinsically oriented towards transit" ((Evans \& Pratt, 2007), p.17-3 ). Such a TOD index can be used to measure characteristics of TOD and to compare different areas objectively. Planning for TOD can benefit from lessons learnt from previous TOD projects. Renne and Wells (2005), p.10, stress for example that "Without measuring the outcomes of TODs, mistakes in investment strategies will continue to be repeated". The literature is rich with case studies, where TOD projects have been evaluated qualitatively or quantified by measuring the changes in transit ridership and development densities amongst others. However, a comprehensive measurement of TOD levels in the form of a single index that can be used to measure TOD-ness for making efficient TOD plans as well as evaluation of TOD projects, has been missing so far.

\subsection{Aims and Objectives of the research}

The aim of this research is to aid planning for TOD by measuring the existing TOD levels of an area using an index i.e. a TOD index. This work will further demonstrate how the results of the index can be used to plan for TOD more effectively for a study area. It is believed that such an index will also be useful in evaluation of success/ failure of a TOD plan.

As we have seen in the earlier sections, TOD is mostly discussed in terms of development around existing transit nodes. We believe, however, that planning for TOD must not be restricted to making the development more transit-oriented. It should also include taking transit to places where development is already transit-oriented but their access to transit is poor. This wholesome approach to planning can be called 'TOD planning'. Hence, 
for complete TOD planning our research has the following three objectives to fulfil:

1. Study the transit nodes served by high-quality transit and identify those nodes where TOD-ness can be improved.

2. Study the TOD-ness over a region and identify those areas where the TOD-ness is high but access to high-quality transit is poor.

3. Develop a Planning Support System (PSS) that uses the above results and helps in making TOD plans for the study area.

For the first objective, TOD needs to be measured at the local scale around existing transit nodes and that scale recommendations will be made to improve TOD conditions. For the second objective, TOD needs to be measured over the regional scale such that areas in the region can be identified where TOD conditions are good but transit access is poor. It may be mentioned here that presence of transit is not a pre-requisite for TOD qualification. As Calthorpe (1993),(pg. 42) said, "Transit-Oriented Developments can, and ironically, should develop without transit - with justifiable focus on pedestrian and healthier community structure". Further, he said that transit is not the only goal of TOD but a 'potential end result' of TOD. For the third objective, a PSS shall be built that uses the results of earlier objectives and supports in making TOD plans. With the achievement of these objectives, we will be able to successfully demonstrate how our TOD index can be beneficial in TOD planning processes at different scales.

When measuring TOD at a regional scale, TOD is characterised by typical urban development characteristics such as density, land use diversity and urban design. However, when measuring TOD at a local scale around an existing transit node, TOD is also affected by transit related characteristics such as frequency of service, comfort, access and others as these characteristics influence people's decisions to use transit. This is not so for the regional scale as not all areas of the region are served by transit. Thus, for our first objective, both development and transit related characteristics need to be measured, while for the second objective only development related TOD characteristics. Since we measure different aspects of TOD for both objectives, one index is not enough. Hence, we developed two TOD Indices each for one of the above mentioned objectives, calling these 'Actual TOD Index' and 'Potential TOD Index'. The Actual TOD index measures TOD around actual transit nodes and the Potential TOD Index measures TOD over the entire region to identify areas that are potential locations for transit connectivity. These indices differ both in terms of where they are measured and what they measure. In the next section, we elaborate our methodology for achieving the above-stated objectives. 


\subsection{Methodology}

As mentioned earlier, Evans and Pratt (2007) have supported the need for characterizing the TOD-ness of an area and they even identified and categorized indicators that 'might likely' make up such a TOD Index. Our work is inspired by and an extension of their work. We took the concept of TOD Index to fruition with an elaborate methodology that calculates a number of spatial criteria and combines these into this TOD index. Our methodology to calculate and interpret TOD index values has been depicted in figure 1.1 .

Broadly, in our methodology, first we identify the criteria and indicators that make the TOD, and then we assess the spatial indicators individually in ArcGIS. Since some of the indicators can be spatial and non-spatial and have different units of measurement, the (Spatial) Multiple Criteria Assessment (MCA) platform in ILWIS (ITC, 2007) is used to assess the spatial indicators to arrive at comprehensive TOD Index values. In a typical MCA/SMCA process, there are a number of indicators, clubbed under criteria that constitute a composite value or an index (figure 1.2). As a part of this process, indicators are standardized and weighed. The advantages of SMCA include its capability of assessing multiple indicators and allowing the decision maker(s) or stakeholders to weigh the criteria (Beuthe (2002), Van Wee (2011)), while being transparent and back-traceable all the way. Using TOD index values, we can recommend how TOD can be improved in certain areas and which areas may be considered for better transit connectivity. 
Identification of Criteria and indicators for both indices

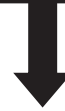

Data Collection and preparation for analysis of indicators in Geographic Information Svatem (GIS)

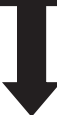

Calculation of individual indicators in ArcGIS

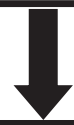

Comprehensive calculation of TOD Indices using (Spatial) Multiple Criteria Analvsis

Comparison of different areas based on TOD Index value

Recommendations on:

1. Which areas need higher TOD levels?

2. Which areas have high TOD levels but need transit connectivity?

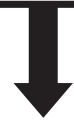

A TOD-Planning Support System to make more targeted and hence more effective TOD plans

Figure 1.1: Research Methodology 


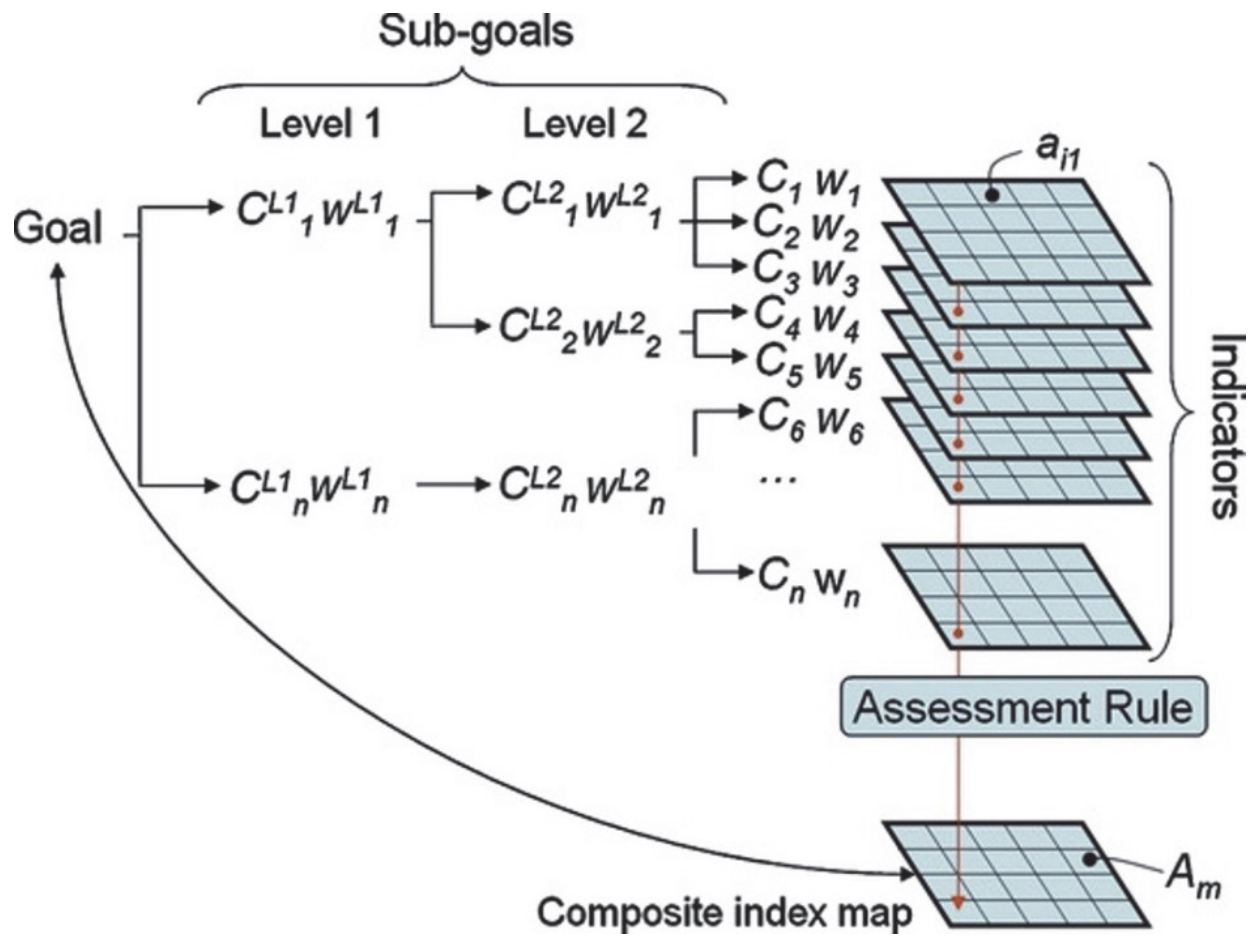

Figure 1.2: Schematic procedure of computing composite index map based on spatial multi criteria analysis.

Source: Abella and Westen (2007)

To showcase our methodology of computing a TOD index at the local as well as regional scale, we needed a regional case study in which TOD planning was proposed to achieve sustainable development. For that and other reasons, the City region of Arnhem and Nijmegen, The Netherlands, was chosen. Since the focus of this research is on developing a methodology to measure TOD-ness, the choice of case study does not restrict the usability or transferability of this methodology to other areas of the world with dissimilar characteristics. Indeed, small modifications will be required depending on the available data. In the next section, the case study is introduced.

\subsection{Case Study Introduction}

The City Region of Arnhem and Nijmegen ('City Region' hereon) aims to stimulate modal shift from cars to public transport and believes that TOD could be an appropriate strategy to achieve their aim and sustainable development on the whole. The City Region is the third largest of the eight city regions in The Netherlands (figure 1.3) and lies in the Province of Gelderland. According to many planners and TOD experts in the country, Gelderland province with its main cities of Arnhem and Nijmegen, has 
become a beacon of TOD in the country outside the 'Randstad' which is the biggest economic centre of the Netherlands (Pojani \& Stead, 2014).

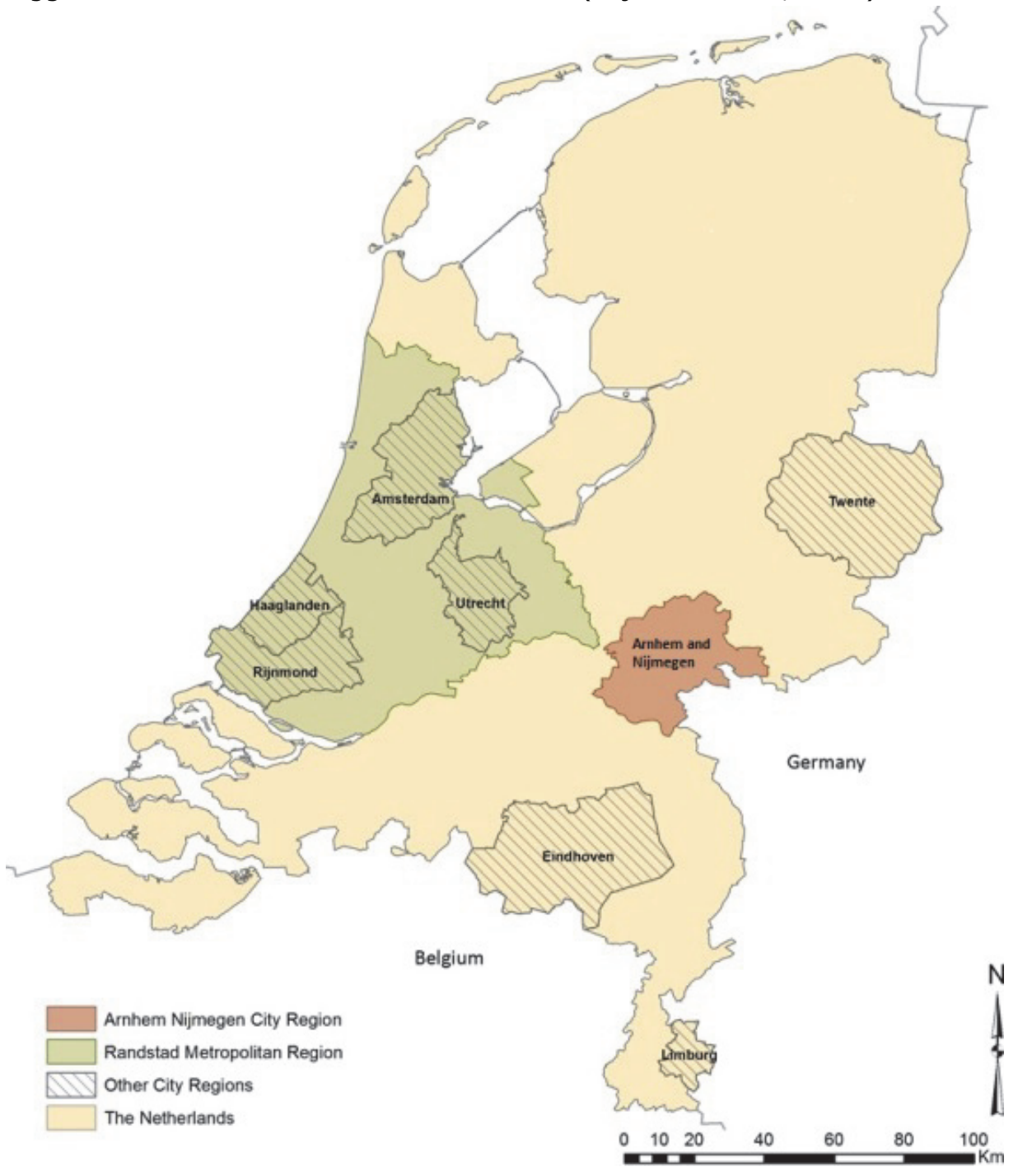

Figure 1.3: Arnhem and Nijmegen City Region in the context of the Netherlands

The City Region's policy vision is focussed on creating more housing and employment and providing higher levels of mobility. However, in the current scenario, car use is increasing for more and longer trips rather than public transport (Rijkswaterstaat, 2010). This observation fits with the overall mobility situation in the country, as reported in the Mobility Report for the Netherlands (KiM, 2013), where cars account for approximately three-fourths 
of the total vehicle-kilometres travelled in the country in 2012. To stimulate a modal shift from cars to transit, the City Region wishes to make public transport as competitive as private transport, to ensure that more commuters use transit for their regional travel demands. To do this, the City Region already offers an existing rail-based transit service and is planning for BRT. Hence, it would benefit from knowing which areas in the region require transit connectivity. Realizing such a modal shift of trips from cars to transit is one of the most difficult tasks to do anywhere in the world. However, TOD is considered a popular and effective planning tool that can bring about the desired change as shown, for example, by Cervero and Murakami (2009) in the case of Hong Kong. The City Region too sees TOD as a powerful tool that can stimulate people to choose transit over their private modes of travel. Hence, the City Region is a natural choice for the purpose of using a TOD Index for TOD Planning.

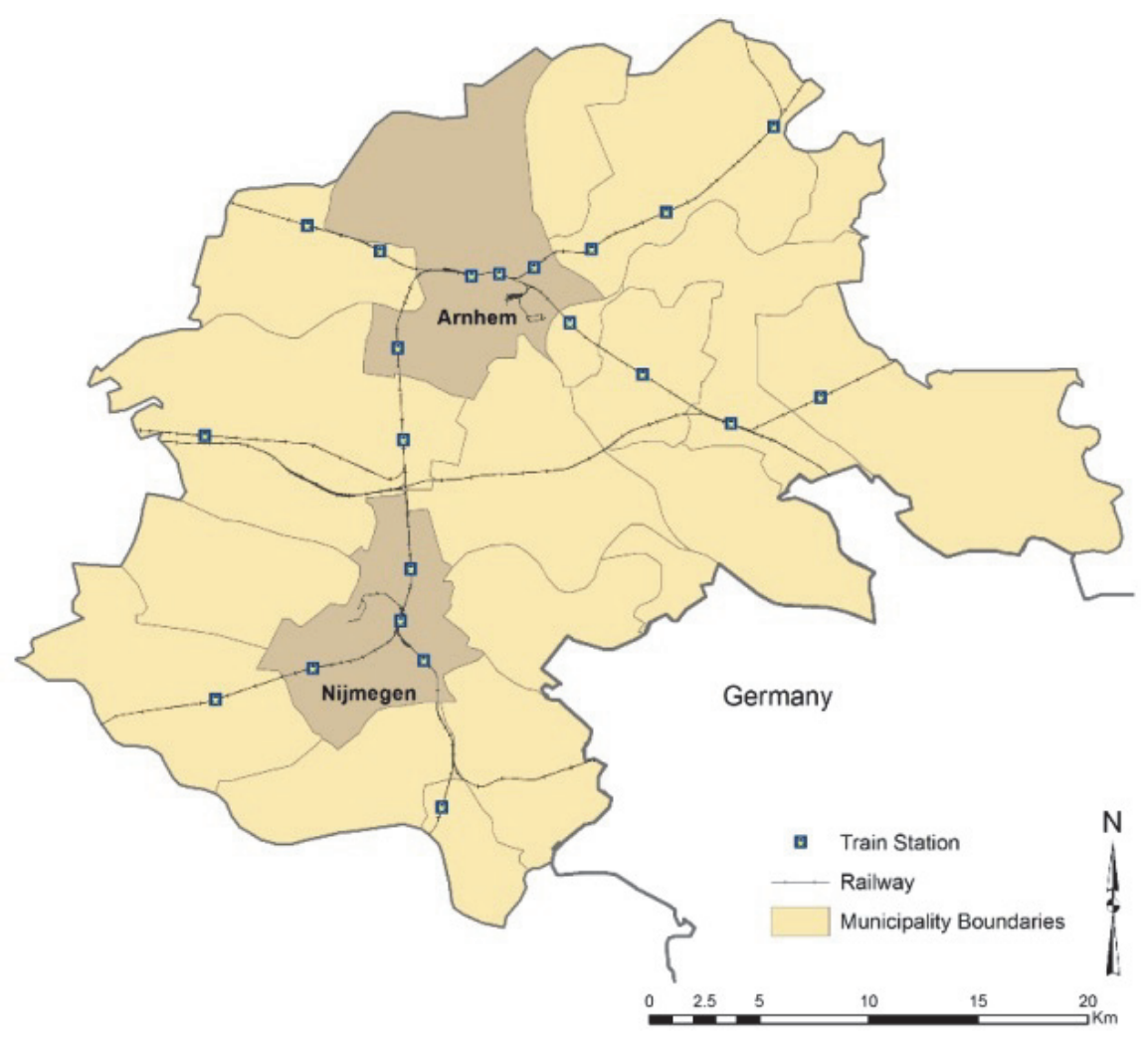

Figure 1.4: The City Region of Arnhem and Nijmegen

The City Region covers more than $1,000 \mathrm{~km} 2$ of area and is home to the two large cities Arnhem and Nijmegen. Total population of the region is about 735,000 . The region has 20 municipalities and is served by a rail-based 
national as well as regional transit system (figure 1.4). There are also regional, urban and neighbourhood bus systems operational within the City Region. In the near future, the City Region officials plan to upgrade a few bus lines to BRT standards. There were 21 train stations in the City Region at the time of computing the TOD index. A couple more have been added since, but not included in this work. In this work, the TOD index has been calculated at the regional scale for the whole City Region and at the local scale for 21 station areas. In the next chapter we will detail out the methodology and results of computing the TOD index at the local scale in the City Region and in chapter 3 we will do the same for computing the TOD index at the regional scale.

In the fourth chapter we will show and discuss the TOD Planning Support System (PSS) that has been built to support planners in making informed and more effective TOD plans for the City Region. The methodology of computing the TOD index and interpreting the results as well as the use of TOD PSS, are not limited to this case study alone. These have been designed in such a way that they can be transferred to any other case study and include changes as desired by the planners. The last chapter, chapter 5, will conclude this work and presents recommendations for future work. 


\section{Chapter 2 - Measuring TOD around existing transit nodes*}

* This chapter is based on the following publications:

Singh, Y. J., Lukman, A., He, P., Flacke, J., Zuidgeest, M. H. P., \& van Maarseveen, M. F. A. M. ( 2015). Planning for Transit Oriented Development (TOD) using a TOD Index. Paper presented at the Transport Research Board 94th Annual Meeting, Washington D.C.

Singh, Y. J., Lukman, A., Flacke, J., Zuidgeest, M. H. P., \& van Maarseveen, M. F. A. M. (2015). Quantifying TOD around transit nodes using an index. Transport Policy, (under review). 


\subsection{Background}

Transit Oriented Development (TOD) has been described as a planning approach that aims to integrate land use and transport planning (Schlossberg \& Brown, 2004). Even though, there are numerous definitions of TOD proposed by Calthorpe (1993), Schlossberg and Brown (2004), Boarnet and Crane (1997b), Parker et al. (2002), (Cervero, 2004); Dittmar and Poticha (2004) and many others, the common goal of planning for TOD remains to encourage people to walk, cycle and use public transit instead of cars. Typically, TODs are mixed use communities developed around transit nodes, with moderate to high densities and a walkable environment.

The benefits of TOD include increased access to public transportation and hence to more opportunities, utilization of already serviced land rather than servicing sprawl, increased transit ridership and reduced vehicular traffic pollution, reduced consumption of oil and gas, and bringing the community together leading to healthier lifestyles. According to Dittmar and Poticha (2004), TOD projects must achieve five main goals of location efficiency, rich mix of choices, value recapture, place making and resolution of tension between node and place. To achieve these goals and to accrue the benefits arising out of them, it is necessary to ensure that the urban development interacts with the transit system. In absence of this interaction, we may create undesirable 'Transit Adjacent Development' (TAD) (Cervero, 2004) that sits close to transit but does not interact with it. Since TOD is about integrating both $\mathrm{T}$ (transit) and $\mathrm{D}$ (development), we believe that wholesome TOD policy and planning for a region must follow two objectives (Singh et al., 2014) - firstly to identify those areas that surround high quality transit but the transit orientation of those places needs improvement and secondly to identify those places where urban development has high transit orientation, but poor access to high quality transit. The remedial actions, as required, should also be identifiable to improve the existing situation. To be able to do both, we build a TOD Index as proposed by (Evans \& Pratt, 2007) as it helps in measuring the 'TOD-ness' of a place i.e. the orientation of land use towards use of transit. An index that quantifies and measures TOD-ness of an area is very helpful in comparing areas in order to identify the areas in need of better transit connectivity or higher TOD-ness. To showcase the use of TOD index in planning for TOD, we worked on the City Region of Arnhem and Nijmegen in the Netherlands ('City Region' henceforth). In this chapter, realization of the first objective as mentioned in section 1.4 shall be demonstrated. The focus of this paper is to measure TOD-ness of the areas within walking distance of a station using the TOD Index and study the results to compare different station areas and identify the reasons for high or low scores. As mentioned in chapter 1, the index used for this purpose has been named 'Actual TOD Index'. The results of Actual TOD Index can be used 
to advise TOD policy by identifying the remedial actions required for improvement of TOD-ness at different station areas. For the City Region, we have analysed TOD around 21 train stations. For reasons mentioned in section 1.2, we believe that rail-based and BRT systems can be qualified as high quality transit system that can invoke TOD benefits and are thus worthy of study. Since the City Region does not have a BRT system with separate ROWs for buses along the whole route, the only other transit system that can be included in our work is the rail-based transit system and that had 21 stations at the time of this work. Our methodology uses geographic information tools and considers land use as well as transit characteristics while calculating TOD index for a station area. The strength of our methodology lies in its high transferability over different geographies and simplicity that makes it repeatable and easy to implement.

In the next section, we discuss other studies on TOD for station areas and in section 2.3, we present our methodology to compute the Actual TOD Index. The detailed calculation of indicators are discussed in section 2.4, while in section 2.5 we elaborate on our TOD Index results and sensitivity analysis carried out to test their robustness. Section 2.6 explains how the results can be interpreted and recommendations be made for improvement. Finally, we conclude this chapter in section 2.7 .

\subsection{Station Area Studies}

In the past, many researchers have studied station areas using various approaches. One of the most recurring approach to station area studies is that of developing station typologies whereby all stations in a study are grouped into types, as has been found in (Bertolini, 1999), (Balz \& Schrijnen, 2009), (Reusser et al., 2008), (Zemp et al., 2011), (CTOD, 2013), (DeltaMetropolisAssociation, 2014), (Chorus \& Bertolini, 2011) to name a few. In (Bertolini, 1999), various transit and urban development characteristics were measured for 17 station areas in Amsterdam region in the Netherlands and a node-place model was suggested resulting in four types of stations. The idea of the node-place model is that in an ideal situation, the node and place characteristics of a station must be in equilibrium. The Stedenbaan project (Balz \& Schrijnen, 2009) also in the Netherlands, created 9 typologies of the 47 stations in Randstad region based on their development potential. In a later SprintCity project, also in the Netherlands (DeltaMetropolisAssociation, 2014), six node and place related criteria were measured and a 'butterfly model' was suggested based on an idea of equilibrium similar to that of Bertolini (1999). There, based on stakeholders' discussions and an assessment of market demand around station areas, 12 station typologies were developed and existing stations were classified in those typologies. Zemp et al. (2011) and Reusser et al. 
(2008) have also both created station typologies based on existing data on station characteristics to group about 1700 stations in Switzerland. The Centre for Transit Oriented Development (CTOD (2013)), similarly, created 15 TOD types over 3760 station areas across 39 regions in Allegheny County, U.S.A. Main benefit of creating typologies of stations is that it reduces management complexity and allows consistency of actions across large geographical areas and identified areas with comparable/ similar strengths and constraints (Zemp et al., 2011). However, it has its own limitations. As the definition of goals differ for all studies, different studies have their unique sets of typologies such that the application and transferability of developed TOD typologies remains very limited (Zemp et al., 2011) (Kamruzzaman et al., 2014). While working with clustering/ typologies, a set of recommendations for improvement are drawn that can be implemented for stations in each typology. Since those station areas can be similar but never the same, the recommendations for improvement will be more effective on some than others, especially because there is no 'one-size-fits-all' solution. This problem may be felt more when the number of station areas under consideration is small because in those cases, the differences between station areas will be magnified and clustering will either become too difficult (because the differences are more than similarities) or useless (if too many typologies are defined for a comparatively smaller number of station areas). Most importantly, with our objective in mind, the methodology of clustering or categorization by any of those cited above cannot be used to denote the TOD-ness of a place. Further, we do not believe that all areas surrounding a transit node can be called TODs, as have been called in (CTOD, 2013), (Nasri \& Zhang, 2014) and others, since an area does not become TOD by the virtue of its location and some areas could be TADs. Using our TOD Index, we can find out how transit-oriented the station areas are and a low score indicates that that area is not TOD enough.

Thus, while these papers have showcased very interesting work on assessing station areas, we chose to work on developing a TOD Index that is a quantified expression of TOD-ness of an area as also proposed by Evans and Pratt (2007). The TOD Index measures TOD characteristics like the earlier studies, but represents the TOD-ness of a single station area using a single TOD Index value and not using typologies. This single value can be very useful in objective comparison of station areas at urban level, corridor level and even regional level, while at the same time allowing for improvement of TOD characteristics at the local level. Another benefit is that each station area can have separate set of recommendations and not as a part of a cluster such that specific recommendations, unique to that station area can be made to improve TOD-ness as desired. The ITDP (2014) also shows a similar attempt to score a new development or a project in terms of its transit orientation. However, it relies heavily on primary data collection related 
mainly to urban design, has a debatable scoring system, has been carried out in a non-GIS based environment and is not a user-friendly methodology for station area studies covering large areas. In the following section, we elaborate on our methodology to calculate TOD index for station areas.

\subsection{Methodology}

The methodology laid out in section 1.5 is broadly followed in this chapter too. However, the difference is in the details and here we describe the detailed steps that were followed to compute the Actual TOD Index. To measure the TOD-ness of a station area using an index, we needed to define the area within a typical $10 \mathrm{~min}$ walking distance i.e. $800 \mathrm{~m}$ (Molster \& Schuit, 2013) Euclidian distance from the station. The area bound by $800 \mathrm{~m}$ can be called 'area of analysis' and is different from the catchment area of a station. Even though the Netherlands is a very cycling friendly country, we chose to use walking distance to define this area because as pointed in (Molster \& Schuit, 2013), everybody can walk but not necessarily cycle. By working on walkable distances, we are covering areas that are accessible by all modes of transport, thereby achieving a sense of equity.

A number of spatial and non-spatial indicators were identified (as given later in table 2.1) that need to be measured in order to arrive at a TOD index value. Since there are multiple spatial and non-spatial indicators having different units of measurement, a Multiple Criteria Analysis (MCA) software (ITC, 2007) is used for combining the various indicators and arriving at a TOD index value. During the MCA process, we also take the views of the stakeholders i.e. a group of decision-makers, into consideration since planning initiatives and proposals are a reflection of the priorities of the decision-makers. Inferences and recommendations can thus be made on how to improve TOD around the transit nodes. In the following sub-sections, we discuss how the indicators were chosen and MCA was carried out.

\section{Identification of Indicators}

Measuring TOD-ness is about measuring how oriented an urban area is towards the use of transit. To do so, various indicators need to be measured that define or characterise TOD. The desirable characteristics of these indicators are that they must be quantifiable, fit for forward-looking assessments rather than backward looking evaluations (Evans \& Pratt, 2007) and can be both spatial and non-spatial. Since TOD is defined by development as well as transit characteristics as shown in (Bertolini, 1999), (CTOD, 2013) (Renne, 2009b), (DeltaMetropolisAssociation, 2014), (Hendricks et al., 2005) and many others, it is imperative to measure both to arrive at a TOD Index. 
Based on the literature on TOD, we formulated the following 'rules' regarding which urban development and transit characteristics positively affect TODness of an area:

Rule 1: Transit system should have enough free capacity. Saturated capacities cannot attract more passengers.

Rule 2: A user-friendly transit system is necessary to encourage people to use transit system.

Rule 3: A node with better access and that provides high accessibility - has increased chances of creating TOD

Rule 4: Parking supply for cycles and cars will help more people to use transit for their longer commutes.

Rule 5: Urban densities are important for developing TOD.

Rule 6: Land use diversity creates a vibrant/ lively place out of a node.

Rule 7: Design of urban space that makes an area walkable and cyclable, is necessary for TOD.

Rule 8: Higher economic development in an area leads to higher TOD.

In line with our eight rules, we also identified eight criteria that represent each of the above. These are - Passenger load in peak and off peak hours, user-friendliness of the transit system, access to and access from the node, parking at the node, urban densities, land use diversity, walkability and cyclability and economic development (see figure 2.1). Our criteria typically include the 3Ds - Density, Diversity and Design, suggested by (Cervero \& Kockelman, 1997b). High urban densities are important because effective utilisation of the transit system may not be possible without minimum transit supportive densities. Similarly, land use diversity creates more balanced and consistent passenger flow - at all times of the day. The increased and varied passenger market contributes to higher revenues and a better utilization of transit capacity. Urban design also plays a significant role in TOD since walkability is the key to TOD and a pedestrian-conducive built environment will encourage people to make their short trips on foot or cycle. Access to and from areas around a transit node are also important factors for consideration of TOD. Our choice of transit characteristics (that should be measured) in the list of eight criteria, is supported by (Renne \& Wells, 2005), (TRB, 2003), (Mulley et al., 2007), (Bhatt et al., 2006) and (Evans \& Pratt, 2007) to represent TOD and their comprehensive measurement is important to understand TOD-ness of an area.

Each of our eight criteria can be measured using different indicators (figure 2.1). To identify these indicators, we studied a number of indicators proposed in literature and as used in various TOD case studies (Curtis et al., 2009b), (Lindau et al., 2010), (Balz \& Schrijnen, 2009), (Bae, 2002), (Cascetta \& Pagliara, 2009), (Yang \& Lew, 2009), (Howe et al., 2009), (Chorus, 2009), (Arrington, 2009), (Hoffman, 2006), (McKone, 2010), (Cervero \& Murakami, 2009), (Schlossberg \& Brown, 2004) or station area studies as discussed in the previous section. In many TOD case studies, 


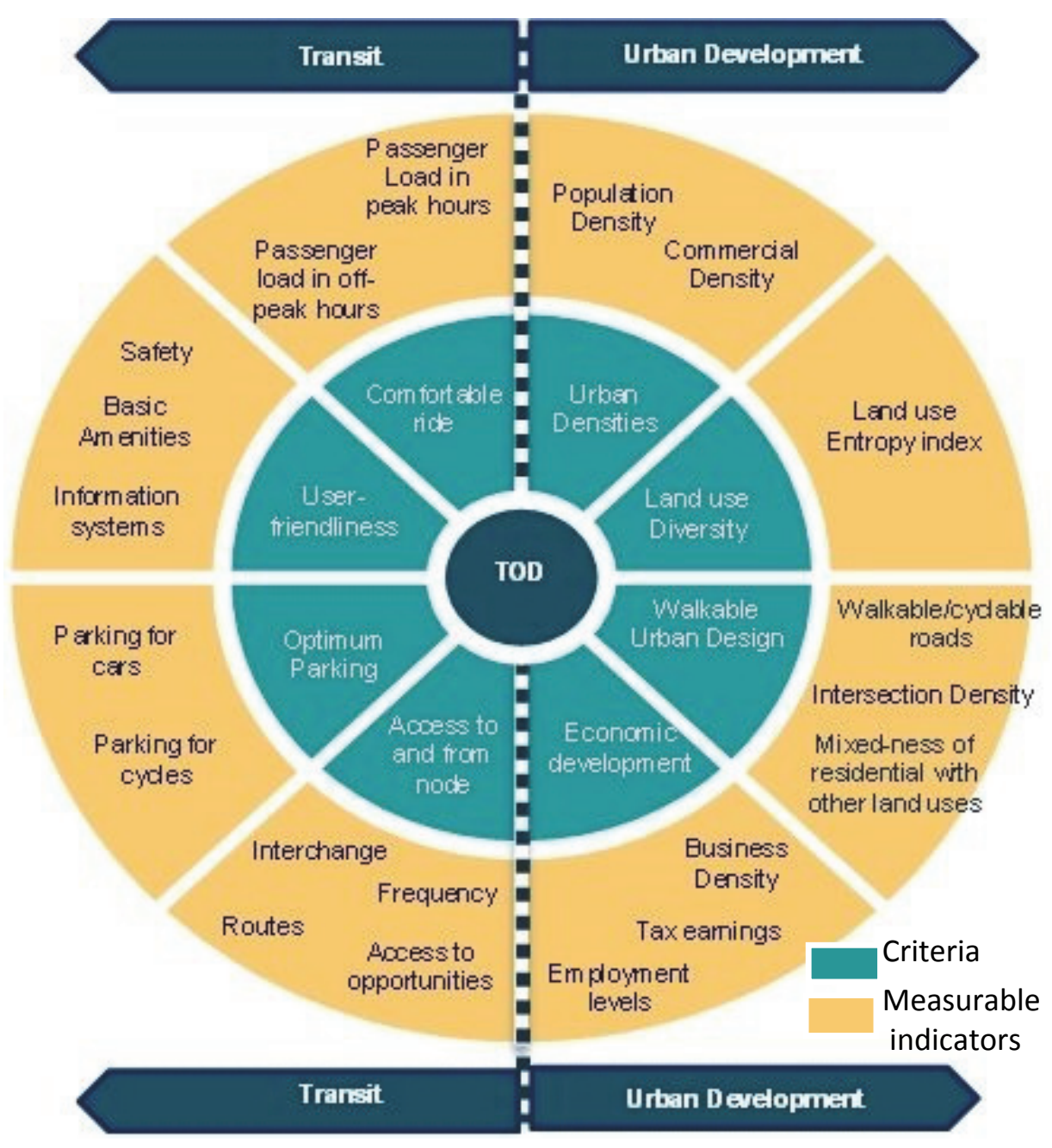

Figure 2.1: Criteria and measurable indicators to measure TOD at local scale

the indicators were meant to measure a 'change' in transit use or densities because their aim is to see what changes a TOD project has brought about. This makes these indicators fit for back-ward looking evaluation. In contrast, our indicators must allow for forward-looking planning by measuring current situation. Thus, from a number of available indicators, we chose about 21 indicators in total that are measurable, quantifiable, assess current situation, and for which data could be readily available from secondary sources. The Table 2.1 lists the rules and corresponding criteria and indicators that we will measure for our TOD index at each transit node. 
Table 2.1: Criteria and Indicators for measuring TOD Index

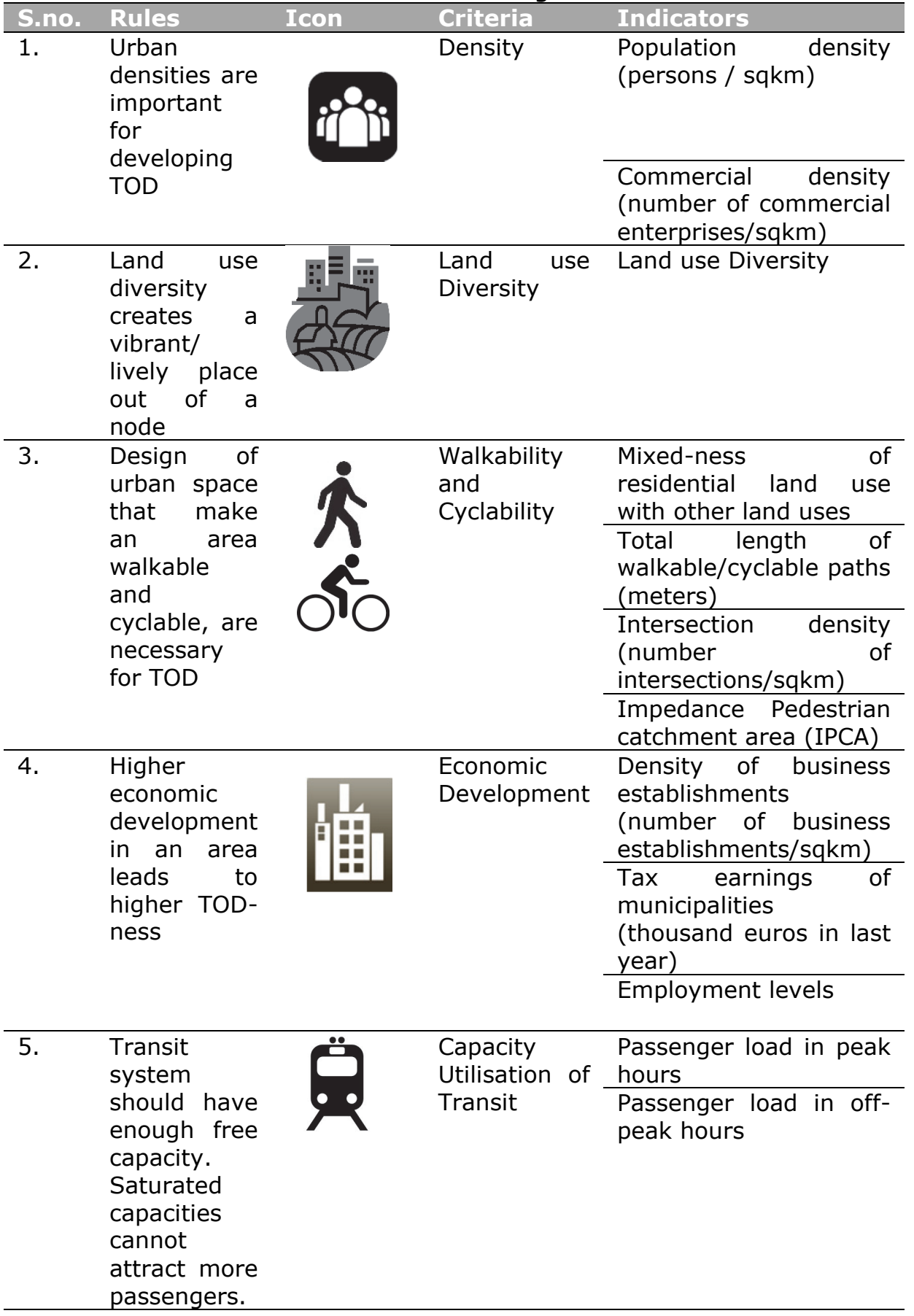




\begin{tabular}{|c|c|c|c|}
\hline \multirow[t]{3}{*}{6.} & \multirow{3}{*}{$\begin{array}{l}\text { A user- } \\
\text { friendly } \\
\text { transit } \\
\text { system is } \\
\text { necessary to } \\
\text { encourage } \\
\text { people to } \\
\text { use transit } \\
\text { system }\end{array}$} & \multirow{3}{*}{$\begin{array}{l}\text { User- } \\
\text { friendliness } \\
\text { of transit } \\
\text { system }\end{array}$} & $\begin{array}{l}\text { Safety of commuters at } \\
\text { the transit stop }\end{array}$ \\
\hline & & & $\begin{array}{l}\text { Basic Amenities at the } \\
\text { station }\end{array}$ \\
\hline & & & $\begin{array}{l}\text { Presence } \\
\text { Information display } \\
\text { systems (Yes/no) }\end{array}$ \\
\hline \multirow[t]{4}{*}{7.} & \multirow{4}{*}{$\begin{array}{l}\text { A node with } \\
\text { better } \\
\text { access and } \\
\text { that } \\
\text { provides } \\
\text { high } \\
\text { accessibility } \\
\text { increased has } \\
\text { chances of } \\
\text { creating } \\
\text { TOD }\end{array}$} & \multirow[t]{4}{*}{$\begin{array}{l}\text { Access and } \\
\text { Accessibility }\end{array}$} & $\begin{array}{l}\text { Frequency of transit } \\
\text { service (number of } \\
\text { trains operating } \\
\text { / hour) }\end{array}$ \\
\hline & & & $\begin{array}{l}\text { Interchange } \\
\text { different routes of } \\
\text { same transit (number } \\
\text { of routes) }\end{array}$ \\
\hline & & & $\begin{array}{l}\text { Interchange to other } \\
\text { transit modes }\end{array}$ \\
\hline & & & $\begin{array}{l}\text { Access to opportunities } \\
\text { within } \\
\text { distance from train } \\
\text { station } \\
\text { jobs) }\end{array}$ \\
\hline \multirow[t]{2}{*}{8.} & \multirow{2}{*}{$\begin{array}{l}\text { Parking } \\
\text { supply for } \\
\text { cycles and } \\
\text { cars will } \\
\text { help more } \\
\text { people to } \\
\text { use to } \\
\text { transit for } \\
\text { their longer } \\
\text { commutes }\end{array}$} & \multirow[t]{2}{*}{$\begin{array}{l}\text { Parking at } \\
\text { Station }\end{array}$} & $\begin{array}{l}\text { Parking supply-demand } \\
\text { for cars/four wheelers }\end{array}$ \\
\hline & & & $\begin{array}{l}\text { Parking supply-demand } \\
\text { for cycles }\end{array}$ \\
\hline
\end{tabular}

\section{Calculation of TOD Index}

Once the indicators are calculated, a Multiple Criteria Analysis (MCA) is adopted to calculate the TOD index for each station area. MCA is a unique method that allows for a comprehensive assessment of multiple criteria or indicators with different units of measurement. When dealing with spatial indicators, GIS-based MCA (Malczewski, 1999) (also known as 'Spatial MCA' or 'SMCA') can be used to assess multiple spatial indicators (Beukes et al., 2011). In this study we have a mix of spatial indicators, such as those related to density, land use and walkability as well as non-spatial indicators, such as those related to frequency or passenger load of the transit system (see our MCA methodology in figure 2.2). Indicators (I) for any station area are partly spatial and partly non-spatial. A transit node (S) is represented as 
a point in space and all spatial criteria such as density, diversity and walkability can be spatially analysed and aggregated in ArcGIS to represent their values for a point i.e. transit node. Other non-spatial criteria, some of those related to transit characteristics, already represent the values for that point. Detailed computation of all indicators is given in section 2.4.

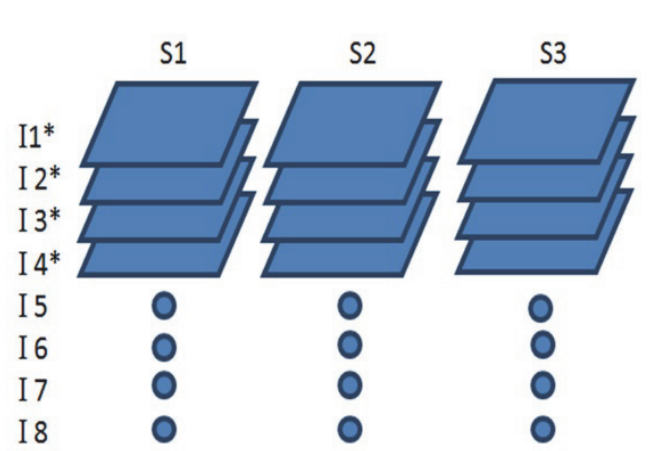

*Spatial indicator

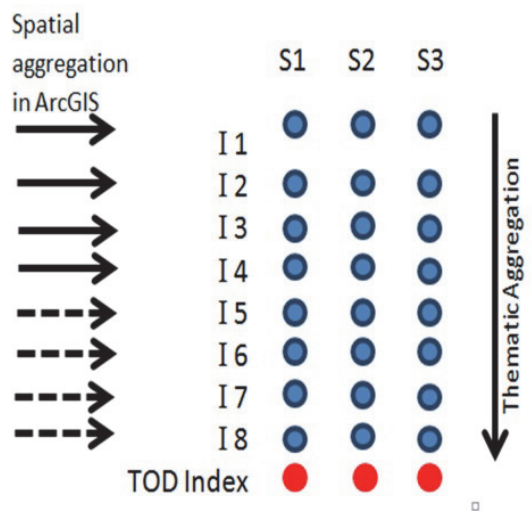

Figure 2.2: MCA process for TOD Index calculations

In order to bring all the indicators to comparable units, they were standardised using the 'maximum standardisation method' where the maximum achieved value of an indicator becomes ' 1 ' and all other values are given a value between 0-1 based on their ratio with the maximum value. Another step of standardisation is required to represent how each indicator affects the value of TOD Index. Most of our indicators have a directly proportional relation with the TOD Index such that a higher value of that indicator contributes positively to the value of TOD Index. Thus, those indicators were standardised using 'Benefit' standardisation. Three indicators - passenger load, parking utilisation and mixed-ness of land use, were exceptions to this standardisation method. The 'goal method' was used for the first two such that the indicator's value is standardised as 'benefit' until it reaches a set goal value of $90 \%$ utilisation of transit capacity and parking supply respectively. After the goal value, any increase in transit or parking use is treated as 'cost' to the TOD index value because higher utilisation levels indicate a pressure on the transit and parking systems. The 'combination method' was used for mixed-ness of land use, such that the indicator acts as a 'benefit' to the index until it reaches a value of 0.5, implying a good balance of residential and other land uses, after which, it acts like a 'cost' to the index and contributes negatively to the TOD index (Singh et al., 2014).

Not every indicator might be equally important for realisation of TOD. Depending on the perception of the stakeholders involved in planning for 
TOD, those differences are reflected by using the weights. The indicators are hence weighed before calculating the TOD Index. For weighing exercise, the municipal heads were consulted in a workshop as stakeholders of the study area who ranked the criteria in order of their importance in realisation of TOD. Within each criteria too, they ranked the indicators in order of their importance for the respective criterion. The questionnaire used for this purpose is attached as Appendix 1 and questions 1 to 8 pertain to this index. The questionnaire was physically filled during the workshop and an interactive digital copy was sent to those who could not attend the workshop. It was also hosted on a survey website for those who preferred to fill it online (Singh, 2013). For our case study, municipal heads were involved at the behest of the City Region officials but in any other case study, weights can be decided based on the views of one or many groups of stakeholders. The final rankings resulting from the workshop using the' Borda Count method' (Reilly, 2002) were converted to weights using a rank sum method as given below:

$$
W_{k}=\frac{n+1-k}{\sum_{i}^{n}(n+1-i)}
$$

where $W_{k}$ is the normalized weight for the criterion with rank ' $k$ ', $n$ is the total number of criteria in the set $\left(52^{\circ}\right.$ North, 2012). The ' $i$ ' is the index of summation that takes the value from 1 to $\mathrm{n}$. The weights for each indicator and criterion are tabulated in the table 2.2. Finally, in the MCA platform, all indicators and criteria values and their weights were used to calculate the TOD Index value for each station area, the results of which are discussed in the section 2.5. The entire methodology is simple, logical, flexible, transparent and transferable across different geographies and different scales. 
Table 2.2: Criteria, indicators and their weights

\begin{tabular}{|c|c|c|c|c|}
\hline \multirow[t]{2}{*}{ S.nor } & \multicolumn{2}{|c|}{ Criteria } & \multicolumn{2}{|c|}{ Indicators } \\
\hline & Description & Weights & Description & Weights \\
\hline \multirow[t]{2}{*}{1.} & \multirow[t]{2}{*}{ Density } & \multirow[t]{2}{*}{0.15} & Population density & 0.67 \\
\hline & & & Commercial density & 0.33 \\
\hline 2. & $\begin{array}{ll}\text { Land } & \text { use } \\
\text { diversity } & \end{array}$ & 0.03 & Land use Diversity & 1 \\
\hline \multirow[t]{4}{*}{3.} & \multirow[t]{4}{*}{$\begin{array}{l}\text { Walkability and } \\
\text { Cyclability }\end{array}$} & \multirow[t]{4}{*}{0.06} & $\begin{array}{l}\text { Mixedness of } \\
\text { residential land use } \\
\text { with other land uses }\end{array}$ & 0.1 \\
\hline & & & $\begin{array}{l}\text { Total length of } \\
\text { walkable/cyclable } \\
\text { paths }\end{array}$ & 0.4 \\
\hline & & & Intersection density & 0.2 \\
\hline & & & $\begin{array}{l}\text { Impedance } \\
\text { Pedestrian } \\
\text { catchment area } \\
\text { (IPCA) }\end{array}$ & 0.3 \\
\hline 4. & $\begin{array}{l}\text { Economic } \\
\text { development }\end{array}$ & 0.22 & $\begin{array}{l}\text { Density of business } \\
\text { establishments }\end{array}$ & 1 \\
\hline \multirow[t]{2}{*}{5.} & \multirow{2}{*}{$\begin{array}{l}\text { Capacity } \\
\text { Utilisation } \\
\text { transit }\end{array}$} & \multirow[t]{2}{*}{0.19} & $\begin{array}{lll}\text { Passenger load at } \\
\text { peak hours }\end{array}$ & 0.67 \\
\hline & & & $\begin{array}{l}\text { Passenger load at } \\
\text { off-peak hours }\end{array}$ & 0.33 \\
\hline \multirow[t]{2}{*}{6.} & \multirow{2}{*}{$\begin{array}{l}\text { User- } \\
\text { friendliness of } \\
\text { transit system }\end{array}$} & \multirow[t]{2}{*}{0.11} & $\begin{array}{l}\text { Safety of commuters } \\
\text { at the transit stop }\end{array}$ & 0.5 \\
\hline & & & $\begin{array}{l}\text { Information display } \\
\text { systems }\end{array}$ & 0.5 \\
\hline \multirow[t]{4}{*}{7.} & \multirow[t]{4}{*}{$\begin{array}{l}\text { Access to and } \\
\text { from the station }\end{array}$} & \multirow[t]{4}{*}{0.15} & $\begin{array}{l}\text { Frequency of transit } \\
\text { service }\end{array}$ & 0.4 \\
\hline & & & $\begin{array}{l}\text { Interchange to } \\
\text { different routes of } \\
\text { same transit }\end{array}$ & 0.3 \\
\hline & & & $\begin{array}{l}\text { Interchange to other } \\
\text { transit modes }\end{array}$ & 0.2 \\
\hline & & & $\begin{array}{l}\text { Access to } \\
\text { opportunities within } \\
\text { walkable distance } \\
\text { from train station }\end{array}$ & 0.1 \\
\hline \multirow[t]{2}{*}{8.} & \multirow[t]{2}{*}{$\begin{array}{l}\text { Parking supply } \\
\text { at the station. }\end{array}$} & \multirow[t]{2}{*}{0.08} & $\begin{array}{l}\text { Parking supply- } \\
\text { demand for cars/four } \\
\text { wheelers }\end{array}$ & 0.67 \\
\hline & & & $\begin{array}{l}\text { Parking supply- } \\
\text { demand for cycles }\end{array}$ & 0.33 \\
\hline
\end{tabular}

\subsection{Calculation of Indicators}

To compute the indicators mentioned in table 2.1 , we required a variety of spatial as well as non-spatial data. The required data was collected from the 
City Region, the Dutch Central Bureau for Statistics (CBS) ("Centraal Bureau voor de Statistiek (CBS),") ("Centraal Bureau voor de Statistiek (CBS),") ("Centraal Bureau voor de Statistiek (CBS),"), the regions transit service's website, ESRI Top 10NL and Open Street Map (OSM). Administrative boundaries, train network, station locations, road network, land use data including building footprints were all available as spatial data layers in vector format. The information available from transit service's website related to service available at the stations was also checked by visiting all the stations. Two indicators - tax earnings and employment levels - had to be dropped since there was no data available on those. One indicator 'basic amenities' also had to be dropped because it was found that all stations had the basic amenities i.e. waiting room, benches to sit, elevators and/or access for disabled and ticket machine and any comparison of TOD over all transit areas, on the basis of this indicator was not possible. Thus, in total 18 indicators were measured for 21 stations.

\section{a. Population and Commercial Densities; Density of Business establishments}

The original data on population, number of commercial and business establishments was available at the neighbourhood level from CBS, and since our areas of analysis does not conform to neighbourhood boundaries, a data apportionment operation was carried out in ArcGIS to proportionately divide data per neighbourhood into the area of analysis. This function used the building foot-print data per land use type that we had for land use information. It is to be noted 'Commercial' establishments represent the services and retail establishments while 'Business' establishments represent the non-services and non-retail establishments such as consultancy business. Hence, the double-counting is avoided.

\section{b. Land use diversity}

Land use diversity was measured using the notion of 'entropy' which has been widely used to measure the level of diversity. Ritsema van Eck and Koomen (2008) used entropy to measure land use diversity in Dutch spatial planning which is adapted in this work as follows in formula (eq. 2):

$$
L U_{d}(i)=\frac{-\sum_{i} Q_{l u_{i}} \times \ln \left(Q_{l u_{i}}\right)}{\ln (n)}
$$

Where 


$$
Q_{l u_{i}}=\frac{S_{l u_{i}}}{S_{i}}
$$

$l u_{i}=$ land use class $(1,2, \ldots \ldots, n)$ within the analysis area $i$

$Q_{l u_{i}}=$ Share of specific land use within the analysis area $i$

$S_{l u_{i}}=$ Total area of the specific land use within the analysis area $i$

$S_{i}=$ Total area of analysis $i$

Higher values of entropy thus mean high levels of land use diversity and hence higher levels of TOD-ness. Figure 2.3 shows the building foot prints around two stations as an example. The land uses used for this indicator were - residential, industrial, commercial, office complexes, health, educational, sport and 'others'.

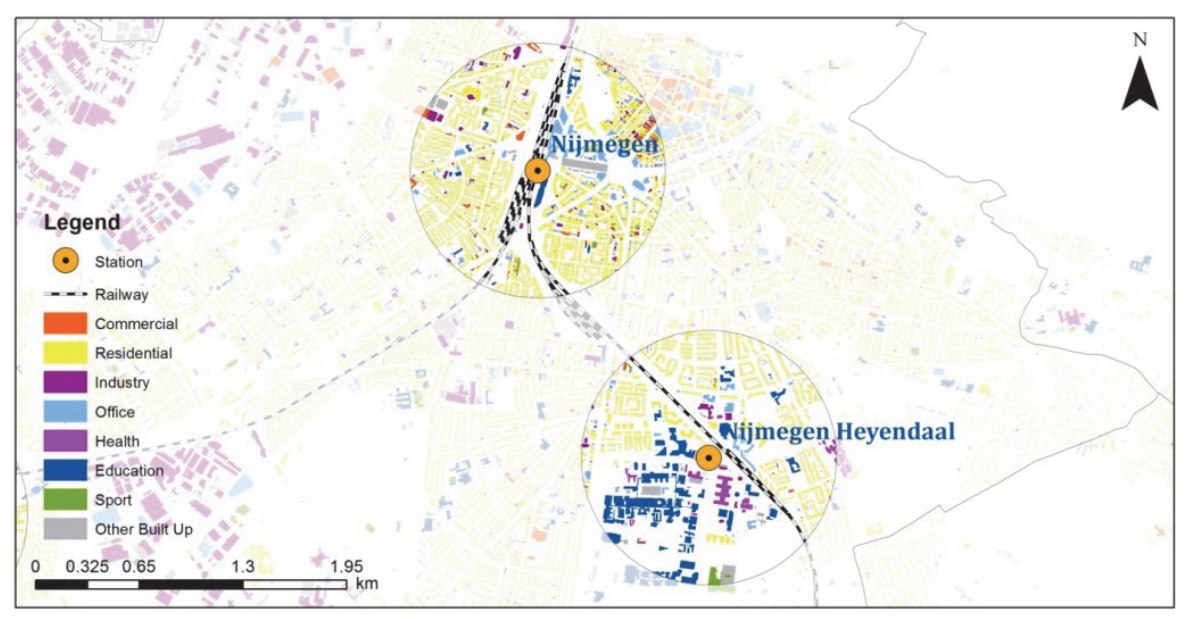

Figure 2.3: Building footprints and their land uses around two stations

\section{c. Mixed-ness of residential land use with other land uses}

This indicator is used to assess walkability and cyclability in the area of analysis. This indicator is different from the land use diversity since this one measure the mixed-ness of residential land use with other land uses. It has been suggested by Jacobs (1961), Zhang and Guindon (2006) and Bach et al. (2006) that many non-work trips can be made on foot or by bicycle if residential land use is sufficiently mixed with other land use types. Thus, we measure mixed-ness of residential land use with other land uses with the following formula, as adapted from (Zhang \& Guindon, 2006):

$$
M I(i)=\frac{\sum_{n i} S_{c}}{\sum_{n i}\left(S_{c}+S_{r}\right)} \quad \forall i
$$

where, $M I$ is the 'Mixed-ness Index' for area of analysis $\mathrm{i}_{1} S_{c}$ shows the sum of the total area under non-residential urban land uses and $S_{r}$ 
represents the sum of the total area under residential land use within $i$. The value of MI can range from 0 to 1 and balanced mixed-ness of land use is 0.5 implying equal share of residential land use with other land uses.

\section{d. Total length of walkable/ cyclable paths}

This indicator is calculated based on the length of accessible roads for pedestrians/cyclists within each TOD area of the stations. The unit of measurement is meters. The road network was reclassified based on the likelihood of the roads to be used for slow traffic. The roads which are used for fast traffic like motorways were removed from the road network data since walking and cycling is not permitted there. The notion of approximating the walkable/cyclable path based on the reclassified road network has been adapted from the research by Schlossberg et al. (2003).

\section{e. Intersection density}

Intersections can make walking and cycling easier because they help in shortening the routes. Higher density of intersections generally means higher walkability (Ewing \& Cervero, 2010) and hence cyclability as they indicate the choice available to pedestrians (Schlossberg \& Brown, 2004) to choose and possibly shorten their routes. The number of intersections per $\mathrm{km}^{2}$ in the area of analysis is used to depict the intersection density. For this, road network data set was used in ArcGIS for computation of the indicator.

\section{f. Impedance Pedestrian Catchment Areas (IPCA)}

Pedestrian Catchment Areas, also known as 'Ped-Sheds', are actual areas that can be covered by walking within a specified walking time from a rail station. The term "impedance" is used because it was applied at the network after removing high speed roads (impedance) (Schlossberg \& Brown, 2004). The IPCA was calculated based on the 800 meters of walking along the network in two-way scenario since in reality pedestrians can move in both directions. The indicator was calculated based on the ratio of each IPCA in $\mathrm{km}^{2}$ compared to the whole area of analysis i.e. $2.9 \mathrm{~km}^{2}$. The value of IPCA can range from 0 to 1 , the latter representing the highest size of catchment area. The resulting IPCA map, for some stations, is presented in figure 2.4. 


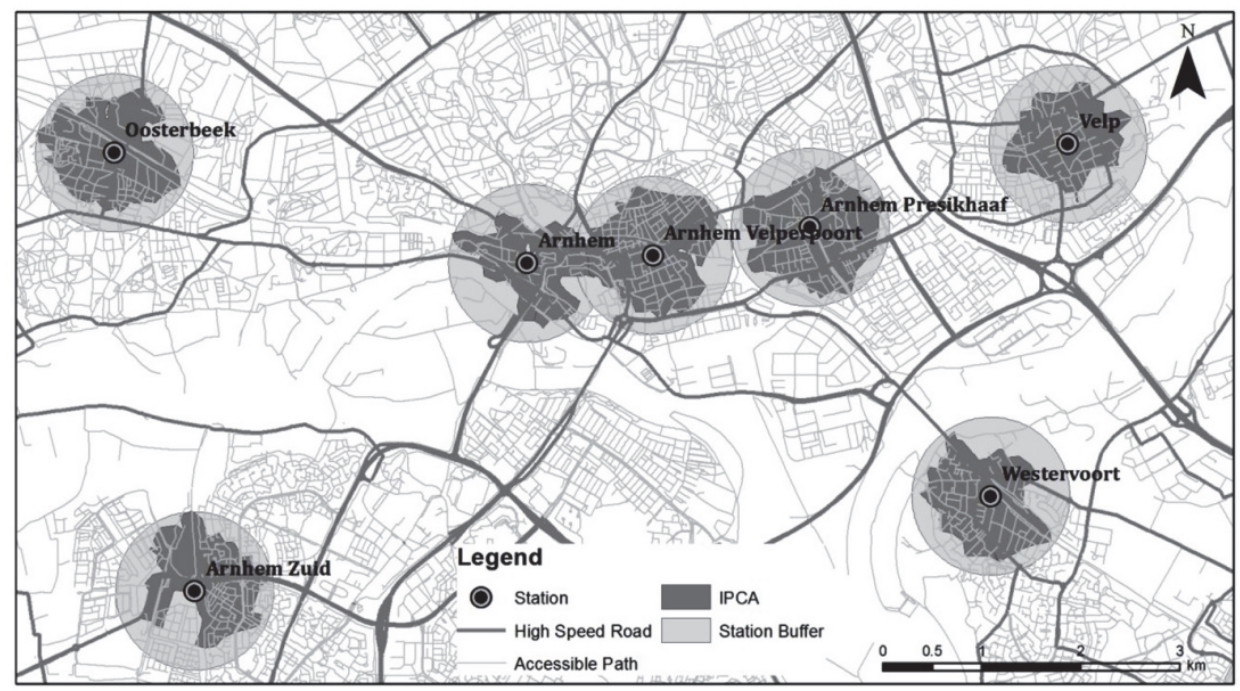

Figure 2.4: Impedance Pedestrian Catchment Area (IPCA) for areas around various stations in the City Region

\section{g. Passenger load}

Transit's capacity utilisation should be optimum since packed to capacity trains can be uncomfortable for riders and empty-like trains can feel quite unsafe. Thus, passenger load was adopted as an indicator to measure the same. It is the ratio of total number of passengers to the total capacity of the transit system. Higher passenger load means better utilisation of transit's capacity and a higher value for TOD. However, passenger load beyond $90 \%$ is considered to imply that the trains are too crowded for a comfortable ride. For data, the total number of passengers per station per day was available. Since we want to compute passenger load for peak and off peak hours, we wanted to split this daily number accordingly. The peak hour and off-peak hour commuter traffic was assumed to be $25 \%$ and $75 \%$ of the daily traffic, respectively, at each station.

For capacity calculations, the frequency of service in peak and off-peak hours was considered. Plus, it was found that there are four types of trains that serve the City Region and the capacity of each is different. From the website of transit service provider, the hours of operation of each type of train was found and accordingly, w.r.t. their frequencies, the total capacity of the transit at each station was calculated. In addition to this, we also considered the fact that trains are not empty when they reach a station, unless it is starting from a terminus station. Thus, $40 \%$ occupancy was assumed for non-terminus stations. There are only two terminus stations - Arnhem and Nijmegen, where various trains terminate or originate from. In view of all these factors, total capacity of 
the transit system in peak hours and off-peak hours is calculated. Finally, the passenger load is computed for each station.

\section{h. Safety of commuters at the transit stop}

The feeling of safety is one of the most important things that influence the choice of use of transit. It is also one of the hardest to quantify. Ideally the safety in the station can be indicated based on the presence of other people in the stations, the layout and design that provide good visibility and good lighting during the day and night. All the stations were found to have good lighting conditions and differed mainly in the presence of other people at the stations. Since the data on 'number of people' at stations was not available, safety was measured using 'number of shops and eating joints' at the station since they attract people and influence the number of people at the station (see photo in figure 2.5a). In the absence of these, fellow passengers will only stay shortly before their departure and leave immediately after their arrival (see photo in figure 2.5b). This is similar to the established fact that diverse land uses add liveliness and safety to a place by having more 'eyes' in that space (Jacobs, 1961).

(a)

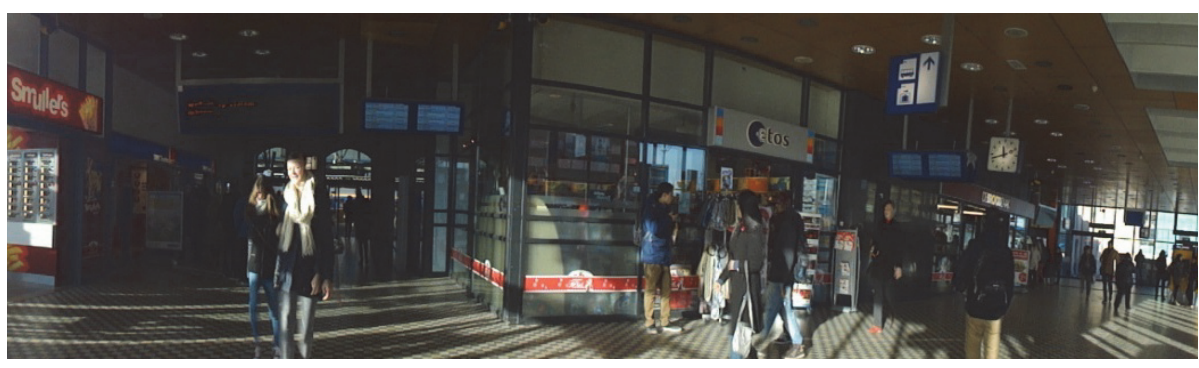

(b)

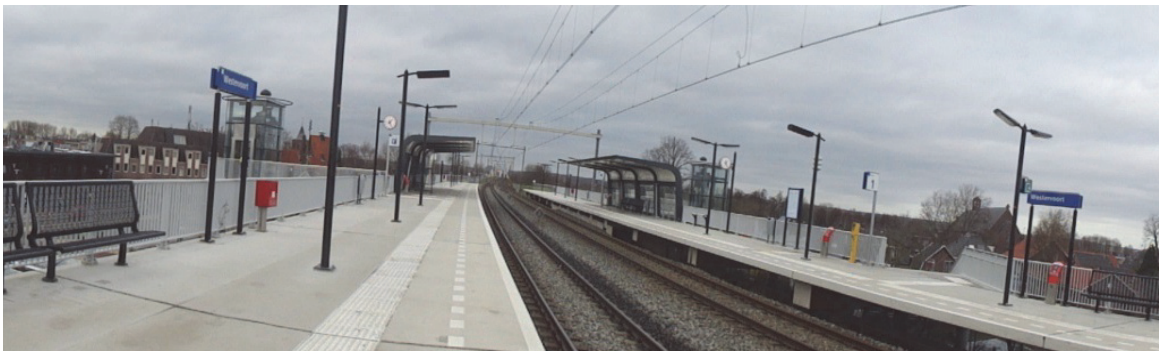

Figure 2.5: (a) Station of Nijmegen with many shops and passengers in contrast to (b) the empty looking station of Westervoort.

\section{i. Information display systems}

Static and dynamic information display systems affect the userfriendliness of the transit. All stations were found to have static 
information displays but presence of dynamic display systems varied over stations. Thus, stations were assessed on the basis of this indicator.

\section{j. Frequency of service}

Access by transit is affected by a measure of its frequency of service. The service frequency of train system was calculated based on the number of trains operating per hour, at each station.

\section{k. Interchange to different routes of same transit}

This indicator measures the number of train routes accessible at each station. Higher number of train routes and hence connecting destinations has the potential to get more people to prefer transit over their cars.

\section{Interchange to other transit modes}

A high quality transit system not just offers accessibility to more destinations but also allows interchange to other transit modes. Since the City Region also has bus-based transit systems, we measured the interchange possibilities at each station to bus-based system. A value of 0 means no interchange possible, value of 1 means interchange possible from an on-street bus stop and value of 2 means interchange possible to many bus routes from an off-street bus terminal. The main stations like Arnhem and Nijmegen have such large bus terminals.

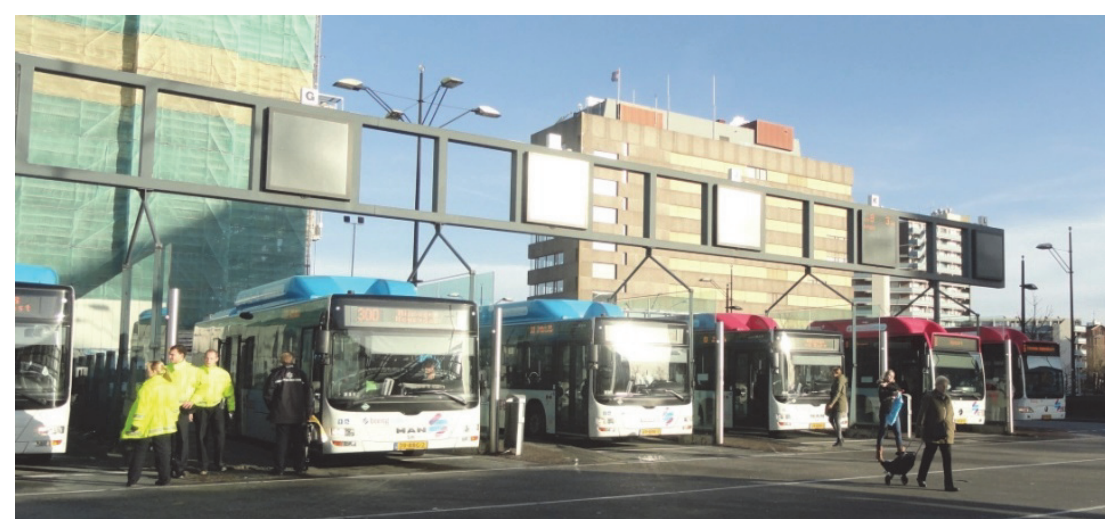


(b)

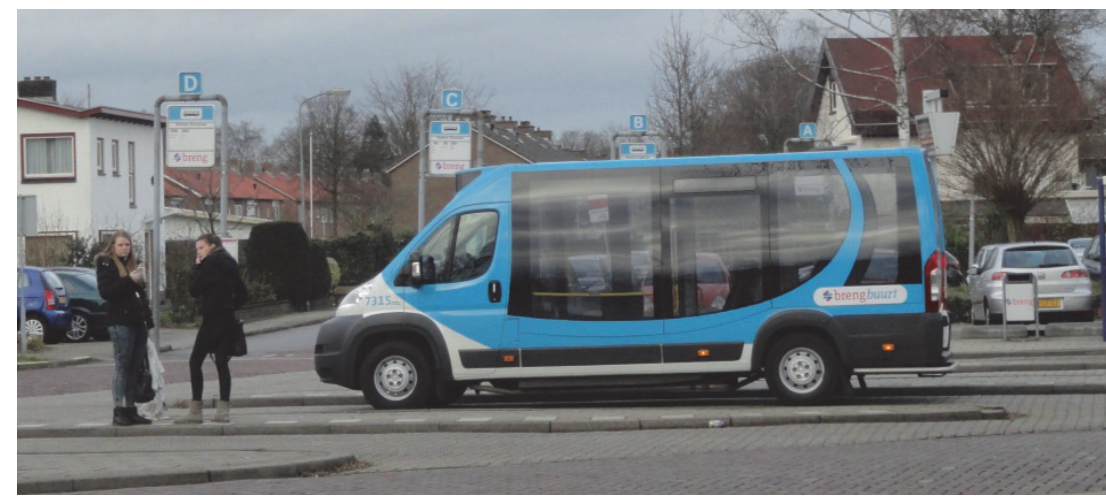

Figure 2.6: (a) The Bus terminal just outside Nijmegen station with bigger buses and many lines. (b) A smaller bus terminal outside Zevenaar station with smaller buses and lesser lines.

\section{m. Access to opportunities within walkable distance from train} station

This indicator measures the number of jobs accessible within the area of analysis for each station. Such a measure is also known as the 'Cumulative Opportunity Measure' or 'contour measure' (Pirie, 1979). We used data on jobs per sector at municipality level. The jobs were divided into sectors such as industry and commerce and matched with building foot prints of the same sectors within the area of analysis.

\section{n. Parking utilisation}

The aim of TOD is not to ban cars, but balance its use (Calthorpe, 1993). Thus, providing parking for cars and cycles is expected to help the riders park and ride for their longer commutes. The data on parking utilisation of cycle and car parking was used to assess if parking at the stations is saturated and requires more parking supply. The parking utilisation of $90 \%$ was considered as the level of saturation for this analysis.

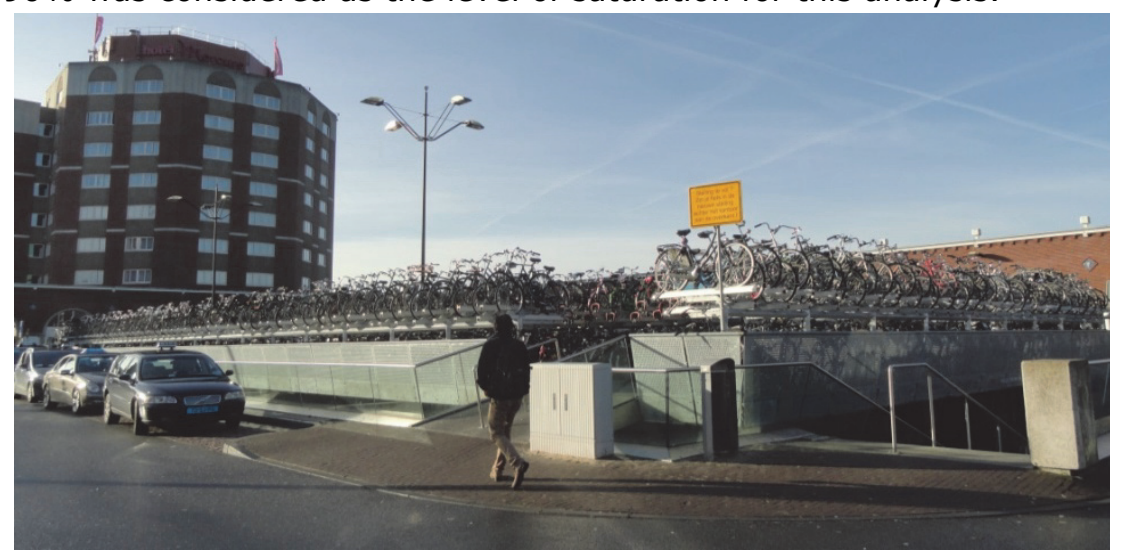


(b)

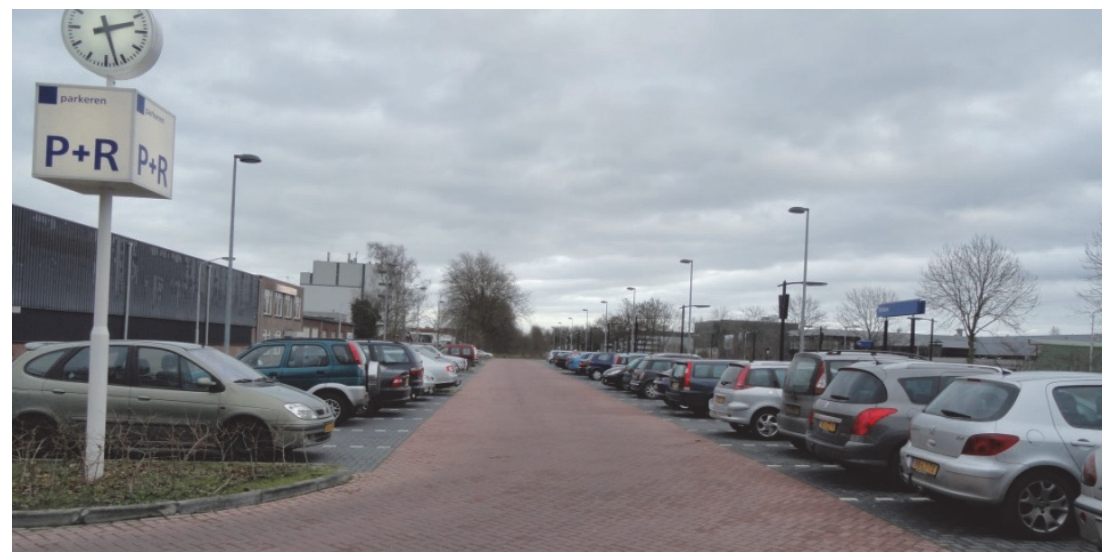

(c)

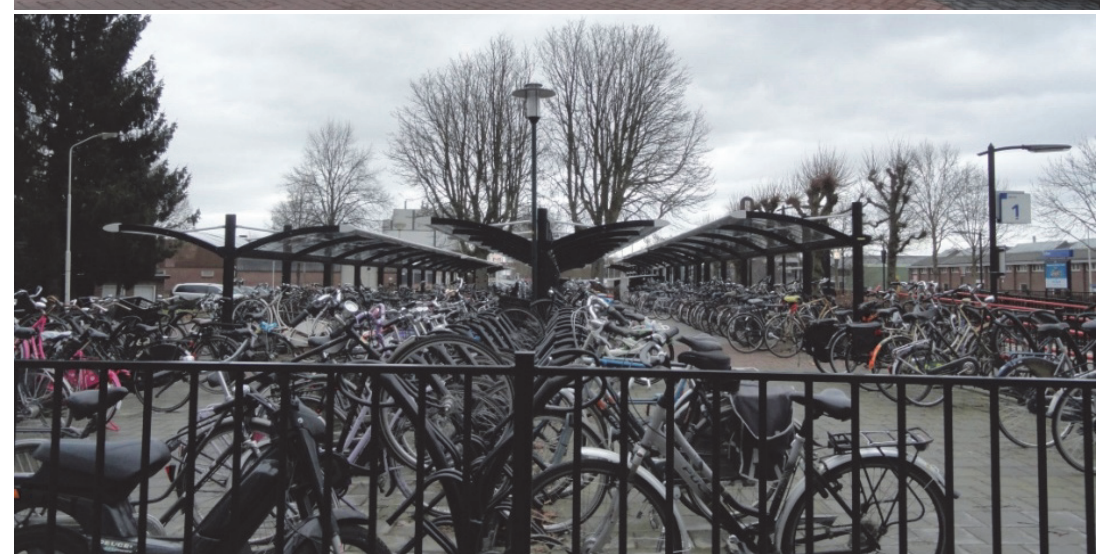

Figure 2.7: (a) Fully utilised cycle parking at Nijmegen station (b) Park and Ride ( $P+R)$ Car parking at Zevenaar station (c) Cycle parking also at Zevenaar station.

\subsection{Results of 'Actual TOD Index' and Sensitivity analysis}

The TOD Index results for all 21 stations in the City Region are tabulated in table 2.3 and shown in figure 2.8. Using these results, the station areas can be compared with each other and we can identify the stations with highest and least TOD-ness in the region. SWOV (Feb'12) says that in absence of a reference value, the values calculated within a group of entities, at the same time, for the same purpose and with the same inputs, can be compared with each other. Since, this study is a first instance of calculating TOD Index for station areas, there are no reference values available from literature. Thus, our TOD index values need to be compared with each other for better understanding. In our region, Arnhem and Nijmegen are the busiest urban centers and their stations (by the same names) have also scored well in the region at 0.75 and 0.57 respectively. Objectively speaking, a score of 0.75 (or higher) over a maximum possible score of 1 can be considered as a good 
score. Thus, it is safe to suggest that Arnhem has a high TOD score. The lowest TOD score of 0.16 was recorded for Wolfeze station.

Table 2.3: TOD Index values for all 21 stations in the City Region

\begin{tabular}{|c|c|c|}
\hline Rank. & $\begin{array}{l}\text { Station Name } \\
\text { (arranged in order of } \\
\text { their TOD score) }\end{array}$ & $\begin{array}{l}\text { TOD Index } \\
\text { score }\end{array}$ \\
\hline 1 & Arnhem & 0.77 \\
\hline 2 & Arnhem Velperpoort & 0.57 \\
\hline 3 & Nijmegen & 0.57 \\
\hline 4 & Rheden & 0.52 \\
\hline 5 & Nijmegen Heyendaal & 0.45 \\
\hline 6 & Wijchen & 0.42 \\
\hline 7 & Duiven & 0.41 \\
\hline 8 & Nijmegen Dukenburg & 0.41 \\
\hline 9 & Zevenaar & 0.37 \\
\hline 10 & Elst & 0.35 \\
\hline 11 & Dieren & 0.33 \\
\hline 12 & Velp & 0.33 \\
\hline 13 & Didam & 0.31 \\
\hline 14 & Arnhem Presikhaaf & 0.30 \\
\hline 15 & Arnhem Zuid & 0.25 \\
\hline 16 & Westervoort & 0.24 \\
\hline 17 & Molenhoek-Mook & 0.22 \\
\hline 18 & Oosterbeek & 0.21 \\
\hline 19 & Nijmegen-Lent & 0.21 \\
\hline 20 & Zetten-Andelst & 0.18 \\
\hline 21 & Wolfheze & 0.16 \\
\hline
\end{tabular}




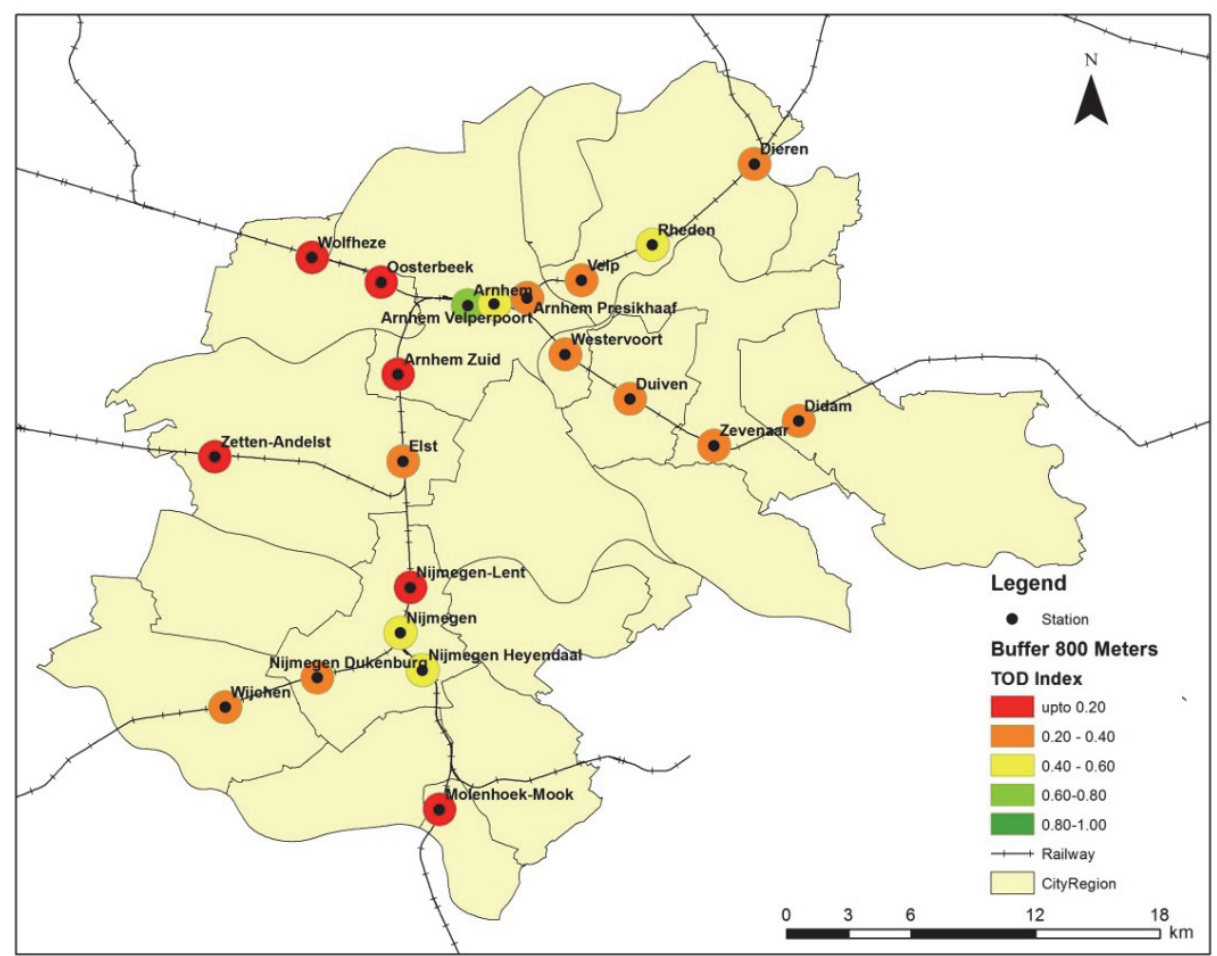

Figure 2.8: TOD Index for all 21 stations in the City Region of Arnhem and Nijmegen

We also carried out a sensitivity analysis to check the robustness of our results and approach with respect to change in weights of criteria. The weighing exercise is always subjective in nature and it is quite likely that the ranks provided by the same stakeholder with the same information may be slightly different in a changed setting or time. To incorporate this subjectivity, the weights of criteria can be changed within a range to conduct the sensitivity analysis (Malczewski, 1999). Thus, the weight for each of the eight criteria was changed by a $\pm 10 \%$, one at a time, while others were equally increased or decreased, thereby creating 16 scenarios for sensitivity analysis. The TOD Index results under all the scenarios changed slightly. The highest TOD Index value ranged from 0.762 to 0.773 and the lowest ranged from 0.152 to 0.162 . Further, the top 5 ranking stations remained the same in all scenarios and the overall ranking of stations remained almost the same in all scenarios. Thus, it can be confirmed that the results are robust.

\subsection{Inferences and Recommendations}

In this section, we infer from our results, compare different stations areas and understand the index results in detail to make a TOD policy for the whole 
region as well as for stations in particular. It is logical to see in Figure 2.8 that the larger stations of Arnhem and Nijmegen show higher TOD levels than most, while the stations between these two have very low TOD levels, suggesting how concentrated is the development around these two main centres.

Our case study area is a polycentric city region and location hierarchies are expected to develop within the network. These hierarchies indicate the difference in development potentials of different stations (Bertolini, 1999). In the SprintCity project (DeltaMetropolisAssociation, 2014), it has been postulated that the level of development around a station is related to the position of that station in the whole network. In our City Region too, the planners have planned and provided the region with a high quality transit system with an intended hierarchy of stations in terms of their size and services. Their priority was to connect the urban and suburban areas with high quality transit system and the City Region authority does not expect or plan to have high TOD-ness around all station areas. However, the TOD score should correlate to the planned hierarchy of stations since a higher priority station is expected to serve more people and hence have higher TOD-ness. Thus, TOD Index scores can be used to identify those stations that should have higher TOD-ness in order to achieve the desired pattern of urbanization and match the transit hierarchy at regional level. As such, the stations of Arnhem-Zuid, Elst and Nijmegen-Lent seem to have high potential for improvement (figure 2.8), given that they are sufficiently close to both Arnhem and Nijmegen (high centers of growth) and yet have low TOD scores. Thus in the TOD policy for the City Region, these stations can be prioritized for improving the TOD conditions around them. Other stations may be similarly identified.

In (Balz et al., 2006) and (DeltaMetropool, 2013), the position of each station in the larger rail network is identified by giving it a score. This score is calculated based on the transit type(s) that serve a station and the frequency of each transit type. Since these works are also in the Netherlands, there is a high applicability of this procedure to our work. Using that procedure, each station in our region can be given a position in the regional rail network and corresponding ranges of TOD index score can be identified. These ranges of TOD score for each station can be the target TOD scores for each station based on which; we can see which station areas need an improvement.

It is a well-established fact that broad investment policies, illustrative maps and plans are not sufficient to spur TOD and they need to be accompanied by specific actions or tools. Thus, separately for each station, the web-diagrams in Figure 2.9 can help in identifying those criteria that scored low and can be improved. 

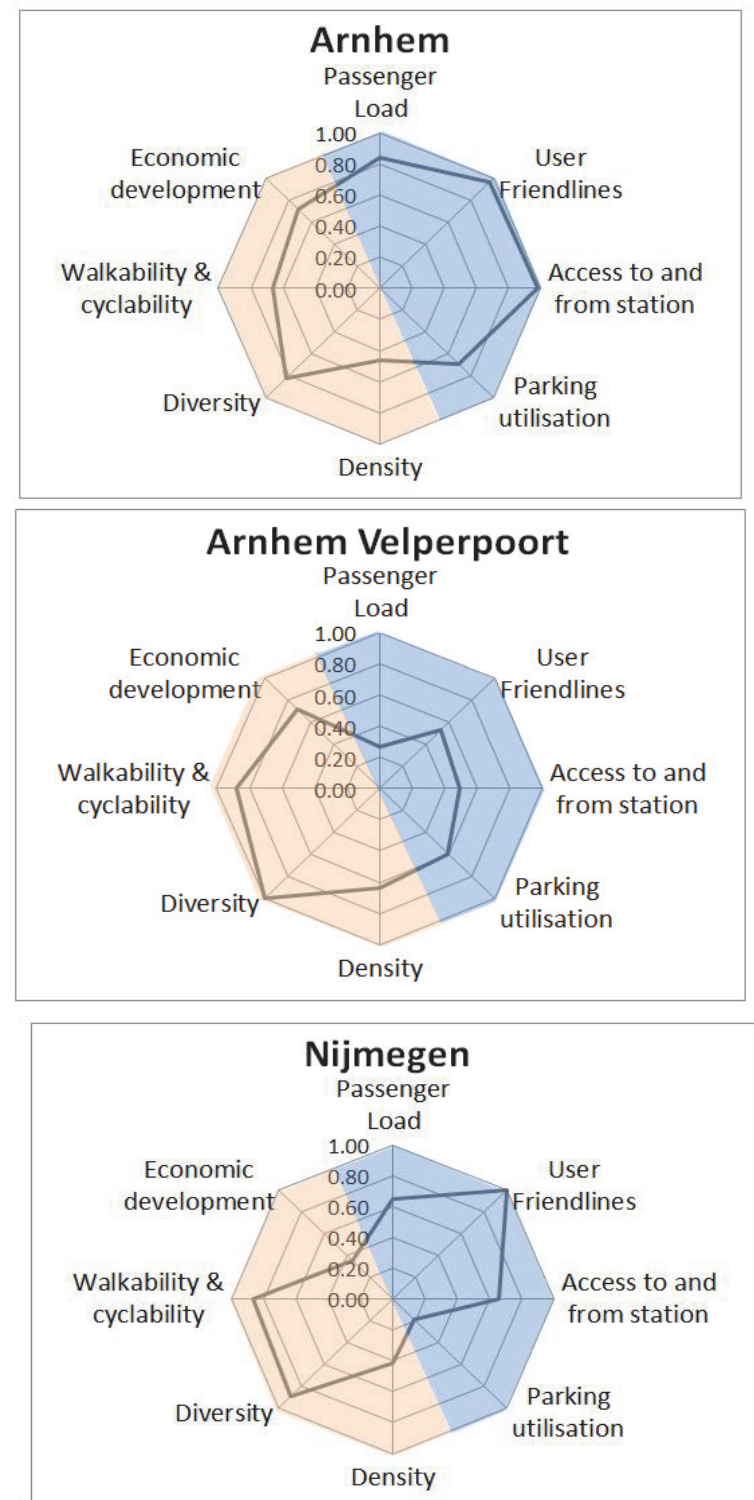

Figure 2.9: Web diagrams for the 3 top-scoring stations (transit related indicators are shown on blue side of the web and land use indictors on the light orange side)

It may be pointed out here that the web-diagrams are made using the standardised values and thus, the standardised score of 1 for userfriendliness at stations Arnhem and Nijmegen means that comparatively, their user-friendliness is 'maximum' among all stations but they still hold potential for improvement. The web-diagrams for all stations are given in Appendix 2. Based on the information in web-diagrams, for each station, 
those criteria were identified that can be improved, if need be, and were tabulated in the table 2.4 .

\section{Table 2.4: Criteria holding potential for improvement at each station}

\begin{tabular}{|c|c|c|}
\hline So. & $\begin{array}{l}\text { Station Name } \\
\text { (arranged in } \\
\text { order of their } \\
\text { TOD score) }\end{array}$ & $\begin{array}{l}\text { Criteria with most potential for improvement } \\
\text { as inferred from the web-diagrams. }\end{array}$ \\
\hline 1 & Arnhem & \\
\hline 2 & $\begin{array}{l}\text { Arnhem } \\
\text { Velperpoort }\end{array}$ & \\
\hline 3 & Nijmegen & \\
\hline 4 & Rheden & \\
\hline 5 & $\begin{array}{l}\text { Nijmegen } \\
\text { Heyendaal }\end{array}$ & \\
\hline 6 & Wijchen & \\
\hline 7 & Duiven & \\
\hline 8 & Nijmegen & \\
\hline 9 & Zevenaar & \\
\hline 10 & Elst & \\
\hline
\end{tabular}




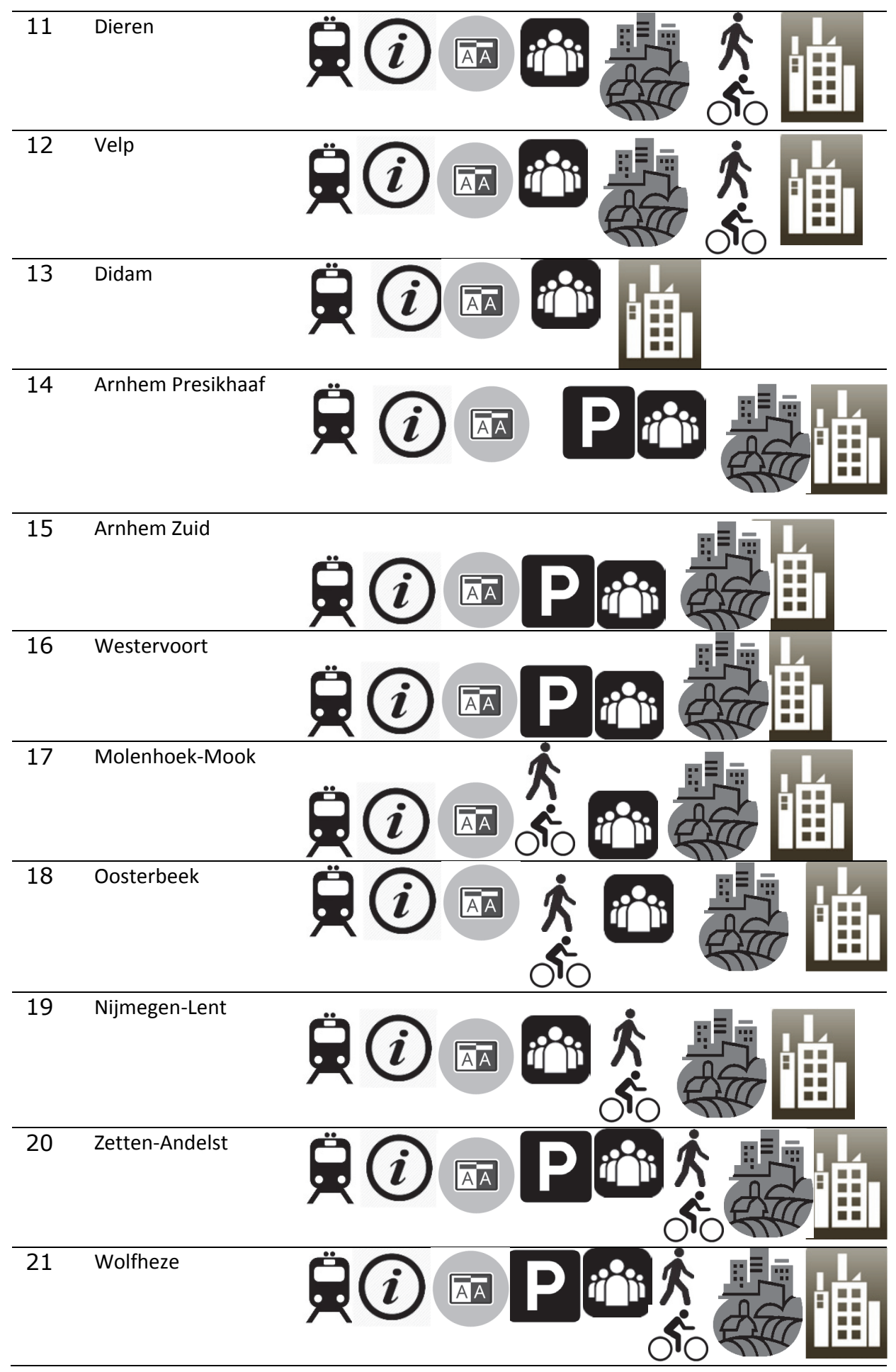


For the Nijmegen Heyendal station, for example, the TOD policy could be to improve the user-friendliness and access of the station and improve the economic development in the area. Any increase in the latter should mean an increase in number of jobs and hence improved accessibility and higher densities in the area. Thus, it can be seen how a TOD index can be used to make TOD policy by comparing different station areas at regional scale and identifying specific problems at each station, separately, at local scale. At the regional level, it also helps in making sure that the regional plans and policies are adhered to and not lost due to local conditions and priorities. We need a Planning Support System (PSS) to help make more detailed TOD plans. A consulting company Het Noordzuiden in Netherlands, has also studied the station areas for the City Region. They made detailed reports about what can be done to improve TOD levels for different station areas (Noordzuiden, 2011c). However, not all existing station areas are covered there.

While we can make policy decisions on the need for improving certain criteria or indicators, we cannot propose what measures should be taken to do so. For instance, we may be able to conclude that density, more specifically residential density around a certain station is low and needs to be increased, but we cannot recommend if that should be achieved by relaxing the building regulations or increasing housing supply for a specific section of society or by utilisation of existing vacant land parcels (if any) or through other measures. For such detailed proposals, planners need to revisit their local and regional policies, political priorities and financial constraints. Thus, these results can be discussed at length among all stakeholders and planners before making TOD proposals for different station areas.

\subsection{Conclusions}

In this chapter we have elaborated our approach on quantifying TOD around existing transit nodes, using a TOD index that is calculated using MCA with stakeholders' involvement and which expresses the TOD-ness of the station areas. The chapter elaborates how the index allows direct comparison of transit node areas over the region or may be even an urban area. To calculate our TOD Index, we used a total of eight criteria that measure the development as well as transit related characteristics as all these factors influence the commuter's choice to use transit over car. The stakeholders were also successfully involved in this process by taking their opinion on the importance of each indicator and criterion in the realisation of TOD. A sensitivity analysis confirmed that the results of our TOD index are robust and inferences were drawn from the results to recommend areas for improvement. 
We demonstrated how this index can be useful for planning practitioners who wish to plan for TOD in their region or urban area as they can compare existing TOD characteristics/ conditions around different transit nodes. Since our method does not cluster stations, planners can treat each station's problems uniquely, thereby getting the best results from their plans. Keeping the broad methodology same, planners can choose their own set of indicators and involve different and multiple stakeholders in weighing exercise. By combining these results with those in the next chapter, the City region can not only improve development around existing transit nodes but also improve access to transit at various locations in the region. This, we believe is the wholesome approach to TOD planning and policy. In future, as more and more studies are done using this index, it would be possible to have a better understanding of what score can be considered as 'generally low' and ' generally high' or 'enough' for an area to qualify as a 'TOD' or 'TAD'. In a gist, this methodology can help the planners inform planning, funding and investment policies for TOD at an urban or a regional level. A TOD Planning Support System (PSS) will be further helpful in making detailed TOD plans for each station. 


\section{Chapter 3 - Measuring TOD at regional scale*}

* This chapter is based on the following publications:

Singh, Y.J., Fard, P., Zuidgeest, M.H.P, Brussel, M., van Maarseveen, M.F.A.M., 2014. Measuring Transit Oriented Development: a Spatial Multi-Criteria Assessment Approach for the City Region Arnhem and Nijmegen. Journal of Transport Geography, 35, 130143.

Singh, Y.J., He, P., Flacke, J., van Maarseveen, M.F.A.M., 2014. Measuring Transit Oriented Development over a region using an Index, 12th Annual Transport Practitioners' Meeting London, U.K.

Singh, Y.J., Lukman, A., He, P., Flacke, J., Zuidgeest, M.H.P., van Maarseveen, M.F.A.M., 2015. Planning for Transit Oriented Development (TOD) using a TOD Index, Transport Research Board 94th Annual Meeting, Washington D.C. 


\subsection{Background}

Transit Oriented Development (TOD) as a planning tool integrates the land use and transport system, thereby creating lively, sustainable, pedestrian and cycling friendly areas and neighbourhoods (CTOD, 2009), while encouraging people to choose transit over cars for their long commutes. A more widely agreed description of TOD is an urban environment with high densities, mixed and diverse land uses, located within an easy walkable area around a transit stop (Calthorpe (1993), The City of Calgary (2004), Parker et al. (2002), Hale and Charles (2006)). But TOD planning is not and should not only be about creating development that is oriented towards transit use. It should also mean bringing transit to those locations, where the development already possesses the physical characteristics of that of a typical TOD, but without having transit connectivity at that place. This actually signifies a two-sided planning approach that ensures that necessary planning interventions are made to either make the urban development more transit oriented or to bring transit to places where the development is already transit oriented. We can also call this wholesome planning approach 'TOD Planning'.

In our last chapter we discussed how we calculated TOD index for 21 station areas in the City region to fulfil our first research objective (section 1.4). In this chapter we demonstrate how we fulfilled the second research objective by measuring existing TOD levels at regional scale over the City Region using the Potential TOD Index. Using the results of Potential TOD index, we will identify those areas where TOD levels are high but access to high quality transit is poor. In the next section, we elaborate our methodology for the same including how the indicators were identified. Section 3.3 explains indicator calculation use of SMCA to assess all indicators together to arrive at TOD Index values representing the existing levels of TOD across the region. As results are obtained at the end of section 3.3, we identify hot-spots based on the TOD Index values in section 3.4. Our recommendations have been made in section 3.5 and in section 3.6, we conclude the chapter.

\subsection{Methodology}

Most literature on TOD deals with evaluation of completed TOD projects. Some case studies present an example of planned TOD at urban, regional or station level (Yang and Lew (2009), Balz and Schrijnen (2009), Cascetta and Pagliara (2009), Howe (2009), Curtis (2009), Arrington (2009)), while some cases represent the successful role of the private sector in TOD implementation (Chorus (2009), Cervero and Murakami (2009) and yet some cases are about TODs centred around Bus Rapid Transit (BRT) (Hoffman (2006), McKone (2010)). It has been found that complete and quantitative measurement of TOD-ness of an area has not been done. Only a few studies 
(Shastry et al., 2011), (Kamruzzaman et al., 2014), (Schlossberg \& Brown, 2004) measured one or more TOD criteria. In (Kamruzzaman et al., 2014), TOD has been studied at regional scale by dividing the region into zones and measuring TOD characteristics. They have then clustered the zones also into the 4 TOD typologies created by them.

Following the broad methodology shown in section 1.5, this section discusses those details that were necessary for measurement of TOD over the entire region.

\section{Spatial unit of analysis for Potential TOD Index calculations}

An actual TOD area has been typically described as the area within walkable limits of a transit node i.e. an area within about $500 \mathrm{~m}$ to $800 \mathrm{~m}$ of a transit node(Calthorpe (1993), The City of Calgary (2004)). However, the Potential TOD Index has no such defined boundary or recommended size of area, yet it has to be measured for the entire City Region. Hence, using tessellation of space (Mitchell, 2009), different grid tessellations of $100 \times 100,200 \times 200$, $300 \times 300$ and $500 \times 500$ meters were created. Keeping in mind the spatial scale of typical TOD area, the cell size of grid, and computational performance factor, a cell size of $300 \times 300$ meters was selected as the basic spatial unit for measuring Potential TOD Index for the entire City Region. Overlaying $1000 \mathrm{~km} 2$ of Arnhem-Nijmegen region with such grid cells resulted in more than 12,000 cells. The index was then calculated for each of these grid cells in the City Region.

\section{Identification of Criteria and indicators}

Arriving at a comprehensive TOD Index score involves measurement of individual indicators and criteria that make the index. Many indicators have been used in various case studies in the past, where TOD has been evaluated for its success. Renne and Wells (2005), Evans and Pratt (2007) and Shastry et al. (2011), have listed the most important indicators that can be used to evaluate TOD. Dittmar and Poticha (2004) and Belzer and Autler (2002) have both identified performance criteria that are necessary for evaluation of TOD's performance and according to Cervero and Murakami (2008), TOD can be best assessed using the five Ds - Density, land use Diversity, urban Design, Destination accessibility and Distance to transit. It is to be noted that most of the proposed indicators and criteria have been proposed for the purpose of evaluation of TOD's performance while our TOD Index measures the existing levels of TOD and does not evaluate them. Further, not all of these indicators can be quantified and hence cannot be used for our index. To fulfil the specific needs of our research, indicators were chosen following the 'Rules', like those set for the Actual TOD index calculations. In section 2.3, eight rules have been identified regarding which urban development and 
transit characteristics positively affect TOD-ness of an area. Since Potential TOD index needs to be calculated for all parts of the region that may or may not have transit connectivity, this index cannot measure transit characteristics for all cells. It can only measure urban development characteristics. Thus, following four rules were adopted for measuring TOD across the region:

Rule 1: Urban densities are important for developing TOD

Rule 2: Land use diversity creates a vibrant/ lively place out of a node

Rule 3: Design of urban space that makes an area walkable and cyclable, is necessary for TOD

Rule 4: Higher economic development in an area leads to higher TOD.

In line with the rules above, the criteria were identified that need to be measured. These are - urban densities, land use diversity, walkability and cyclability and economic development. To be able to measure these criteria, specific indicators were identified for each criterion that help in quantified analysis of the same. Various TOD case studies (Curtis et al., 2009b), (Lindau et al., 2010), (Balz \& Schrijnen, 2009), (Bae, 2002), (Cascetta \& Pagliara, 2009), (Yang \& Lew, 2009), (Howe et al., 2009), (Chorus, 2009), (Arrington, 2009), (Hoffman, 2006), (McKone, 2010), (Cervero \& Murakami, 2009), (Schlossberg \& Brown, 2004) and others were studied to choose our indicators that were fit for quantified analysis of the criteria and for which data could be available from secondary sources. The indicators finally chosen for our work are tabulated in table 3.1 and shown in figure 3.1.

Table 3.1: Criteria and indicators for measuring Potential TOD index

\begin{tabular}{|c|c|}
\hline & Potential TOD index \\
\hline Criteria & Indicators \\
\hline \multirow{3}{*}{ Urban densities } & Population density (number of persons / km2) \\
\hline & $\begin{array}{l}\text { Employment density (number of employees/ } \\
\mathrm{km} 2 \text { ) }\end{array}$ \\
\hline & $\begin{array}{l}\text { Commercial density (number of commercial } \\
\text { enterprises/ km2) }\end{array}$ \\
\hline Land use Diversity & $\begin{array}{l}\text { Land use diversity measured using Entropy } \\
\text { index }\end{array}$ \\
\hline \multirow{3}{*}{$\begin{array}{l}\text { Design of urban space to } \\
\text { encourage walking and } \\
\text { cycling }\end{array}$} & $\begin{array}{l}\text { Mixed-ness of residential land use with other } \\
\text { land uses }\end{array}$ \\
\hline & $\begin{array}{l}\text { Intersection density (number of intersections/ } \\
\mathrm{km} 2 \text { ) }\end{array}$ \\
\hline & $\begin{array}{l}\text { Total length of road fit for walking and cycling } \\
\text { (meters or } \mathrm{km} \text { ) }\end{array}$ \\
\hline \multirow{3}{*}{$\begin{array}{l}\text { Level of Economic } \\
\text { development }\end{array}$} & $\begin{array}{l}\text { Density of business establishments (number of } \\
\text { business establishments } / \mathrm{km} 2 \text { ) }\end{array}$ \\
\hline & $\begin{array}{l}\text { Tax earnings of municipalities (thousand Euros in } \\
\text { last year) }\end{array}$ \\
\hline & Employment levels \\
\hline
\end{tabular}




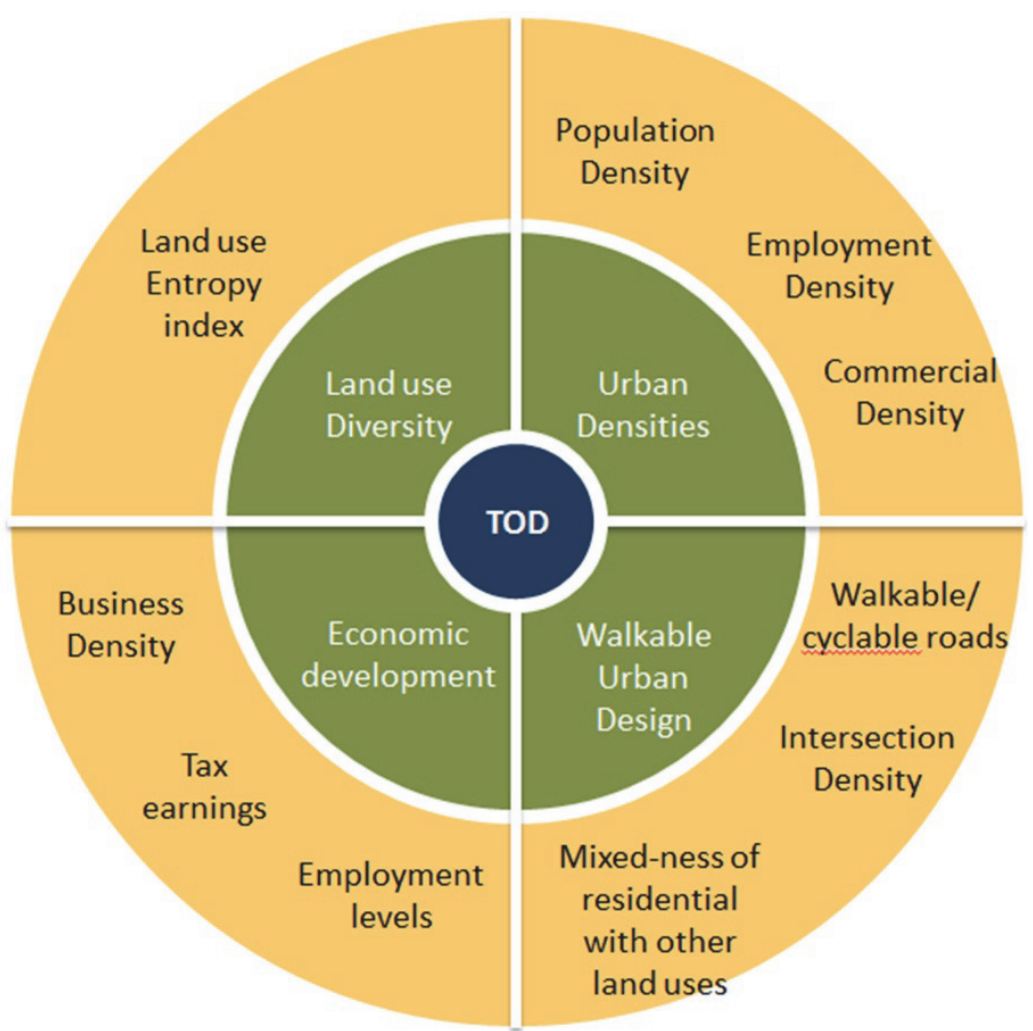

Figure 3.1: Criteria and measurable indicators to measure TOD at regional scale

\section{Data collection}

For measurement of the indicators listed in table 3.1, various spatial (land use data with building foot prints and road network) and non-spatial data (mostly statistical data) at the regional level was required and was collected from credible secondary sources including the City Region itself, ESRI Nederland, Central Bureau of Statistics, Netherlands (CBS), and Open Street Map (OSM). Gathering data from these fragmented sources involved issues like incomplete map coverage, inconsistent administrative boundaries, conflicting land use classifications, different map projections and so on, which in most cases were addressed by comparison between sources and also with the help of a third party reference like Google Maps. Some data was not available as a result of which, those indicators from table 3.1 had to be dropped from our analysis. The final indicators that we used have been put in bold in table 3.1, and cover all four criteria classes. 


\section{Computation of the Potential TOD index}

Since Potential TOD index involved working with spatial indicators, Spatial Multi-Criteria Analysis (SMCA) was adopted to calculate the index values as it allows spatial aggregation of the indicators. In SMCA, two main steps of standardisation and weighing are required and they are explained below.

\section{a. Standardisation of indicators}

As mentioned before, all our indicators have different units. In order to be compared and combined we standardised the indicators such that the values of all indicators range from 0 to 1 . Using the 'maximum' method, all maximum values of the indicators were set to 1 and proportionately, all other values of the indicator were reduced to a value less than 1 .

There is another standardization that is required to indicate the relationship of each indicator to the final index. If an indicator is directly proportional to the index i.e. an increase in the value of an indicator increases the TOD index value, then there is a 'benefit' relationship between the two. An inverse of this relation is called 'cost'. All our indicators are directly related to the index and were hence standardised using 'benefit' method, except for the 'mixed-ness' indicator that was standardised using a 'combination' method. Under this method, increase in the value of mixed-ness is beneficial to the index value till it reaches a value of 0.5 after which, it acts as a 'cost'. This was done since 0.5 is the optimal score for this indicator, indicating a balanced mix of residential with other land uses.

\section{b. Weighing the indicators}

The next step in SMCA is weighing indicators. Our TOD Index has four criteria and each criterion has a number of measurable indicators. The weight of each indicator is an indication of its importance to its respective criterion and the weight of each criterion indicates its importance to creation or realisation of TOD. The most commonly used method to weigh the indicators is ranking, where all criteria and their indicators are ranked in terms of their importance and it can be done by one or many groups of stakeholders. As mentioned in last chapter, the municipal heads of the City Region were involved and in a special workshop, they were asked to rank the indicators and criteria with respect to their importance in realization of TOD. The questionnaire used for this purpose is appended as Appendix 1 and questions 9 to 12 pertain to this index. The ranks given by municipal heads were then aggregated using the 'Borda Count method' (Reilly (2002)) and the ranks were further converted to weights in ILWIS using the rank sum method eq. 5 (ITC (2007)). 


$$
=\frac{W_{k}}{\sum_{i}^{n}(n+1-k)}
$$

where $W_{k}$ is the normalized weight for the criterion with rank ' $k$ ', $n$ is the total number of criteria in the set ( $52^{\circ}$ North, 2012). The ' $i$ ' is the index of summation that takes the value from 1 to $\mathrm{n}$. The table 3.2 shows the weights that were used for SMCA. The final weights were then input in ILWIS along with the respective indicators' maps. By standardizing the indicators in the manner described earlier and using these weights, the Potential TOD Index was calculated for all 12,000 (approx.) grid cells in the City Region.

\begin{tabular}{|c|c|c|c|}
\hline Criteria & Weights & Indicators & Weights \\
\hline \multirow{3}{*}{ Urban densities } & \multirow[t]{3}{*}{0.3} & Population density & 0.5 \\
\hline & & Commercial density & 0.33 \\
\hline & & Employment density & 0.17 \\
\hline $\begin{array}{l}\text { Land use } \\
\text { Diversity }\end{array}$ & 0.2 & $\begin{array}{l}\text { Land use diversity } \\
\text { measured using } \\
\text { Entropy index }\end{array}$ & 1.0 \\
\hline \multirow{3}{*}{$\begin{array}{l}\text { Design of urban } \\
\text { space to } \\
\text { encourage } \\
\text { walking and } \\
\text { cycling }\end{array}$} & \multirow[t]{3}{*}{0.1} & $\begin{array}{l}\text { Mixed-ness of } \\
\text { residential land use } \\
\text { with other land uses }\end{array}$ & 0.17 \\
\hline & & $\begin{array}{l}\text { Total length of road fit } \\
\text { for walking and cycling }\end{array}$ & 0.50 \\
\hline & & Intersection density & 0.33 \\
\hline $\begin{array}{l}\text { Level of Economic } \\
\text { development }\end{array}$ & 0.4 & $\begin{array}{l}\text { Density of business } \\
\text { establishments }\end{array}$ & 1.0 \\
\hline
\end{tabular}

Table 3.2: Indicators, Criteria and their weights

\subsection{Calculation of Indicators}

As given in table 3.1, eight indicators were calculated to measure the TOD Index across the City Region. The following sub-sections detail out the calculations for each indicator.

\section{a. Density indicators}

High densities are important to support higher frequency transit service and to foster lively, walkable communities (Bach et al., 2006). They also optimize transit rider convenience (The City of Calgary, 2004). Thus, high density development is an indication of high travel demand, possibly high transit patronage and hence high TOD levels in an area. Under the hierarchy of administrative units, the City Region is divided into 20 municipalities that are further divided into 78 districts and 443 neighbourhoods. The data from CBS on the number of people, employees 
and commercial establishments was available at neighbourhood level and had to be disaggregated to the grid level. Since our area of analysis i.e. $300 \times 300 \mathrm{~m}$ grid cell does not conform to neighbourhood boundaries, the ArcGIS function on data apportionment for non-coterminous polygons was carried out to proportionately divide statistical data per neighbourhood into the area of analysis. This function used the building foot-print data that we had for land use information. Thus, for population density, data apportionment was based on the proportion of land covered by residential building foot-prints in the area of analysis and the neighbourhood. Similarly for employment density, building foot prints of non-residential land uses were used and for commercial density, building foot prints of commercial land use were used. The resulting maps representing the population, employment and commercial densities (figures 3.2, 3.3, 3.4) are as shown. As expected, the densities are more around the cities of Arnhem and Nijmegen and are quite low outside the urban areas.

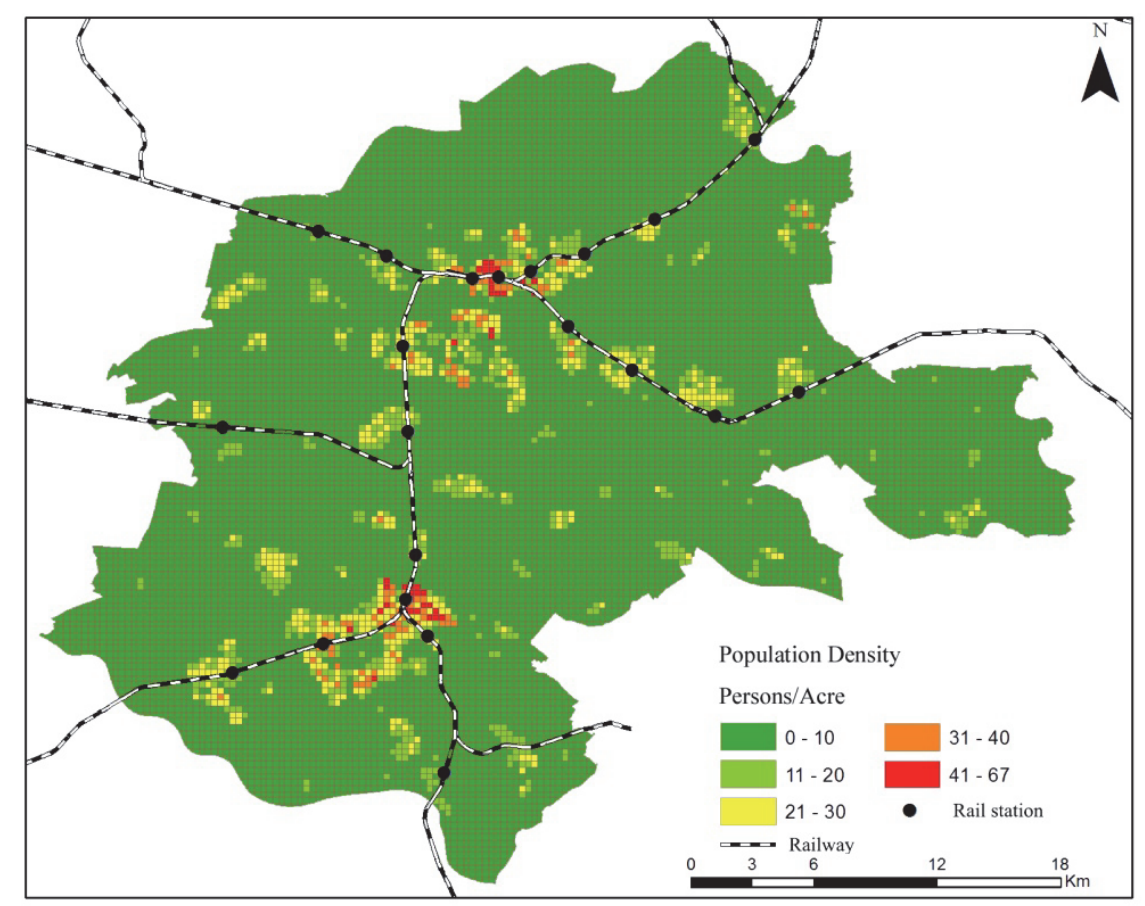

Figure 3.2: Population Density 


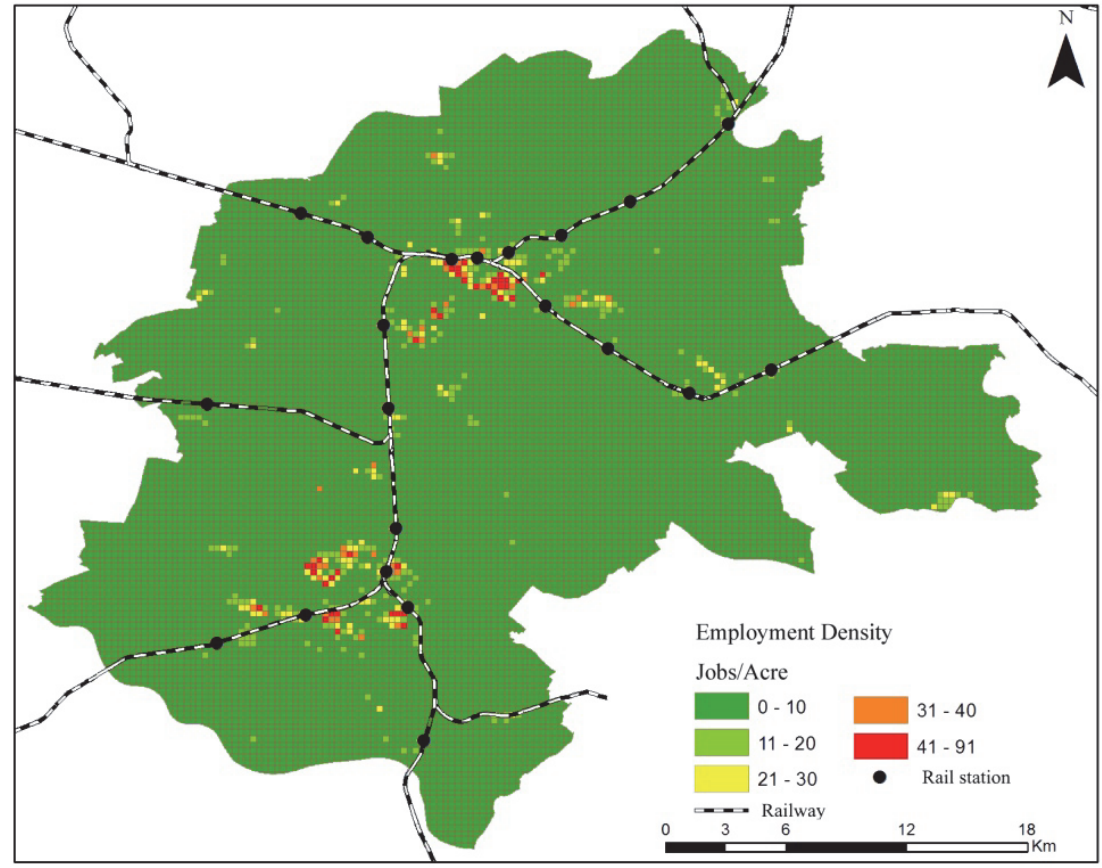

Figure 3.3 Employment Density

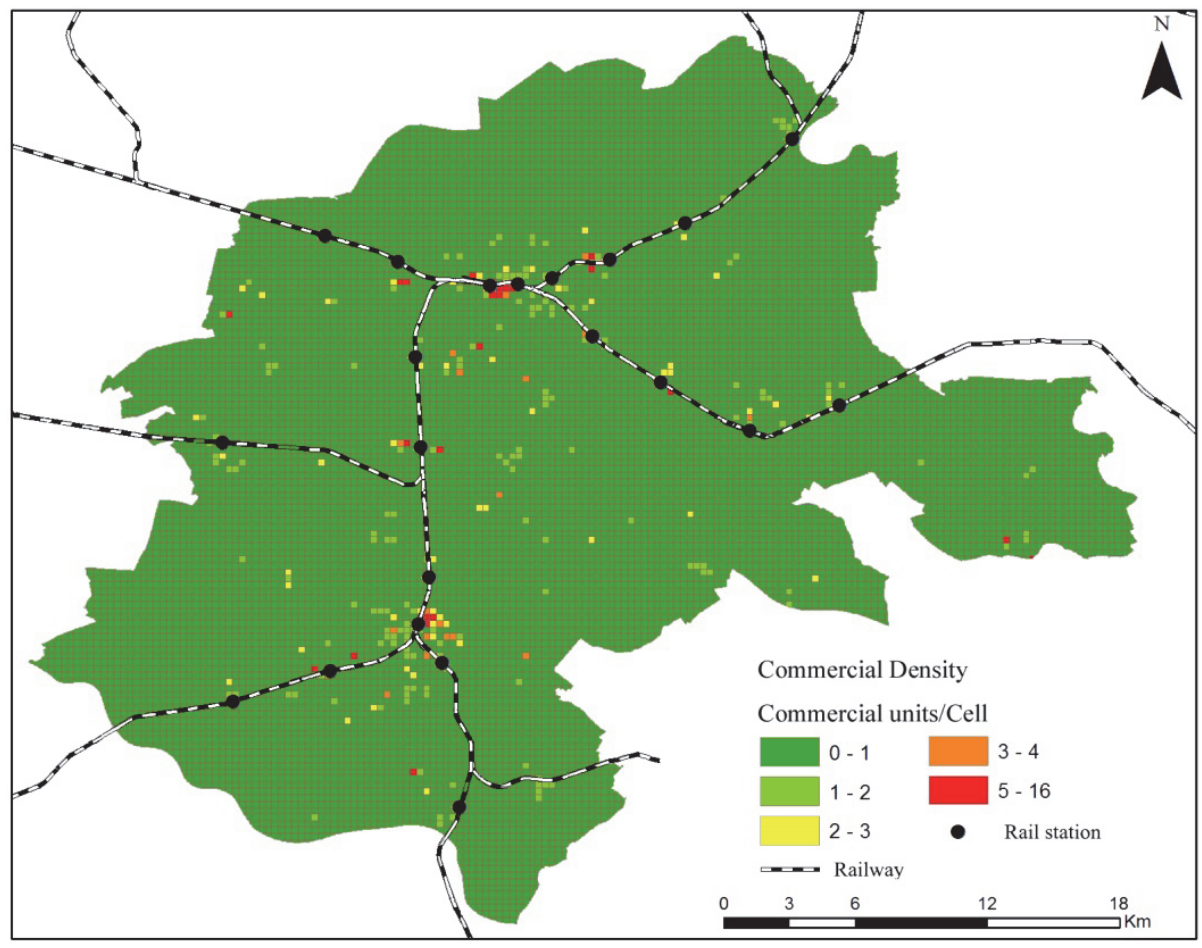

Figure 3.4 Commercial Density 


\section{b. Land use Diversity indicator}

Presence of diverse land uses creates more balanced and consistent passenger flow at all times of the day, all days of the week and throughout the year. The increased and varied passenger market contributes to higher revenue and better utilization of transit capacity (Bach et al., 2006). If the areas are not dominated by a single land use, we can assume that people will feel livelier, safer and that the areas will be lighted for longer periods of time that would encourage better interaction among people from all walks of life.

Land use diversity is a measure of spatial heterogeneity of land use types within an area $i$ and measured here by use of entropy. The established methods of computing land use diversity use raster data where each pixel or portion of space represents one dominant land use rather than a set of land uses, as is in vector data. Since our study uses vector data, the research of Ritsema van Eck and Koomen (2008) was considered and a geo-processing model was developed capable of computing diversity over vector data.

During the calculations of the land use diversity indicator, our first approach was to calculate the index for each grid cell independently. However, one cell of $300 \mathrm{~m} \times 300 \mathrm{~m}$ which covers an area as small as nine hectares, only has limited diversity since it cannot accommodate a variety of land uses (Cervero \& Kockelman, 1997a). Hence we used a neighbourhood function and conducted a moving window analysis, as shown in figure 3.5, to compute entropy for each grid cell adapting the equation from (Cervero \& Kockelman, 1997b) as given in eq.(6).

$$
\text { Entropy }=-1 * \sum_{n} \frac{P i * \ln (P i)}{\ln (n)}
$$

where,

$$
P i=\frac{S j i}{S i}
$$

$S_{j i}=$ Total area of land use $j$ within area of analysis $i$.

$S_{i}=$ Total area of analysis $i$.

$n=$ total number of land use types.

The entropy method produces an index between 0 and 1 , where a value of 1 implies most balanced mix of land uses and a value of 0 indicates the presence of no or just one kind of land use. Only urban land uses such as residential, commercial, industrial, office, service, health care, education 
and sports were used for this calculation. The resulting land use diversity map for the City Region is shown in figure 3.6.

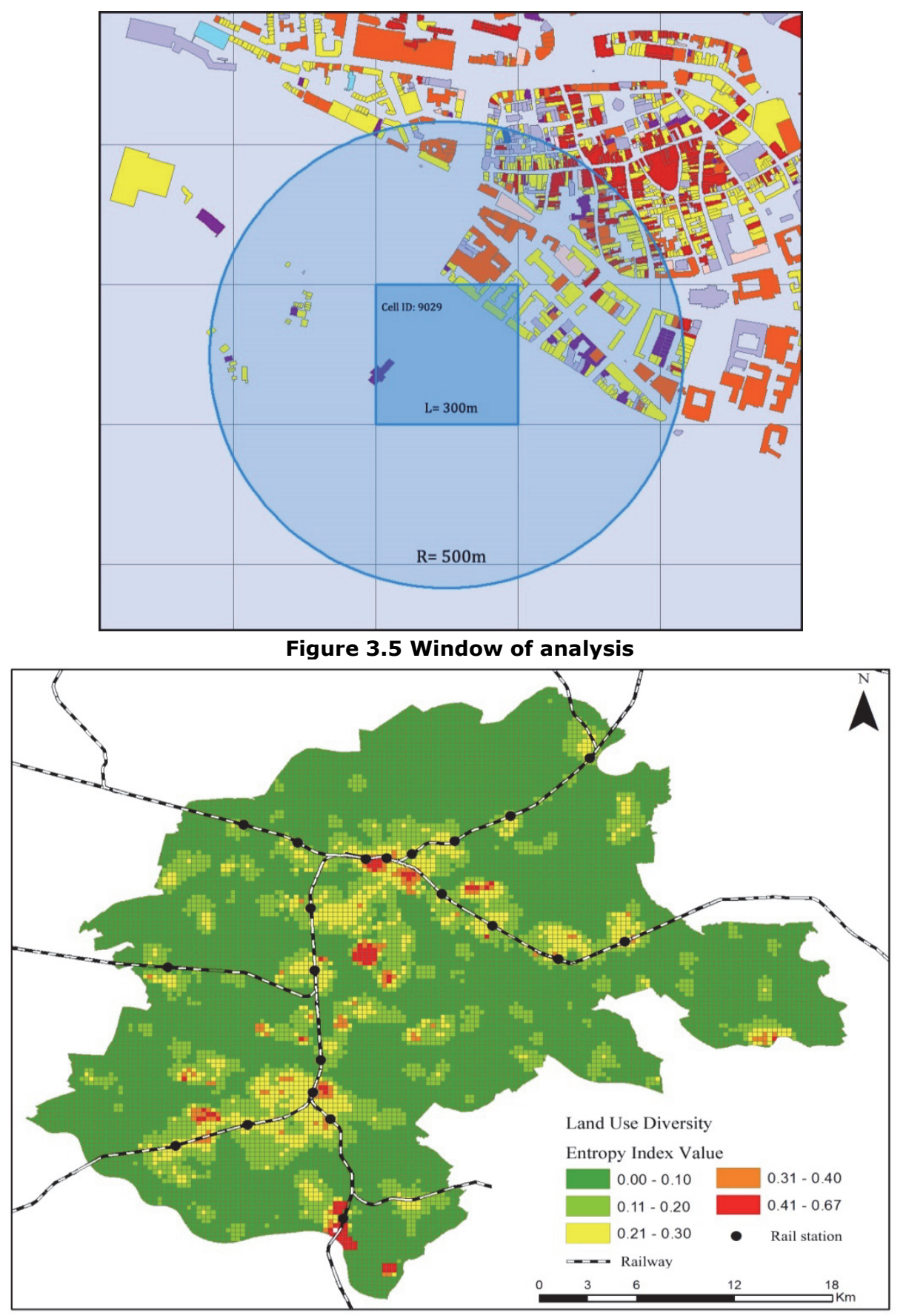

Figure 3.6: Land use Diversity in the region 


\section{c. Mixed-ness of Land use}

Calthorpe (1993), p.17, has already mentioned that "Our investments in transit must be supported by land use patterns which put riders and jobs within an easy walk of stations." Since walkability is very important for high TOD levels, it is an important indicator to be measured. Walkability is encouraged primarily by urban design and land use mix (Molster \& Schuit, 2013). Zhang and Guindon (2006), p.159, quote from (CST, 2002) that "... to support a high degree of walking and cycling, residential and employment uses must be mixed on a very small scale." This notion of mixed-ness is different from that of diversity and centers around how the residential land use is supported by other land uses such as commercial, industrial, institutional put together. According to Bach et al. (2006), a healthy mix of land uses w.r.t. residential land use can encourage people to carry out their daily chores on foot or on cycle. To calculate the mixed-ness of residential land use w.r.t commercial, industrial or other land uses, we adapted the formulae used by Zhang and Guindon (2006) to our context and for our use of vector land use data. Once again, a window of analysis as shown in figure 3.5 was used to calculate the level of mixed-ness of land uses in a grid cell. The formula used by us is as follows in eq. (8):

$$
M I(i)=\frac{\sum_{\cap i} S_{c}}{\sum_{n i}\left(S_{c}+S_{r}\right)} \quad \forall i
$$

where MI is the 'Mixed-ness Index', Sc shows the sum of the total area under commercial, industrial and other land uses and Sr represents the sum of the total land area under residential land use within the analysis neighbourhood $\mathrm{i}$. The value of this indicator is most balanced at 0.5 because that's when residential land use is equally supported by other land uses. The resulting indicator map for City Region is shown in figure 3.7 that shows that index values are low outside urban areas. The dark green patches showing null levels of land use mixed-ness also indicate that there are no residences found in those areas. It is interesting to see that mixed-ness of land use is high in various parts of the region and is not concentrated around stations. In fact, it is quite low in areas just next to the stations, which could be because of little residential land use around stations and more non-residential land use. 


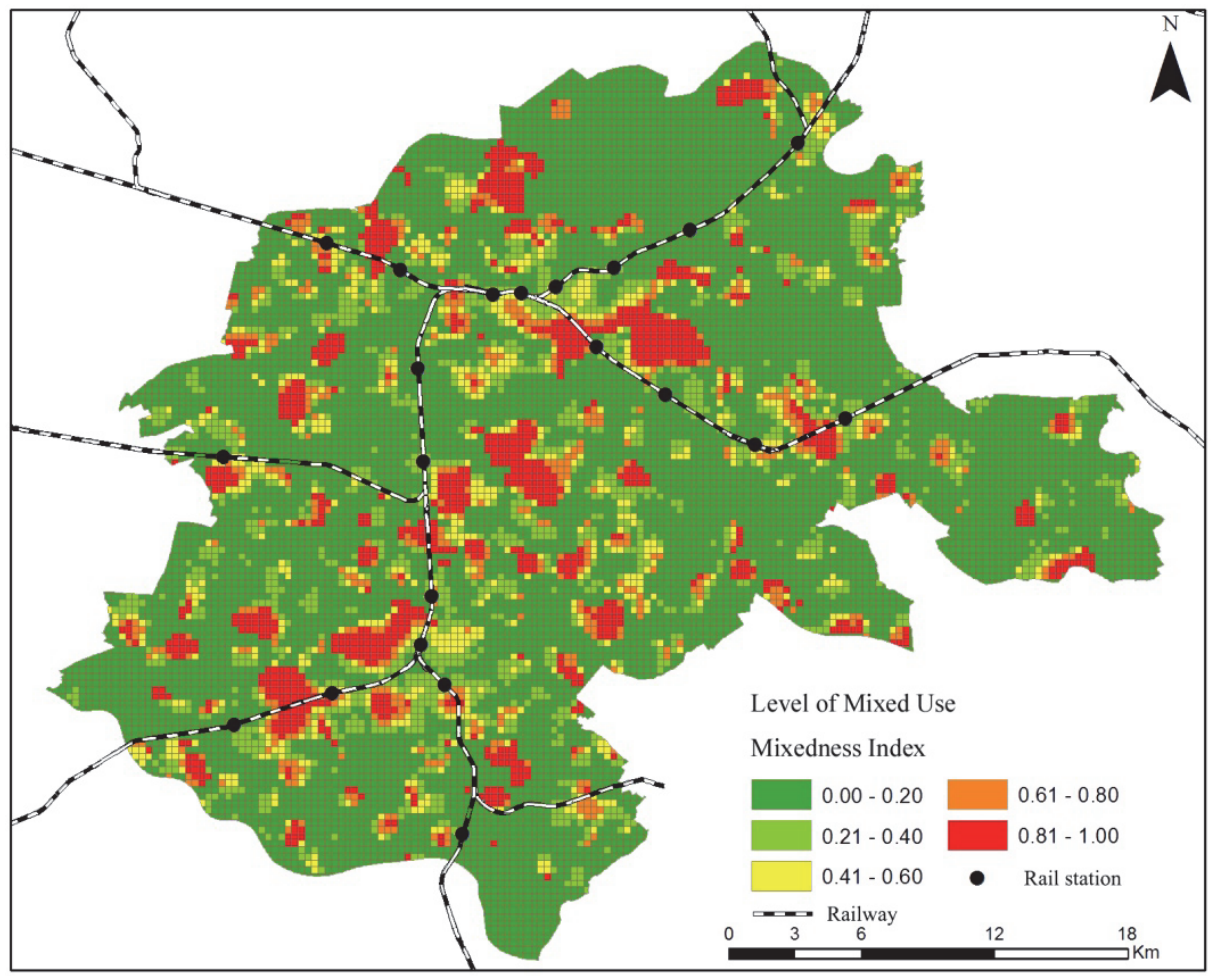

Figure 3.7: Mixed-ness of land use

\section{d. Intersection Density}

The number of intersections and total length of accessible paths for walking and cycling are simple measures of walkability. An area with higher number of intersections (3-way or more) can create a pedestrianfriendly environment as people can shorten their walking distances. The intersection density was thus calculated for each grid cell and is shown is figure 3.8 .

\section{e. Length of total network suitable for walking and cycling}

Streets that are accessible to pedestrians are important for people to walk or cycle. Major roads like highways are excluded from this calculation since it is not safe to walk or cycle on such roads. The total lengths of walkable and cyclable paths in each grid cell of the City Region were calculated and are mapped in figure 3.9. It is nice to see that many areas in the City Region, inside and away from main cities, have walkable/ cyclable roads. 


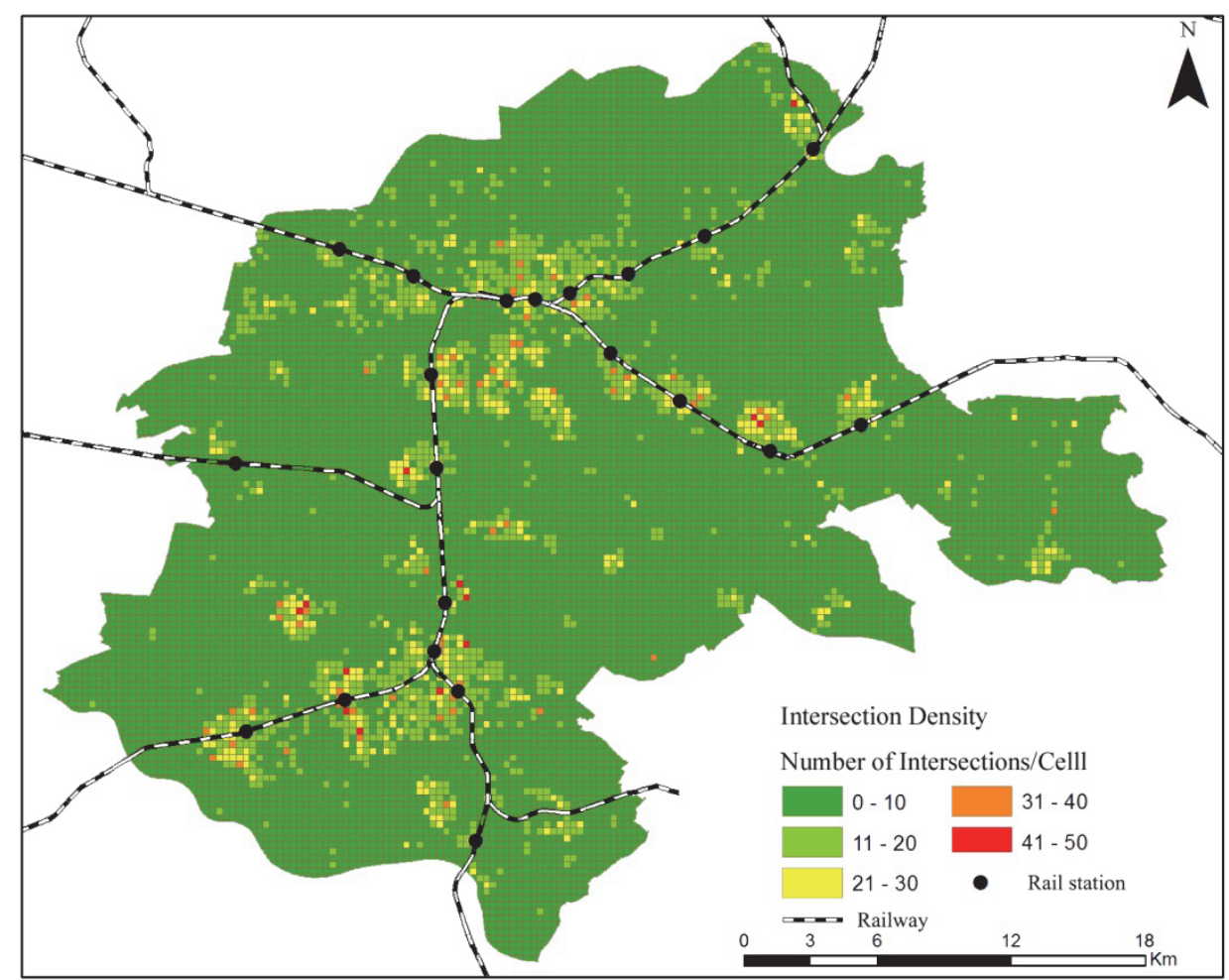

Figure 3.8: Intersection Density

\section{f. Density of business establishments}

Economic activity has been proposed as an indicator of TOD levels by Renne and Wells (2005) and Evans and Pratt (2007) since a high economic activity indicates higher travel demand and hence higher levels of TOD in the area. Density of business establishments in the area is one of the indicators of economic activity mapped as shown in figure 3.10 using the data from CBS. As expected, like commercial densities, it was found that the density of business establishments is also higher in Arnhem and Nijmegen implying that these have higher economic development and possibly higher TOD levels. Rest of the City Region has very little economic development.

\subsection{Results of 'Potential TOD Index' and Sensitivity Analysis}

Upon conducting SMCA, the TOD index results were derived and those are shown in the figure 3.11. As can be seen, higher TOD values exist around the main cities of the region and most of the region has very low TOD values. 


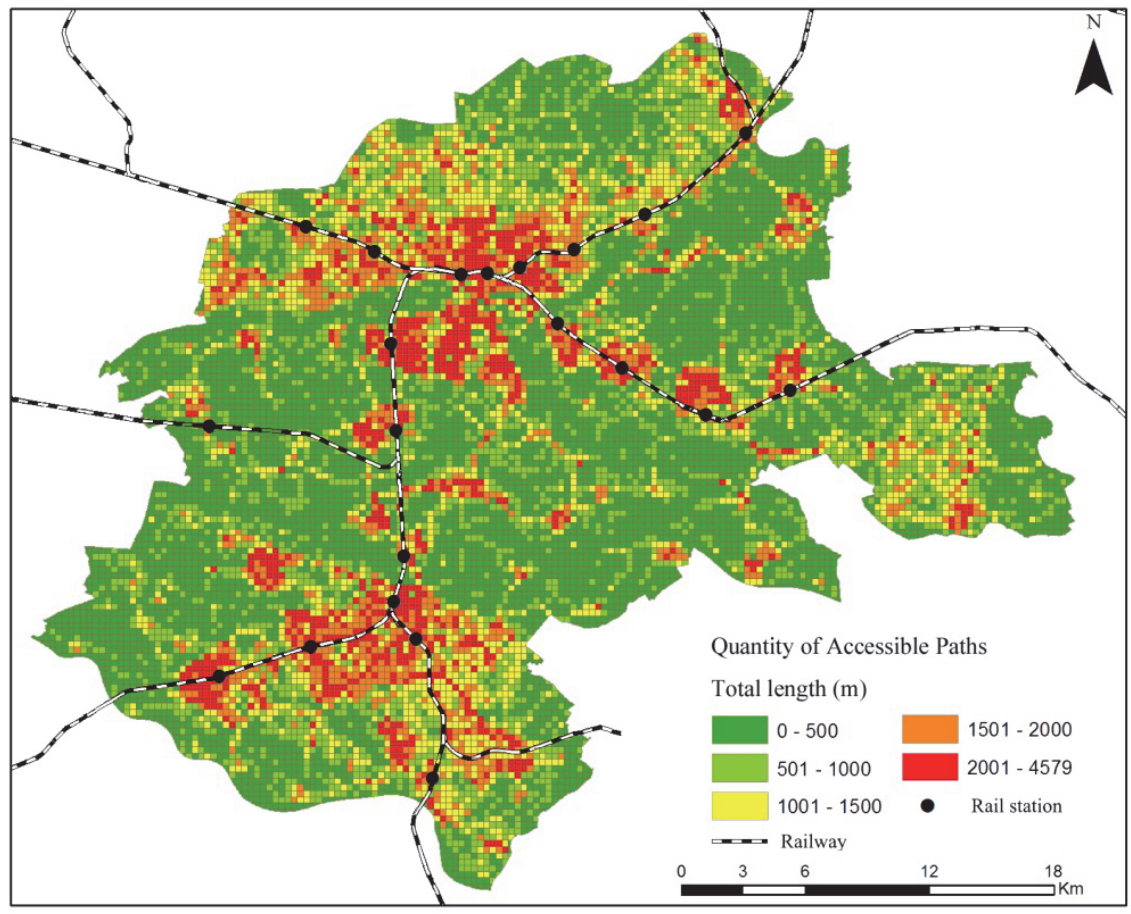

Figure 3.9: Length of walkable/ cyclable paths

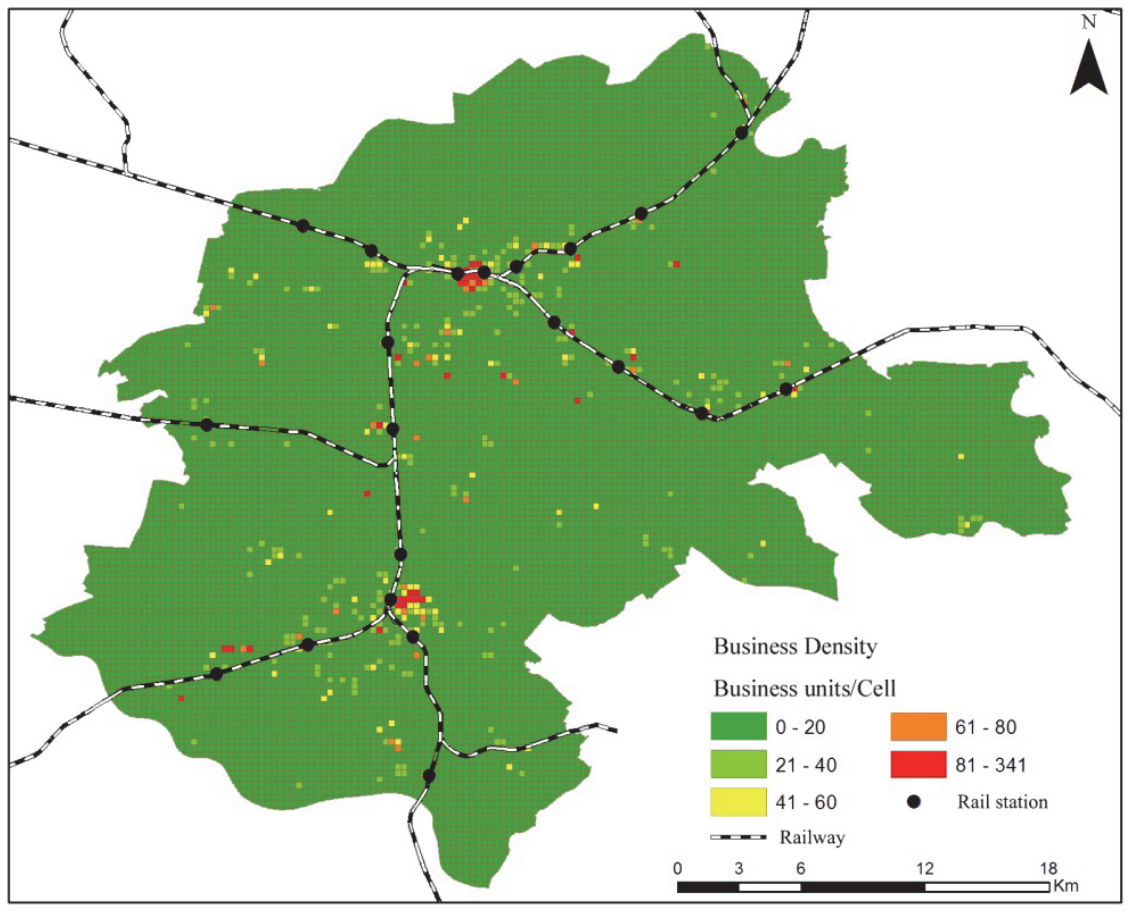

Figure 3.10: Number of business establishments 
It is interesting to see that the average TOD index value for the City region is only 0.0447 while the maximum stands at 0.55 . The reason for an overall low TOD score is that this is an urban region that also includes large forests and rural areas engaged in agriculture activities.

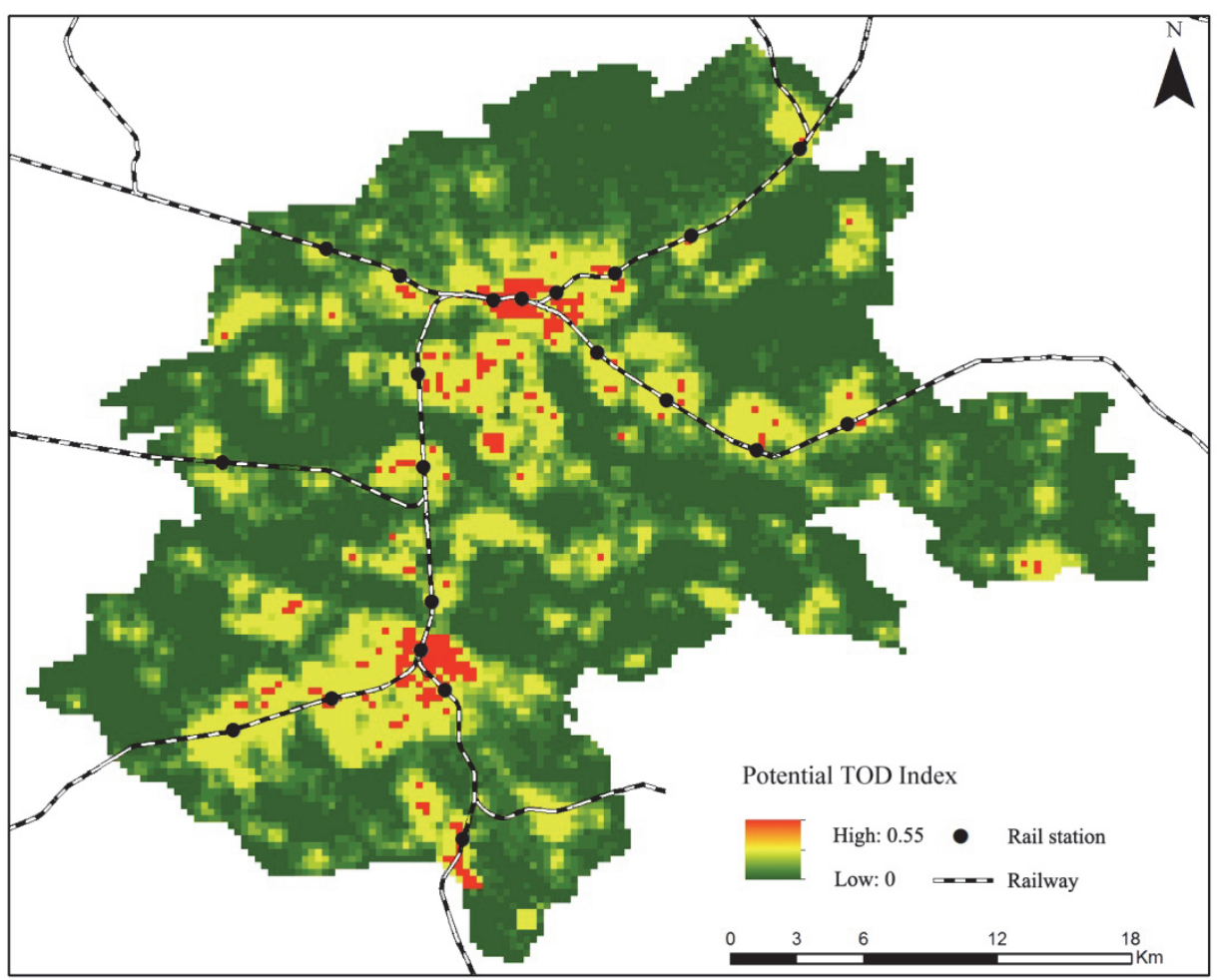

Figure 3.11: Potential TOD index values in the City Region

Since all the indicator values have been standardised and weighted, the maximum value of the TOD index cannot go beyond 1 . Also, as this research has not been carried out at any other place, we do not have reference values of what could be called a 'high-enough' TOD index value. Nonetheless, as the areas around existing stations at Arnhem and Nijmegen have highest TOD levels of about 0.55 , it can be inferred that hot spots of similarly high TOD index values can be recommended for better transit connectivity. However, before the identification of hot-spots, it is required to ensure through a sensitivity analysis that our results are robust.

SMCA has become a well-established tool for solving spatial choice problems, but it has also been criticized for uncertainty present in outputs (Van Wee (2011), Beuthe (2002)) especially because this method involves weights. There is an inherent uncertainty in the weights specified by the people that may be present due to limited or imprecise information and knowledge 
(Malczewski (1999)). The people involved in weighing exercise may weigh the same indicators differently in a different setting or time. Thus, a sensitivity analysis is required to assess the robustness of the results and at an uncertainty level of $10 \%$, the results of TOD Index were assessed. The weights of each criterion were increased or decreased by $10 \%$ while the weights of others were accordingly changed such that the total of weights never exceeds 1 . With these changes, eight scenarios were produced with different TOD index results. It was found that in all the eight scenarios, the maximum index values remained the same and the mean value ranged from 0.0432 to 0.0461 . These minor changes prove that our TOD index results are quite robust and we can move on to find hot-spots of high TOD index in the City Region.

A visual inspection of figure 3.11 shows that some form of clustering is visible. However, this visual representation can easily change by changing the legend of the map. Thus, we need to analyse the clustering using spatial statistical methods. Using spatial statistical analysis, the clusters of high index values can be mapped and further analysed.

Firstly, the potential TOD index data were tested using spatial autocorrelation statistics to determine the degree of spatial dependency of the results. To this end, the Global Moran's I statistic was applied to the potential TOD index scores, where the null-hypothesis indicated complete spatial randomness of results. We used a distance band of $500 \mathrm{~m}$ as a threshold distance, where cells within $500 \mathrm{~m}$ of a central grid cell were considered as neighbours and were compared with the average scores of the whole region. This resulted in a Moran's I score of 0.81 with a very high $z$-score value (174), which indicates the presence of clustering in the region.

To further analyse spatial patterns and locations of the actual clusters, we employed cluster mapping using selected spatial statistics. Three local statistical techniques of spatial association were used that are capable of detecting spatial concentration of high or low value locations or 'hot' or 'cold' spots as suggested by Páez and Scott (2005). These statistical techniques are Getis and Ord's Gi* statistic (Getis and Ord, 1992), Anselin's Local Indicators of Spatial Association (LISA) and Anselin Local Moran's I index (Anselin 1995). The Getis-Ord Gi* statistic considers a feature as a hot spot when it has a high value and is also surrounded by neighbours having high values, whereby the sum of the values of the feature and its neighbours compared to the total sum of all feature values across the study area reflects a statistically significant difference. Anselin's LISA on the other hand is used to provide information on spatial dissimilarities between neighbouring features. Both approaches can be used for comparison. 


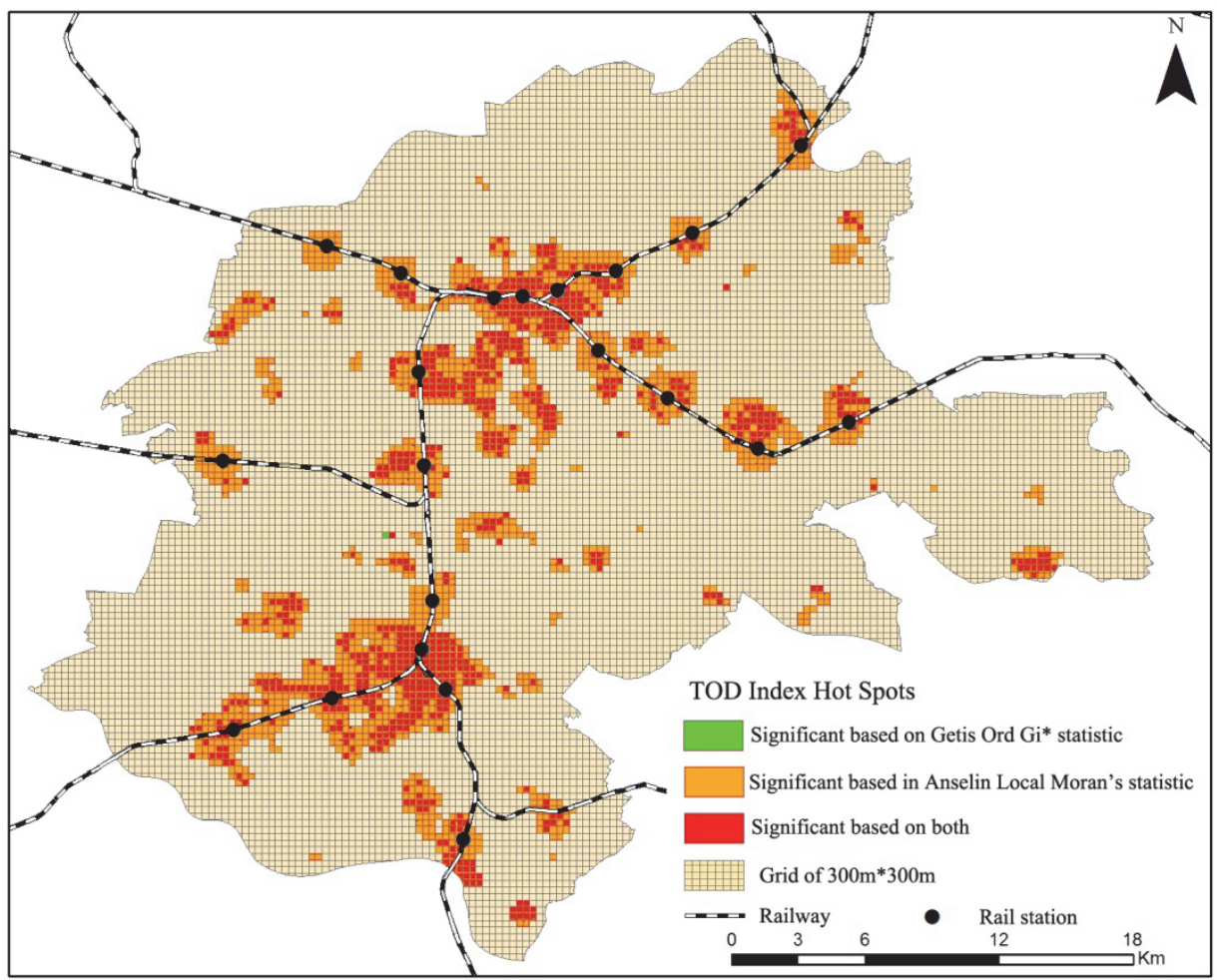

Figure 3.12: Potential TOD Index hot spots (clusters of high index scores) identified by both statistics

To map the location of clusters and to find their intensity, Getis-Ord Gi* and Anselin Local Moran's I were computed for every grid cell across the city region. Using the Getis Ord Gi* and Anselin Local Moran's I statistics, the hot spots were accordingly identified. These statistically significant hot spots were identified at a confidence level of $95 \%$ as shown in figure 3.12. It can be seen that there are vast areas of light brown across the region which could either mean that Potential TOD Index values are dispersed, randomly distributed or that these areas are fairly homogeneous non-urbanized areas characterized by low variation in TOD index values among the cells. For the City Region, the latter seems more likely even though, in either case these areas have overall low TOD levels and are hence not of interest. The areas in red are the hot spots identified by both statistics. Each cluster or hot spot of grid cells has a high average index value which is significantly higher than the average of the entire region. It was also observed that the Anselin Local Moran's I recognized more cells as hot spots. Since this method relies on similarity more than magnitude of the values, it represents the clusters better and hence its results were used for further analysis. The final hotspots have been shown in figure 3.13. 


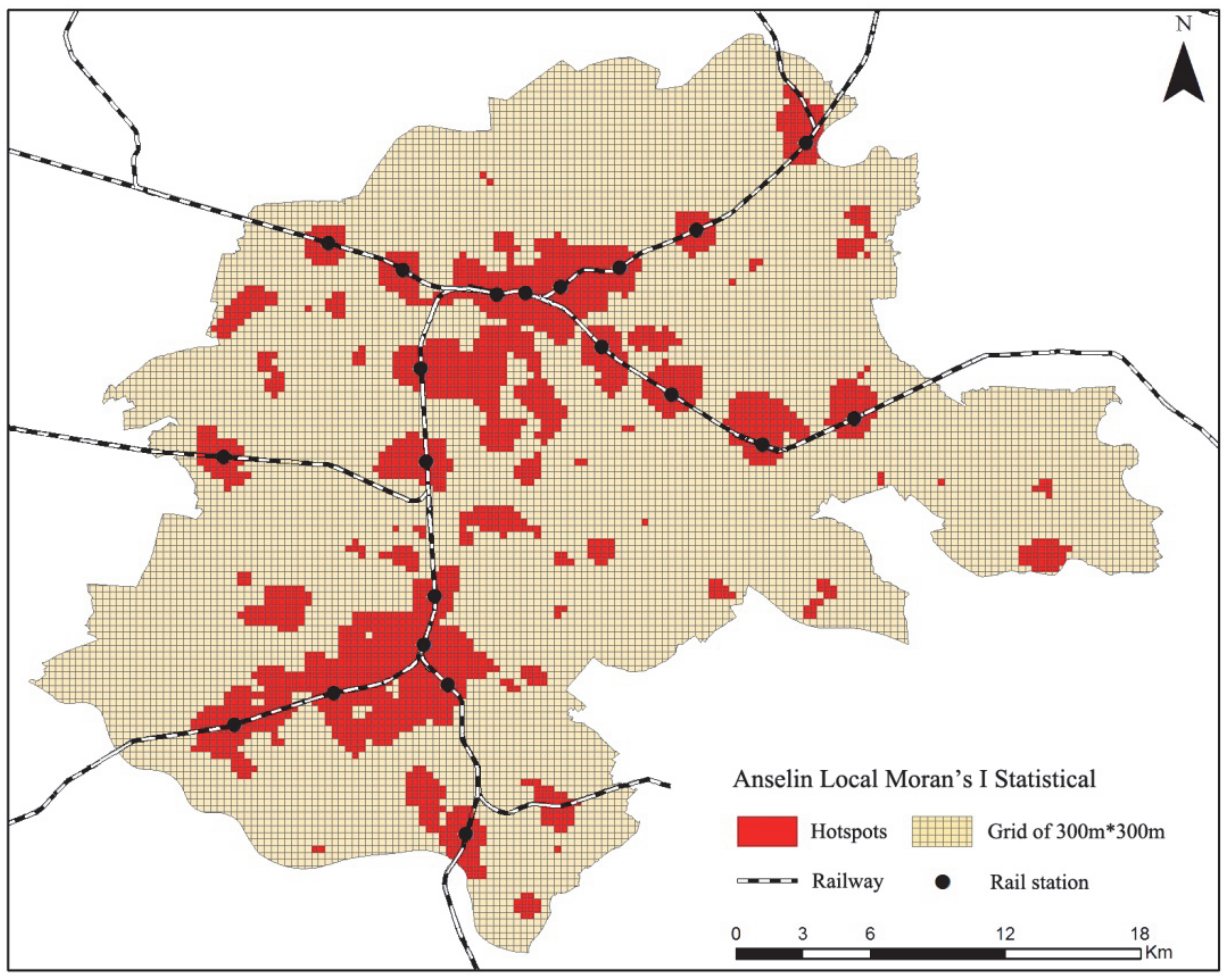

Figure 3.13: Final hot spots of Potential TOD Index

\subsection{Recommendations}

Now that the hot spots have been identified, it remains to identify them for transit connectivity, ensuring in the process that areas with existing train connectivity are not included in our recommendations. Thus, in this step, we remove those parts of hot spots that fall within a walkable distance of $800 \mathrm{~m}$ from a train station and hence are close to an existing transit node. The excluded areas have also been studied separately in Actual TOD Index calculations, where we study the levels of TOD around existing train stations. The final clusters of high Potential TOD Index value that are sufficiently away from a high quality transit system are shown in figure 3.14. 


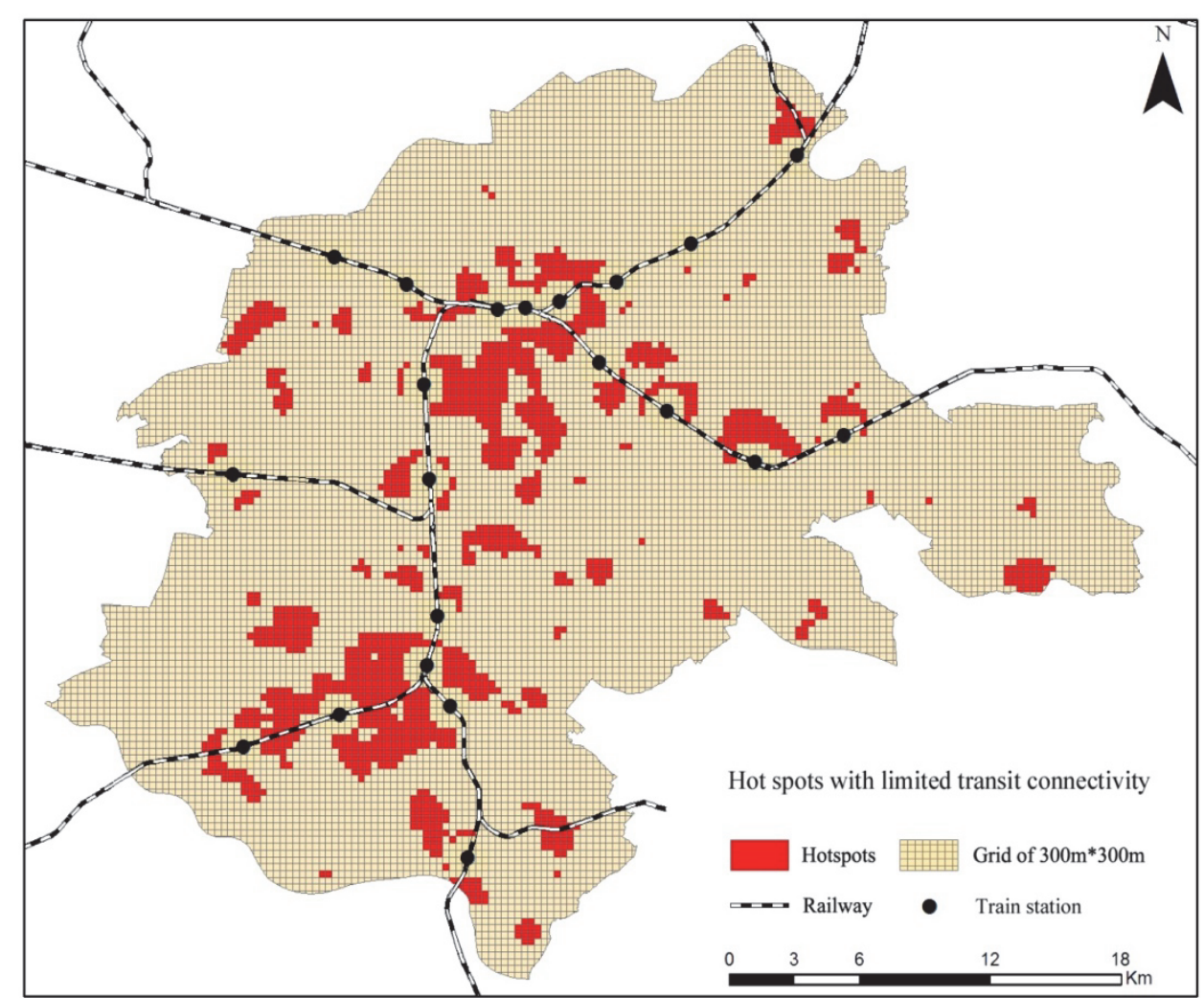

Figure 3.14: Hot spots that are sufficiently away from the existing train stations

As can be seen in the figure 3.14, there are many such clusters all across the region. These hot spots or clusters are recommended to the City Region for further detailed demand assessment, technical feasibility analysis, network studies, financial - economic feasibility analyses and others. These analyses will be important to make decisions about which location(s) within the clusters should be connected by transit and how. The chosen locations/ areas could be either connected by train or by BRT since they provide better transit connectivity than a regular bus.

\subsection{Conclusions}

The Arnhem-Nijmegen City Region, in the Netherlands, seeks to stimulate sustainable development in its territory and TOD is one of the tools to achieve this goal. In this chapter, we have measured TOD levels across the City Region. Under the SMCA framework and using multiple spatial criteria, Potential TOD Index values for the City Region were calculated. The index values were found to be higher in the urban areas of Arnhem and Nijmegen, which implies that existing TOD levels are higher in the urban areas, while 
the rest of the region generally scores low on TOD levels. The results were further analysed and clusters of high index values, also known as hot spots, were identified and mapped. These hot spots were further analysed to identify those locations where the TOD levels are high but train connections are farther than $800 \mathrm{~m}$. It is recommended that these locations are considered for better transit connectivity through train or BRT systems. Since train- based solutions can be very costly, BRT is preferred. These results can be further followed up with detailed demand assessment, technical feasibility analysis, financial - economic feasibility analyses and others.

The novelty of this work lies in the development of a spatial index capable of assessing multiple criteria and arriving at a comprehensive TOD index score representing existing levels of TOD at regional scale. Our methodology to measure TOD is very comprehensive since it allows for multiple indicators to be included for measurement and they need not be only spatial or non-spatial in nature. It is also transparent and can be easily adapted/ adopted for other case studies. SMCA also allows for reflection of the planning priorities by involving the stakeholders or decision makers in the weighing exercise.

In the next chapter, we will demonstrate the use of TOD index in TOD planning. For the same a TOD-Planning Support System (PSS) is built to aid planners in making more effective targeted TOD plans. 
Chapter 4 - A Planning support Tool for TOD planning 


\subsection{Background}

"Urban planning concerns the design and organisation of urban physical and socioeconomic space and the measures undertaken to solve existing problems and/or anticipate future problems. The general objective is usually to provide for an organisation of activities (or of urban space) which in some way is better than the pattern existing without planning" (Vonk and Geertman (2008), p153). Planning for development that is oriented towards transit requires transit as well as urban planning measures. Planning requires the knowledge to analyse and to identify the problems to be addressed, and to evaluate and implement a set of interventions or actions. So far we have been able to find out the TOD-ness of different areas in the City Region using a TOD Index. However, computing the TOD Index alone is not useful unless the results can be used in planning for more transit-oriented development. Thus, in this chapter we aim to demonstrate how the TOD Index can be successfully used in planning for better TOD conditions in the study area.

In the previous chapter on developing a Potential TOD index, we have identified the areas where urban development has high orientation to use of transit, but poor access to high quality transit. For those areas, transit access should be improved and to plan for new transit mode, stops and alignment of network, detailed technical, economic and financial feasibility analyses are required. The political priorities will also have a bearing on these studies. This is, however, not within the scope of this research. In chapter 2, using the results of Actual TOD Index, we found out how different stations score on TOD-ness and which criteria can be improved around each of the 21 stations. We can use the results further to effectively plan for better TOD conditions around stations. To do so, we need to first identify which stations should have a higher TOD score than present and how much more should that be. Further, the planners should know not only which criteria to improve upon (as known from the web-diagrams), but also how much change in different criteria can help them achieve the intended increase in TOD score. In this manner, station-specific TOD plans can be made.

For any given region, there are a number of physical plans drawn at different scales. At the regional scale is a regional plan, which may be followed by a number of urban development plans for the urban areas in the region, then the zonal / district/ ward plans within each urban plan and for some specific projects, site-level detailed project plans are also prepared. At a regional scale, the plans are more policy like where regional policies are made as guiding principles for plans at a lower scale. As we go down to the smaller scale plans, these policies turn into clearer physical plans and detailed proposals and it is made sure that all these plans, though at different scales, are in conformity with each other. For our City region too, there is a Regional 
plan (Regionaal Plan 2005-2020)(Regionaal Plan 2005-2020) prepared and published by the City Region office in 2007. Thus, as a part of this planning exercise it would be interesting to see how the regional policies and plans affect the TOD scores at local scales in the study area. This will be the topdown approach wherein the regional plans will be implemented at the smaller scale. In addition to the regional plan, there are also existing TOD plans (Noordzuiden, 2011c) for some existing (but relatively new station areas) and for some proposed-but-yet-to-be-built stations. These plans propose planning interventions like adding the number of houses, office area, parking etc. around a station area to improve the surrounding development and in the process also make it more transit-oriented. These plans were drawn by the consultants from Het Noordzuiden as a part of a separate study for the City Region in 2010-2011. We would also like to evaluate these plans using our Actual TOD index for some of the existing stations.

Thus, in this chapter, using the results of our Actual TOD index, we shall demonstrate how the following sub-objectives can be achieved:

a. Identifying points of interventions for improving TOD around a station.

b. Evaluating the existing TOD plans for station areas

c. Evaluating the effect of Regional Plan on the TOD scores.

To do all of the above, we intend to build a Planning Support System (PSS) that allows to simulate changes in TOD index score for each station, in response to changes in indicators and criteria values, which are to be seen as planning interventions. The PSS will provide all necessary information related to how the TOD scores were calculated, which input values were used and how they affect the final TOD index score. It also provides the flexibility to interact with it and change the input factors/ data such as number of people, commercial enterprises, number of jobs, area under different land uses and such.

To fulfil our sub-objectives, our first step is to first identify the stations where a higher TOD score is required than its current score. The 'Target TOD scores' for those stations also needs to be identified that define to which level of TOD the station should be raised. In the next section, we will discuss how such stations were short-listed.

\subsection{Identifying stations in need of a higher TOD score}

In chapter 2, we mentioned that not all station areas have or need a high TOD score. Depending on the scale of the station and the transit services, the scale of urban development around the station is also affected. Bertolini (1999) says that different kinds of activities require or choose their locations depending on how much human contact they need. Thus, while production 
activities can decentralize, high quality financial and business services tend to concentrate. Such concentrations also automatically occur around the place where movement of people is concentrated such as around transit nodes where different kinds of people from different strata's of society and with different travel purposes come together and cross paths. Bertolini (1999) mentions how intense and diverse flows of people at transit nodes have the potential of translating into equally intense and diverse patterns of human interactions and social and economic activities still requiring physical proximity can thrive in these areas. Thus, diversity and intensity of activities or urban development has a direct relation with the intensity of flows of people at a transit node and that in turn is related to the frequency and diversity of transit services accessible at that transit node. Every station has a particular position or hierarchy in the transit network (Balz et al., 2006) and stations in our case study are no different. Some stations are surrounded by very active areas of high economic development while some are located in the quieter retirement neighbourhoods. Depending on its location and transit service and hence its position in the OV-network, every station creates a potential for transit-complementary urban development or transit-oriented development (TOD). Thus, a station with higher position in the OV-network should ideally also have a higher, complementing TOD environment around it.

With this understanding, it is logical to first find the position of each station in the OV-network and corresponding to that position, a matching (expected) TOD score should be proposed. If a particular station's Actual TOD index score is less than its expected score, then that station can be identified as the one needing improvement in its TOD score. This simple method should help the planners in shortlisting the stations that need a more transitoriented built environment.

To find the stations' position in the OV-network, we use the methodology proposed and used in (Balz et al., 2006) and (DeltaMetropool, 2013). Based on the formula used by them, following formula (eq.9) was used to find the OV score of each station in the City Region, the results of which are tabulated in table 4.1 .

OV score $=($ score $1+$ score $2+$ score $3+$ score 4$)+[($ score $1 \times F \times R \times 0.2)+$ (score $2 \times \mathrm{F} \times \mathrm{R} \times 0.2)+($ score $3 \times \mathrm{F} \times \mathrm{R} \times 0.2)+($ score $4 \times \mathrm{F} \times \mathrm{R} \times 0.2)]$..eq(9)

where:

score $_{1}=$ Score if the node is connected by HSL (Hogesnelheidlijn or ICE) trains $=125$

score $_{2}=$ Score if the node is connected by IC (InterCity) trains $=100$

score $_{3}=$ Score if the node is connected by SPR (Sprinter) trains $=75$ 
score $_{4}=$ Score if the node is connected by ST (Streekbus) $/$ Regional Bus $=50$

$\mathrm{F}=$ Service Frequency of the respective transit mode

$\mathrm{R}=$ number of routes served by the respective transit mode

The OV scores are further clustered into five categories using Jenk's natural breaks classification method (DeltaMetropool, 2013),(Balz et al., 2006). The resulting categories and their legend are depicted in table 4.1 and the stations falling into those categories have also been formatted as per the legend. These categories are expected to represent the real hierarchical positions of the stations in the OV network.

Table 4.1: OV scores for all 21 stations in the City Region

\begin{tabular}{ll}
\hline Station & OV score \\
\hline Arnhem & 2250 \\
\hline Arnhem Presikhaaf & 220 \\
\hline Arnhem Velperpoort & 750 \\
\hline Arnhem Zuid & 480 \\
\hline Didam & 395 \\
\hline Dieren & 480 \\
\hline Duiven & 315 \\
\hline Elst & 610 \\
\hline Molenhoek-Mook & 235 \\
\hline Nijmegen & 730 \\
\hline Nijmegen-Lent & 480 \\
\hline Nijmegen Dukenburg & 220 \\
\hline Nijmegen Heyendaal & 235 \\
\hline Oosterbeek & 220 \\
\hline Rheden & 195 \\
\hline Velp & 195 \\
\hline Westervoort & 395 \\
\hline Wijchen & 220 \\
\hline Wolfheze & 220 \\
\hline Zetten-Andelst & 155 \\
\hline Zevenaar & \\
\hline
\end{tabular}




\begin{tabular}{ll}
\multicolumn{3}{l}{ Jenks Classification of ov score } \\
\hline Classes & $\begin{array}{c}\text { Score } \\
\text { ranges }\end{array}$ \\
\hline Class 1 & $155-235$ \\
\hline Class 2 & $236-395$ \\
\hline Class 3 & $396-480$ \\
\hline Class 4 & $481-750$ \\
\hline Class 5 & $751-2250$ \\
\hline
\end{tabular}

As can be seen from the table, Arnhem station has the highest position in the OV network at the regional scale. Even though, within the City Region, Nijmegen and Arnhem are biggest urban centres of comparable scale, Arnhem station stands apart due to the international trains serving this station that also carry higher score. It is also the only station in the City Region in the highest class. Nearly half of the stations fall in the lowest class of OV score which confirms to the fact that at the regional scale, the OVnetwork serves also the laid-back non-urban areas of the region. Corresponding to the OV score categories, we made five TOD scores' categories of equal intervals (see table 4.2). This categorization is very straight-forward and it may even be debatable, but we believe that it gives the research a much needed direction which is important to test a bigger goal at hand, which is to demonstrate the usability of TOD index for planning purposes. There may be improvised ways to match the OV scores with TOD scores and this methodology only stands to gain from such a possibility. As of now, we go ahead with the matched categories as shown below in table 4.2. We did not classify TOD scores using the Jenk's method of natural breaks classification because, unlike OV scores that are a result of planned OV services, TOD scores are not representative of TOD-ness around each station as a result of planned Transit -Oriented-Development. They only represent the existing TOD-ness of a station area. The TOD categories should ideally match or correspond to the OV score categories and if the existing TOD scores for some stations are lower than what their corresponding OV score relates to, then those stations need improved TOD scores.

Table 4.2: Classification of OV and TOD scores.

\begin{tabular}{lll}
\hline Classes & $\begin{array}{c}\text { OV score } \\
\text { ranges }\end{array}$ & Legend \\
\hline Class 1 & $155-235$ & $\begin{array}{l}\text { TOD score } \\
\text { ranges }\end{array}$ \\
\hline Class 2 & $236-395$ & $0-0.20$ \\
\hline Class 3 & $396-480$ & $0.201-0.40$ \\
\hline Class 4 & $481-750$ & $0.401-0.60$ \\
\hline Class 5 & $751-2250$ & $0.601-0.80$ \\
\hline
\end{tabular}


Upon matching the OV and TOD scores (see table 4.3), we found that while some stations score lower than they should, some stations also score higher. Some of those stations like Rheden and Nijmegen Hyendaal are striking because their OV score is of the lowest category yet their TOD scores are quite high. A careful look at their web-diagrams (as discussed in section 2.6 and appended in appendix 2) shows that for Rheden, high TOD score is due to high economic development and densities even though its passenger load is very low that may be because the level of transit service is low (as suggested by the OV score and the web-diagram). For Nijmegen Hyendaal, the passenger load is very high even though the economic development and densities are low. This is the reverse case of Rheden and it is so because the Radboud University is located next to Nijmegen Hyendaal station. It appears that the students going to the university are using the transit and large area being used by the university has lowered the economic development, density and diversity criteria. A higher TOD-ness is, however, not a problem for any area. Higher TOD-ness could also mean that those areas have good walkability and cyclability as seen for Wijchen and Nijmegen Dukenburg stations. Thus, even though there are scope for improvements to transit or development characteristics at all stations, it was decided to attend to those stations that have lower TOD score than desired.

Table 4.3: Matching the OV and TOD scores for all stations in the City Region

\begin{tabular}{llll}
\hline Station & OV score* & $\begin{array}{l}\text { TOD } \\
\text { score* }\end{array}$ & $\begin{array}{l}\text { Minimum } \\
\text { desirable } \\
\text { increase in } \\
\text { TOD score }\end{array}$ \\
\hline Arnhem & 2250 & 0.77 & 0.031 \\
\hline Arnhem Presikhaaf & 220 & 0.3 & - \\
\hline Arnhem Velperpoort & 750 & 0.57 & 0.031 \\
\hline Arnhem Zuid & 480 & 0.25 & 0.151 \\
\hline Didam & 395 & 0.31 & - \\
\hline Dieren & 480 & 0.33 & 0.071 \\
\hline Duiven & 315 & 0.41 & - \\
\hline Elst & 610 & 0.35 & 0.251 \\
\hline Molenhoek-Mook & 235 & 0.22 & - \\
\hline Nijmegen & 730 & 0.57 & 0.031 \\
\hline Nijmegen-Lent & 480 & 0.21 & 0.191 \\
\hline Nijmegen Dukenburg & 220 & 0.41 & - \\
\hline Nijmegen Heyendaal & 235 & 0.45 & - \\
\hline Oosterbeek & 220 & 0.21 & - \\
\hline
\end{tabular}




\begin{tabular}{llll}
\hline Rheden & 195 & 0.52 & - \\
\hline Velp & 195 & 0.33 & - \\
\hline Westervoort & 395 & 0.24 & - \\
\hline Wijchen & 220 & 0.42 & - \\
\hline Wolfheze & 220 & 0.16 & - \\
\hline Zetten-Andelst & 155 & 0.18 & - \\
\hline Zevenaar & 395 & 0.37 & - \\
\hline
\end{tabular}

*Formatting of OV scores and TOD scores is as per table 4.2.

Seven station areas with lower TOD scores were identified and they are Arnhem, Arnhem-Velperpoort, Arnhem-Zuid, Dieren, Elst, Nijmegen and Nijmegen-Lent. Of these, Arnhem-Zuid, Elst and Nijmegen Lent are relatively newer stations, opened to harness the development potential of their regionally important locations. That is why their planned transit services are good but urban development has not yet been completely realised. All these station areas also have a considerable development going on around the station area and very soon, in a couple of years, it is expected to be completely realised. Once that happens, the TOD score shall increase and hopefully be more than their Target TOD scores. In the table 4.3, a minimum desirable increase in the TOD score per station is also identified in order to match its OV score. With this information, and with the help of a PSS, our sub-objectives of identifying TOD planning interventions, evaluating existing TOD plans and implementing the regional plans can be fulfilled. Our next step, is thus building the PSS capable of fulfilling the objectives of our work.

\subsection{Building a PSS}

There are a number of Geographic Information Systems (GIS) that exist and are used by different planners and planning agencies around the world. Before we build our own Planning Support System (PSS), it is imperative to study various such systems, their uses and how they differ from a PSS. The strengths, weaknesses, benefits and pitfalls of a PSS should be studied before embarking upon our own venture.

\section{Related work}

Geo-Information technology developers have long provided support to urban planners in handling the knowledge and information required for planning purposes (Vonk \& Geertman, 2008). Geo-Information systems (GIS) are not used for typical planning tasks but mainly for basic information functions that are also important for executing the planning functions. Spatial Decision Support Systems (SDSS) have been widely developed in past and are generally designed to support shorter-term policy making by individuals or 
organisations (Geertman, Stan \& Stillwell, John, 2009). They are more focussed towards making decisions rather than helping out in strategic planning activities. A newer generation of GIS is a Planning Support System (PSS) which is much more dedicated to fulfilling the demands and capabilities of the planners. They first appeared in the late 1980s (Pelzer et al., 2014) and have been defined in past as "a subset of geo-information technologies dedicated to supporting those involved in planning, in exploring, representing, analysing, visualizing, predicting, prescribing, designing, implementing, monitoring and discussing issues associated with the need to plan" (Vonk \& Geertman, 2008) p154. As mentioned before, planning involves rational analysis, foresight, evaluation aiming to achieve desired outcomes (Geertman, Stan \& Stillwell, John, 2009). A typical PSS aims at supporting such informed forward-looking actions. Within the PSS domain, there are 3 types of PSS - Information PSS, Communication PSS and the Analysing PSS. The Information PSS are meant to provide information to the users of the PSS by way of interactive maps, 3D visualisations and such and some examples from Dutch planning context are the web-based Information PSS built for Brabant region, Overijssel Region and Utrecht province (Geertman, 2014). The Communication PSS allows multiple users at a time to communicate with it. One of the prime examples of a Communicating PSS in the Dutch context is the website (www.verbeterdebuurt.nl), where the citizens can pin specific points in their neighbourhood that need an improvement and also provide reasons for the same. The Analysing PSS are meant to improve the planning outputs but are primarily used by researchers and academicians (Geertman, 2014). Traditionally, the added value of PSS was mainly seen as improving the outcome of planning, however, in the last two decades, this has shifted to the improvement in planning process (Pelzer et al., 2014).

All Planning Support Systems (PSS), SDSS and GIS models can come under the gambit of planning models. In 1973, Lee (1973) criticised the large-scale planning models by highlighting the seven sins of such models. Since then, PSS have improved tremendously and most of the identified problems are things of past. However, it can help to know what those typical problems are so that they can be avoided. The seven sins mentioned by him are - hypercomprehensiveness (trying to shoot multiple birds with one arrow), grossness (of scale), (data) hungriness, wrongheadedness (ignoring the interrelationships between various indicators), complicatedness (black-box like behaviour), mechanicalness (getting lost in trivial details and losing the bigger picture) and expensiveness. A PSS can become too comprehensive if it tries to do more than necessary. A specific focus of the PSS is likely to be more effective since "Trying to do everything at once simply means that all are more likely to be done poorly" ((Lee, 1973) pg. 164). Nowadays, most PSS start by mentioning the limited boundaries of their specific role and it is 
widely accepted now that we need humility to accept the limitations of our knowledge as well as our models (te Brommelstroet et al., 2014). The PSS should also not require too much data as this can impede the utility of the same. In the current times, the increased availability of data has only increased our appetite for the same and we risk using a highly biased data (eg. more data for car users and less for pedestrians and cyclists) thereby excluding certain sections of the society and users (te Brommelstroet et al., 2014). The wrongheadedness of models and PSS has not been resolved until now (te Brommelstroet et al., 2014) as insights into interrelationships between various indicators used in a model can be seldom completely known. The complexity of the model also increases with the number of components. Lee (1973) said that for a model with 20 variables, there are 180 possible interactions if they are symmetric and simultaneous. Thus, working on a large scale model reduces the understanding of the process and while we know what goes in and what comes out, we do not know the process by which the input becomes the output. The mechanicalness of the models can make the users too involved in the trivial and minor details of the model and lose their sight of the bigger objective. As Lee (1973) (p. 168), said, "The effort of making the computer understand is then mistaken for intellectual activity and creative problem solving". The current PSS suite can now boast of visual gadgetry, map tables, 3D visualisations, computer-game-like experiences and others that have the potential to keep the participants actively involved and look at the bigger picture most of the times (te Brommelstroet et al., 2014). However, these systems can also be biased in highlighting one aspect more than the other. Lee (1973) observes that the most important attribute of any model should be its transparency such that it is readily understandable with 'reasonable investment of effort'. Such a model may still likely be wrong, he adds, but at least the users can investigate the points of disagreement.

Thus, we intend to build a PSS that is simple, transparent, easy to use and does not intend to solve too many purposes at the same time. Our PSS should be able to provide specific policy guidance by obtaining just enough information. It shall be transparent such that its assumptions, inputs and outputs can be seen and understood and the users can verify the model whenever desired.

There are however, other obstacles to the use of PSS in practice. Vonk and Geertman (2008) say that the PSS are often low on utility and userfriendliness. The advanced PSS available in the market are very advanced and do not match the user capabilities as practice demands simpler systems. While the advancement of technology has led to development of complex and sometimes complicated PSS, the fashionable planning concepts like sustainability, participation, evaluation and others are demanding more skilful 
and technologically aware human resources (Geertman, Stan \& Stillwell, John, 2009). Vonk and Geertman (2008) also suggest that often, having a geo-information specialist like in Dutch province of Overijssel or an innovation manager like in Dutch provinces of Noord-Brabant and Limburg, can help bring the planners closer to the PSS by translating latter's' planning needs to available PSS functions. Our aim is to build a PSS that does not require the users to look for PSS operators as it defies the purpose of helping the planners on its own. A simple, uncomplicated and easy to use PSS is what our PSS would be.

In recent times, a number of station-area projects have been done in different parts of Netherlands, for example in Randstad (Stedenbaan project), Utrecht, Rotterdam, Gelderland province, and different PSS were developed for the same. Sprintstad v.2, Decision-Lab, Dashboard uiterwaardenbeheer, Game voor uiterwaardenbeheer, Duckstad and Virtueel Regionaal Grondbedrijf are some of the Planning Support Systems called 'the serious games' made for simulating different environments and solving different planning problems. The 'Decision-Lab' developed by Radboud university, Nijmegen, The Netherlands, aimed at applying the 'formal games' or group modelling decision making processes to make decisions concerning regional development and use of infrastructure (Smits et al., 2012). The 'Dashboard uiterwaardenbeheer' is an instrument developed by Wagningen University, Wageningen, The Netherlands, which simulates the consequences of different control measures for the stakeholders/players/users (Smits et al., 2012). For the floodplains along the area of river 'Waal' (in Waalweelde, The Netherlands), a simulation game 'Game voor uiterwaardenbeheer' was developed wherein T-exchange (University of Twente), Tigron and the Gelderland province were involved (Smits et al., 2012). 'Duckstad' is another serious game developed to simulate the consequences of the 'urban consolidation' instruments (Smits et al., 2012). The Stadsregio Arnhem and Nijmegen (City Region office of Arnhem and Nijmegen) worked with the MpRO on another serious game 'Virtueel regionaal Grondbedrijf' a simulation tool to explore how the land and property markets operate in area development plans (Smits et al., 2012). 'Sprintstad' is a Planning Support tool developed by Delta Metropolis that simulates the spatial developments around stations that lie along the corridor in response to an increase in train frequencies (DeltaMetropolisAssociation, 2012). Earlier to its latest version 2, the 'Sprintstad' had been tested for Leuven in Belgium, Bangalore and Delhi in India, North-Holland (Rotterdam area) and Utrecht in Netherlands and also for our City region of Arnhem and Nijmegen. The Sprintstad was tested on the Arnhem-Doetinchem section of the OV corridor in consultation with the City Region officials and Radboud University, Nijmegen (DeltaMetropolisAssociation, 2014). The tool simulates effects of new housing plans and the new stations planned on this corridor. Of all these tools, 
Sprintstad is the most talked about tool in the Netherlands and other countries and is also linked to the TOD concept as it deals with station area development and is based on the relationship between transit and urban development. The English version 'Sprintcity' was also introduced in 2013. Using the butterfly model (as discussed in section 2.2), station area typologies were made and using Sprintstad, the consequences of planned interventions were simulated. The results were used to plan for the station areas. An online TOD database or a Planning Information System (PIS) by the name of 'iNode' for the Netherlands was also created at Wageningen University in collaboration with The Delta Metropolis Association ("Vereneging Deltametropool," 2009) that shows the results of the butterfly model for stations that were studied as part of this project and covers some parts of the City Region too. All the planning-support models discussed in this paragraph are large scale complex models and require a multi-user setting. Our PSS, in comparison, will be a small-scale model, much simpler and can be used as a single-seat or a desktop version, for the reasons of simplicity and user-friendliness. Primarily, our PSS would be used only by those planners who have used TOD index to plan for better TOD environment in their area.

\section{Conceptual Framework of our PSS}

Before we discuss how the PSS was built, it is important to discuss the concepts behind the same. This shall explain the inputs, the outputs and broad process of calculations and how the sub-objectives will be achieved. Figure 4.1 shows the conceptual framework of our PSS.

TOD index is composed of a number of criteria, which in turn are made of a number of indicators. To calculate the indicators too, different variables were used for which data was collected. For example, for the criterion 'Density', 'Population density' was one of the indicators and the variable used for its calculation was 'number of people'. Such variables shall become the 'input' to PSS. Any planning intervention to improve TOD score would be reflected as changes to these variable values such as increasing the planned number of residents/ people around a station. Similarly, number of commercial establishments, number of jobs and area under different land uses and other such data can be changed in the PSS. In response to the proposed changes, the indicators, criteria and the TOD index would be recalculated or revised. These shall become the outputs of our PSS. The PSS shall also create three analyses to achieve our three sub-objectives. Any changes in the variables can be done separately in all three scenarios at the same time such that the TOD index will also be revised separately in three analyses. This shall allow the user to choose the most effective planning interventions in improving the TOD score. 


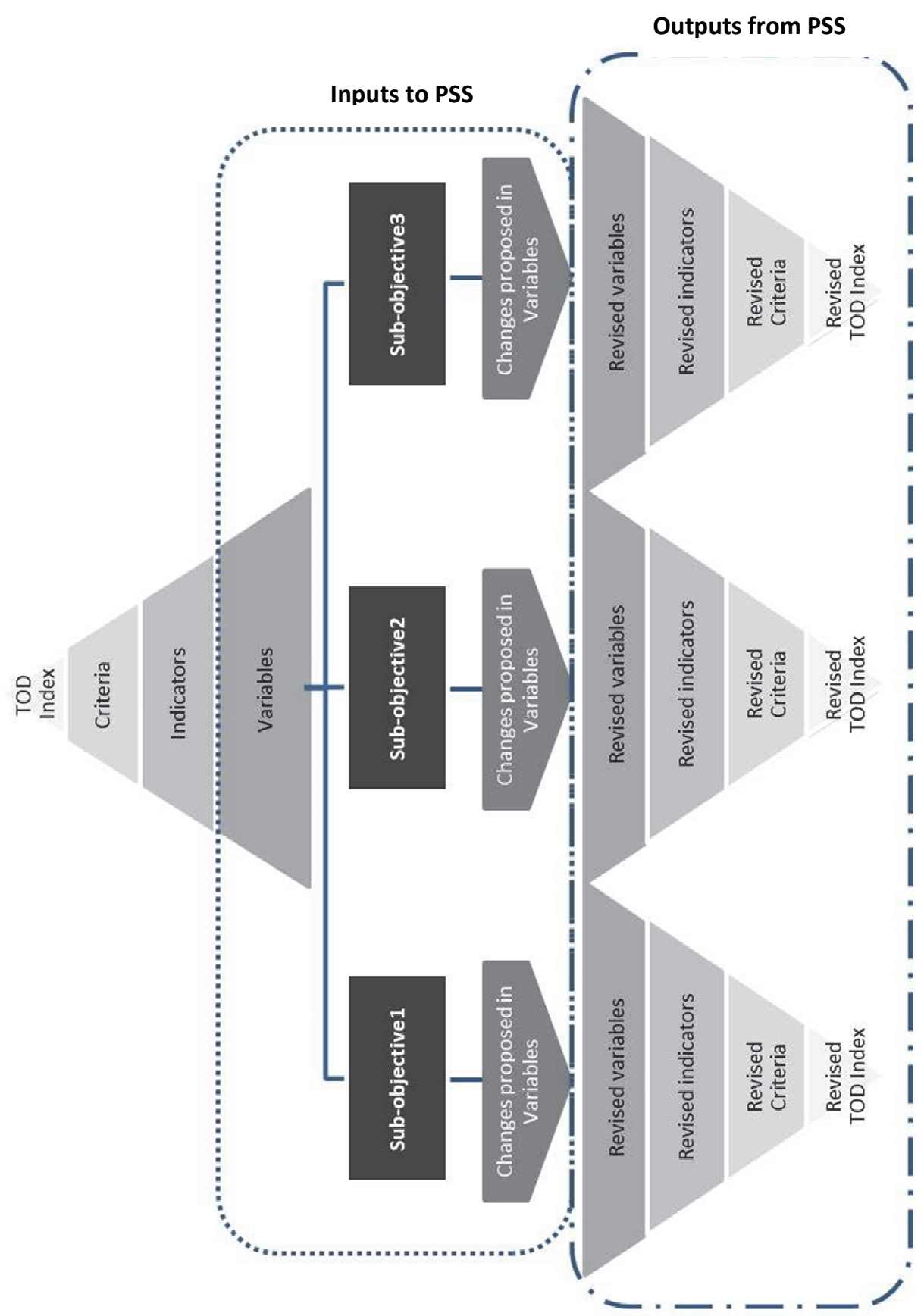

Figure 4.1: Conceptual Framework of our PSS

It is important to mention here that not all variables can be changed in the PSS. Of the 18 indicators that make the Actual TOD Index, many relate to 
the transit system and since the expected PSS users are urban planners who do not have the jurisdiction over the transit services and characteristics, we did not build any flexibility in transit related characteristics. These characteristics are namely - transit capacity, transit frequency, number of shops at stations, display systems and their types. There are also some urban development indicators that cannot be changed such as 'number of intersections' and the length of road network. If in future, a PSS is built for any other case study and the PSS users, such as transit agencies, have the powers to change the transit characteristics, the flexibility can be easily added for them. It should be noted, however, that when the transit characteristics are changed for a station, the OV scores and hence the target TOD scores will need to be revised too. The PSS architecture is described in the next section.

\section{PSS architecture}

Vonk and Geertman (2008) mention that there are various bottlenecks that prevent the widespread use of PSS in practice. One of these bottlenecks is that they do not conform to the planning requirements. Even so, they mention a range of world-class PSS that are being applied in practice on a broader scale in the planning fraternity including CommunityViz (www.communityviz.org ), Index (www.crit.com ), What-If? (www.what-ifpss.com) and Maptalk (www.mapsup.nl ). These PSS are available off-theshelf, customisable and have a strong people-support component and are hence more successful than others in users' acceptance. Of these, we chose to work with CommunityViz as it is an extension to the ArcGIS software that we have used for our earlier spatial analysis.

To build our PSS in CommunityViz, we first prepared the data table containing all the input data (i.e. variables) that we need for calculation of the TOD index. Using this data, all our indicators and criteria calculations are made again in CommunityViz environment so as to build the connections between data and criteria. This also makes all calculations transparent to the PSS users such that it does not feel like a black box. While building these connections, we also create 'assumptions' that are the assumed changes in the variable values as also explained in previous section. For all the variables that can be changed by planners in PSS, an assumption is created. An assumption, if positive, is added to the existing number and if negative, is deducted from the existing number. For example, an assumption of 5,000 persons means that 5,000 people will be added to the existing population. Similarly, an assumption of ' -60 ' car parking spaces means that the car parking supply will be reduced by 60 parking spaces. Figure 4.1 shows a snapshot of the PSS where the City Region with existing 'Actual TOD Index' scores around station areas are shown. On the left of figure 4.2 are charts showing the existing TOD scores for stations that need a higher score. In the 
same charts, the line represents the target TOD score (as discussed in section 4.2) or the desired level of TOD for that station.

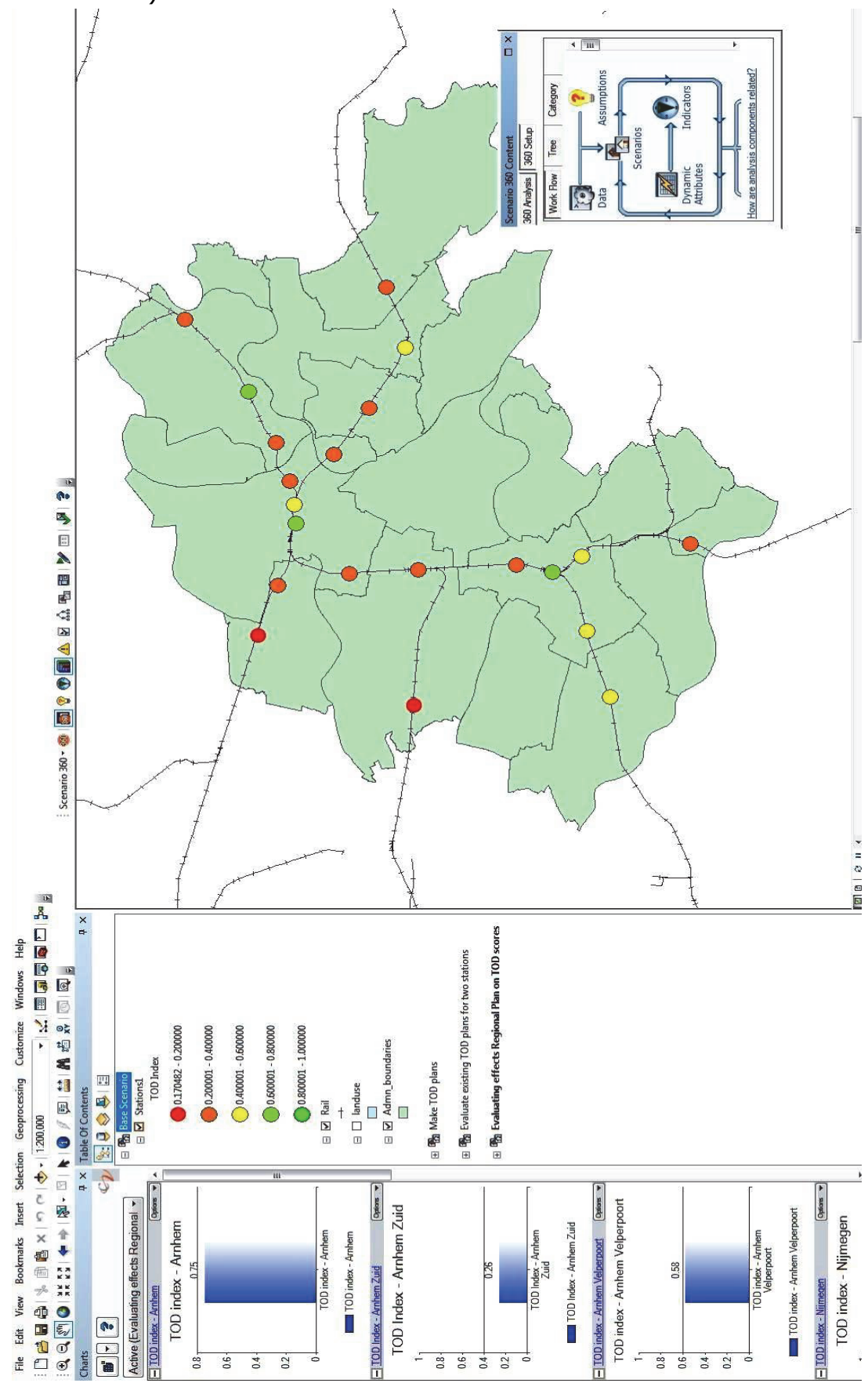

Figure 4.2: First look of the PSS 
In order to show how PSS actually works, figure 4.3 shows some of the 'assumptions' listed with a slider bar for each. As a test, station 'Arnhem Velperpoort' was selected and the population was increased by 9000 persons. At the same time, more assumptions can be changed and the effect of all those changes will be reflected in the re-calculated TOD score only for the selected station i.e. Arnhem Velperpoort. With the shown assumptions, in figure 4.3, the TOD score for the station changed from an initial 0.58 to more than 0.60 which was also its Target TOD score. The graph on the left for this station shows the new score by a hatch pattern and the map in the background shows that the colour of that station changed as its TOD score moved to a higher range (in figure 4.2 , it was a yellow colour). This demonstrates how users can adjust/change the variables of the calculation itself and increase their understanding of the way in which calculations are made. They can then work more with the data itself, and thereby think more about it.

It may be pointed out that in this PSS, three applications (called 'scenarios' in the terminology of CommunityViz) were created corresponding to our subobjectives. To work in different applications and change assumptions, we need to first select the application (or 'scenario') in the window of 'assumptions' as shown in figure 4.3. These applications come in handy when we wish to compare how a station is affected by different plans under different applications. The working of all the three applications is same as they all use the same formulae, however in the end, reports can be created within the PSS for each application. A comparison report of all applications can also be printed summarising changes proposed in each application and the resulting TOD score for that station under each applications.

A summary report of PSS was created that gives the details and basic descriptions of all PSS components such as the applications, the variables, indicators, their formulae and the assumptions. That report has been appended to this chapter as Appendix 3. With the described functionalities, our PSS is up and running. In the next section, we will use this simple tool to fulfil our sub-objectives for this chapter. 


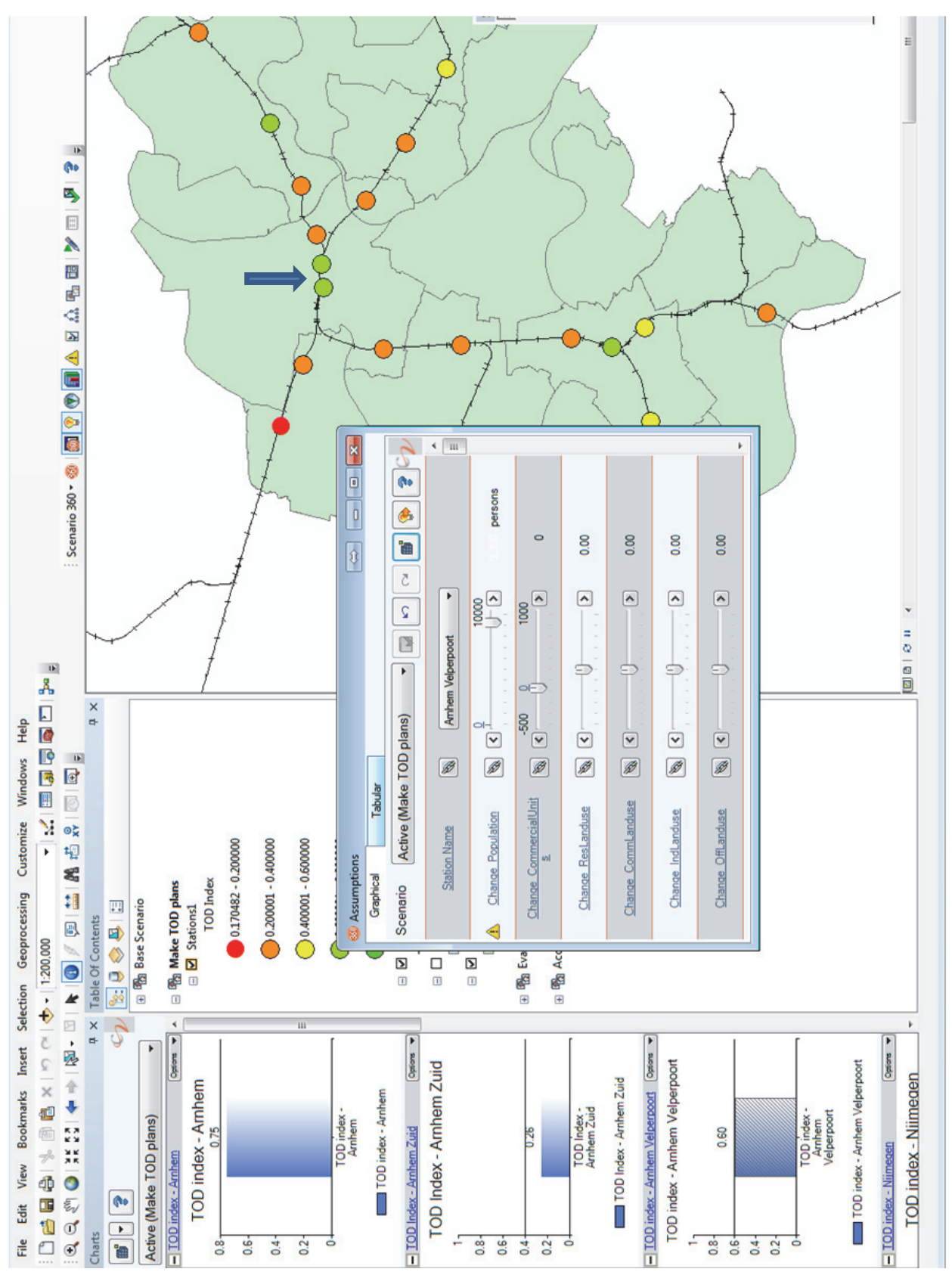

Figure 4.3: Simulated change in TOD index score for selected station 


\subsection{Fulfilling sub-objectives using PSS}

\section{a. Identifying points of interventions for improving TOD around a station}

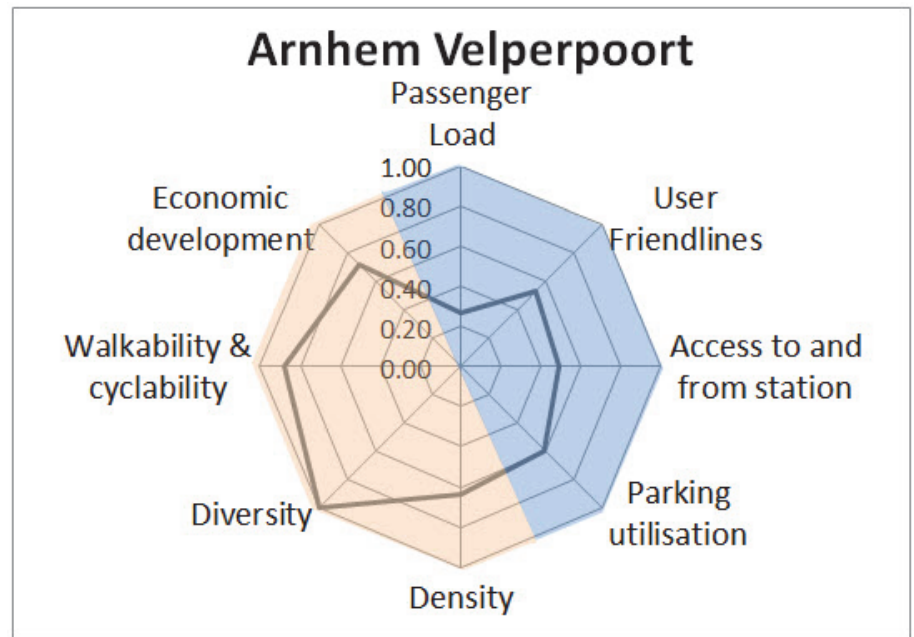

Figure 4.4: Web-diagram of the criteria for TOD score (Arnhem Velperpoort station)

Under this sub-objective, we shall use the PSS in identifying planning interventions for a station area. For demonstration purposes, the plans for Arnhem-Velperpoort and Arnhem Zuid station areas will be made. These were chosen from the list of seven stations that score lower than their target TOD score and their respective target TOD scores are 0.6 and 0.4. For the former, its web-diagram (figure 4.3) shows that density and economic development score low and can be improved upon. Improving the access to opportunities will also help in alleviating the TOD score. To bring up the TOD score to the desired level i.e. the Target TOD score, a number of development options can be created.

In the PSS, at first, the first application is selected, then the station name is selected and thereafter the assumptions are made by assuming an addition of 1500 persons, 150 commercial enterprises, 50 businesses and about 600 jobs (as a result of adding commercial and business establishments). Adding 1500 persons translates to about 685 houses since the average household size in the Netherlands in 2013 was 2.19 (Central Bureau of Statistics www.cbs.nl ). Assuming an average size of house to be $75 \mathrm{sqm}$, about 51350 sqm was added to the residential area. The parking utilisation can also be improved by reducing the car parking supply by $40 \%$ (as it is utilised only $47 \%$ ) and increasing the cycle parking supply by at least $15 \%$ as it is almost $96 \%$ utilised. The assumptions thus made changed the TOD index from 0.57 
to more than 0.60 , which was also its Target TOD score. Figure 4.4 shows the snapshot of the PSS where the new TOD score for Arnhem-Velperpoort station is shown in the graph on left. The assumptions window is also shown in the snapshot. Notice the change in the colour of the station in map from yellow to green as the TOD score moved from one class to another.

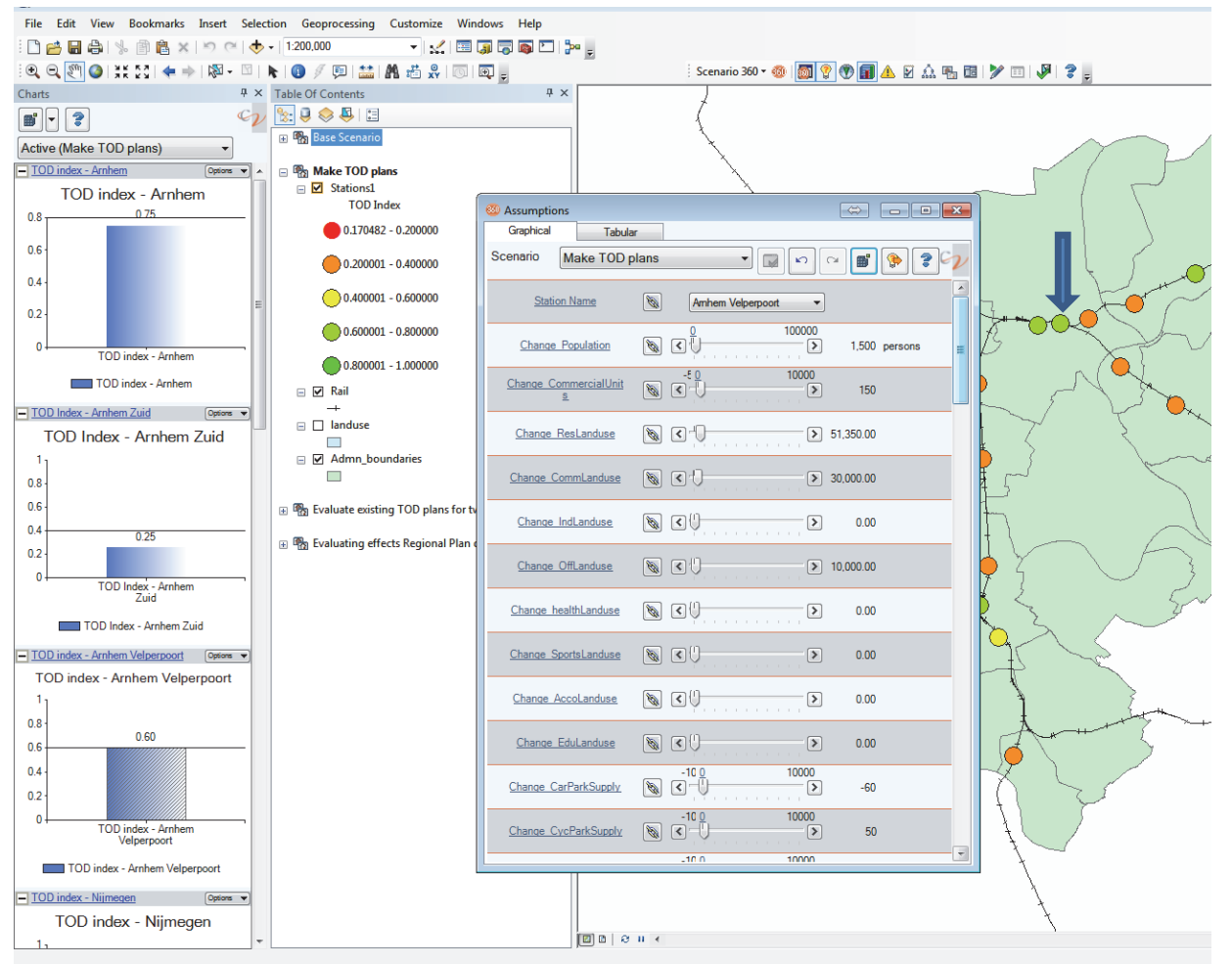

Figure 4.5: Snapshot of the PSS after making changes to assumptions for Arnhem Velperpoort station

These assumptions are then the planning interventions identified for the station Arnhem Velperpoort as they help in alleviating the TOD score as desired. These plans however, do depend on the market demand for the residential or commercial sector and the planners must study the same to ensure implementable plans. Implementing increase in any land use type can be done by either using vacant land spaces if any, changing the land use from one type to another, or by relaxing the zoning regulations and allowing more development vertically over the same land parcels. Planners will need to further work out such details for the TOD plans.

For the Arnhem Zuid station, the web-diagram (figure 4.5) shows that this station area would benefit from higher densities and economic development. The parking utilisation is also high and adding more parking spaces should 
also improve the parking situation. For cars, the parking utilisation is as high as $96 \%$ and increasing the car parking supply could alleviate the situation and encourage people to park-and-ride from the station.

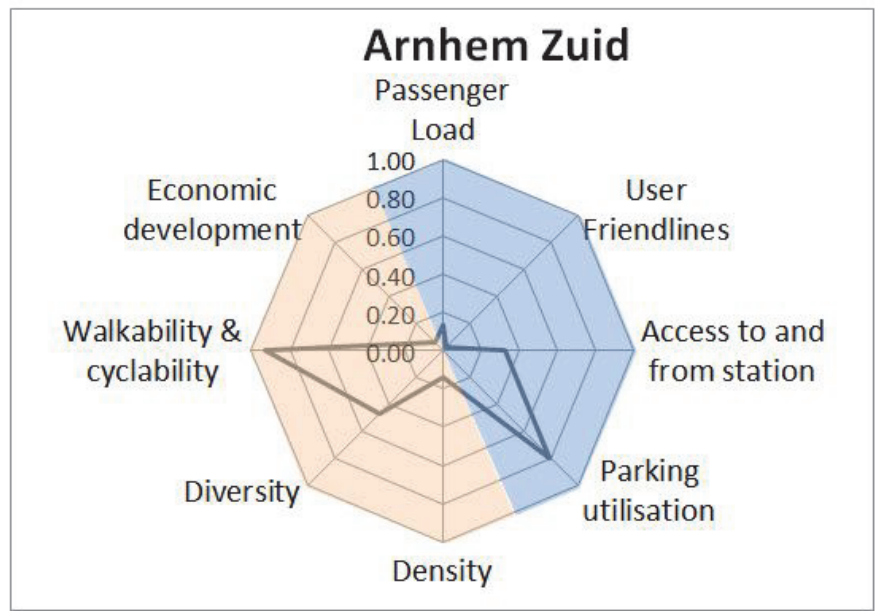

Figure 4.6: Web-diagram of the criteria for TOD score (Arnhem Zuid)

The desirable increase in TOD score for this station is 0.14 , which is considerably higher than that for the previous station. Thus, we made comparatively higher assumptions to development. An increase of 4000 persons, 300 commercial establishments and about 5,000 sqm of office space were assumed. Car parking supply was increased by $20 \%$ so as to lower parking utilisation than currently $96 \%$. Jobs and number of commercial and non-commercial establishments were also added to the PSS for this station. A resulting increase in TOD score from 0.26 to 0.28 was recorded in this application for Arnhem Zuid station. It's not much, but is in the right direction and is helping the station improve. If deemed feasible, planners may increase these assumptions to get better results. This is just one set of assumptions or recommendations and there are more combinations possible for each station.

The PSS was thus helpful is estimating how the planning interventions would affect the TOD index for a station. More accurate decisions can thus be made. Also, it is a very user-friendly system as all one has to do it to change the assumptions on the slide-bar and the changed TOD index is recalculated and shown the graph on the left and on the map behind. All changes can also be printed as a report for further reference, before new changes are made.

\section{b. Evaluating existing TOD plans}

As mentioned before, as a part of an earlier project in 2010-2011 on transit node areas, Het Noordzuiden, a consulting body, had developed TOD plans 
on behalf of the City Region office, for development of the new train station areas. Of the seven existing stations identified for improved TOD score (see table 4.3), we found that Het Noordzuiden has prepared TOD plans for the stations of Arnhem-Zuid and Elst that are relatively newer than other stations. For these station areas, we will evaluate the efficacy of their TOD plans w.r.t. the TOD score i.e. we will examine if the recommendations made in the TOD plans lead to an improved TOD score or not and how much.

\section{Arnhem Zuid}

For this station area, the TOD plan has some short term and some long term recommendations for development (Noordzuiden, 2011a). Under the short term plan, the recommendations are to build the 'Wijkcentrum' at Schyutgraaf (no. 3 in figure 4.6) on the west side of the station (no. 1 in figure 4.6), develop office space and residences on the south-eastern side of the station (no. 2 in figure 4.6), increase parking space for cars and cycles among others. Over the long-term, the plan recommends development of the north-eastern side of the station and developing the station as a sub-centre of main Arnhem station.

On its south-east location, the plan recommends adding 10,000sqm of office space and 150 houses meant for different types of residents such as 55+ers, double income households, starters, singles, families and others. For the 'Wijkcentrum' at Schuytgraaf on the west of the station, about 350 houses, a school, a sport centre, a health centre, parking and office space are proposed. Increasing the parking space is also recommended because the station's improved connectivity with nearby motorways of N837 and A50 could encourage drivers to park at station and take the train to their farther destinations. We can assess how these recommendations affect the TOD score for the station. It should also be seen if the recommendations match what lacks at the station for a wholesome TOD environment around the station.

For Arnhem Zuid station, the web-diagram (figure 4.5) shows that this station area would benefit from higher densities, economic development and better parking utilisation. However, the TOD plan does not specifically recommend how many parking spaces to add. It also does not say how much area shall be built for a number of activities such as health-centre, sport centre, school and others. For that, we will need to assume areas dedicated for these individual uses and assumptions were made regarding the typical size of each activity - health centre - 550sqm, sports centre - 5,500sqm, school - 1,500sqm and office space $-2,000$ sqm. 


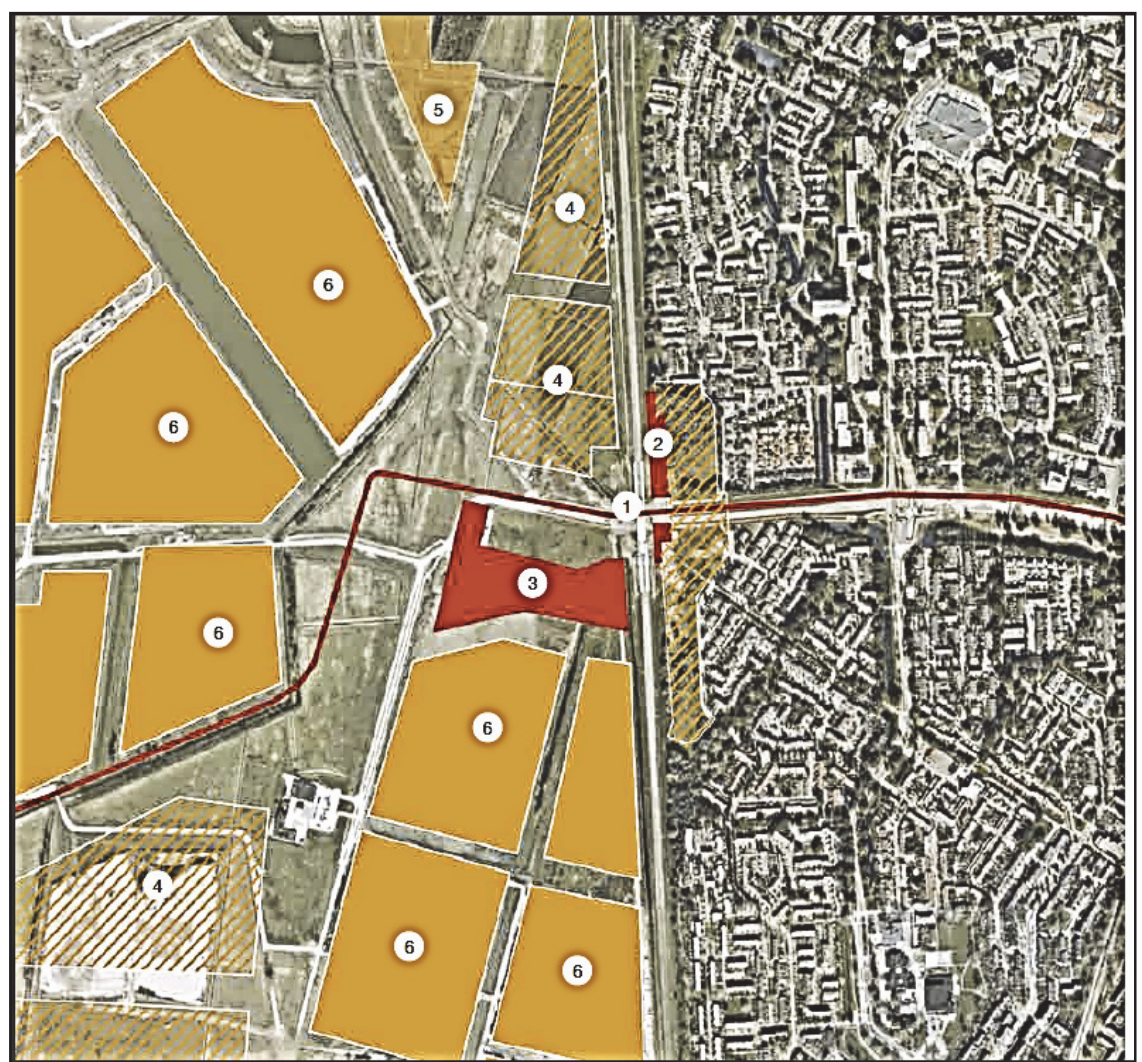

Figure 4.7: Development recommendations for area around Arnhem- Zuid station (Source: Noordzuiden (2011a)

The number of people, area under residential land use and the jobs created by other activities were also added as per assumptions made in previous section. The car parking supply was increased by $20 \%$ of its current capacity. Making those assumptions, the PSS simulated the changed TOD index score for the station. It was found that the TOD index score improved a little from 0.26 to 0.27 while the target TOD score is 0.4 .

It seems that even though the recommendations are in the right direction, the changes are too little to bring about the desired change. More drastic changes are required, but may not be desirable, to increase the TOD score from 0.25 to more than 0.4 that may not be desirable. It is suggested that the TOD plan should also consider improving the user-friendliness of the station in addition to its existing recommendations. Adding more shops at the station will improve the perception of safety there. It is hoped that by implementing the plan, transit ridership at the station will also increase, thereby increasing the TOD score. 


\section{Elst}

For Elst station area, the TOD plan has some short term and some long term goals (Noordzuiden, 2011b). This station is located between the main stations of Arnhem and Nijmegen and City Region officials as well as the municipality of Elst want this station to be transport hub of the region as it is almost in the centre of the City Region. Under the short term goals, the plan recommends improving the station environment and surroundings by improving the urban design. That shall make the area more attractive, walking and biking friendly. Building the municipal hall next to the station is also recommended in short term. Over the long term, the plan proposes development of office space, residences and commercial space around the station. In terms of numbers, it is proposed to build 3,400sqm of commercial space, 11,000 sqm of office space for Municipal hall, 6,500sqm of general office space, 196 apartments, 108 single family houses, 1000 parking spaces for cycles and 900 parking spaces for cars. These proposals shall be evaluated w.r.t their impact on the TOD index score for the station. According to the web-diagram of TOD score for this station (figure 4.7), the density and economic development can be increased and parking utilisation can be improved to bring about positive change in TOD index score. The OV score for the station is high as most of the trains moving between Arnhem and Nijmegen also serve Elst. Thus, increasing densities and economic development should also increase the passenger load at the station, leading to a more effective utilisation of transit services. It seems that the recommendations under the TOD plan address the existing problems at the station and adding different kinds of land uses, houses and parking should improve the TOD score at the station.

To estimate the number of people and the area under residential land use, the number of houses was used. The area under office and commercial land use was used to estimate the addition of new business and commercial establishments and the number of jobs. 


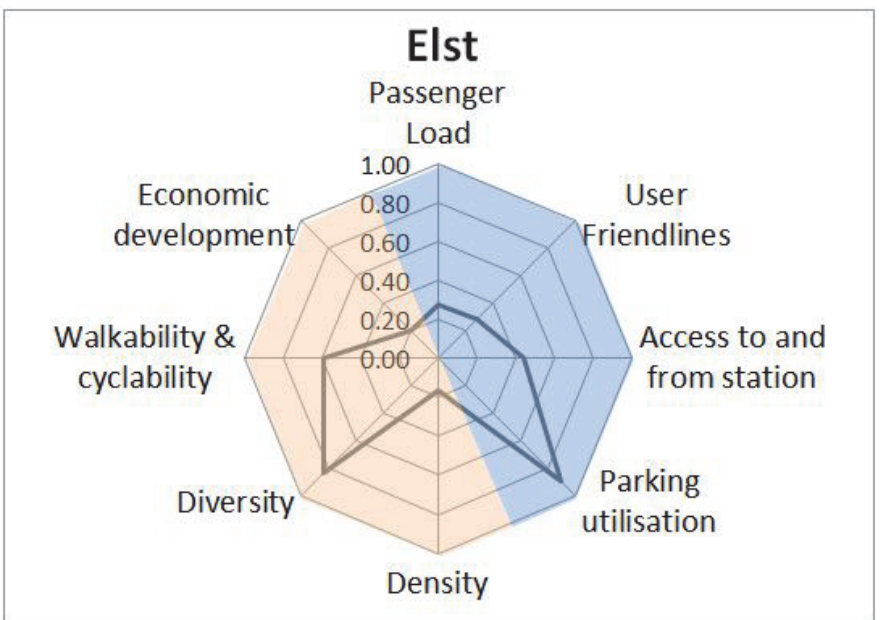

Figure 4.8: Web-diagram of criteria for TOD score (Elst)

Upon making the assumptions as proposed in the TOD plan, surprisingly, the TOD score changed negatively from 0.35 to 0.31 and the recommendations, collectively, seem to make the situation worse. Upon a closer look, we believe that adding a considerable number of parking spaces without assuming an increased parking demand is responsible for bringing the TOD score down. Due to very high parking supply, the parking utilisation reduced considerably thereby reducing the TOD score. Even if we assume it, it would not be as high as the supply and that the proposal on car parking spaces is too high for a positive effect on TOD.

According to the TOD plan by Het Noordzuiden, the station capacity shall also be increased in near future because the transit service will be increased by adding a number of InterCity trains, Sprinters and goods trains. Once that is realised, the OV score for the station should be recalculated as should the Target TOD score.

\section{c. Evaluating the effect of Regional Plan on the TOD scores}

The Regional plan for the City (Regionaal Plan 2005-2020) prepared by the City Region officials and the Gelderland province (the City Region is a part of Gelderland Province) was published in 2007. It is the second such plan after the previous one for 1995-2005. While the last one aimed at building new infrastructure, new businesses, industries and such, this plan proposes to make the existing facilities and areas stronger, gives special attention to smaller villages and also hopes to build stronger European connections w.r.t commerce and business. The aim of the plan is to build an attractive, internationally competitive region, where residents, entrepreneurs and businessmen choose to settle down. Thus, four areas are of particular 
importance in this plan - economy, mobility, housing and landscape. In the 1970s and 1980s, the plan describes how the two cities of Arnhem and Nijmegen remained dominant and while the city of Arnhem grew towards the East, the city of Nijmegen grew towards the west (figure 4.8). In the 1990s, the two cities started to grow towards each other - Arnhem had a planned extension 'Schyutgraaf' and Nijmegen had 'Lent'. In the new plan, the planners aim to build an 'urban network' consisting of not just the main cities of Arnhem and Nijmegen, but also the smaller towns and villages that surround the two main cities or fall between them. The development shall be encouraged not just around the stations but also in the inner cities, districts, along the motorways and highways and forests and nature shall be preserved.

Of the ten priorities mentioned in the plan, one is about bringing synergy between the operations of different transit systems i.e. bus, train, regiotaxi and others, another is about intensifying urban development around multimodal transit nodes, including some sub-urban stations around Arnhem and Nijmegen and another priority is about strengthening the metropolitan character of the two cities. For strengthening the metropolitan character, two projects have been in the pipeline - first including Arnhem Central, Rijnboog and Stadsblokken-Meinerswijk, second including Nijmegen and NijmegenLent. New sub-urban stations have also been proposed at different locations, the feasibility and planning studies for which have been done by consultants Noordzuiden ("Publicaties - OV/RO Knooppunten,")("Publicaties - OV/RO Knooppunten,").

In line with their plan to build an 'urban network', large scale housing projects at Schyutgraaf near Arnhem Zuid station, at Westeraam near Elst station and at Waalsprong near Nijmegen-Lent station are planned by the government. From the market perspective, it is expected that most marketled development, in the coming years, would be around Arnhem at Schuytgraaf, Kronenburg/ Gelredome, Pleij, Arnhem-Noord and Dieren. Around Nijmegen, it is expected that most development would be around Lent, Heyndaal, Winkelsteeg and Wijchen-oost. Currently, not all new stations have been operationalised and we looked at the plan further to know if definite estimates of housing and commerce have been made for the government projects at Schyutgraaf, Westeraam and Waalsprong. Such information can be used for simulating changes in TOD-ness around the stations. Since the plan is at the regional scale, it is not very definitive and gives the general direction of planning for different areas. However, it is conclusive that in the period of 2005-2020, atleast 34,000 houses would be added and 8000 existing houses will be demolished and rebuilt in the whole 

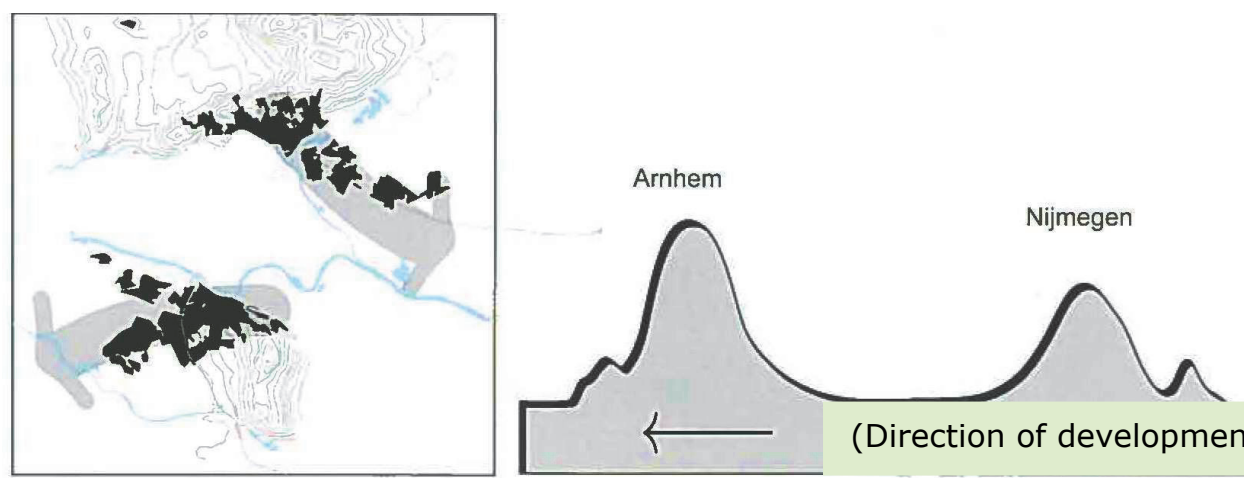

(Direction of development)

ontwikkelingsrichting
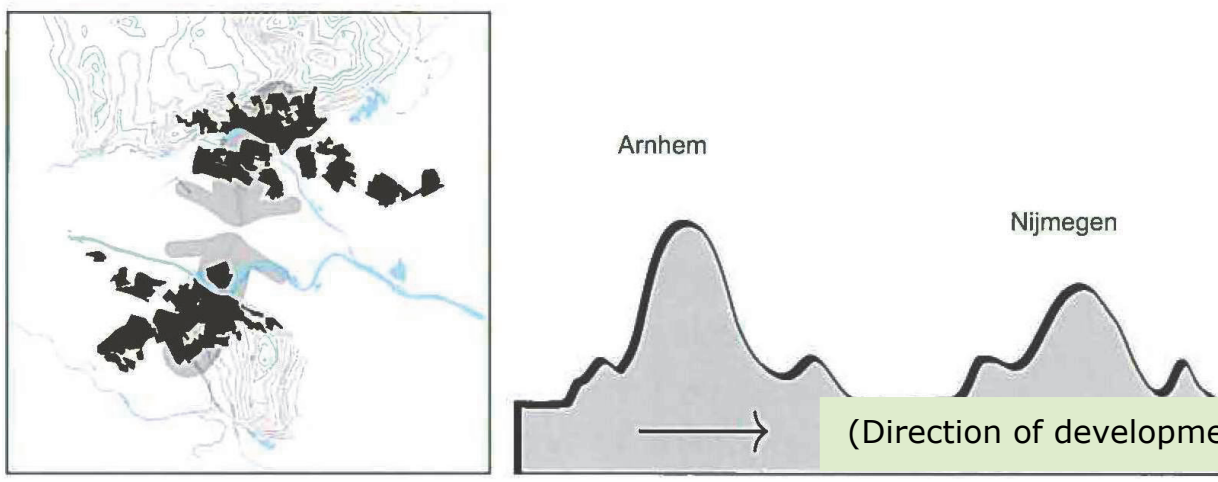

(Direction of development)

ontwikkelingsrichting
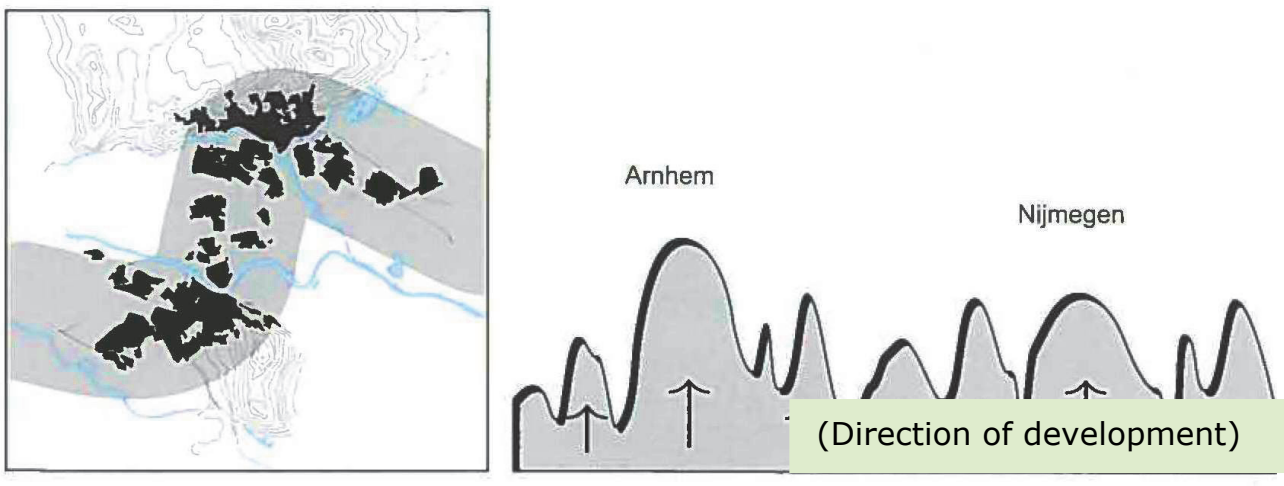

ontwikkelingsrichting

Figure 4.9: Three phases of development of the City Region.

Source - Regionaal Plan 2005-2020,(p18). 
region. In total, about 42,000 houses shall be built in the region from 20052020. Although there are no specific plans as to how many houses are planned to be built at what location in the region, it is mentioned that atleast $30 \%$ of the stock shall be built in existing built-up areas all around the region. It is thus assumed that $70 \%$ of these houses shall be added by the government in its own new projects like those at Schuytgraaf, Westeraam and Waalsprong and around the new stations proposed in the City Region. The plan also mentions that the area between the two rivers, essentially between Arnhem and Nijmegen (figure 4.8), is expected to develop and house more than 160,000 people. The three projects named before also lie in the area between the two rivers.

Currently, there are a number of housing projects that are in various stages of construction in the areas of Schuytgraaf, Westeraam and Waalsprong (Lent)

http://www.woneninvierslag.nl/situatie,

(http://www.horstenhoogte.nl/, nijmegen.nl/projecten/). The number of houses built at Schuytgraaf is about 6500 , at Westeraam about 1000 and at Waalsprong about 3500. It is not clear if some or all of these projects are offered by the government or private sector. In either case, we make the assumptions that approximate number of new houses built at Schuytgraaf is 6,500 (near Arnhem Zuid), at Westeraam is 3,500 (near Elst) and Waalsprong is 4,000 (near Nijmegen-Lent). If the houses are built and offered by the government, then of the 23,000 new houses ( $70 \%$ of the total new housing stock) that are to be built by the government as per the regional plan, 14,000 houses are assumed to be built at these locations and the rest 9,000 houses are assumed to be built at the new station areas or other new development projects proposed in the Regional Plan. Thus, for the relevant station areas of Arnhem Zuid, Elst and Nijmegen-Lent, number of houses shall be added and the new TOD score shall be simulated in the PSS. Coincidently (or rather not), these are also the stations where TOD score is less than desirable and need an improvement. While adding the number of houses to station areas, the population and the area under residential space shall also be added. It is expected that by adding these assumptions, the density will be increased and hence TOD score will be increased. However, addition of high residential land use could adversely affect the land use diversity and mixed-ness of land use at these station areas. These issues need to be carefully observed. Upon making these assumptions in the PSS, the new TOD scores for the stations were simulated.

It is interesting to see how implementing a regional plan can affect the TOD scores around the stations. The TOD scores for Arnhem Zuid and Elst do show a small increase (an increase of 0.03 for Arnhem Zuid and 0.02 for Elst) but that for Nijmegen Lent is not affected at all. This is because of the reasons given before that high residential land use would reduce the land use 
diversity and mixed-ness, even while adding density to the area. Thus, changes in housing are not sufficient by themselves and need to be supported by other developments and other uses to bring about a meaningful increase in the TOD score.

Even though there have been a number of assumptions made in this section, the objective was to demonstrate how PSS can be used to simulate the changes to TOD score in response to regional plans. The exact numbers could be different but the approach doesn't have to. By locating some of the entire housing stock at those stations, not only are we able to improve the TODness of the stations (even if not much) and possibly improve utilisation of the transit service, but are also able to keep in line with the proposals of the Regional Plan. This way, the local station area plans will be in conformity with the larger regional plans.

It may be noticed that in all the three applications, we have made assumptions for Arnhem Zuid station and a comparison of all applications for the station can be printed in the form of a report. Such a report records all the assumptions for each application and also reports changes to the TOD index for that station. A report thus created in the PSS has been appended as Appendix 4. Based on the increase in TOD score for Arnhem Zuid station, the last application where regional plan was implemented, seems to the best suited of the three applications. However, as pointed out before, the recommendations of the regional plan need to be supported by recommendations to improve other criteria such as economic development, parking utilisation, land use diversity and such. Also, even though an application may lead to highest increase in TOD score, it is possible that the assumptions made are not physically or financially feasible. In terms of feasibility then, some other application may be more suitable for the station. The recommendations of the regional plan, of the three applications, are also closest to the reality since the assumptions are based on the information from websites of various new projects. Thus, for this case, it can be said that not only are the recommendations of Regional Plan beneficial for the TOD score of Arnhem Zuid station, but are also practically feasible as is seen.

Other than evaluating the Regional Plan, we could also use our Actual TOD index results to find appropriate locations for the new houses as proposed in the Plan. About 34,000 new houses are proposed to be built in new and old developments not just around the station areas but also along motorways and villages. In a case where these new houses need to be located in the region, we should be able to propose probable/ suitable locations for these houses. Going by the results of our Actual TOD index, we have identified station areas that would benefit from higher densities. We believe that the first priority should be given to those seven stations with lower TOD index 
such that their transit services are well supported by transit oriented development. In addition to housing, other measures may also be needed in conjunction to improve the TOD score in totality for those stations. As a second priority, it is suggested that the new stations should get additional housing stock as these areas would be served by a high quality transit service for the efficient utilisation of which, urban densities are required. Other areas of the region can be then considered for adding housing stock.

\subsection{Limitations of the PSS}

Lee (1973) and te Brommelstroet et al. (2014) mention that most urban systems are inherently complex and any model can only capture a part of their relations. Thus, we should embrace the ignorance of the models as may be known and assumed. Our PSS also has some limitations that we embrace and have listed here for better understanding of the users.

a. Theoretically, even though we may be changing the input data values (like population) for one particular station area, the TOD index will change for all station areas. That's because the indicators values are standardized in the process of calculating TOD index and this requires a comparison of values of all 21 stations. This is not a limitation of the PSS but a character of TOD index itself. Depending on the changes in input values, the change in TOD index values may or may not be noticeable.

b. If we were to improve one thing across all stations- like increasing density - it is possible that the TOD index may or may not notably change overall for all stations because the index value is calculated by standardization.

c. Increasing houses, for example, may improve TOD index value but may not be feasible on the ground. To this, we also agree that the PSS only helps the planner understand the 'outcome' of his plan of increasing houses or others. In other words, it helps decide 'what' to do. 'How' to do it is another question and becomes a project in itself. For example, houses can be increased by either building vertically by way of relaxing building bye-laws or horizontally by expanding the developable area; by a public or by a private party; or replacing one land use by another. All these options need to be studied in detail with regard to the technical and financial feasibility.

d. To make physical plans, planners will need additional information such as building guidelines, land use plans, planning policies, political motivations and all of such information are NOT a part of this PSS. The planner will 
have to gather this information and refer to it as and when the need arises, outside the PSS.

e. The PSS cannot advise on the market demand of different land uses. For that a separate market study may be required. The PSS and index can help in understanding what is needed from TOD point of view, but not from market point of view.

f. The PSS cannot simulate how other stations are affected by increasing the supply of a certain use/ activity at one station. This will also require a detailed study into the market dynamics of how the demand for one activity around a station is affected by supply at another. Such work, even though very interesting, was not within the scope of this thesis.

g. The PSS cannot simulate how increasing the densities or jobs translates to the increase in number of passengers. We do not have enough information to understand how many of the residents/ workers/ visitors are expected to take the transit. Thus, even though we believe that any increase in density, jobs or economic development should logically mean an increase in transit ridership too, our PSS cannot simulate how much that increase shall be.

Even though our PSS is developed for our very specific purpose, it is hoped that it is not just one one-off application PSS that is seldom used again for future (Klosterman, 2009). We hope that more people in professional practice and in academia become interested in using our PSS which we would be happy to share. This PSS can be easily customized for their particular needs and hopefully, they would benefit from using this in planning for TOD around transit nodes.

\subsection{Conclusions}

In this chapter we demonstrated the utility of Actual TOD index in planning for TOD at stations and also made a Planning Support System for the purpose. While in the chapter 2 , we showed how the index can be used for quantifying the TOD-ness of an area and objective comparison of the station areas, in this chapter we demonstrate how it can be used further to improve TOD-ness of a station area. With the PSS, it becomes possible to evaluate various plans, before implementation such that outcomes of the same can be simulated and the plans can be bettered. Comparison of different possible plans for a single station area can also be compared to choose the most appropriate plan. It is hoped that the TOD index, along with the PSS, are used by more and more urban planners and professionals working towards TOD planning. 
Chapter 5 - Synthesis 
The literature on TOD is very vast and, as mentioned in the first chapter, covers many aspects of the concept such as impact of high densities, land use diversities and urban design on the travel behaviour of people, how to measure the success of TOD projects, various TOD case studies around the world, handbooks and guidebooks on how to plan for TOD, and others. However, we identified that in the scientific literature on TOD, there is insufficient work on quantifying the concept of TOD with the purpose of enabling the preparation of improved and more efficient TOD planning. Although some station-area studies made an attempt to measure TOD, they have not quantified levels of TOD. The methodology used there primarily clusters the station areas into types which, we believe, does not do justice to the unique characters of different stations however similar they may be. Furthermore, there is scant literature on studying TOD at the regional scale, which is also a gap. In this research we have shown that levels of TOD are measurable and quantifiable in a very comprehensive way. We believe that measuring TOD using a TOD Index can assist in more effective planning for TOD as it helps in identifying what lacks in the current situation and what needs to be improved upon. We also expand the common notion of TOD limited to transit nodes and go to the regional level and measure TOD at that scale. With this research, we believe that we are filling that gap. Our PSS improves the utility of our TOD Index even further by helping in making unique TOD plans for single station areas.

At the beginning of the thesis, we laid out our three objectives on TOD planning and we have showcased how a TOD index can be used to achieve those objectives. The methodology adopted to arrive at TOD indices is very logical, straightforward, easy to implement and these are the strengths of this methodology coupled with its high transferability over different geographies. With the results presented here, planners can make more accurate planning proposals knowing what exactly misses around each transit node and what can be improved to improve TOD conditions. The ambiguity of qualitative assessments can thus be avoided by quantitative assessment. After the TOD plans are drawn and implemented, the same index can be used to measure the TOD conditions again and gauge the success of those TOD plans. Identification of hot-spots in the region also helps in highlighting areas that need better access to high quality transit. Views of the decision makers have also been incorporated (in a workshop) in defining and measuring TOD for a case study. Such results of a TOD Index for any other case will be extremely helpful to the planners when making specific TOD planning proposals at the regional and local scale. Applying this concept of the TODindex to different contexts will further improve it and could lead to a readyto-implement assessment and evaluation guidance tool. The Planning Support System (PSS) for the TOD Index assists in successfully taking the results forward to the stage of TOD planning. We demonstrated in chapter 4 
how the index not just helps in making TOD plans for the station areas, but also in evaluating the other TOD plans, regional plans and other such plans.

\subsection{Conclusions}

In this concluding section, the main observations and results of our work can be enumerated as mentioned hereunder.

a. TOD is a widely used concept or approach for sustainable development and has been defined and interpreted in different ways by different people. There are also varying views on which transit system is necessary for creating TODs; which characteristics are important for TOD; if TOD should be studied at the local scale or also at the urban and regional scale; and how TOD should be evaluated for success.

b. In the past, TOD has been planned and implemented at various locations including the Netherlands, Singapore, Perth (Australia), Portland (North America), Curitiba (Brazil) and Hong Kong.

c. TOD plans and projects are evaluated for success or failure using some indicators proposed in the literature. However, there is need to improve the TOD planning process by measuring the existing TOD situation in a study area in a more comprehensive way.

d. Many studies such as (Bertolini, 1999), (Balz \& Schrijnen, 2009), (Reusser et al., 2008), (Zemp et al., 2011), (CTOD, 2013), (DeltaMetropolisAssociation, 2014), have measured the existing transit and development characteristics in order to understand TOD around railway stations in their study areas. These studies cluster the stations into typologies and recommendations are for each 'type' of stations. The disadvantage of this methodology is that station-specific TOD recommendations cannot be made, thereby neglecting that stations within a 'type' are similar but never the same.

e. We also believe that TOD should not be limited to the local scale around stations, but also need to be studied at the regional scale.

f. Our objectives have thus been three-fold:

- Study the nodes served by high-quality transit and identify those nodes where TOD-ness can be improved.

- Study the TOD-ness over a region and identify areas where the TODness is high but access to high-quality transit is poor.

- Develop a Planning Support System (PSS) that uses the above results and assists in making TOD plans for a study area.

g. For the achievement of these objectives, it is required to be able to quantify TOD for an area such that different areas can be compared and 
a detailed assessment of specific areas is possible. This was made possible by developing a TOD index, as proposed by Evans and Pratt (2007).

h. For the first two objectives, two separate indices were developed since they not only deal with different scales (local and regional scale), but also different types of areas (those with transit access and those that may or may not have transit access). The TOD characteristics measured for each of these are different. The two indices developed were 'Actual TOD Index' and 'Potential TOD Index'. The former can be applied in areas with actual transit access and the latter helps in identifying areas with potential locations for transit connectivity.

i. Since characteristics or indicators of TOD can be spatial or non-spatial and have different units of measurement, the (Spatial) Multiple Criteria Assessment (MCA) methodology was chosen to compute the TOD indices. Some of these indicators can be considered more important than others in creating TOD and different stakeholders may have divergent views on such importance. The MCA method also allows for incorporation of such priorities awarded to different indicators for TOD index calculation.

j. After a comprehensive and extensive literature review, lists of indicators were identified that are appropriate to be involved in the two indices. It was important that these indicators are suitable for assessment of the existing situation, as well as quantifiable, practical and effective. The indicators typically include the 3 Ds of development - Density, Diversity of land uses and Design of urban space. These also comprise relevant transit characteristics (wherever applicable), required to attract higher patronage.

k. To showcase our methodology, we use the City region of Arnhem and Nijmegen in the Netherlands. The data for our indicators was mostly collected from internet and from officials of the City region. Using the GIS software, all the spatial and non-spatial indicators were calculated.

I. A workshop was conducted with the municipal alderman of the 20 municipalities of the City Region, in which they received information about some details of our project and were requested to rank the indicators (separately for both indices) in terms of importance with respect to realization of the TOD concept. The results were used to assign weights to the various indicators.

$m$. The indicator values together with the weights were used to calculate the TOD indices in the MCA/SMCA. The Actual TOD Index was calculated for all the existing 21 stations in the City region whereas the Potential TOD Index was calculated over the entire City Region. 
n. A sensitivity analysis was carried out to confirm the robustness of the results after which inferences were drawn from the results.

o. With the results for the Actual TOD index, stations were identified that scored very low on the TOD index scale of 0 to 1 . The larger stations like Arnhem and Nijmegen scored higher than all other stations, which does not come as a surprise because these are the main urban centres of the region. Using the method proposed in (Balz et al., 2006) and (DeltaMetropool, 2013), every station's hierarchy in the OV network (national rail network) was measured using the OV score for each station. Matching the OV score with its TOD score, those stations were identified that should have a higher TOD score.

p. With the results for the Potential TOD Index and by statistically clustering using 'Anselin Moran's I' - hot-spots of high TOD scores were identified. Moreover, those hot-spots were identified that have poor access to high quality transit.

q. A Planning Support System (PSS) was developed in CommunityViz that can be used to prepare TOD plans and to evaluate plans. We demonstrated how the PSS can be used for three main purposes: preparing TOD plans, evaluating the efficacy of existing TOD plans and assessing the regional plan on TOD scores around the stations.

\subsection{Recommendations for future work}

a. As the TOD index is adopted for a larger number of case studies, there would be a better understanding of what can be considered as 'generally high' or 'generally low' or 'enough' to characterize an area as 'TOD'. This understanding is vital for determination of success or failure of TOD projects.

b. Our PSS has some limitations as mentioned in last chapter and in future, these may be further improved.

c. Real estate around station areas is usually very expensive, at least more expensive than those farther from the station. The market dynamics of station areas are thus very complicated and differ from place to place. The high value of real estate can be captured by either allowing affordable housing that means more people and lower rents per house or by allowing luxury housing meaning lesser people and higher rents per house. In many American studies, it has been discussed how very high real estate prices actually drive away residents of affordable housing as houses seize to remain affordable. The dynamics of an area, the policies of the government and the demography of that area all have an impact on the number of people living in proximity to a station. This in turns has an impact on their travel behaviour. A study in Haaglanden, Netherlands, 
(Borkens \& Jansen, 2014) discusses how some station areas have luxury houses in immediate proximity of the station and the people in those areas drive their luxurious cars and do not use transit at all. Even though our TOD index has proven to be useful for planning purposes in our case study area, it is recommended to study travel behaviour of residents of station areas in more detail.

d. It may be interesting to study Actual TOD index over 'cycling distance' than 'walking distance' for some communities like in Netherlands where cycling is a way-of-life. We expect that this will significantly lower the TOD index values overall because larger areas will have lower compactness of development thus impacting densities, diversities and other such indicators. 


\section{Bibliography}

52North. (2012). ILWIS 3.x User's Guide Retrieved 2012-12-12, 2012, from http://52north.org/communities/ilwis/ilwis-userguide

Abella, E. A. C., \& Westen, C. J. (2007). Generation of a landslide risk index map for Cuba using spatial multi-criteria evaluation. Landslides, 4(4), 311-325. doi: 10.1007/s10346-007-0087-y

Arrington, G. B. (2009). Portland's TOD Evolution: From Planning to Lifestyle. In C. Curtis, J. L. Renne \& L. Bertolini (Eds.), Transit Oriented Development: Making it Happen (pp. 109-124): Ashgate e-Book.

Bach, B., Hal, E. v., Jong, M. I. d., \& Jong, T. M. d. (2006). Urban Design and Traffic - a selection from Bach's toolbox. The Netherlands: CROW.

Bae, C. H. C. (2002). Orenco Station, Portland, Oregon: A successful transit oriented development experiment? Transportation Quarterly, 56(3), 9-15.

Balz, V., Gerretsen, P., Edens, C., \& Atelier, Z. (2006). Ruimte en lijn : ruimtelijke verkenning stedenbaan 2010-2020 : zuidvleugel van de Randstad. Den Haag: Provincie Zuid-Holland.

Balz, V., \& Schrijnen, J. (2009). From Concept to Projects: Stedenbaan, The Netherlands. In C. Curtis, J. L. Renne \& L. Bertolini (Eds.), Transit Oriented Development: Making it Happen (pp. 75-90): Ashgate eBook.

Belzer, D., \& Autler, G. (2002). Transit Oriented Development: Moving from Rhetoric to Reality: The Brookings Institution Center on Urban and Metropolitan Policy and The Great American Station Foundation.

Bertolini, L. (1999). Spatial Development Pattern and Public Transport: The application of an analytical model in the Netherlands. Planning Practice \& Research, 14(2), 199-210.

Beukes, E. A., Vanderschuren, M. J. W. A., \& Zuidgeest, M. H. P. (2011). Context sensitive multimodal road planning: a case study in Cape Town, South Africa. Journal of Transport Geography, 19, 452-460.

Beuthe, M. (2002). Transport Evaluation Methods : From Cost-Benefit Analysis to Multicriteria Analysis and the Decision Framework. In L. Giorgi \& A. Pearman (Eds.), Project and Policy Evaluation in Transport (pp. 209 - 241). England: Ashgate Publishing Limited.

Bhatt, C., Bricka, S., Mondia, J. L., Kapur, A., Guo, J., \& Sen, S. (2006). Metropiltan Area- Transit Accessibility Analysis Tool.

Boarnet, M., \& Crane, R. (1997a). L.A. story - A Reality Check for TransitBased Housing. Journal of the American Planning Association, 63(2), 189-204.

Boarnet, M., \& Crane, R. (1997b). L.A. story - A reality check for transitbased housing. Journal of the American Planning Association, 63(2), 189-204.

Borkens, E., \& Jansen, B. (2014). Transit Oriented Development in Haaglanden. Paper presented at the Nationaal verkeerskundecongress 2014, Utrecht, The Netherlands.

Calthorpe, P. (1993). The Next American Metropolis - Ecology, Community and the American Dream. Canada: Princeton Architectural Press. 
Cascetta, E., \& Pagliara, F. (2008). Integrated railways-based policies: The Regional Metro System (RMS) project of Naples and Campania. Transport Policy, 15(2).

Cascetta, E., \& Pagliara, F. (2009). Rail Friendly Transport and Land-use Policies: The Case of the Regional Metro System of Naples and Campania. In C. Curtis, J. L. Renne \& L. Bertolini (Eds.), Transit Oriented Development: Making it Happen (pp. 49-64): Ashgate eBook.

Centraal Bureau voor de Statistiek (CBS). Retrieved 2012 http://www.cbs.nl/nl-NL/menu/home/default.htm

Cervero, R. (2004). Transit-oriented development in the United States: experiences, challenges, and prospects: Transportation Research Board of the National Academies.

Cervero, R., \& Bosselmann, P. (1998). Transit villages: Assessing the market potential through visual simulation. Journal of Architectural and Planning Research, 15(3), 181-196.

Cervero, R., \& Dai, D. (2014). BRT TOD: Leveraging transit-oriented development with bus rapid transit investments. Transport Policy, 36, 127-138.

Cervero, R., \& Kockelman, K. (1997a). Travel Demand and the 3Ds: Density, Diversity and Design. Transportation Research, 2, 199-219.

Cervero, R., \& Kockelman, K. (1997b). Travel demand and the 3Ds: Density, Diversity, and Design. Transportation Research Part D: Transport and Environment, 2(3), 199-219. doi: http://dx.doi.org/10.1016/S13619209(97)00009-6

Cervero, R., \& Murakami, J. (2008). Rail + Property Development: A model of sustainable transit finance and urbanism: UC Berkely Centre for Future Urban transport.

Cervero, R., \& Murakami, J. (2009). Rail and Property Development in Hong Kong: Experiences and Extensions. Urban Studies, 46(10), 20192043. doi: $10.1177 / 0042098009339431$

Chorus, P. (2009). Transit Oriented Development in Tokyo: The Public Sector Shapes Favourable Conditions, the Private Sector Makes it Happen. In C. Curtis, J. L. Renne \& L. Bertolini (Eds.), Transit Oriented Development: Making it Happen (pp. 209-224): Ashgate e-Book.

Chorus, P., \& Bertolini, L. (2011). An application of the node place model to explore the spatial development dynamics of station areas in Tokyo. The Journal of Transport and Land Use, 4(1), 45-58. doi: 10.5198/jtlu.v4i1.145

CST. (2002). Sustainable Transportation Performance Indicators (STPI) Project (Phase 3): Centre for Sustainable Transportation (CST).

CTOD. (2009). Why Transit - Oriented Development and Why Now? U.S: Reconnecting America - Centre for Transit Oriented Development (CTOD).

CTOD. (2013). Transit-oriented development typology strategy for Allegheny County.

CTOD. (Oct. 2010). Transit Corridors and TOD: Connecting the Dots is Important (pp. 1-28): Centre for Transit Oriented Developement (CTOD).

Curtis, C. (2009). Implementing Transit Oriented Development through Regional Plans: A Case Study of Western Australia. In C. Curtis, J. L. 
Renne \& L. Bertolini (Eds.), Transit Oriented Development: Making it Happen (pp. 39-49): Ashgate e-Book.

Curtis, C., Renne, J. L., \& Bertolini, L. (2009a). Introduction. In C. Curtis, J. L. Renne \& L. Bertolini (Eds.), Transit Oriented Development: Making it Happen (pp. 3-12): Ashgate e-Book.

Curtis, C., Renne, J. L., \& Bertolini, L. (2009b). Transit oriented development: making it happen: Ashgate e-Book.

Dalkmann, H., Brannigan, C. (2007). Transport and Climate Change. In GTZ (Ed.), Sustainable Transport:A Sourcebook for Policy-makers in Developing Cities. Frankfurt

DeltaMetropolisAssociation. (2012). SprintCity Update 5: Delta Metropolis Association.

DeltaMetropolisAssociation. (2014). SprintCity Update 6: Delta Metropolis Association.

DeltaMetropool. (2013). Maak Plaats! Werken aan Knooppuntenontwikkeling in Noord-Holland. The Netherlands.

Dittmar, H., \& Poticha, S. (2004). Defining Transit-Oriented development: The New Reginal Building Block. In H. Dittmar \& G. Ohland (Eds.), The New Transit Town - Best Practices in Transit Oriented Development (pp. 19-39): Island Press.

Evans, J. E., \& Pratt, R. H. (2007). Transit Oriented Development Transit Cooperative Research Program (TCRP) Report 95: Traveler Response to Transportation System Changes Handbook (3 ed., pp. 17(11) 17(138)). U.S.A: Transport Research Board of the National Academies.

Ewing, R., \& Cervero, R. (2010). Travel and the Built Environment. Journal of the American Planning Association, 76(3), 265-294.

Geertman, S. (2014). Planning support and planning support systems for urban areas.

Geertman, S., \& Stillwell, J. (2009). Planning Support Systems Best Practice and New Methods: Springer Netherlands.

Geertman, S., \& Stillwell, J. (2009). Planning Support Systems: Content, Issues and Trends. In S. Geertman \& J. Stillwell (Eds.), Planning Support Systems Best Practice and New Methods (Vol. 95, pp. 1-26): Springer Netherlands.

Halbur, T. (2007). TOD's Evil Twin: Transit-Adjacent Development. Mass Transit: Better Transit through better management, from http://www.masstransitmag.com/article/10221228/tods-evil-twintransit-adjacent-development

Hale, C., \& Charles, P. (2006). Making the Most of Transit Oriented Development Opportunities. Paper presented at the 29th Australasian Transport Research Forum Gold Coast, Queensland.

Hendricks, S. J., Winters, P., Wambalaba, F., Barbeau, S., Catala, M., \& Thomas, K. (2005). Impacts of Transit Oriented Development on Public Transportation Ridership: Centre for Urban Transportation Research, Florida.

Hoffman, A. (2006). Transit: Can it Sustain TOD? The Forum at Redwood City. Retrieved from http://www.missiongrouponline.com/sitebuildercontent/sitebuilderfile s/HoffmanTODpt2a.pdf

www.missiongrouponline.com 
Howe, A., Glass, G., \& Curtis, C. (2009). Retrofitting TOD and Managing the Impacts: The Case of Subi Centro. In C. Curtis, J. L. Renne \& L. Bertolini (Eds.), Transit Oriented Development: Making it Happen (pp. 65-74): Ashgate e-Book.

Howe, A., Glass, Geoff., Curtis, Carey., . (2009). Retrofitting TOD and Managing the Impacts: The Case of Subi Centro. In C. Curtis, J. L. Renne \& L. Bertolini (Eds.), Transit Oriented Development: Making it Happen (pp. 65-74): Ashgate e-Book.

ITC. (2007). ILWIS 3.3 User manual: International Institute for GeoInformation Science and Earth Observation, Enschede, The Netherlands, . Retrieved from http://www.itc.nl/ilwis

ITDP. (2014). TOD Standard v2.1: Institute for Transportation \& Development Policy.

Jacobs, J. (1961). The death and life of great American cities. New York: Random House.

Kamruzzaman, M., Baker, D., Washington, S., \& Turrell, G. (2014). Advance transit-oriented development typology: case study in Brisbane, Australia. Jounal of Transport Geography, 34, 54-70.

KiM. (2013). Mobiliteitsbalans 2013. The Netherlands: Kennisinstituut voor Mobiliteitsbeleid (KiM).

Klosterman, R. E. (2009). In S. Geertman \& J. Stillwell (Eds.), Planning Support Systems Best Practice and New Methods: Springer Netherlands.

Lee, D. B. (1973). Requiem for large scale models. Journal Of Americal Institute of Planners, 39, 163-178.

Li, C.-N., \& Lai, T.-Y. (2009). Why should cities change from DOT to TOD? [Research Article]. Proceedings of the ICE - Transport, Volume 162(Issue 2), pages 71-78. doi: 10.1680/tran.2009.162.2.71

Lindau, L. A., Hidalgo, D., \& Facchini, D. (2010). Bus Rapid Transit in Curitiba, Brazil: A Look at the Outcome After 35 Years of BusOriented Development. Transportation Research Record: Journal of the Transport Research Board(2193), 17-27. doi: Doi 10.3141/219303

Loo, B. P. Y., Chen, C., \& Chan, E. T. H. (2010). Rail-based transit-oriented development: Lessons from New York City and Hong Kong. Landscape and Urban Planning, 97(3), 202-212. doi: DOI 10.1016/j.landurbplan.2010.06.002

Malczewski, J. (1999). GIS and Multicriteria Decision Analysis. United States of America: John Wiley \& Sons, Inc.

McKone, J. (2010). Cities in Focus: Curitiba Retrieved Nov. 15, 2011, from http://thecityfix.com/blog/cities-in-focuscuritiba/?utm_source=feedburner\&utm_medium =feed\&utm_campaig $\mathrm{n}=$ Feed $\% 3 \mathrm{~A}+$ thecityfix $\% 2$ Fposts $\% 28$ TheCityFix $\% 29$

Mitchell, A. (2009). ESRI guide to GIS analysis : Vol 2. Spatial measurements and statistics. Redlands: ESRI.

Molster, A., \& Schuit, S. (2013). Voetsporen Rond het Station. Paper presented at the Het Nationaal Verkeerskunde Congres, Netherlands.

Mulley, D., Bunker, J., \& Ferreira, L. (2007). Evaluating transit Quality of Service for Transit- Oriented Development. Paper presented at the 30th Australasian Transport Research Forum, Melbourne. 
Nasri, A., \& Zhang, L. (2014). The analysis of transit-oriented development (TOD) in Washington, D.C. and Baltimore metropolitan areas. Transport Policy, 34, 172-179. doi: 10.1016/j.tranpol.2013.12.009

Nelson, D., \& Niles, J. (1999). Essential for Transit Oriented Development Planning : Analysis of Non-Work Activity Patterns and a Method for Predicting Success. Paper presented at the Seventh TRB Conference on the Application of Transportation Planning Methods, Boston, Massachusetts

Newman, P. (2009). Planning for Transit Oriented Development: Strategic Principles. In C. Curtis, J. L. Renne \& L. Bertolini (Eds.), Transit Oriented Development: Making it Happen (pp. 13-22): Ashgate eBook.

Newman, P., \& Kenworthy, J. (2007). Greening Urban Transportation. In L. Starke (Ed.), State of the world 2007 : our urban future (digital edition) (pp. 66-89). New York etc.: W.W. Norton \& Company.

Noordzuiden. (2011a). Arnhem Zuid, Knooppuntnotitie: Stadregio Arnhem NIjmegen, Gemeente Arnhem, Het Noordzuiden.

Noordzuiden. (2011b). Elst, Knooppuntnotitie: Stadregio Arnhem NIjmegen, Gemeente Arnhem, Het Noordzuiden.

Noordzuiden. (2011c). Publicaties - OV/RO Knooppunten Retrieved 2014, 2014, from http://www.destadsregio.nl/publicaties/publicatiesruimte/ov-ro-knooppunten

Páez, A., \& Scott, D. (2005). Spatial statistics for urban analysis: A review of techniques with examples. GeoJournal, 61(1), 53-67. doi: 10.1007/s10708-005-0877-5

Parker, T., McKeever, M., Arrington, G., \& Smith-Heimer, J. (2002). Statewide Transit-Oriented Development Study: Factors for Success in California (C. D. o. Transportation, Trans.).

Pelzer, P., Geertman, S., Heijden, R. v. d., \& Rouwette, E. (2014). The added value of Planning Support Systems: A practitioner's perspective. Computers, Environment and Urban Systems, 48(0), 16-27. doi: http://dx.doi.org/10.1016/j.compenvurbsys.2014.05.002

Pirie, G. H. (1979). Measuring accessibility: a review and proposal. Environment and Planning A, 11(3), 299-312.

Pojani, D., \& Stead, D. (2014). Dutch Planning Policy: The resurgence of TOD. Land Use Policy, 41, 347-367.

- Publicaties - OV/RO Knooppunten. Retrieved 2014, 2014, from http://www.destadsregio.nl/publicaties/publicaties-ruimte/ov-roknooppunten

. Regionaal Plan 2005-2020. Stadsregio Arnhem Nijmegen, The Netherlands.

Reilly, B. (2002). Social Choice in the South Seas: Electoral Innovation and the Borda Count in the Pacific Island Countries. International Political

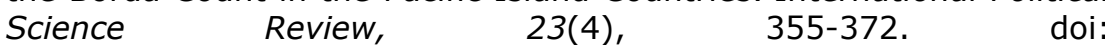
$10.1177 / 0192512102023004002$

Renne, J. L. (2007). Measuring the Performance of Transit Oriented Development in Western Australia: Planning and Transport Research Centre and Institute for Sustainability and Technology Policy, Murdoch University.

Renne, J. L. (2009a). Evaluating Transit-Oriented Development Using a Sustainability Framework: Lessons from Perth's Network City. In S. Tsenkova (Ed.), Planning Sustainable Communities: Diversity of 
Approaches and Implementation Challenges. Canada: University of Calgary.

Renne, J. L. (2009b). Measuring the Success of Transit Oriented Development. In C. Curtis, J. L. Renne \& L. Bertolini (Eds.), Transit Oriented Development: Making it Happen (pp. 241-257): Ashgate eBook.

Renne, J. L., \& Wells, J. S. (2005). Research Results Digest 294 - Transit Oriented Development: Developing a Strategy to Measure Success: Transport Research Board of the National Academies.

Reusser, D. E., Loukopoulos, P., Stauffacher, M., \& Scholz, R. W. (2008). Classifying railway stations for sustainable transitions - balancing node and place functions. Jounal of Transport Geography, 16, 191202.

Rijkswaterstaat. (2010). Mobiliteitsonderzoek Nederland 2009

Tabellenboek. The Netherlands: Ministerie van Verkeer en Waterstaat/ Rijkswaterstaat.

Ritsema van Eck, J., \& Koomen, E. (2008). Characterising urban concentration and land-use diversity in simulations of future land use. The Annals of Regional Science, 42(1), 123-140. doi: 10.1007/s00168-007-0141-7

Schlossberg, M., \& Brown, N. (2004). Comparing Transit-Oriented Development Sites by Walkability Indicators. Transportation Research Record: Journal of the Transportation Research Board(1887), 34-42.

Shastry, S., Zuidgeest, M. H. P., \& Munshi, T. (2011). Spatially assessing transit oriented development (TOD) in Ahmadabad, India. Paper presented at the The 1st Conference of Transportation Research Group India : CTRG 2011, Bangalore, India.

Singh, Y. J. (2013). Ranking the Stars! Prioriteren van criteria en indicatoren voor twee TOD indices (gebiedsbreed en OV knooppunt specifiek) Retrieved 2013, 2013, from https://www.surveymonkey.com/s/TODonderzoek

Singh, Y. J., Fard, P., Zuidgeest, M. H. P., Brussel, M., \& van Maarseveen, M. F. A. M. (2014). Measuring Transit Oriented Development: a Spatial Multi-Criteria Assessment Approach for the City Region Arnhem and Nijmegen. Journal of Transport Geography, 35(0), 130-143. doi: http://dx.doi.org/10.1016/j.jtrangeo.2014.01.014

Smits, T., van der Krabben, E., Kooistra, L., Opdam, E., \& van Uum, E. (2012). Tussentijdse rapportage: URD1-project 'Delta Oost - regio Arnhem Nijmegen'.

SWOV. (Feb'12). Fact Sheet - Measuring (un)safety of roads. Leidschendam, the Netherlands: SWOV - Institute for Road Safety Research in Netherlands.

te Brommelstroet, M., Pelzer, P., \& Geertman, S. (2014). Forty years after Lee's Requiem: are we beyond the seven sins? Environment and Planning B: Planning and Design, 41(3), 381-387.

The City of Calgary. (2004). Transit- Oriented Development : Best Practices Handbook: The City of Calgary.

TRB. (2003). TCRP Report 100- Transit Capacity and Quality of Service Manual U.S.A.

Van Wee, B. (2011). Transport and Ethics : Ethics and the evaluation of transport policies and projects. UK: Edward Elgar Publishing Ltd. 
. Vereneging Deltametropool. (2009) Retrieved 2015, 2015, from http://www.deltametropool.nl/nl/inode

Vonk, G., \& Geertman, S. (2008). Improving the Adoption and Use of Planning Support Systems in Practice. Applied Spatial Analysis and Policy, 1(3), 153-173. doi: 10.1007/s12061-008-9011-7

Yang, J., Shen, Q., Shen, J., \& He, C. (2012). Transport Impacts of Clustered Development in Beijing: Compact Development versus Overconcentration. Urban Studies, 49(6), 1315-1331.

Yang, P. P., \& Lew, S. H. (2009). An Asian Model of TOD: The Planning Integration in Singapore. In C. Curtis, J. L. Renne \& L. Bertolini (Eds.), Transit Oriented Development: Making it Happen (pp. 91108): Ashgate e-Book.

Yang, P. P., Lew, Seng H. (2009). An Asian Model of TOD: The Planning Integration in Singapore. In C. Curtis, J. L. Renne \& L. Bertolini (Eds.), Transit Oriented Development: Making it Happen (pp. 91108): Ashgate e-Book.

Zemp, S., Stauffacher, M., Lang, D. J., \& Scholz, R. W. (2011). Classifying railway stations for strategic transport and land use planning: Context matters! Journal of Transport Geography, 19, 670-679.

Zhang, Y., \& Guindon, B. (2006). Using Satellite Remote Sensing to Survey Transport-related Urban Sustainability. Part 1: Methodologies for Indicator Quantification. International Journal of Applied Earth Observation and Geoinformation, 8, 149-164.

Zimbabwe, S., \& Anderson, A. (2011). TOD 204 Planning for TOD at Regional Scale: The Big Picture (pp. 1-28): The Center for Transit-Oriented Development. 


\section{Appendix 1}

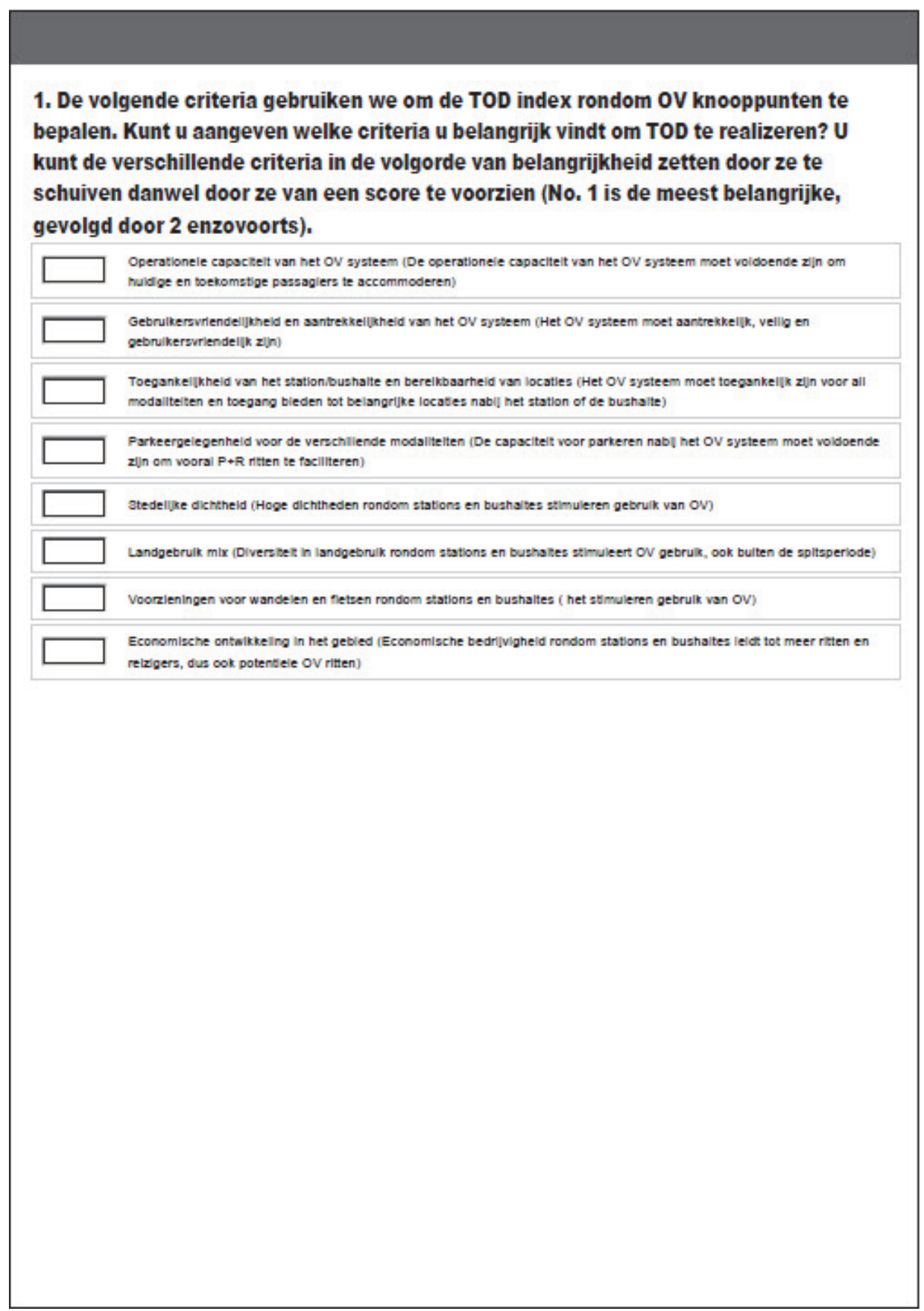


2. Om 'Operationele capaciteit van het OV systeem' te bepalen gebruiken we de volgende indicatoren. Welke indicatoren vindt u belangrijk bij het bepalen hiervan? $\mathrm{U}$ kunt de verschillende indicatoren in volgorde van belangrijkheid zetten door ze te schuiven danwel door ze van een score te voorzien (No. 1 is de meest belangrijke, gevolgd door 2 enzovoorts).

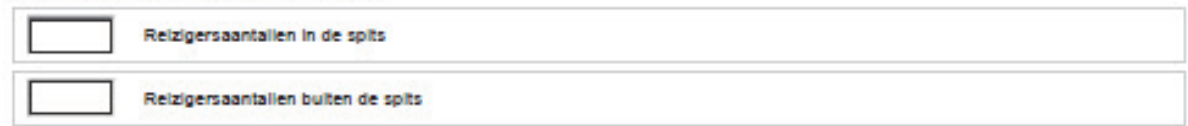

3. Om 'Gebruikersvriendelijkheid en aantrekkelijkheid van het OV systeem' te bepalen gebruiken we de volgende indicatoren. Welke indicatoren vindt u belangrijk bij het bepalen hiervan? $\mathbf{U}$ kunt de verschillende indicatoren in volgorde van belangrijkheid zetten door ze te schuiven danwel door ze van een score te voorzien (No. 1 is de meest belangrijke, gevolgd door 2 enzovoorts).

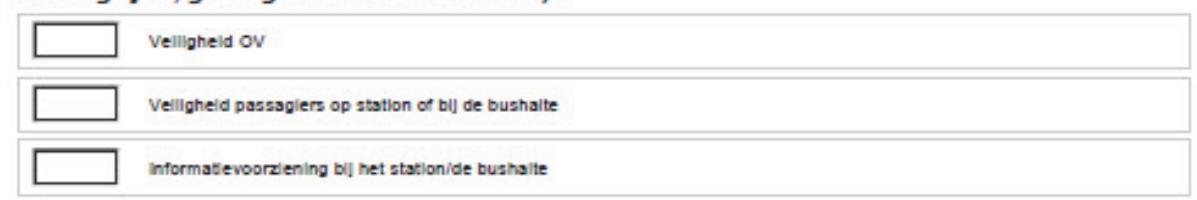

4. Om 'Toegankelijkheid van het station/bushalte door verschillende modaliteiten en bereikbaarheid van locaties vanuit het station/vanaf de bushalte' te bepalen gebruiken we de volgende indicatoren. Welke indicatoren vindt u belangrijk bij het bepalen hiervan? $\mathrm{U}$ kunt de verschillende indicatoren in volgorde van belangrijkheid zetten door ze te schuiven danwel door ze van een score te voorzien (No. 1 is de meest belangrijke, gevolgd door 2 enzovoorts).

\begin{tabular}{|c|}
\hline Frequente van trein/bus \\
\hline Aantal asnslultingen nasar andere routes voor dezelfide modaltelt \\
\hline Aantal overatapmogelukheden naar andere modalteiten \\
\hline Toegankelikheid station/bushalte \\
\hline Toegankellikheid locaties vanat station/bushalte \\
\hline
\end{tabular}


5. Om 'Parkeergelegenheid voor de verschillende modaliteiten bij het station/bushalte' te bepalen gebruiken we de volgende indicatoren. Welke indicatoren vindt $u$ belangrijk bij het bepalen hiervan? $U$ kunt de verschillende indicatoren in volgorde van belangrijkheid zetten door ze te schuiven danwel door ze van een score te voorzien (No. 1 is de meest belangrijke, gevolgd door 2 enzovoorts).

\begin{tabular}{|c|}
\hline Aantai parkeerplastven voor auto's bul het station/bushaite \\
\hline Aantal parkeerpisatsen voor fetsen bu het gtation/buahaite \\
\hline
\end{tabular}

6. Om 'Stedelijke dichtheid rondom het station/de bushalte" te bepalen gebruiken we de volgende indicatoren. Welke indicatoren vindt u belangrijk bij het bepalen hiervan? $U$ kunt de verschillende indicatoren in volgorde van belangrijkheid zetten door ze te schuiven danwel door ze van een score te voorzien (No. 1 is de meest belangrijke, gevolgd door 2 enzovoorts).

\begin{tabular}{|l|l|}
\hline & voor wonen \\
\hline & voor whikels en bedriven \\
\hline & voor werkgelegenteld \\
\hline
\end{tabular}

7. Om 'Voorzieningen voor wandelen en fietsen rondom het station/de bushalte" te bepalen gebruiken we de volgende indicatoren. Welke indicatoren vindt u belangrijk bij het bepalen hiervan? $\mathbf{U}$ kunt de verschillende indicatoren in volgorde van belangrijkheid zetten door ze te schuiven danwel door ze van een score te voorzien (No. 1 is de meest belangrijke, gevolgd door 2 enzovoorts).

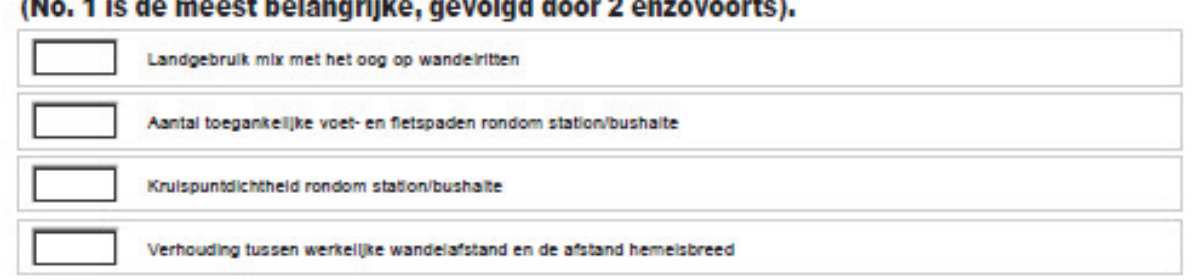

8. Om 'Economische ontwikkeling in het gebied rondom het station/bushalte' te bepalen gebruiken we de volgende indicatoren. Welke indicatoren vindt u belangrijk bij het bepalen hiervan? $U$ kunt de verschillende indicatoren in volgorde van belangrijkheid zetten door ze te schuiven danwel door ze van een score te voorzien (No. 1 is de meest belangrijke, gevolgd door 2 enzovoorts).

\begin{tabular}{|l|l|}
\hline & investeringen in bedrivigheid rondom stationa/bushalte \\
\hline & Aantal winkels of servicepunten \\
\hline & Belastingasdracht in het gebied \\
\hline
\end{tabular}


9. De volgende criteria gebruiken we om de TOD index voor locaties voor potentiele TOD ontwikkeling in de Stadsregio te kunnen bepalen. leder criterium representeert een karakteristiek van stedelijke ontwikkeling en/of OV. Kunt u aangeven welke criteria u belangrijk vindt bij het bepalen van TOD? $U$ kunt de verschillende criteria in de volgorde van belangrijkheid zetten door ze te schuiven danwel door ze van een score te voorzien (No. 1 is de meest belangrijke, gevolgd door 2 enzovoorts).

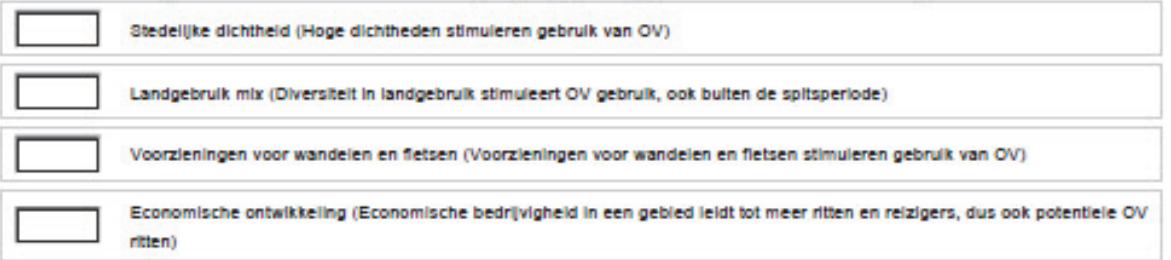




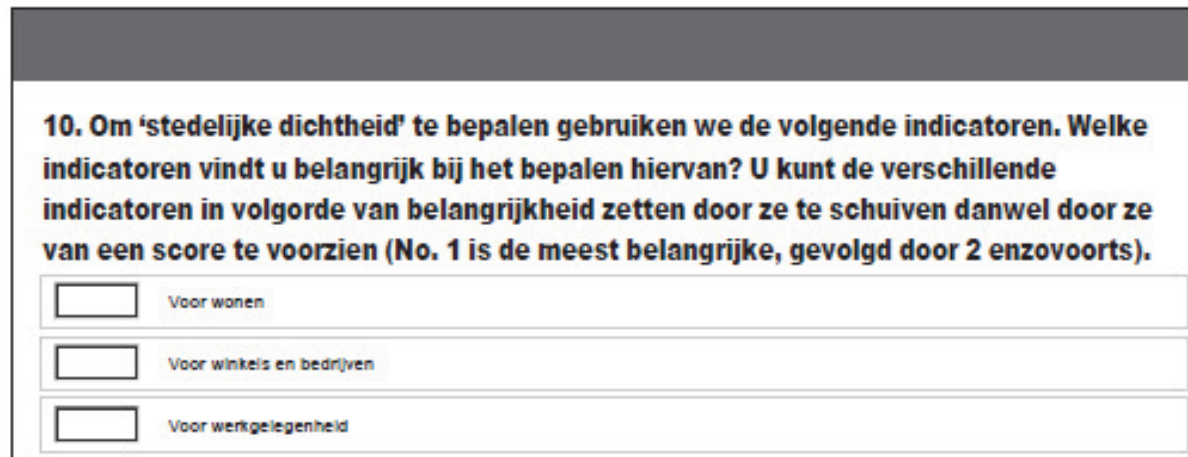

11. Om 'Voorzieningen voor wandelen en fietsen' te bepalen gebruiken we de volgende indicatoren. Welke indicatoren vindt $u$ belangrijk bij het bepalen hiervan? $\mathrm{U}$ kunt de verschillende indicatoren in volgorde van belangrijkheid zetten door ze te schuiven danwel door ze van een score te voorzien (No. 1 is de meest belangrijke, gevolgd door 2 enzovoorts).

\begin{tabular}{|l|l|}
\hline & Hoeveeimeld toegankelilke voet- en fletspaden \\
\hline & Krulspuntdichtheid \\
\hline & Landgebruik mix met het oog op wandeiritsen \\
\hline
\end{tabular}

12. Om 'economische ontwikkeling' te bepalen gebruiken we de volgende indicatoren. Welke indicatoren vindt $u$ belangrijk bij het bepalen hiervan? $U$ kunt de verschillende indicatoren in volgorde van belangrijkheid zetten door ze te schuiven danwel door ze van een score te voorzien (No. 1 is de meest belangrijke, gevolgd door 2 enzovoorts).
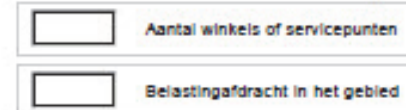

13. Heb jij elke suggesties? 


\section{Appendix 2}

\section{Web diagrams of all 21 train stations, showing their standardised scores on each criterion.}
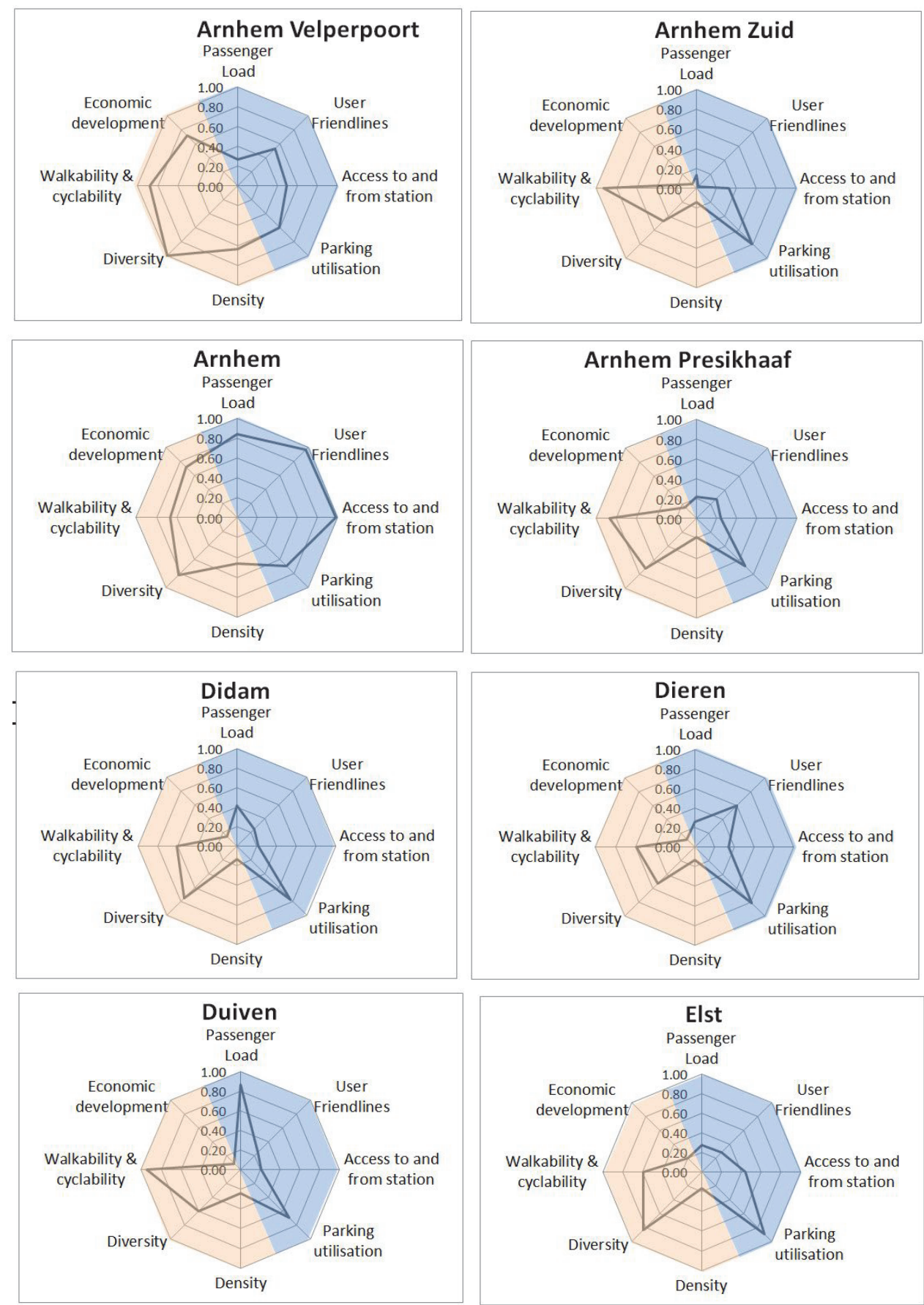

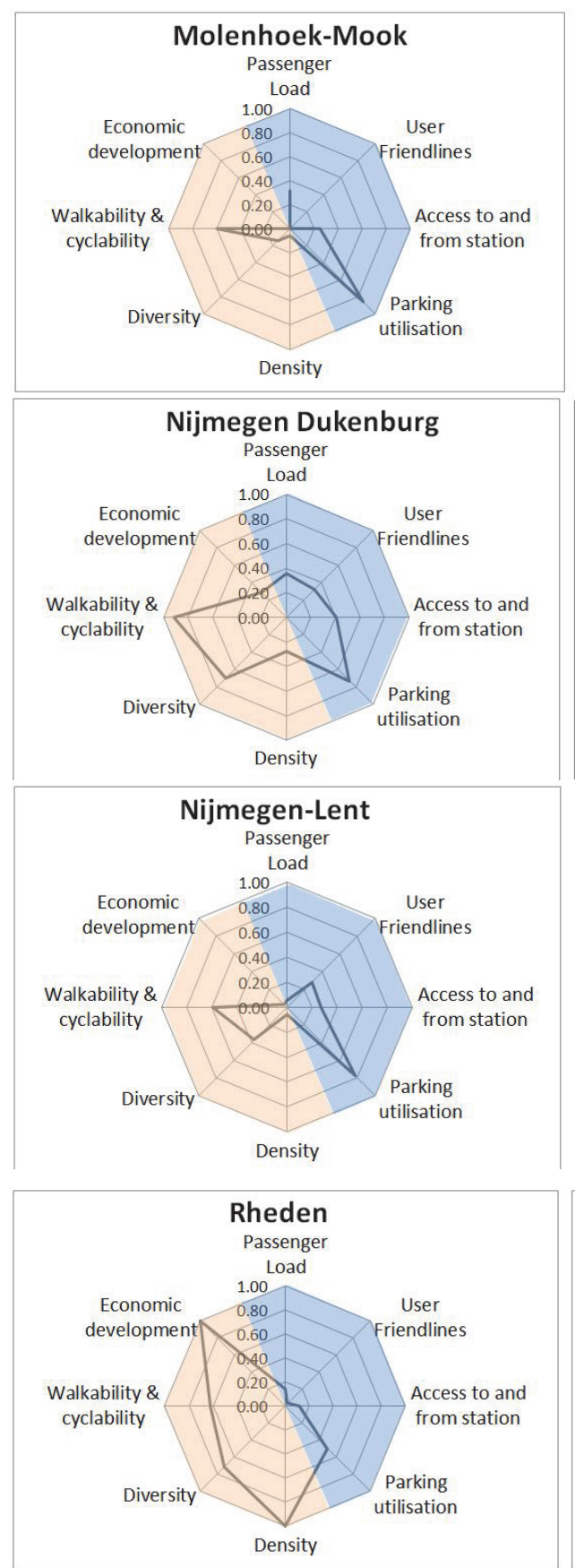
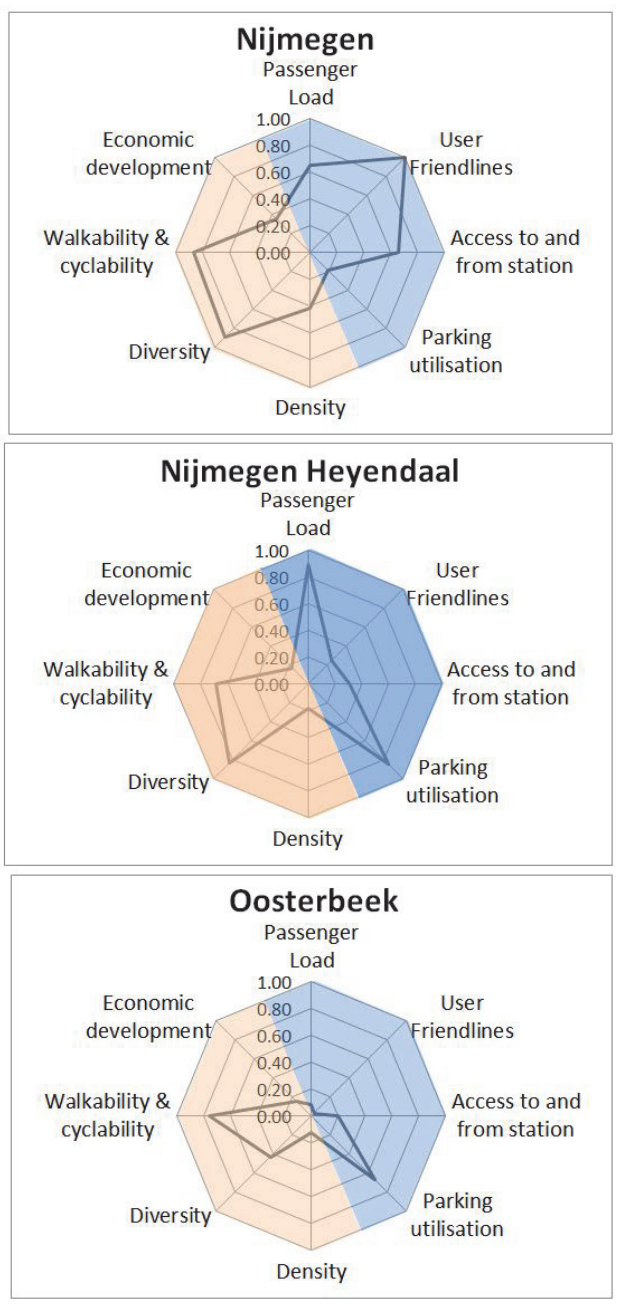

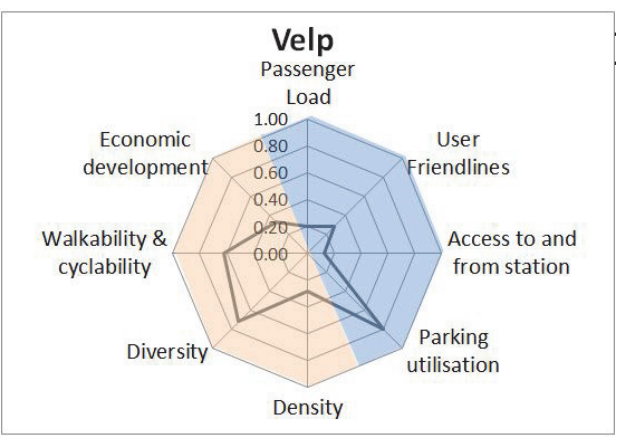



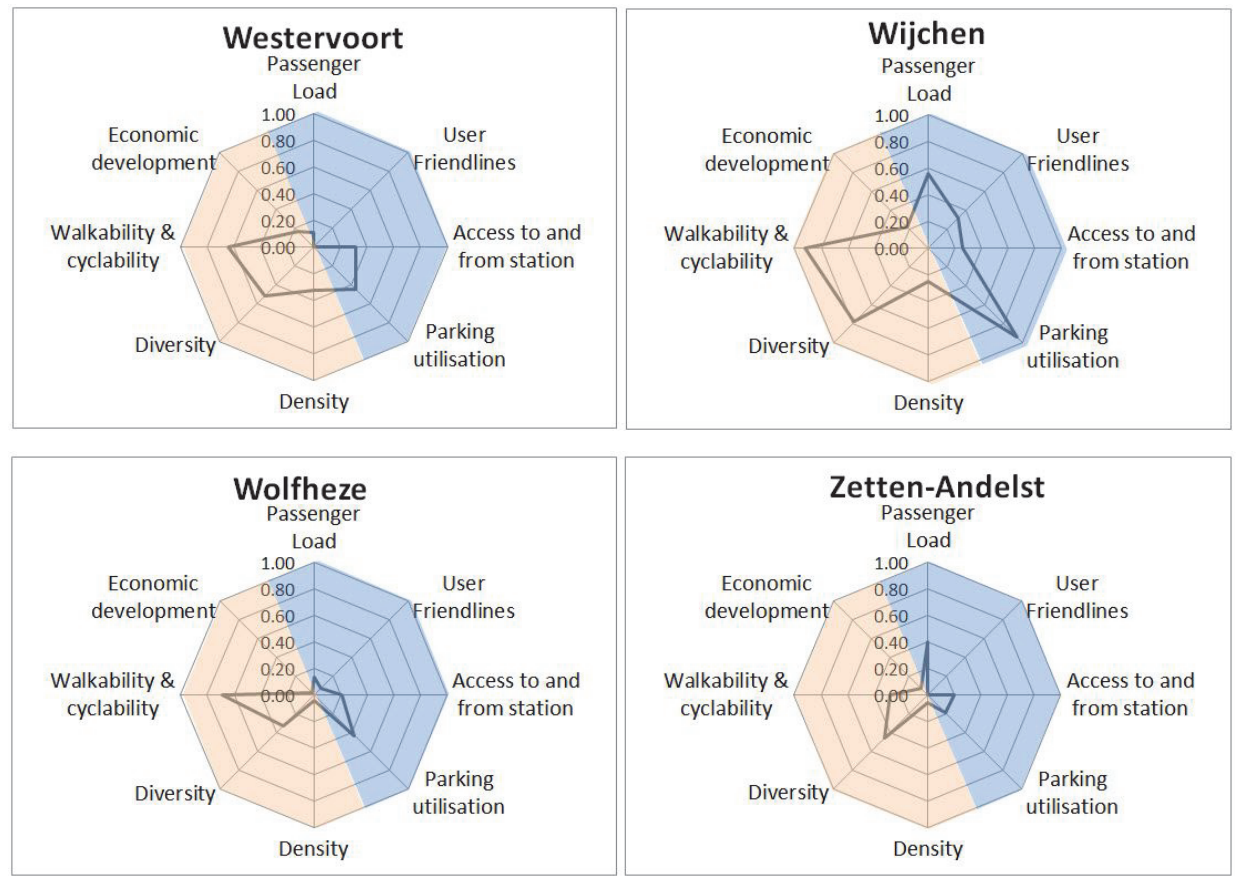

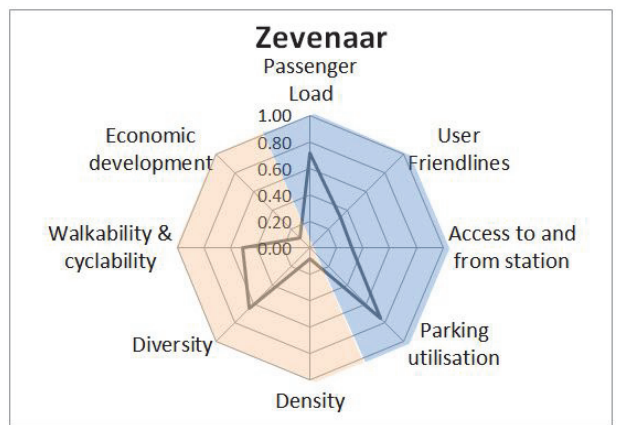




\section{Appendix 3}

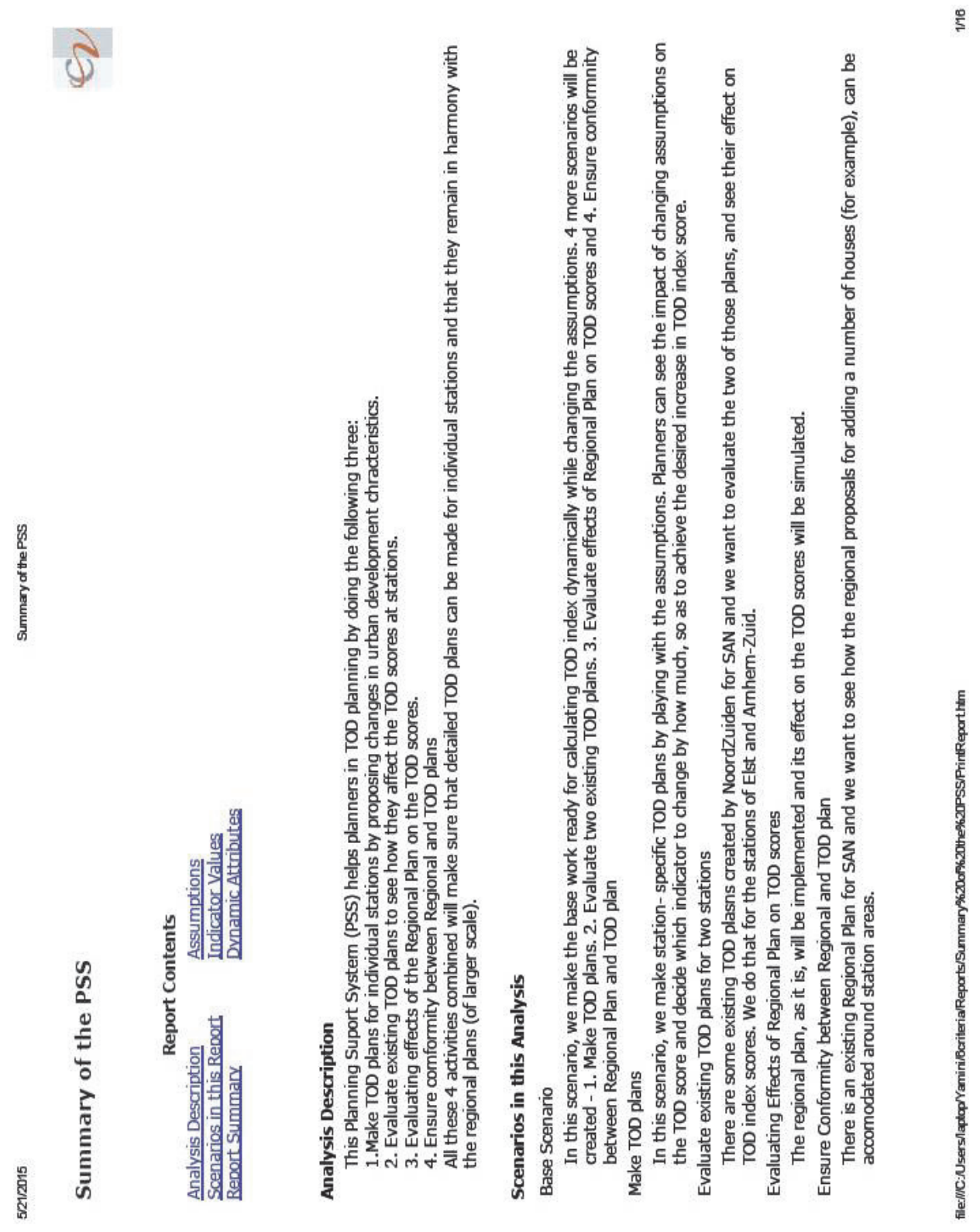



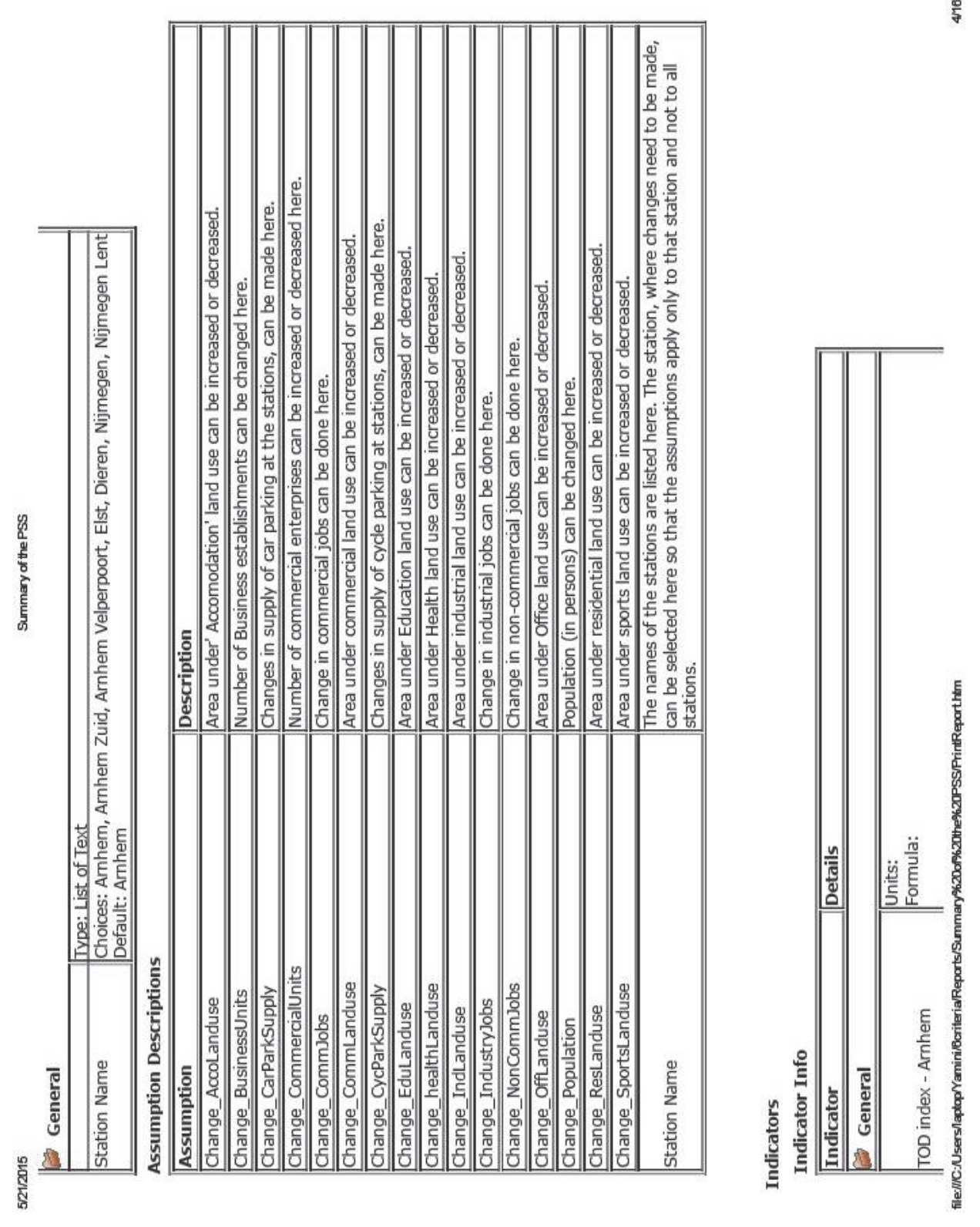


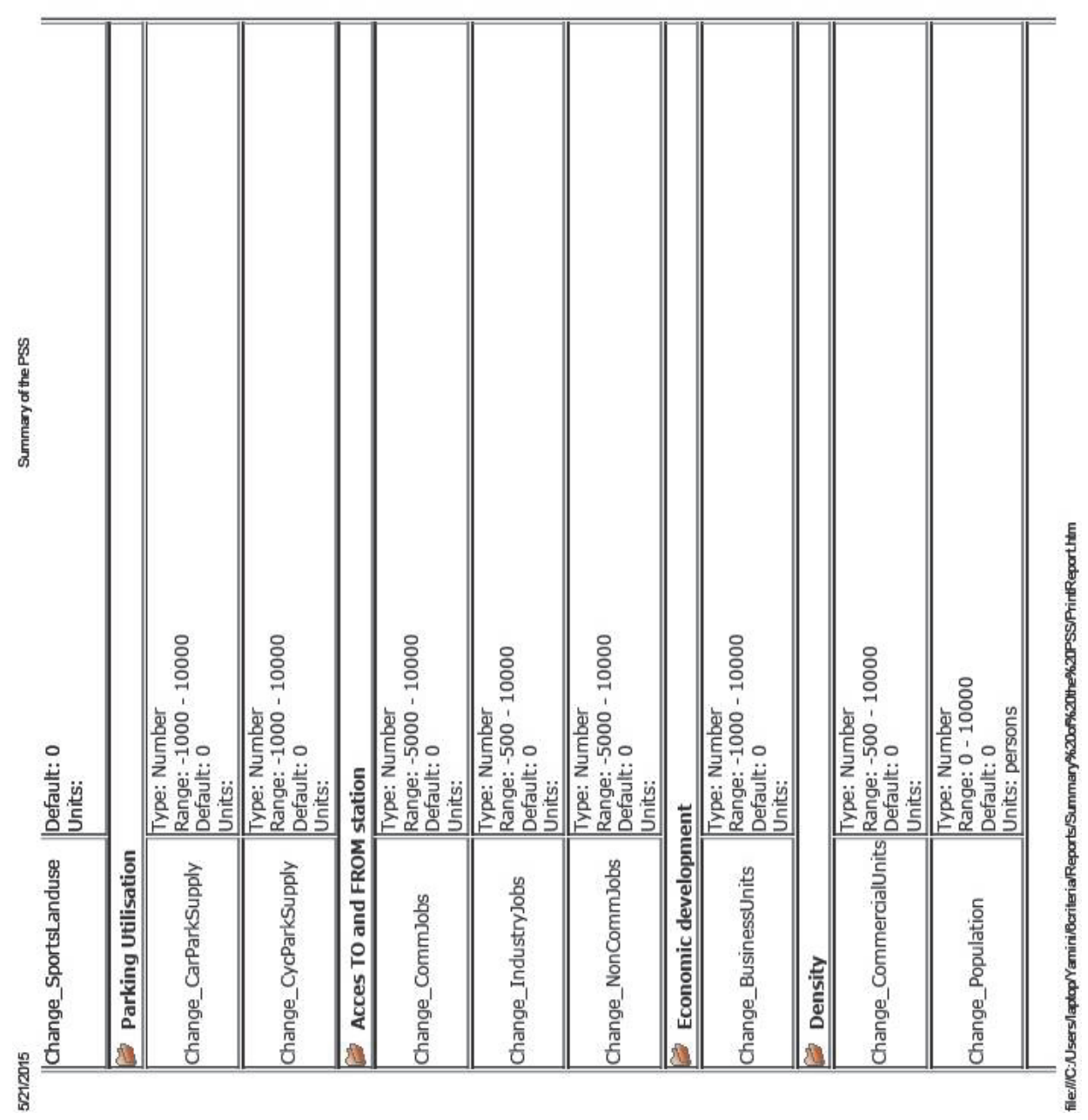




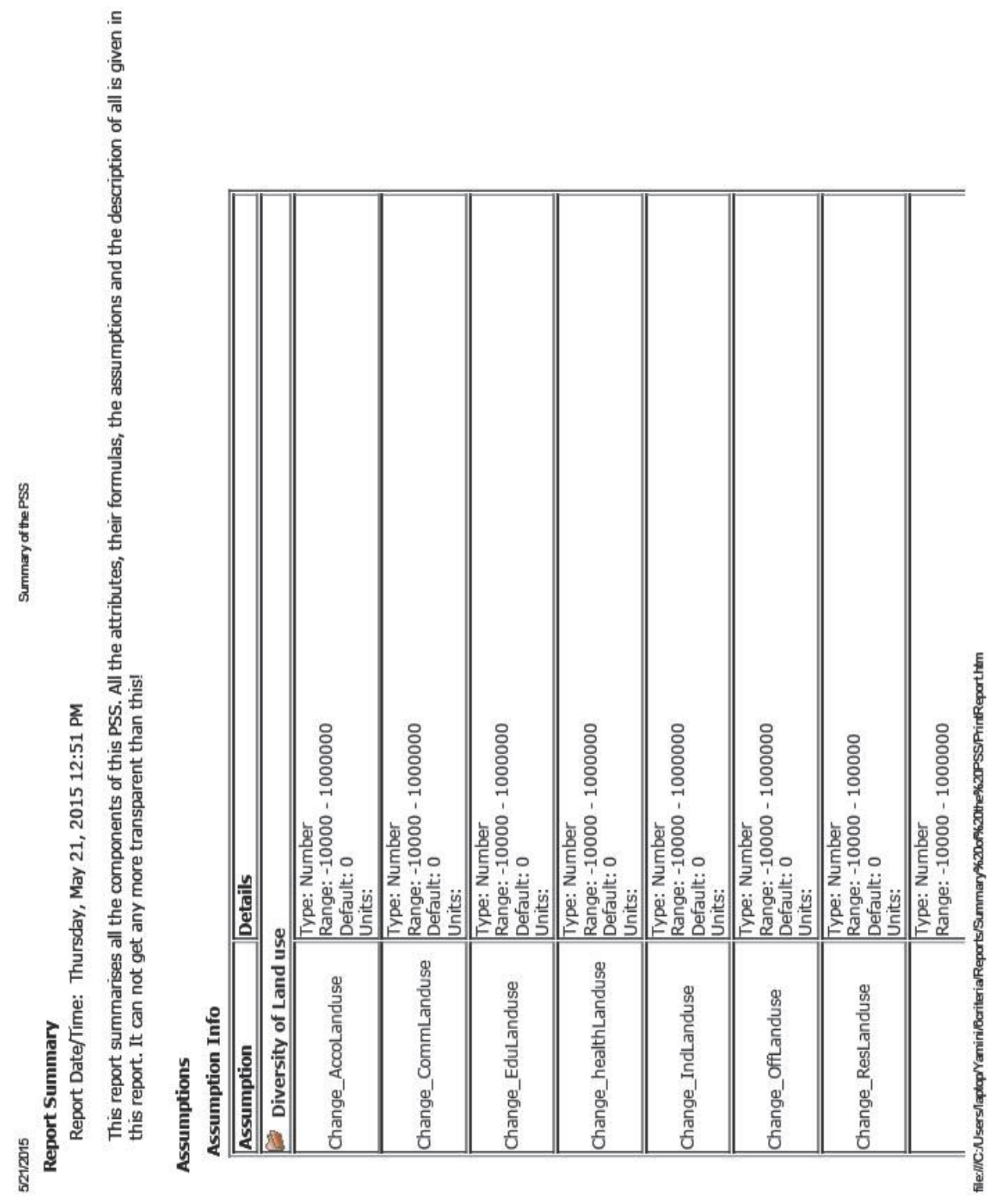




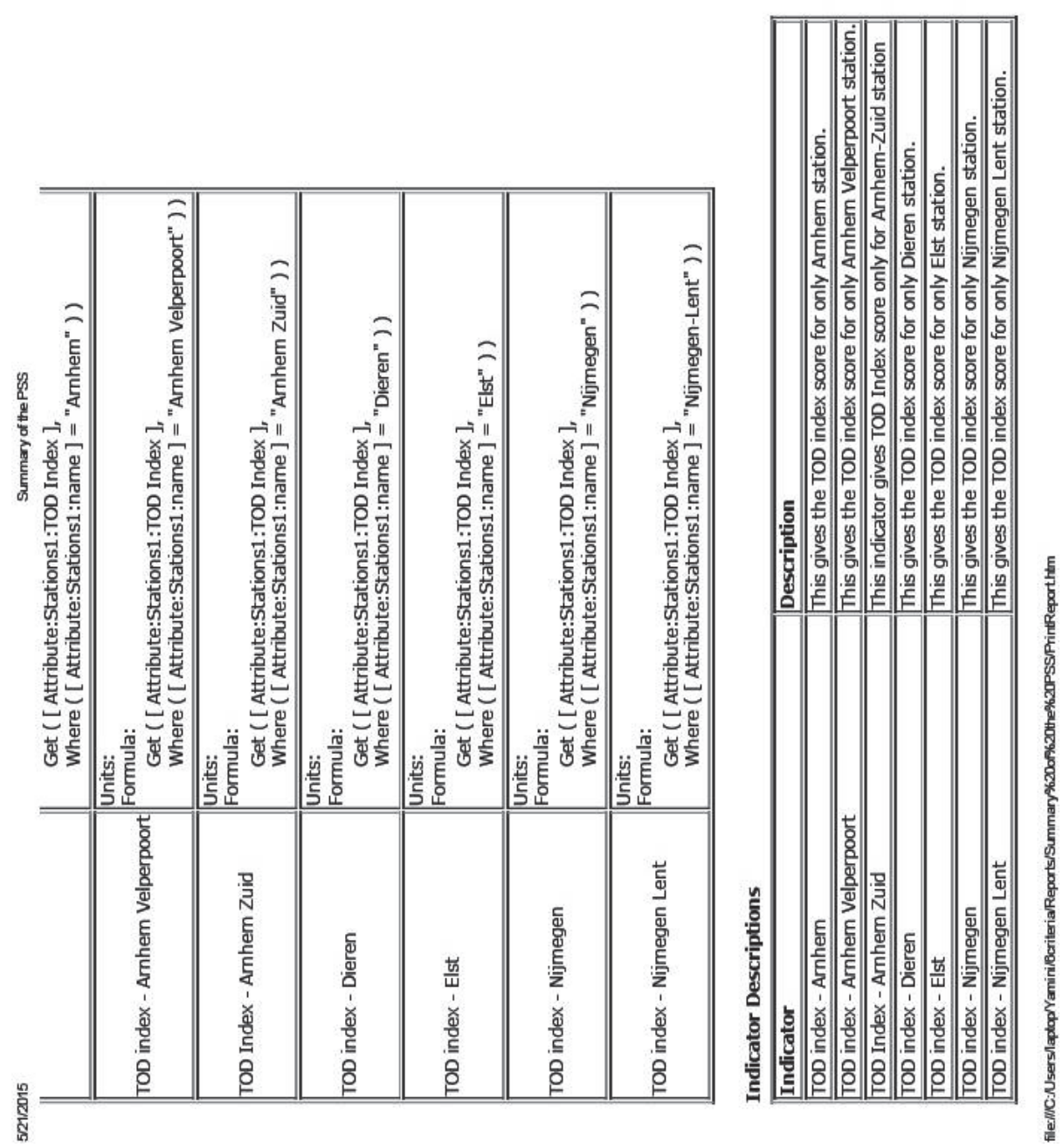




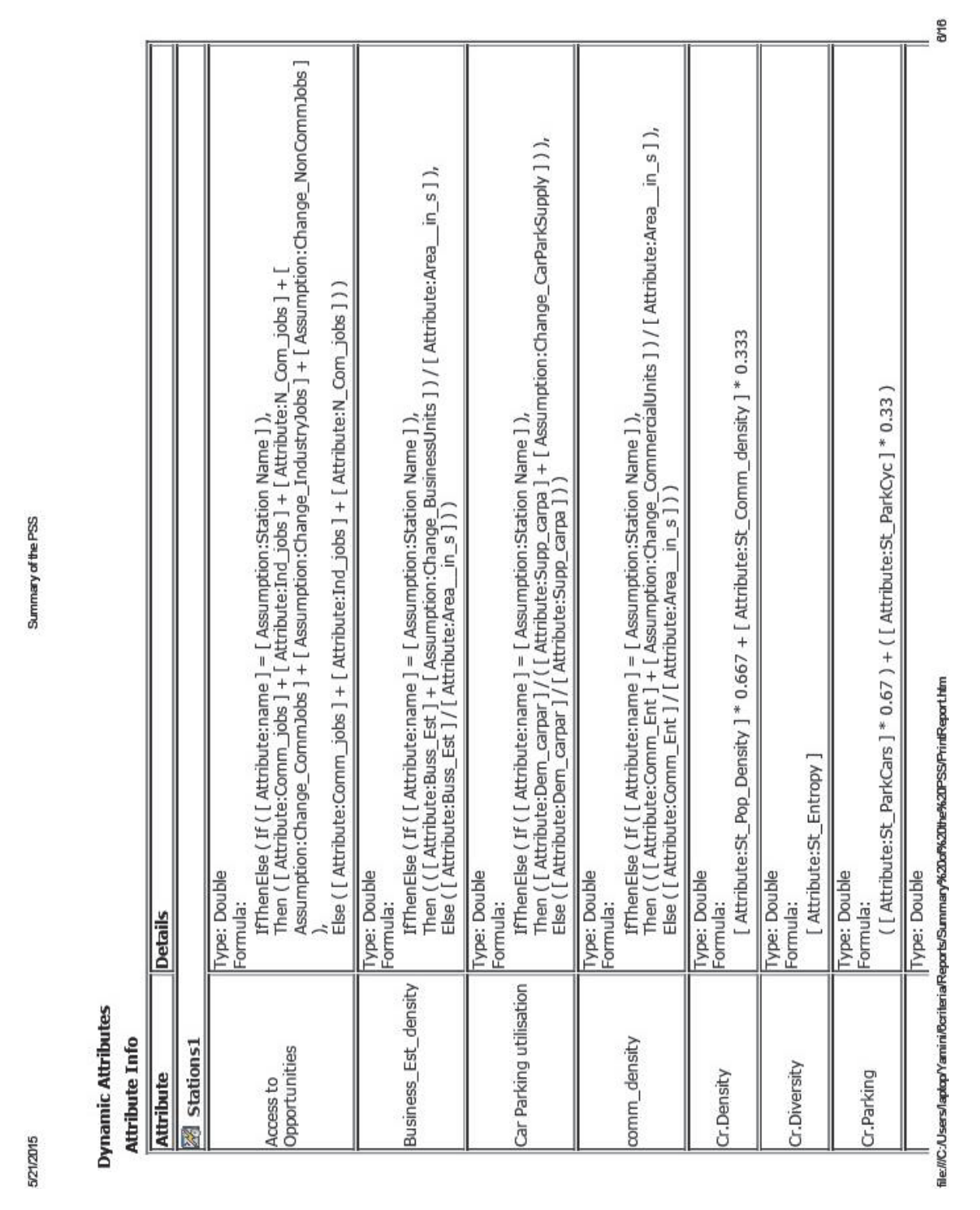




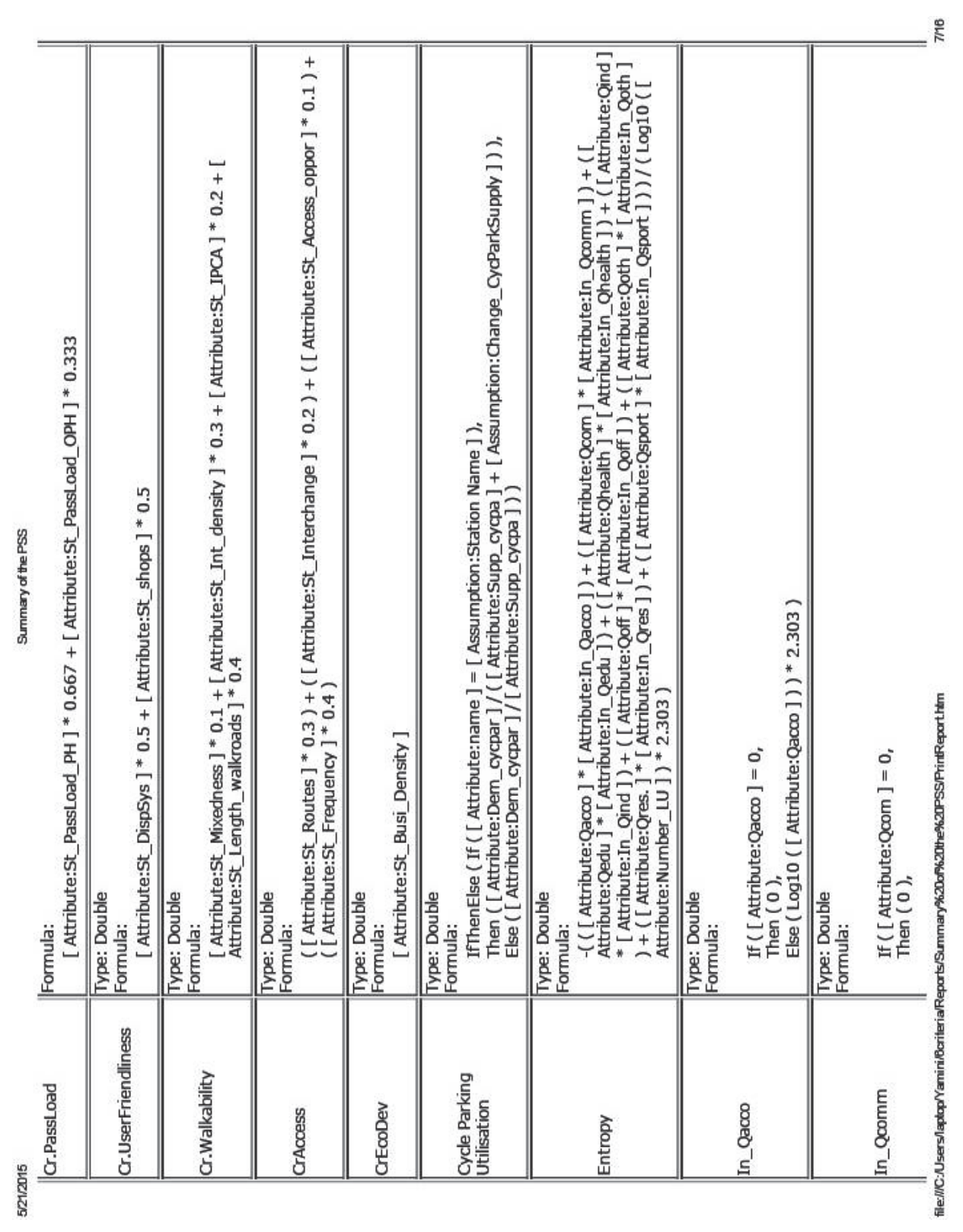




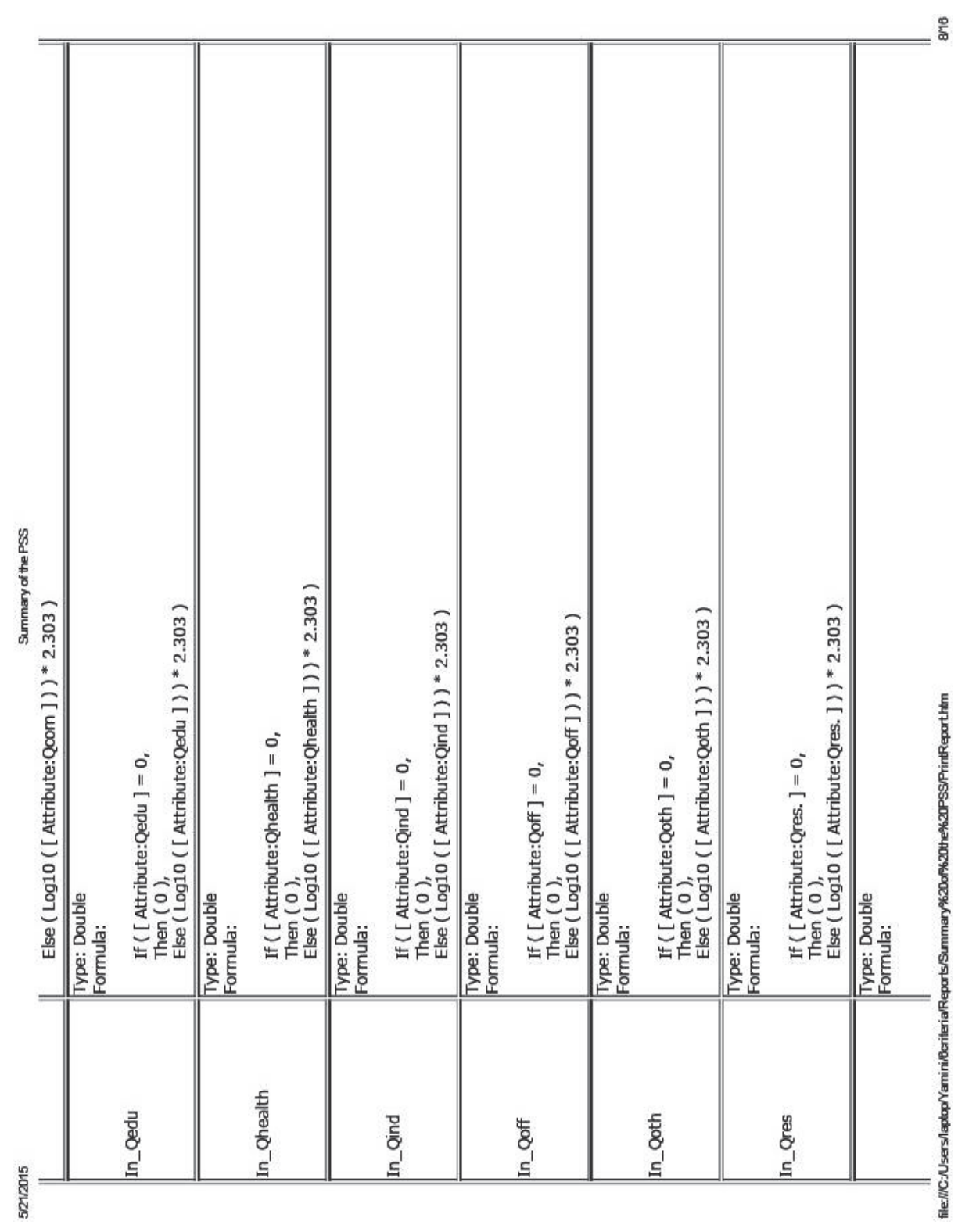




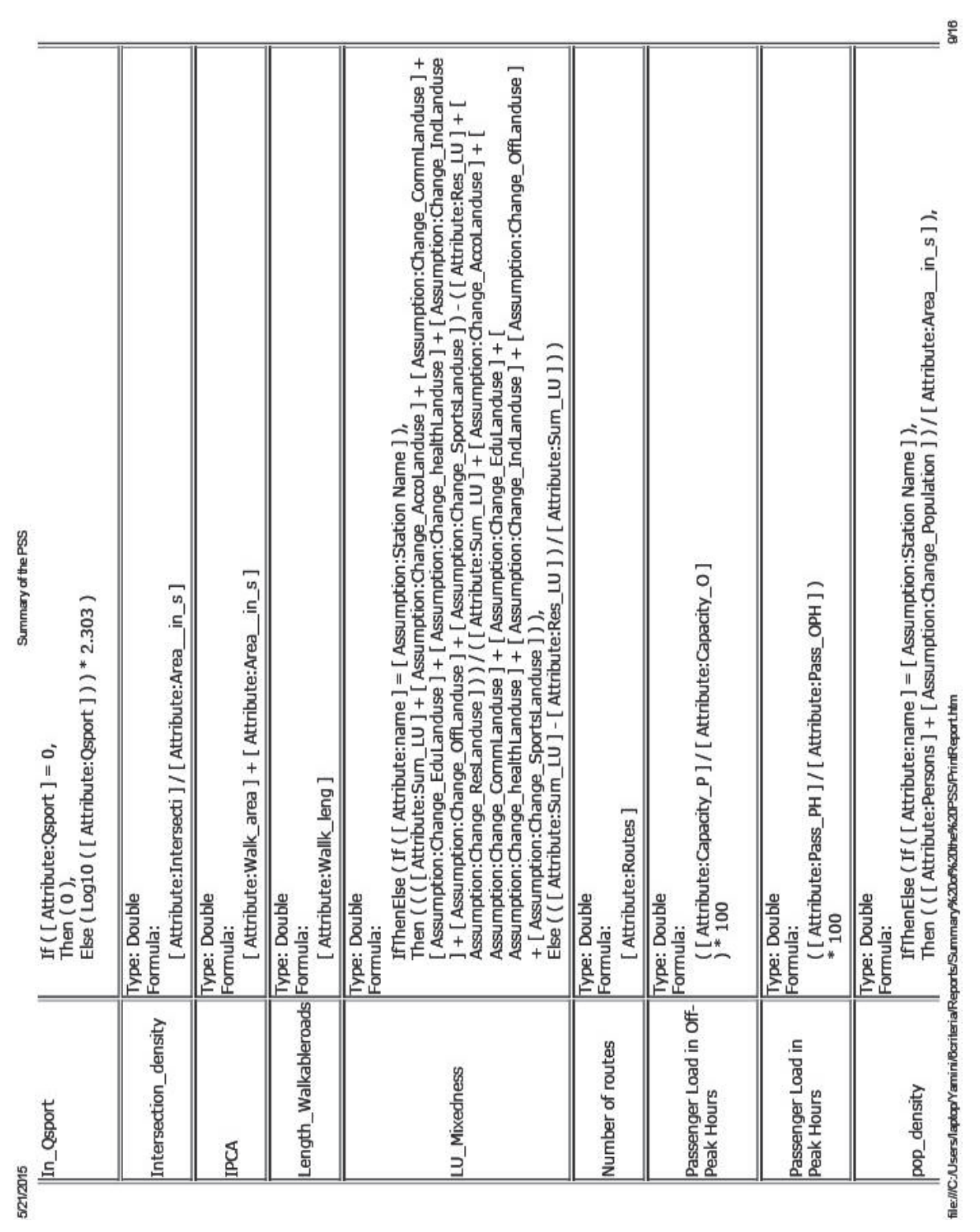




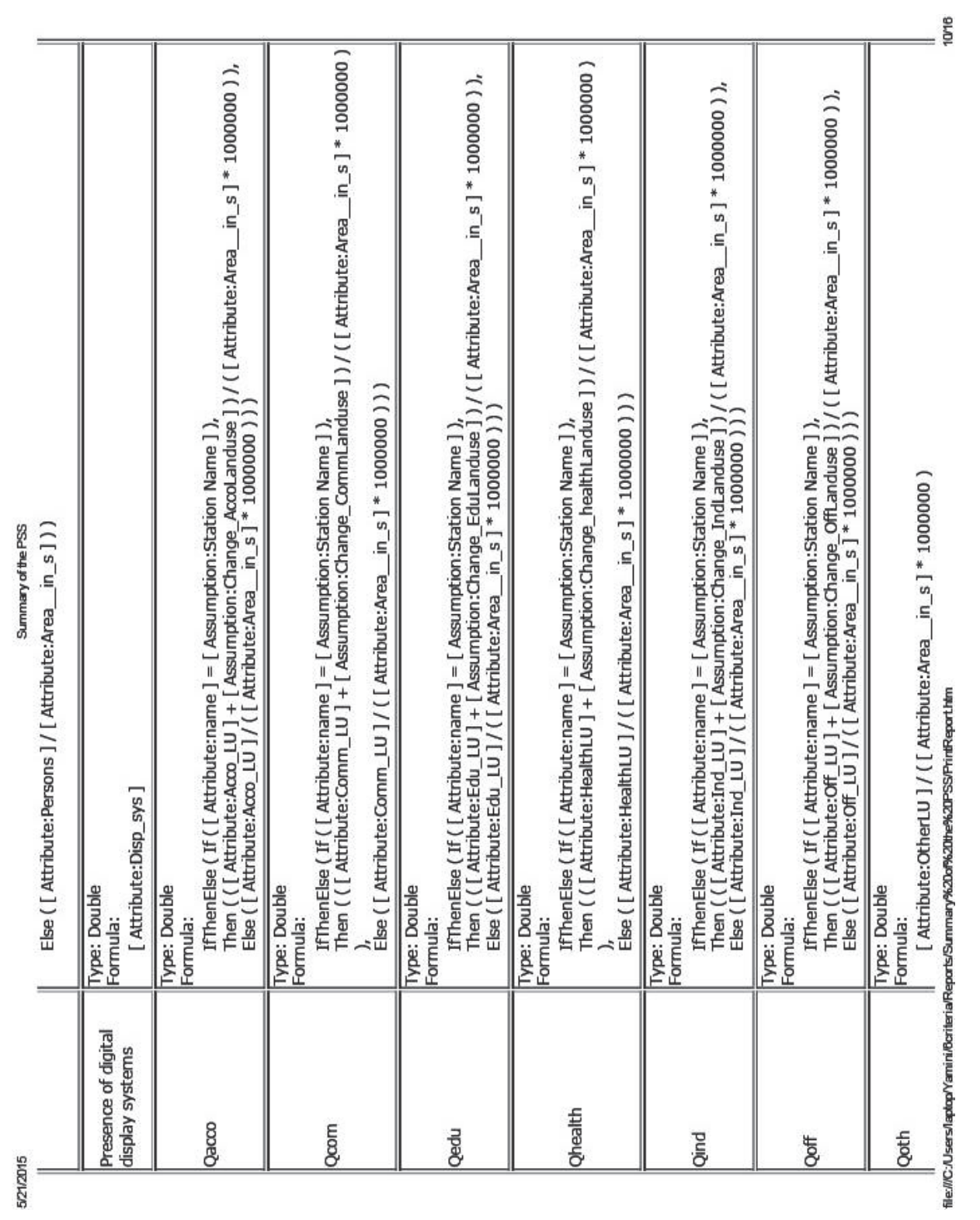




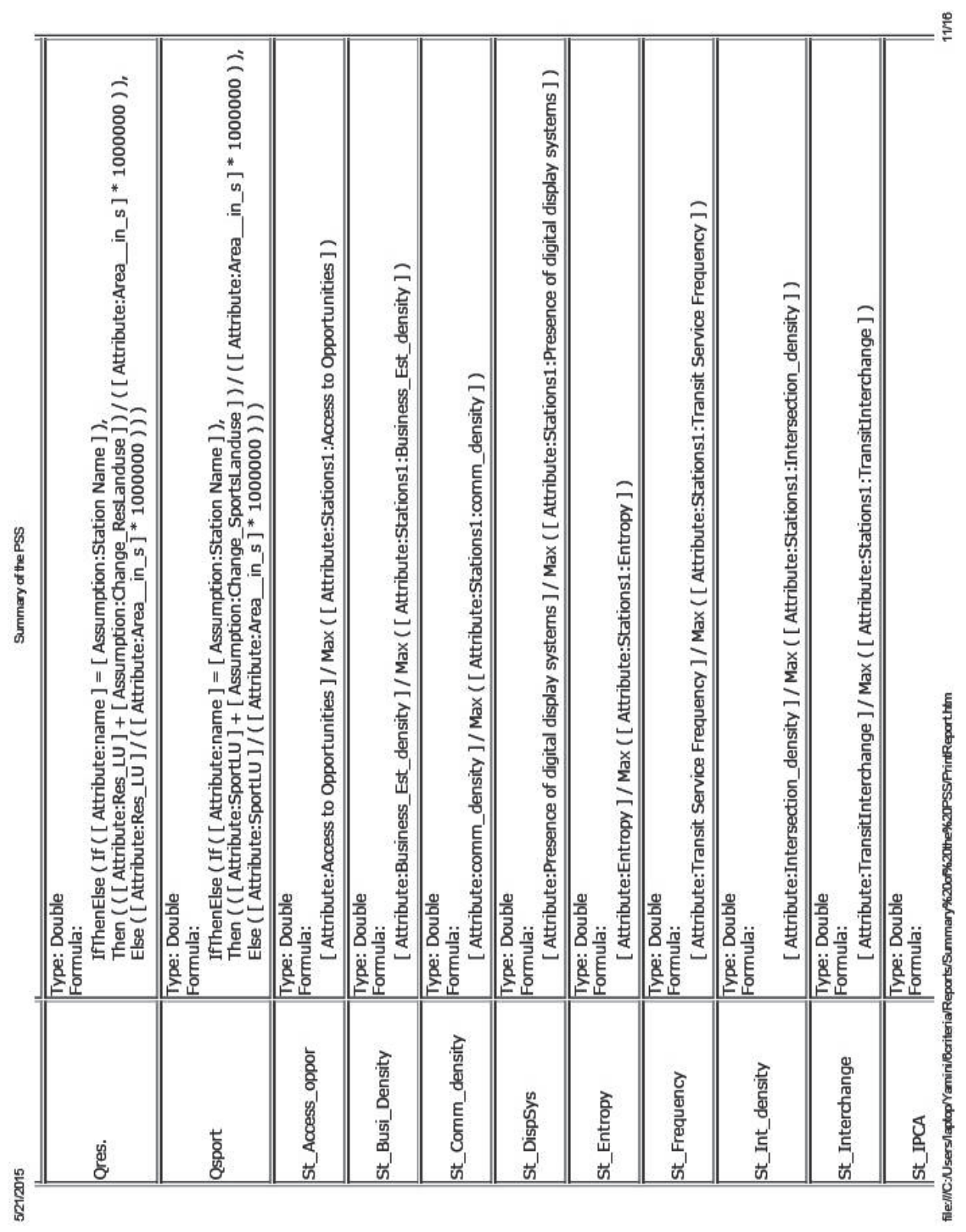




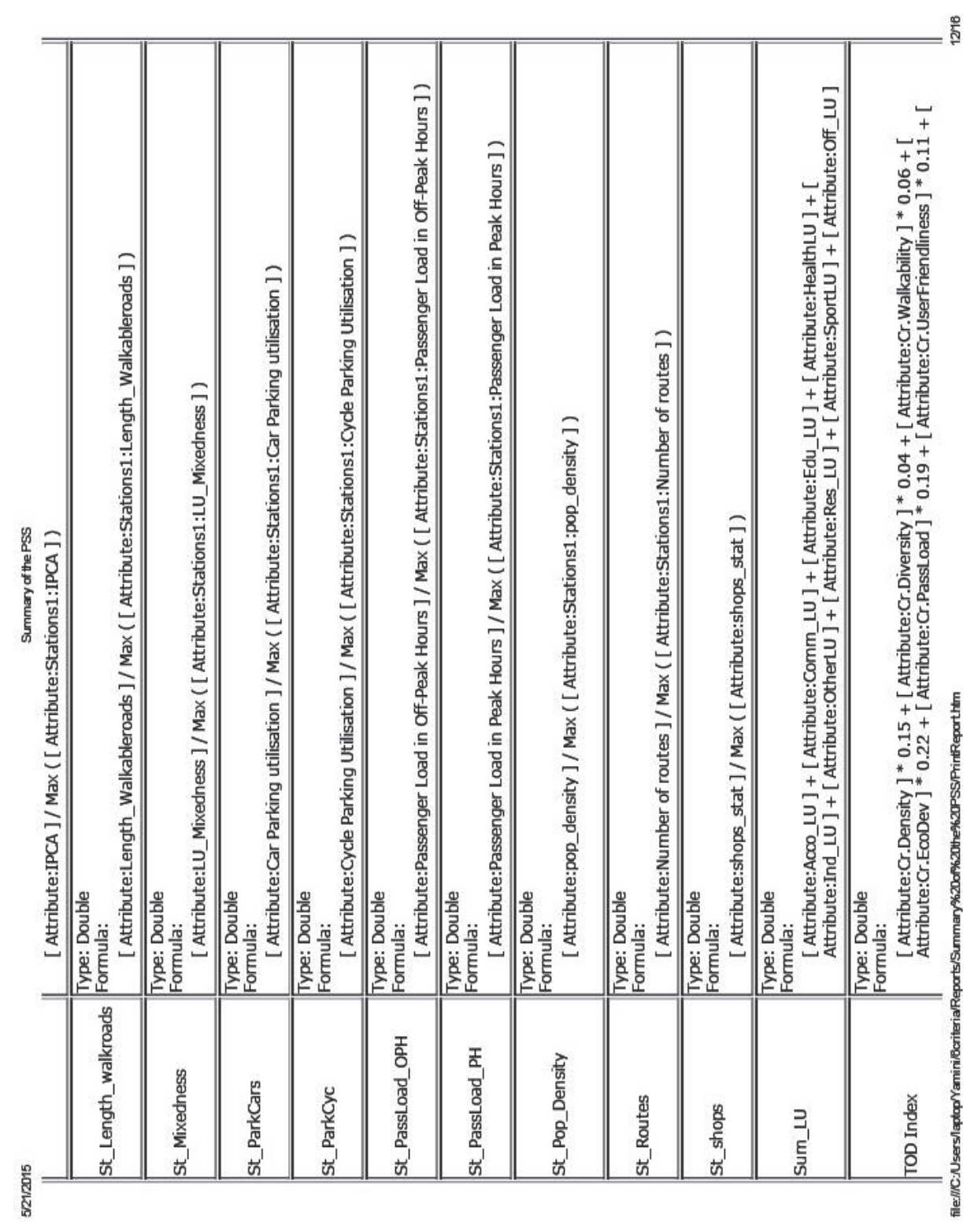




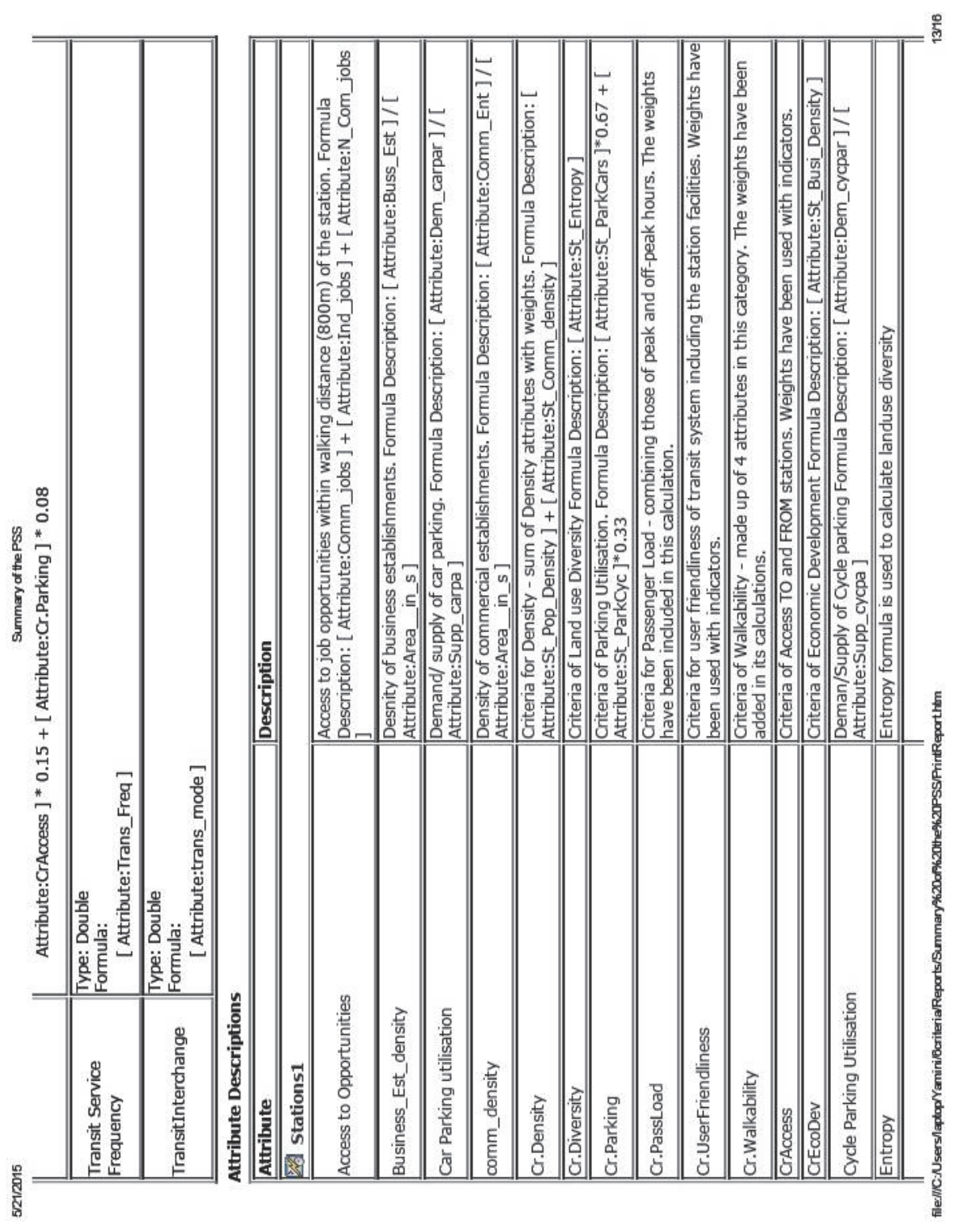




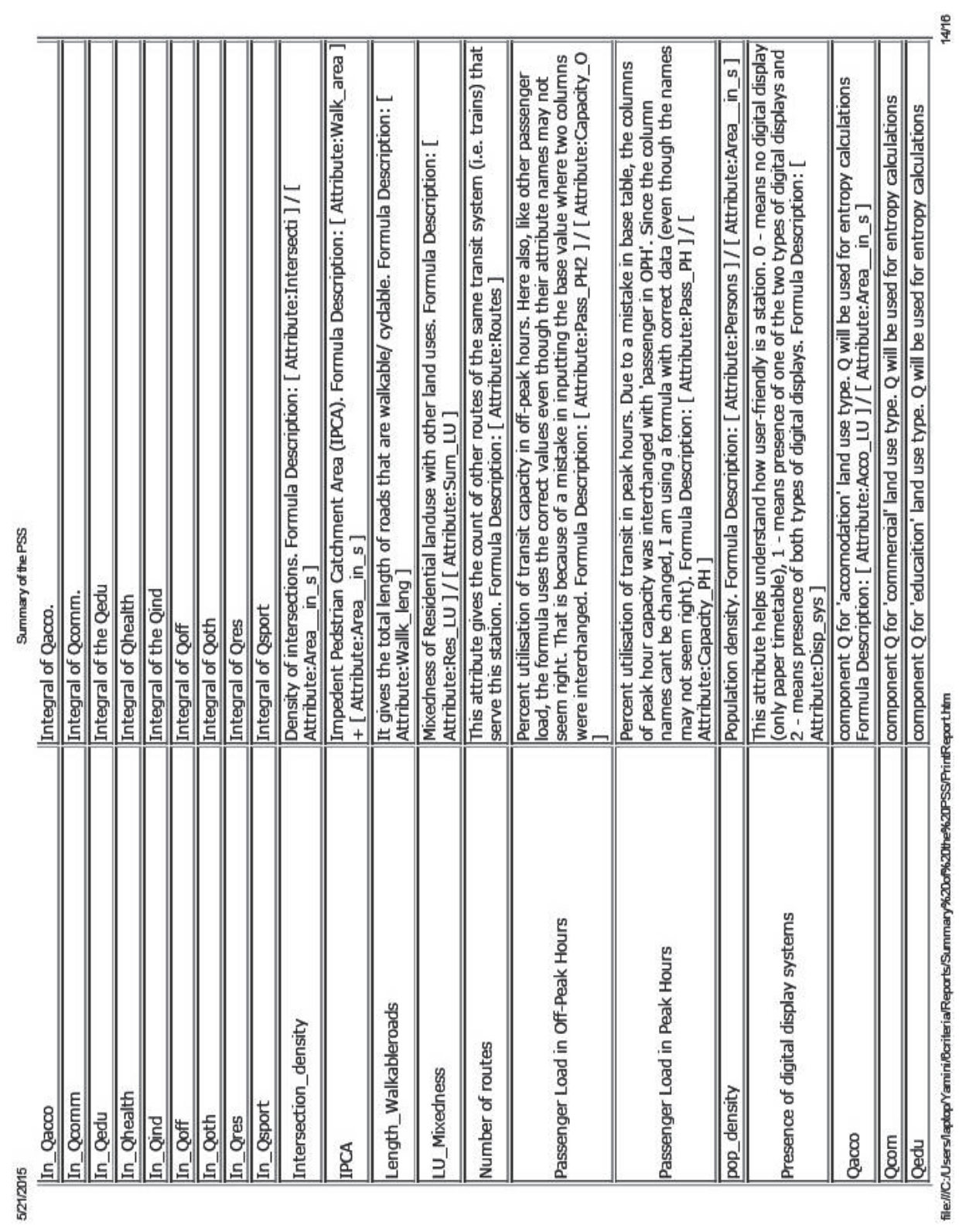




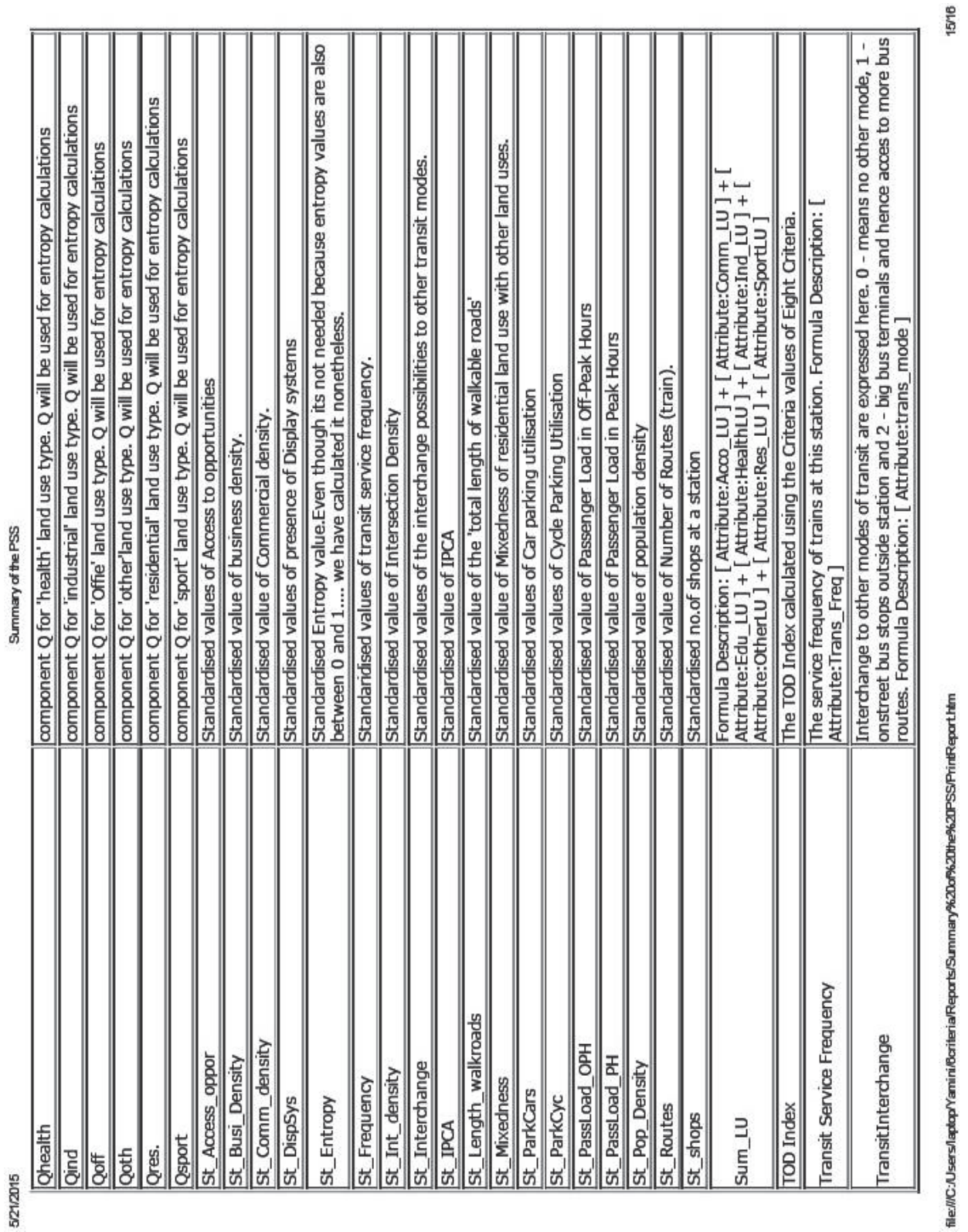



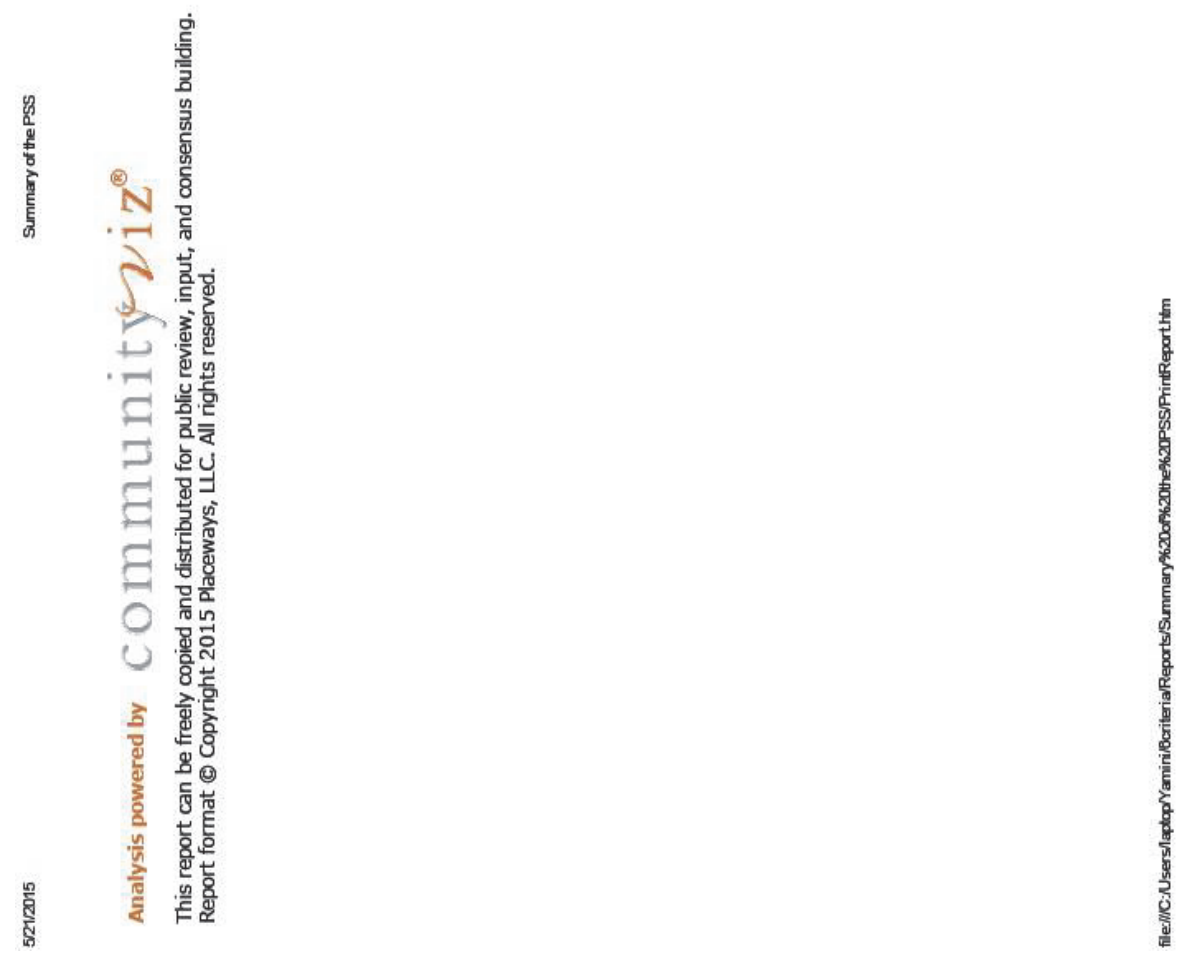


\section{Appendix 4}

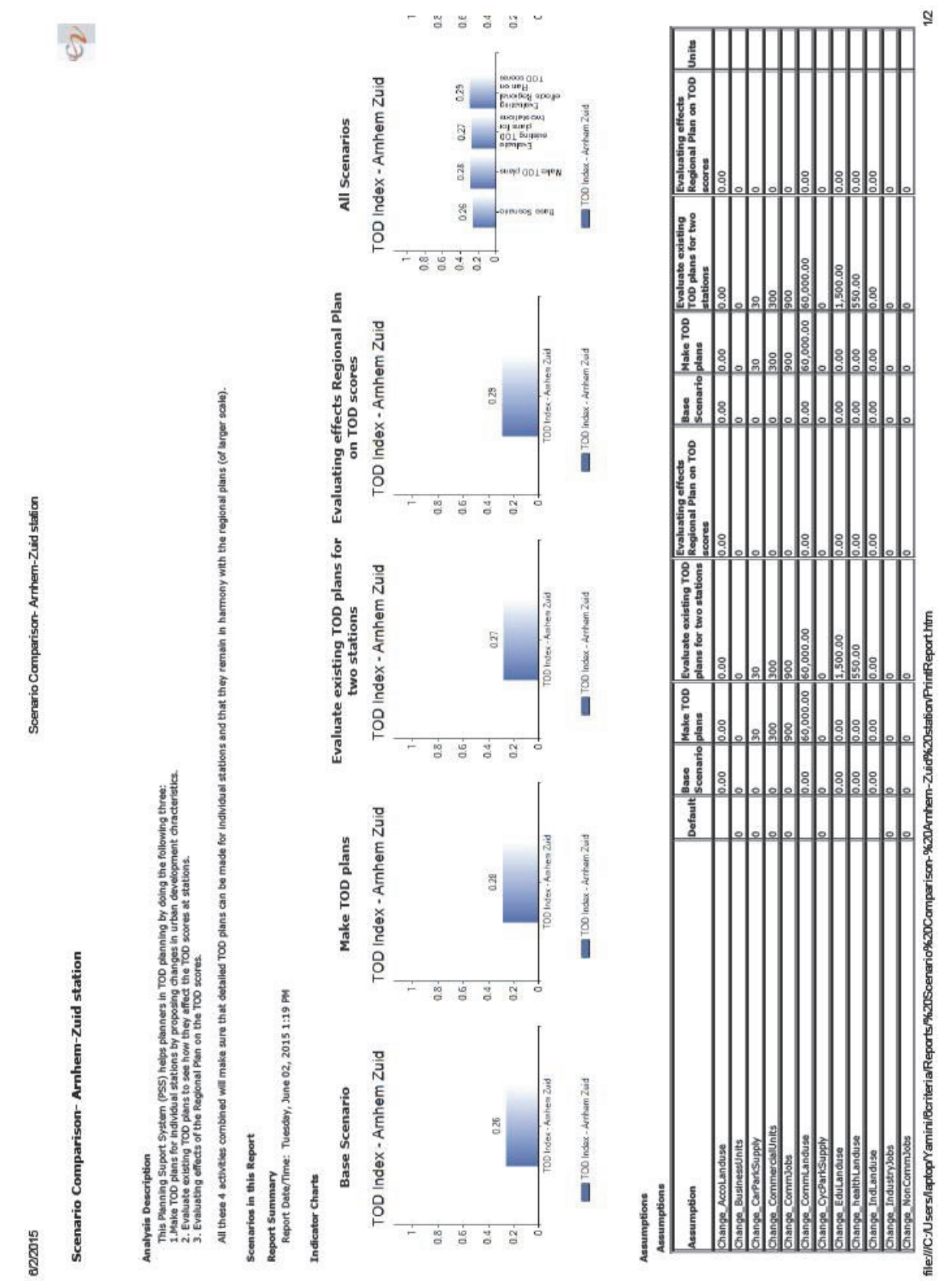



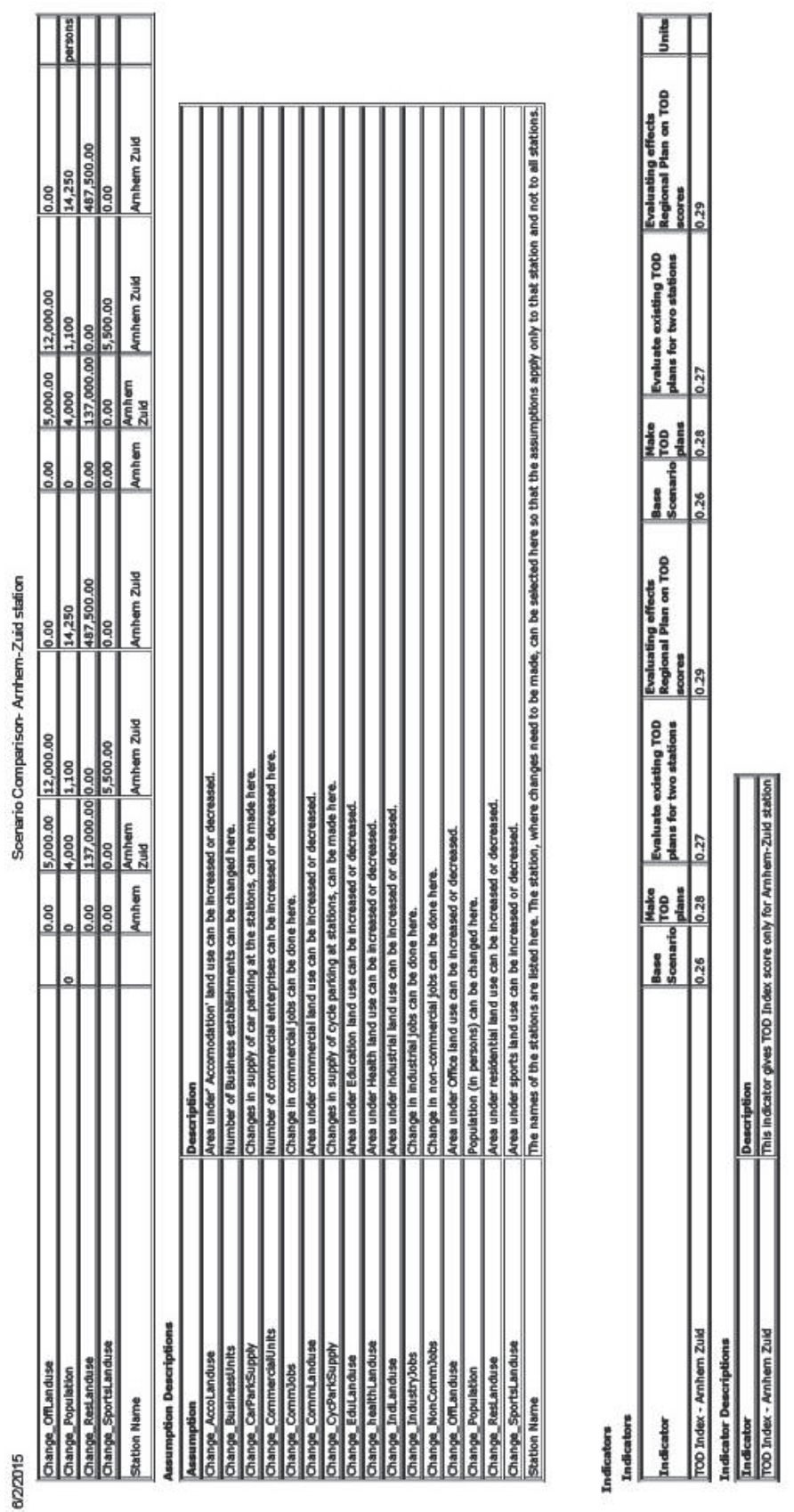

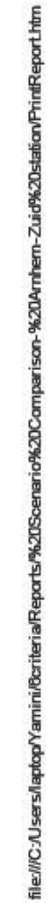




\section{Biography}

Yamini J. Singh is an urban and transport planner with keen interest in sustainable development issues. She completed her Bachelors in Urban Planning from School of Planning and Architecture, New Delhi, India in 2001 and later completed her Masters in Transport Planning, also from the same university in 2002. For her Masters, she was the recipient of GATE scholarship (from Government of India) and also received a gold medal for her academic performance. Over the next 7 years, she worked with various corporate organizations on transport planning projects all over India.

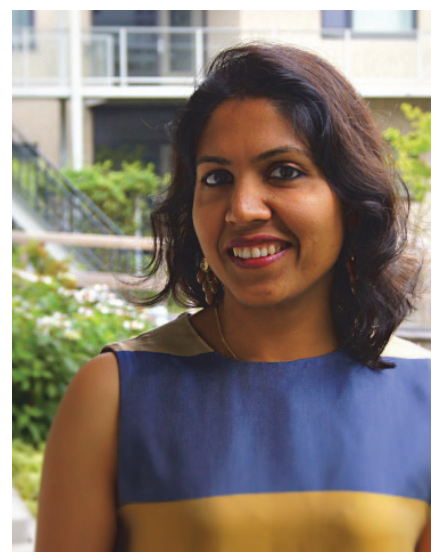
She particularly found the subject of Public-Private Partnerships (PPP) very interesting in implementation of urban and transport projects in the country. Having also worked under the Ministry of Urban Development, as Assistant Director, she worked on implementation of water supply, sewerage and electricity projects in small towns of India. In September 2011, she started her PhD on Erasmus Mundus scholarship with the PGM department at ITC. During her PhD, she has published journal papers, conference papers, a book chapter and has participated in various courses too. She also reviews papers for various international journals. For the year 2012, she was one of the elected members to represent the students at the Faculty Council. Other than the regular work that keeps her busy, she loves to travel and likes to remain involved in issues back home in India. She has also become a trustee at 'Foundation for Critical Choices for India' hoping to contribute towards a better India. 


\section{ITC Dissertation List}

http://www.itc.nl/research/phd/phd graduates.aspx 